Um método para o desenvolvimento de software baseado em componentes e aspectos 
SERVIÇO DE PÓS-GRADUAÇÃO DO ICMC-USP

Data de Depósito: 4 de julho de 2006

Assinatura:

\title{
Um método para o desenvolvimento de software baseado em componentes e aspectos
}

\author{
Marcelo Medeiros Eler
}

Orientador: Prof. Dr. Paulo Cesar Masiero

Dissertação apresentada ao Instituto de Ciências Matemáticas e de Computação - ICMC/USP como parte dos requisitos para obtenção do título de Mestre em Ciência de Computação e Matemática Computacional.

\section{USP - São Carlos}

Julho/2006 


\section{Agradecimentos}

Creio que esta é uma parte muito difícil e ao mesmo tempo alegre de se escrever. Difícil pelo medo de esquecer algum nome a quem devo meus agradecimentos e alegre porque quando se escreve os agradecimentos é porque a dissertação já está prontinha - ou quase :D.

Quero agradecer primeiramente e sobretudo a Deus, pelo cuidado com que me criou e me conduz os passos, pelo amor e carinho que sempre me revelou, e por Jesus Cristo, aquele que entregou a si mesmo por mim.

Agradeço a meus pais, Rubens e Glória, pelo grande amor que me criaram e me dedicam. São pessoas maravilhosas e meus maiores exemplos de integridade, honra, caráter e fé. Pai, mãe, sem vocês eu não teria a alegria, a força e a vontade para seguir os caminhos que hoje trilho. Obrigado pelo incentivo e pela oportunidade que me deram de concluir mais esta etapa da vida. Amo vocês.

Ao Prof. Masiero, por ter aceitado me orientar e me dado um voto de confiança, meus sinceros agradecimentos. Agradeço de coração o cuidado, a seriedade e a extrema competência com que conduziu este trabalho. Obrigado pelo exemplo e por tudo que me ensinou nestes dois anos que se passaram.

Não posso deixar de agradecer também a meus irmãos Danilo e Daniela que eu amo demais, e também à Juliana, minha cunhada querida que é praticamente uma irmã também. Agradeço também aos meus demais familiares, tios, tias, primos, primas, avós, avôs, que são muitos e seria difícil citá-los todos aqui.

Quero fazer um agradecimento especial também a meu ex-professor/orientador da graduação Reginaldo Ré, hoje amigo de laboratório e de mesmo orientador. Agradeço por ter me incentivado e me ajudado a entrar nas pesquisas em Engenharia de Software, o que me levou naturalmente a continuar na mesma e vir pra São Carlos fazer mestrado. Valeu Ré.

Lembro-me que no meu último ano do curso de graduação surgiu uma oportunidade de trabalhar no CPD da faculdade, o que exigiria que eu mudasse para o turno da noite e para o curso de Sistemas de Informação e, trabalhando, não faria um projeto de conclusão de curso, apenas o estágio. Fui me aconselhar com o coordenador do meu curso e pedir um conselho sobre o que eu deveria fazer. O coordenador era nada mais e nada menos que o Rogério, hoje também amigo aqui da pós-graduação, que me aconselhou a terminar meu curso, fazer um projeto de graduação bem feito e fazer o mestrado que ele sabia que eu queria. Dito e feito, não pensei duas vezes e hoje estou escrevendo os agradecimentos desta dissertação :D. Valeu Rogério.

Agradeço também aos meus amigos e professores do LabES (em ordem alfabética): Adenilso, Alessandra, André(s), Antonielly, Bira, Camila, Cláudio (importado do LCAD), Darley, Débora, Delamaro, Dinho, Elisa, Ellen, Érika, Fabiano, Ivan, Kicho, Luciana, Maldonado, Marcão, Marcella, Maris, Masiero, Otávio, Paula, Percy, Reginaldo, Rogério, Rosana, Rosely, Sandro (KLB), Simone(s), Stanley, Tati, Valter. Foi muito trabalho, muitas pausas para o café da pós, na cantina, 
muitos bolos de aniversários, brincadeiras e confraternizações que tornaram o período de mestrado mais divertido.

Aos meus grandes amigos da PgCompUSP04 e agregados de outros anos (:D), fica uma gratidão especial. Nunca imaginei que teria uma turma de pós-graduação tão divertida, tão amiga e tão unida como encontrei aqui. Muitos jogos de futebol no CEFER, muitas jam sessions, confraternizações, e-mails na nossa lista, etc, além dos subgrupos como clube da garapa, os small e jack (bauer e lost) session, etc. Valeu demais. Todos foram muito marcantes e deixarão muitas saudades. Não me atrevo a listar todos aqui por medo de cometer o pecado de esquecer algum nome.

Meus agradecimentos também aos outros amigos dos vários laboratórios do ICMC; aos companheiros de várias origens do futebol; ao pessoal da portaria: Robertão, s. Arli, Dornelas e Camilo; ao pessoal da faxina e da limpeza dos laboratórios que sempre foram tão simpáticos e sempre se esforçaram para manter tudo em ordem; ao pessoal da secretaria da pós, Ana Paula, Beth e Laura, que sempre foram tão atenciosas e de alta competência no trabalho que realizam; aos funcionários da biblioteca, do bandejão e de todos os demais que ajudam a faculdade funcionar e permitem o desenvolvimento de nossos estudos com qualidade e em um campus organizado.

Deixo aqui também registrados meus agradecimentos a uma turma de amigos muito especial lá de Martinópolis: os Beltranos. Somos amigos desde crianças e temos acompanhado cada passo pessoal e profissional uns dos outros. Não foi diferente comigo neste mestrado. Caros beltranos, obrigado pelo apoio, pelo incentivo e pela amizade de todos vocês. Obrigado pela amizade de hoje, de ontem e de sempre.

Quero ainda manifestar minha gratidão aos dois outros moradores lá de casa: Caio e Danilo. Foram dois anos de paz, tranquilidade, divertimento, muitas pizzas e comilanças, :). Valeu Caio e valeu Dão.

Agradeço também à minha namorada Simone pela atenção e carinho que tem por mim. Há pouco que estamos juntos mas o suficiente pra perceber o quanto é especial e importante para mim. Pessoa formidável.

Agradeço também à Igreja Batista Unida de Martinópolis, pelas orações e pelo carinho dos irmãos a quem tanto amo. Senti muitas saudades da minha amada igreja nestes dois anos. Moram todos no meu coração.

Agradeço ao CNPq pelo auxílio financeiro. 
I believe in Christianity as I believe that the sun has risen: not only because I see it, but because by it

I see everything else.

(C. S. Lewis) 
Uma investigação sobre como a programação orientada a aspectos combinada com a tecnologia de componentes pode encapsular os interesses transversais de um sistema é apresentada. Como resultado desta investigação, um método para o desenvolvimento de software baseado em componentes e aspectos é proposto, cujas etapas, atividades e artefatos são mostrados por meio do exemplo de um Sistema de Reservas de Hotéis, juntamente com sua implementação nas linguagens JAsCO e AspectJ. O método é uma extensão do método UML Components e utiliza a UML com algumas adaptações. Além disso, uma estratégia de generalização e documentação de componentes transversais para que possam ser reusados em outras aplicações é proposta. Adicionalmente, o método proposto foi usado para o projeto de um Sistema de Locação de Carros e o resultado foi comparado com uma outra solução para o mesmo problema, baseada em UML Components e uma arquitetura geral para sistemas na Web. O resultado dessa comparação é apresentado e discutido. 
An investigation about how aspect oriented programming combined with the components technology can encapsulate the crosscuting concerns of a system is presented. As result of this research, a method for the aspect and component based software development is proposed, whose phases, activities and design's elements are shown by means of an example of a Hotel Reservation System, with its implementation in the JAsCO and AspectJ languages. The method is an extension of the UML Components method and uses UML with some adaptations. Moreover, a strategy to the generalization and documentation of crosscutting (or aspectual) components to be reused in other applications is proposed. Additionally, the proposed method was used to design a Car Rental System and the result was compared with another solution for the same problem, based on UML Components and a general architecture for Web systems. The results of the comparation are presented and discussed. 
Resumo

$\begin{array}{ll}\text { Abstract } & \text { ii }\end{array}$

1 Introdução $\quad 1$

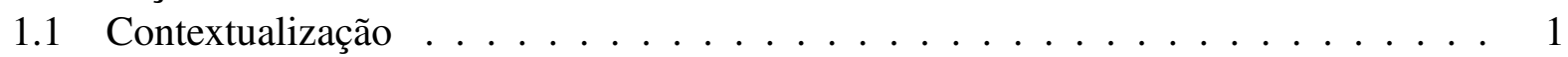

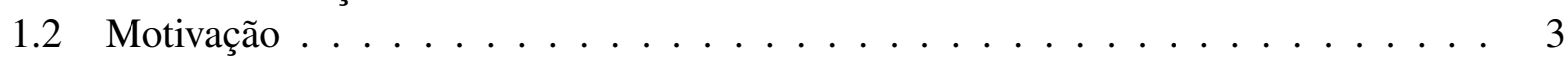

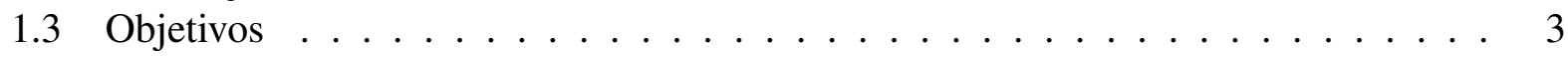

1.4 Organização . . . . . . . . . . . . . . . . . . . . 4

2 Desenvolvimento de Software Baseado em Componentes 6

2.1 Considerações Iniciais . . . . . . . . . . . . . . . . . . . . 6

2.2 Introdução ao conceito de componentes de software . . . . . . . . . . . . . . . 7

2.2 .1 Princípios . . . . . . . . . . . . . . . . . 10

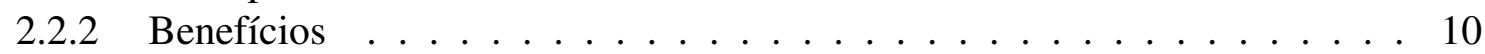

2.3 Métodos para o Desenvolvimento de Software Baseado em Componentes . . . . . 12

2.3 .1 O Método UML Components . . . . . . . . . . . . . . . . . . . 12

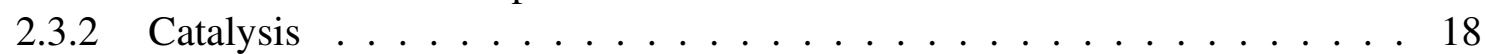

2.3 .3 O Método KobrA . . . . . . . . . . . . . . . . . . 18

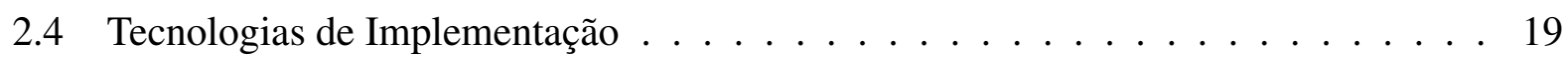

2.4.1 Componente Object Model (COM) _ . . . . . . . . . . . . . . . 20

2.4 .2 Java Beans . . . . . . . . . . . . . . . . . . . 20

2.4.3 Commom Object Request Broker Architecture (CORBA) . . . . . . . . . . 21

2.5 Considerações Finais . . . . . . . . . . . . . . . . . . 22

3 Componentes e Aspectos $\quad 24$

3.1 Considerações Iniciais . . . . . . . . . . . . . . . . . . . . . . . 24

3.2 Desenvolvimento de Software Orientado a Aspectos . . . . . . . . . . . . . . . 26

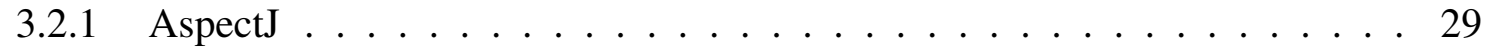

3.3 Métodos de Desenvolvimento de Software Orientado a Aspectos . . . . . . . . . . 32

3.3.1 Análise e Projeto Orientado a Aspectos: a Abordagem Tema . . . . . . . . 32

3.3.2 Um Enfoque Baseado em Modelos para o Projeto Orientado a Aspectos . . 33

3.3.3 Desenvolvimento de Software Orientado a Aspectos com Casos de Uso . . 33

3.4 Desenvolvimento de Software Baseado em Componentes e Aspectos . . . . . . . . 34

3.4.1 A abordagem de Grundy: Aspect-Oriented Component Engineering(AOCE) 35 
3.4.2 Componentes e Aspectos com UML . . . . . . . . . . . . . . . . . . . 39

3.4.3 Desenvolvimento de Componentes com Aspectos . . . . . . . . . . . . . . 41

3.4.4 Abordagens baseadas em linguagens . . . . . . . . . . . . . . . . 42

3.5 Considerações Finais . . . . . . . . . . . . . . . . . . . . . . 54

4 Proposta de um Método Para o Desenvolvimento de Software Baseado em Componentes e Aspectos (DSBC/A)

4.1 Considerações Iniciais . . . . . . . . . . . . . . . . . . . 56

4.2 O processo de construção do método . . . . . . . . . . . . . . . . . . 57

4.3 Visão Geral do Método . . . . . . . . . . . . . . . . . . . . . . . . 58

4.4 Análise de Requisitos . . . . . . . . . . . . . . . . . . . . . . . . 60

4.4.1 Criar Modelos de Processos de Negócio . . . . . . . . . . . . . . . 61

4.4 .2 Identificar casos de uso funcionais . . . . . . . . . . . . . . . . . 62

4.4 .3 Identificar atores . . . . . . . . . . . . . . . . . . 63

4.4.4 Construir o diagrama de casos de uso funcionais . . . . . . . . . . . 63

4.4.5 Descrever os casos de uso funcionais . . . . . . . . . . . . . . 64

4.4.6 Identificar casos de uso não-funcionais . . . . . . . . . . . . . . . . 65

4.4.7 Descrever os casos de uso não-funcionais . . . . . . . . . . . . . . 66

4.4.8 Integrar casos de uso não-funcionais no diagrama de casos de uso funcional 68

4.4.9 Criar Modelo Conceitual de Negócio (F / NF) . . . . . . . . . . . . . . . 69

4.4 .10 Identificar Casos de Uso Transversais . . . . . . . . . . . . . . . . . . 70

4.5 Especificação . . . . . . . . . . . . . . . . . . . . 71

4.5.1 Identificação dos Componentes-Base . . . . . . . . . . . . . . 72

4.5.2 Interação dos Componentes-base . . . . . . . . . . . . . . . . . . 75

4.5.3 Identificação dos Componentes Transversais . . . . . . . . . . . . . 76

4.5.4 Interação entre os Componentes-base e transversais . . . . . . . . . . . . . . . 90

4.5.5 Especificação dos Componentes-Base e Transversais . . . . . . . . . . . . 94

4.6 Provisionamento . . . . . . . . . . . . . . . . . . 95

4.6.1 Estratégias de implementação dos componentes transversais . . . . . . . . 97

4.6 .2 Generalização . . . . . . . . . . . . . . . . . . . . . . . . . . . . . . . . . . . . . . . . .

4.6 .3 Documentação . . . . . . . . . . . . . . . . . . . . . . . . . . . . . . . . . . . . . . . . .

4.7 Montagem . . . . . . . . . . . . . . . . . . . . . . 112

4.8 Considerações Finais . . . . . . . . . . . . . . . . . . . 115

5 Uso e Avaliação Comparativa do Método Proposto 117

5.1 Considerações Iniciais . . . . . . . . . . . . . . . . . . . . 117

5.2 Projeto do Sistema de Locação de Carros(SLC) pelo método DSBC . . . . . . . . 118

5.3 Projeto do Sistema de Locação de Carros(SLC) pelo método DSBC/A . . . . . . . 120

5.4 Reúso de Componentes Transversais . . . . . . . . . . . . . . . . . 126

5.4.1 Mudança nos requisitos do Sistema de Locação de Carros . . . . . . . . . 126

5.4.2 Análise da documentação do componente GerRegistroOp . . . . . . . . 126

5.4 .3 Reúso no projeto . . . . . . . . . . . . . . . 127

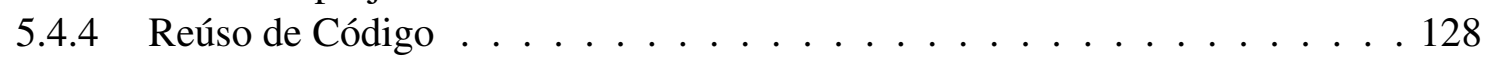

5.4.5 Avaliação desta experiência de reúso . . . . . . . . . . . . . . . . 130

5.5 Comparação entre o projeto DSBC/A e DSBC . . . . . . . . . . . . . . 130

5.5 .1 Avaliação Geral . . . . . . . . . . . . . . . . . . . . . 131

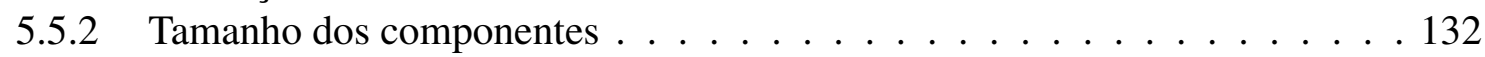

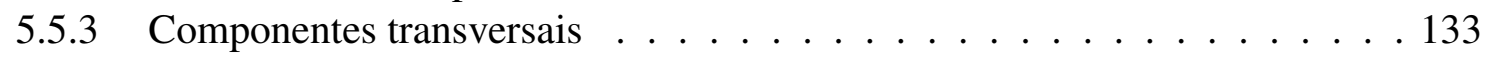


5.6 Considerações Finais . . . . . . . . . . . . . . . . . . . . 135

6 Conclusão 136

6.1 Considerações Iniciais $\ldots \ldots$. . . . . . . . . . . . . . . . . 136

6.2 Contribuições . . . . . . . . . . . . . . . . . . . . . . . . . . . . . . . . . . . . . . . . . . . . . . .

6.3 Trabalhos Futuros . . . . . . . . . . . . . . . . . 138

A Documento de Requisitos do Sistema de Reservas de uma Rede de Hotéis 145

A.1 Descrição Geral do Sistema . . . . . . . . . . . . . . . . . . . . . 145

A.2 Requisitos Funcionais . . . . . . . . . . . . . . . . . . 146

A.2.1 Operações básicas do sistema . . . . . . . . . . . . . . . . 146

A.2.2 Reserva . . . . . . . . . . . . . . . . . 146

A.2.3 Emissão de relatórios e consultas . . . . . . . . . . . . . . . . . . 147

A.3 Requisitos Não Funcionais . . . . . . . . . . . . . . . . . . . . . . 147

A.3.1 Segurança . . . . . . . . . . . . . . . . 147

A.3.2 Controle de Acesso . . . . . . . . . . . . . . . . . . . . . . 148

A.3.3 Persistência . . . . . . . . . . . . . . . . . . . . . . . . . . . . . . . . . . . . . . . . . . .

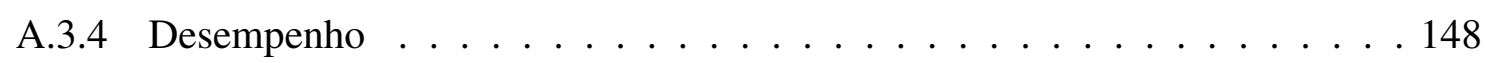

A.4 Glossário . . . . . . . . . . . . . . . . . . . . . . . . . 148

B Documento de Requisitos do Sistema de Locação de Carros 150

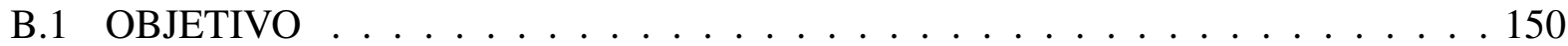

B.2 DEFINIÇÃO DO PROBLEMA . . . . . . . . . . . . . . . . . 150

B.2.1 DESCRIÇÃO DOS SERVIÇOS . . . . . . . . . . . . . . . . 152

C Plano de Estudo de Caso para a Avaliação Comparativa entre os métodos DSBC e DSBC/A

C.1 Identificação do Contexto do Estudo de Caso . . . . . . . . . . . . . . . . . . . 154

C.2 Definição das Hipóteses . . . . . . . . . . . . . . . . . . . . . . 155

C.3 Seleção do Projeto Piloto . . . . . . . . . . . . . . . . . . . . . 156

C.4 Identificação do Método de Comparação . . . . . . . . . . . . . . . . . . . . . . . . . . . . . . . . . . . . . . .

C.5 Redução dos Efeitos dos Fatores de Distorção . . . . . . . . . . . . . . . . . . 156

C.6 Planejamento do Estudo de Caso . . . . . . . . . . . . . . . . . . . . . . . . . . . . . . . . . . . . . . . . . . . . . . .

C.6.1 Definição . . . . . . . . . . . . . . . . . . . 157

C.6.2 Planejamento . . . . . . . . . . . . . . . 157

C.6.3 Operação . . . . . . . . . . . . . . . . . . . 158

C.6.4 Interpretação . . . . . . . . . . . . . . . . . 158 


\section{Lista de Figuras}

2.1 Substituição de componentes com baixo impacto (Cheesman e Daniels, 2000) . . . 11

2.2 Etapas do método de desenvolvimento com componentes (Cheesman e Daniels, 2000). . . . . . . . . . . . . . . . . . . 13

2.3 Refinamento da Etapa de Especificação (Cheesman e Daniels, 2000) . . . . . . . . 14

2.4 Um arquitetura de componentes inicial para um sistema de reserva para hotéis (Cheesman e Daniels, 2000) . . . . . . . . . . . . . . 15

2.5 Interfaces do Sistema e assinaturas de suas operações . . . . . . . . . . . . . . 16

2.6 Interfaces de Negócio e assinaturas de suas operações . . . . . . . . . . . . . . . 16

2.7 Especificação da Interface IGesCliente . . . . . . . . . . . . . . . . 17

2.8 Especificação do componente SistemaReserva . . . . . . . . . . . . 18

3.1 Implementação de rastreamento - espalhamento e entrelaçamento de código. . . . . 27

3.2 Implementação de rastreamento com aspectos. . . . . . . . . . . . . . . . . . . . 28

3.3 Implementação de Rastreamento em AspectJ . . . . . . . . . . . . . . . . . . . . . 29

3.4 Implementação de um adendo identificando os pontos de junção a entrecortar . . . 31

3.5 Exemplo de declaração inter-tipos . . . . . . . . . . . . . . . . . . 32

3.6 Componentes do Sistema de Vídeo e alguns de seus aspectos (Grundy e Patel, 2001) 37

3.7 Projeto orientado a aspectos de uma parte do sistema de vídeo locadora (Grundy e Patel, 2001) . . . . . . . . . . . . . . . . . 38

3.8 Diagrama de componentes na fase de especificação (Clemente et al., 2002) . . . . . 40

3.9 Interação entre componentes na fase de interação (Clemente et al., 2002) . . . . . . 41

3.10 Interação entre componentes na fase de interação (Clemente et al., 2002) . . . . . . 42

3.11 aspect bean implementando controle de acesso (adaptado de Suvée et al. (2003) . . 44

3.12 Um Conector que instala um gancho nos componentes Printer e Fax . . . . . . . . 45

3.13 Estratégias de Precedência (Suvée, 2005) . . . . . . . . . . . . . . . 46

3.14 Modelo de Componentes JAsCo Beans (Suvée et al., 2003) . . . . . . . . . . . . . 47

3.15 Arquitetura de Componentes Unificada (adaptado de Suvée et al. (2005)) . . . . . 49

3.16 Interface do Componente Booking Service (Suvée et al., 2005) . . . . . . . . . 51

3.17 Interface do Componente Discount Service (Suvée et al., 2005) . . . . . . . . 51

3.18 Interface do Componente Payment Service (Suvée et al., 2005) . . . . . . . . . 52

3.19 Conector que descreve uma composição regular entre componentes (Suvée et al.,

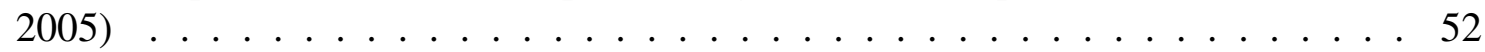

3.20 Conector que descreve uma composição aspectual entre componentes (Suvée et al., 2005) 
4.1 Processo do Método UML Components (Cheesman e Daniels, 2000) com pequenas adaptações . . . . . . . . . . . . . . . . . . . . . . 59

4.2 Atividades da Análise de Requisitos . . . . . . . . . . . . . . . . . . . . 61

4.3 Diagrama de Atividades do Sistema de Reservas de Hotel . . . . . . . . . . . . . . 62

4.4 Diagrama de Casos de Uso Funcionais do Sistema de Reservas de Hotel . . . . . . 65

4.5 Gabarito para descrição de casos de uso funcionais . . . . . . . . . . . . . . 65

4.6 Descrição do caso de uso funcional Fazer Reserva . . . . . . . . . . . . . . . . . 66

4.7 Descrição do caso de uso não-funcional Registrar Operação . . . . . . . . . . . . . . . 67

4.8 Diagrama Parcial de Casos de Uso Funcionais e Não-Funcionais ～. . . . . . . . . . . 68

4.9 Modelo Conceitual de Negócio Funcional . . . . . . . . . . . . . . . . . . . . . . 69

4.10 Modelo Conceitual de Negócio Não-Funcional . . . . . . . . . . . . . . . . 70

4.11 Etapa de Especificacao dos Componentes . . . . . . . . . . . . . . . . 72

4.12 Etapa de Identificação dos Componentes-Base . . . . . . . . . . . . . . . . . 73

4.13 Modelo de Tipos Básicos Funcional . . . . . . . . . . . . . . . . . . . . . . 74

4.14 Arquitetura Inicial de Componentes-Base . . . . . . . . . . . . . . . . 75

4.15 Atividades da etapa de Interação de Componentes-Base . . . . . . . . . . . . . . 75

4.16 Diagrama de colaboração para a operação fazer reserva . . . . . . . . . . . . . 76

4.17 Interface IGesCliente detalhada . . . . . . . . . . . . . . . . . 76

4.18 Etapa de Identificação dos Componentes Transversais . . . . . . . . . . . . . 77

4.19 Exemplo da aplicação do critério de atomicidade . . . . . . . . . . . . . . . 78

4.20 Interface Transversal de Sistema ITRegistrarOperacao . . . . . . . . . . . . . . . 83

4.21 Modelo de Tipos Básicos Não-Funcionais . . . . . . . . . . . . . . . . . . . . 84

4.22 Algoritmo de criação de novas interfaces para entrecorte . . . . . . . . . . . . 86

4.23 Nova Interface IGerEntrada . . . . . . . . . . . . . . . . . . . . 87

4.24 Notação para indicar operações entrecortadas . . . . . . . . . . . . . . . . . 88

4.25 Arquitetura Parcial de Componentes-Base e Transversais - Registrar Operação . . . 89

4.26 Atividades da etapa de Interação de Componentes-Base e Transversais . . . . . . . 90

4.27 Diagrama de Colaboração da operação registrarOperacaoExecutada( op ) . . . . . . 91

4.28 Interface de Negócio IGesAcesso . . . . . . . . . . . . . . . . . . . . 91

4.29 Diagrama de Colaboração de um entrecorte do tipo before . . . . . . . . . . . . . 92

4.30 Diagrama de Colaboração de um entrecorte do tipo after . . . . . . . . . . . . . 93

4.31 Diagrama de Colaboração de um entrecorte do tipo before e after juntos . . . . . . 93

4.32 Diagrama de Colaboração de um entrecorte do tipo around . . . . . . . . . . . . . 94

4.33 Atividades da etapa de Especificação de Componentes Base e Transversais . . . . . 94

4.34 Especificação da interface IGesHotel . . . . . . . . . . . . . . . . . . . 995

4.35 Especificação da interface ITRegistrarOperacao . . . . . . . . . . . . . . . . . 96

4.36 Mapeamento do projeto de um componente transversal para a linguagem JAsCO . . 98

4.37 Projeto do componente GerRegistroOp . . . . . . . . . . . . . . . . . . . 99

4.38 Código-fonte do componente transversal GerRegistroOp em JAsCO . . . . . . . . 100

4.39 Mapeamento do projeto de um componente transversal para a linguagem AspectJ . 101

4.40 Código-fonte do componente transversal GerRegistroOp em AspectJ . . . . . . . . 102

4.41 Componente Transversal Genérico de Registro de Execução de Operações . . . . . 103

4.42 Conector que liga o componente GerLog ao componente Impressora . . . . . . . . 103

4.43 Reuso caixa-branca em JAsCO . . . . . . . . . . . . . . . . . . . . . 104

4.44 Componente Transversal Genérico de Registro de Execução de Operações . . . . . 105

4.45 Conector que liga o componente GerLog ao componente Impressora (after) . . . 105

4.46 Conector que liga o componente GerLog ao componente Impressora (before e after) 106

4.47 Componente Transversal Genérico de Registro de Execução de Operações . . . . . 106 
4.48 Conector que liga o componente GerLog ao componente Impressora . . . . . . . 107

4.49 Conector que liga o componente GerLog ao componente Impressora . . . . . . . . 107

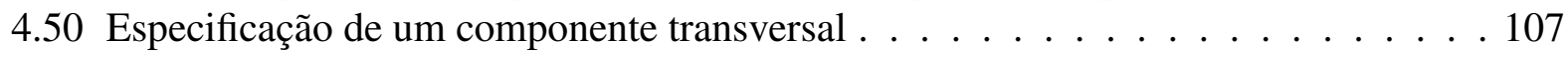

4.51 Especificação da interface de um componente transversal . . . . . . . . . . . . . . 108

4.52 Comportamento de uma das operações de um componente transversal . . . . . . . 109

4.53 Comportamento de entrecorte de um componente transversal . . . . . . . . . . . 109

4.54 Especificação do componente transversal GerRegistroOp . . . . . . . . . . . . . 110

4.55 Especificação da Interface ITRegistrarOperacao . . . . . . . . . . . . . . . . . . 110

4.56 Comportamento da operação registrarOperacaoExecutada(op) . . . . . . . . . . . 111

4.57 Comportamento do entrecorte do componente GerRegistroOp . . . . . . . . . . 111

4.58 Cenários genéricos de entrecorte . . . . . . . . . . . . . . . . 113

4.59 Implementação de Conectores na linguagem JAsCO e AspectJ . . . . . . . . . . . 113

4.60 Diagrama parcial de componentes (GerReserva e GerRegistroOp) . . . . . . . . . 114

4.61 Código-fonte do conector que liga o componente GerReserva ao GerRegistroOp . . 114

4.62 Aspecto concreto que determina os pontos em que GerReserva é entrecortado por GerRegistroOp . . . . . . . . . . . . . . . . . 115

5.1 Arquitetura do Sistema de Locação de Carros produzido com o uso do método UML Componentes (Sass, 2003) … . . . . . . . . . . . . . 119

5.2 Diagrama de Casos de Uso Funcional do SLC . . . . . . . . . . . . . . . . . . . 121

5.3 Diagrama de Casos de Uso Funcional e Não-Funcional (Controlar Acesso) . . . . . 122

5.4 Modelo Conceitual Funcional do SLC . . . . . . . . . . . . . . . . . . 122

5.5 Modelo Conceitual Não-Funcional do SLC . . . . . . . . . . . . . . . 123

5.6 Arquitetura de componentes-base do SLC . . . . . . . . . . . . . . . . . 123

5.7 Operações das interfaces de sistema do SLC . . . . . . . . . . . . . . . . . . . 124

5.8 Arquitetura de componentes-base e transversais (GerControleAcesso) . . . . . . 125

5.9 Arquitetura de Componentes do Sistema de Locação de Carros com o componente transversal GerRegistroOp . . . . . . . . . . . . . . . . . . 128

5.10 Interação entre GerRegistroOp e GerLocadoraPub (entrecorte) . . . . . . . . . . . 129

5.11 Conector em JAsCO para GerRegistroOp ～. . . . . . . . . . . . . . . . 129

5.12 Conector em AspectJ para GerRegistroOp . . . . . . . . . . . . . . . . . . 129 


\section{Lista de Tabelas}

3.1 Tipos de pontos de junção do AspectJ e suas respectivas sintaxes (adaptado de Laddad (2003)) . . . . . . . . . . . . . . . . . . . . . 30

4.1 Modelo de Tabela que relaciona requisitos e casos de uso . . . . . . . . . . . . 62

4.2 Casos de Uso Funcionais do Sistema de Reservas de Hotel . . . . . . . . . . . . . 63

4.3 Casos de Uso Não-Funcionais do Sistema de Reservas de Hotel . . . . . . . . . . . 67

4.4 Casos de Uso Transversais do Sistema de Reservas de Hotel . . . . . . . . . . . 71

4.5 Análise dos casos de uso transversais . . . . . . . . . . . . . . . . . . 83

4.6 Tabela de entrecorte . . . . . . . . . . . . . . . . . . . 86

4.7 Operações do Componente-Base GerReserva entrecortadas pelo Componente Transveral GerRegistroOp ........................... 86

5.1 Interfaces e Operações dos Componentes do SLC . . . . . . . . . . . . . . . 120

5.2 Comparação entre os Componentes de Negócio da arquitetura DSBC/A e DSBC . 132

5.3 Comparação entre os Componentes de Sistema da arquitetura DSBC/A e DSBC . . 133

5.4 Comparação entre os Componentes Transversais da arquitetura DSBC/A e DSBC . 134

A.1 Glossário . . . . . . . . . . . . . . . . . . . . . . . 149 


\subsection{Contextualização}

O crescimento da demanda e da complexidade dos sistemas de software nas últimas décadas fez com que as linguagens e paradigmas de programação evoluíssem para cada vez mais permitir a decomposição dos sistemas em partes gerenciáveis com o objetivo de diminuir a complexidade do seu desenvolvimento. O princípio de decompor o software em módulos gerenciáveis para tratar separadamente cada funcionalidade, requisito ou característica do sistema é chamado de separação de interesses ${ }^{1}$ (Dijkstra, 1976), o que aumenta a flexibilidade, a compreensibilidade e a reusabilidade do software (Parnas, 1972; Tarr et al., 1999; Ossher e Tarr, 2000). .

A separação de interesses foi um dos motivos pelo qual as linguagens de programação evoluíram, como, por exemplo, das linguagens não estruturadas para as estruturadas, que passaram a ter funções, procedimentos e unidades, até chegar às orientadas a objetos, com classes, métodos e atributos. O princípio de separação de interesses também foi uma das motivações para o surgimento da abordagem de desenvolvimento de software baseado em componentes (DSBC), que propõe o desenvolvimento com componentes independentes, reusáveis e com funções claras e específicas para implementar interesses importantes de um sistema.

Apesar de contribuir para o aumento da separação de interesses nos sistemas, a evolução das linguagens comentada no parágrafo anterior não solucionam totalmente o problema, pois as linguagens de programação são afetadas por um problema chamado de tirania da decomposição dominante (Ossher e Tarr, 2001). Esta refere-se ao fato de que uma linguagem ou paradigma possui

\footnotetext{
${ }^{1}$ Um interesse (do inglês, concern) pode ser entendido como uma funcionalidade, característica ou preocupação do sistema, como, por exemplo, as regras de negócio e as entidades de dados (Ossher e Tarr, 2001)
} 
mecanismos capazes de encapsular apenas certos tipos de interesses e que se for usada para implementar outro tipo de interesse, estes são codificados de maneira inapropriada no sistema.

Como exemplo dos problemas causados pela tirania da decomposição dominante pode-se mencionar a utilização das classes do paradigma OO (orientado a objetos), que são adequadas para encapsular dados e operações relativas a uma funcionalidade do sistema. Quando há a necessidade de implementar um interesse como o rastreamento, por exemplo, este não pode ser encapsulado adequadamente por uma classe e sua codificação fica espalhada e entrelaçada pelos módulos do sistema. Isso significa que há código de rastreamento em várias classes do sistema e existem várias classes que implementam parte do rastreamento, além do interesse que deve implementar. Esse espalhamento e entrelaçamento de código tornam os sistemas mais difíceis de compreender, projetar, evoluir, manter e reusar (Kiczales et al., 1997).

Os interesses que tendem a ficar entrelaçados e espalhados pelos módulos do sistema por não poderem ser adequadamente encapsulados pela decomposição dominante de uma certa linguagem são chamados de interesses transversais ${ }^{2}$. Os interesses transversais em geral são provenientes de requisitos não-funcionais do sistema, mas também existem interesses transversais funcionais.

Recentemente, um novo paradigma de programação surgiu como evolução do paradigma OO para resolver ou amenizar os problemas causados pelo entrelaçamento e espalhamento de código dos interesses transversais e promover uma clara separação de interesses na implementação dos sistemas de software. Esse novo paradigma tem o nome de programação orientada a aspectos e foi inicialmente idealizado por Kiczales et al. (1997) e muitas pesquisas têm sido realizada na área desde então. A programação orientada a aspectos fornece mecanismos para o encapsulamento adequado dos interesses transversais por meio de módulos chamados de aspectos. Algumas linguagens de propósitos gerais e específicos foram desenvolvidas para o novo paradigma e a principal delas é a AspectJ (Kiczales et al., 2001a,b).

O paradigma de desenvolvimento de software baseado em componentes (DSBC) também sofre da tirania da decomposição dominante e interesses transversais são implementados entrelaçados e espalhados por vários componentes, o que dificulta a manutenção, evolução e reúso dos componentes (Clemente e Hernández, 2003). Com o objetivo de amenizar esses problemas, as tecnologias de implementação de componentes passaram a implementar alguns interesses transversais em contêineres e oferecer como serviços aos componentes. Um contêiner é um programa ou subsistema no qual os componentes do sistema são executados.

Com os interesses transversais implementados nos contêineres e podendo ser usados pelos componentes, esses interesses transversais não precisam ser implementados pelos componentes do sistema. Apesar disso, as chamadas aos serviços oferecidos pelos contêineres continuam espalhadas pelos componentes do sistema que usam os serviços. Outro problema é o fato de os serviços oferecidos pelos contêineres serem fixos e a implementação de um interesse transversal não previsto pela tecnologia ficar espalhada e entrelaçada pelos componentes (Duclos et al., 2002).

\footnotetext{
${ }^{2}$ Tradução do termo crosscutting concern
} 
Diante disso, para que os sistemas baseados em componentes possam ser implementados de forma mais legível, mais fácil de projetar, manter e evoluir, além de projetar componentes mais coesos, flexíveis e reusáveis, pesquisas têm sido realizadas com o intuito de integrar os conceitos da programação orientada a aspectos e componentes. Os objetivos são introduzir os mecanismos de composição aspectual nos componentes e tornar os aspectos mais independentes, livres de contexto e reusáveis.

Nas pesquisas nessa área, surgiram tanto abordagens baseadas em linguagens pra desenvolver componentes com aspectos, como JAsCo (Suvée et al., 2003), FuseJ (Suvee, 2003) e Open Modules (Aldrich, 2004), quanto métodos de desenvolvimento, como o Aspect-Oriented Component Engineering (Grundy, 2000; Grundy e Patel, 2001) e o trabalho de Clemente et al. (2002).

\subsection{Motivação}

Por ser um tema de pesquisa muito recente, os pesquisadores da área primeiramente preocuparamse em estabelecer os conceitos e desafios da integração entre as tecnologias de componentes e aspectos, bem como a criação de linguagens específicas que oferecessem mecanismos adequados para a implementação de sistemas com componentes e aspectos. Trabalhos nessa linha já estão em andamento e alguns resultados estão disponíveis (Lieberherr et al., 1999; Suvée et al., 2003; Vanderperren et al., 2005; Suvée, 2004; Suvée et al., 2005; Aldrich, 2004).

Neste segundo momento está clara a necessidade de criação de métodos para apoiar o desenvolvimento de software baseado em componentes e aspectos. Como há na literatura poucas propostas de métodos para desenvolver software combinando componentes e aspectos, há muito espaço para pesquisas e experimentação. É neste contexto que este trabalho está inserido.

Um método para o desenvolvimento de software baseado em componentes e aspectos que leve em consideração as características essenciais de cada tecnologia permitiria que os sistemas baseados em componentes fossem construídos de forma mais legível, ou seja, sem haver interesses transversais espalhados e entrelaçados pelo sistema. Isso permitiria que o acoplamento entre os componentes diminuísse e aumentasse sua coesão, facilitando, conseqüentemente, sua manutenção, evolução e reúso.

\subsection{Objetivos}

O objetivo geral desta dissertação é investigar como projetar sistemas de software baseados em componentes que considere a tecnologia de desenvolvimento com aspectos. Além disso, também é objetivo investigar como generalizar e documentar componentes transversais (aspectos) para serem reusados em outras aplicações.

O objetivo específico é apresentar um método para o desenvolvimento de software baseado em componentes e aspectos (DSBC/A) como resultado da investigação realizada e da adaptação do 
método UML Components (Cheesman e Daniels, 2000) para considerar aspectos no desenvolvimento. O objetivo de integrar as duas tecnologias é desenvolver software com uma clara separação de interesses pela introdução de mecanismos da programação orientada a aspectos para encapsular os interesses transversais e, dessa forma, tornar os componentes mais coesos, fáceis de evoluir, manter e reusar.

Adicionalmente, apresenta-se um estudo comparativo com o projeto de um sistema baseado apenas em componentes normais e também um estudo de caso simples de reuso de componente transversal (aspecto).

\subsection{Organização}

Nos capítulos 2 e 3 é apresentada a revisão bibliográfica desta dissertação, que contém a fundamentação teórica para o desenvolvimento deste trabalho. No capítulo 2 são apresentados os fundamentos do desenvolvimento de software baseado em componentes, apresentando conceitos, princípios, objetivos, métodos e tecnologias de implementação. No capítulo 3 são abordados conceitos relativos à programação orientada a aspectos. Além disso, são discutidas propostas de pesquisas que se propõem a integrar os conceitos relativos a componentes e a aspectos, tanto para as linguagens de programação quanto para processos de desenvolvimento de software.

No capítulo 4, o método de desenvolvimento com componentes e aspectos é apresentado. As etapas gerais do método, suas atividades incluídas e alteradas em relação ao método UML Components, juntamente com as diretrizes e recomendações para melhor atingir o objetivo da etapa são descritas detalhadamente em cada seção do capítulo. Na descrição do método, as etapas e atividades que permaneceram inalteradas em relação ao UML Components não são apresentadas em detalhes. Cada artefato requerido por atividade é apresentado com as adaptações necessárias à notação UML para construí-los. Para apresentar o método proposto, é utilizado como exemplo o projeto de um Sistema de Reservas de Hotel (SRH), cujos requisitos foram extraídos e estendidos do livro de Cheesman e Daniels (2000). Além do projeto do SRH, também são apresentadas as diretrizes para mapear o projeto de componentes transversais (aspectos) para o código e a forma de generalizá-los e documentá-los para serem reusados posteriormente em outras aplicações.

No capítulo 5 é apresentada uma avaliação do método proposto. Primeiramente utilizou-se o método para desenvolver um Sistema de Locação de Carros, para avaliar se o método é adequado para desenvolver sistemas baseados em componentes e identificar, modularizar e projetar componentes transversais (aspectos). Em seguida realizou-se uma comparação dos resultados obtidos pelo método para o DSBC/A com uma solução construída para o mesmo problema por um método para o (DSBC), como o UML Components. Por fim, realizou-se uma experiência de reúso de um componente transversal que foi implementado para o Sistema de Reservas de Hotel e em seguida generalizado e documentado. O componente transversal foi reusado no Sistema de Locação de Carros e os resultados da experiência são relatados no capítulo. 
No capítulo 6 são apresentadas as conclusões deste trabalho, enfatizando-se as suas principais contribuições e apresentando-se propostas de trabalhos futuros em continuidade ao que foi realizado.

Por fim, nos apêndices A, B e C são mostrados, respectivamente, o documento de requisitos do sistema de reservas de hotel usado como exemplo nesta dissertação; o documento de requisitos do sistema de locação de carros usado no capítulo 5; e o plano de estudo de caso para a avaliação comparativa também apresentada no capítulo 5. 


\section{Desenvolvimento de Software Baseado em Componentes}

\subsection{Considerações Iniciais}

Com o surgimento de uma crescente demanda por sistemas de software cada vez maiores e mais complexos, e a necessidade de construir e evoluir esses sistemas em prazos curtos sem sacrificar a qualidade do processo e do produto, tornou-se necessária a utilização de tecnologias que promovam fortemente o reúso e facilitem a evolução de um software. Dentre essas tecnologias está a abordagem de Desenvolvimento de Software Baseado em Componentes (DSBC).

O desenvolvimento de software baseado em componentes tem o foco nas técnicas e práticas usadas para construir sistemas de software a partir de componentes previamente existentes, sejam comprados de terceiros ou implementados pelos próprios desenvolvedores do sistema. A abordagem procura libertar os programadores de pensar sobre detalhes de implementação para que possam se preocupar mais com a programação utilizada para a composição de sistemas de software. O foco deste paradigma de desenvolvimento é a a identificação, qualificação, adaptação, integração e atualização de componentes de software reusáveis (Kunda e Brooks, 2000; Pressman, 2002), que abrangem desde controles de interfaces com usuários até componentes para distribuição e de domínios específicos (Szyperski, 1998).

O desenvolvimento com componentes é um paradigma que pressupõe que há muitos pontos em comum entre vários sistemas de software e busca a construção de componentes independentes de contexto, que sejam reusáveis em vários domínios e que tenham foco na gestão de mudanças, o que implica a diminuição do tempo de desenvolvimento das aplicações e redução potencial dos 
custos de desenvolvimento e manutenção, permitindo aos desenvolvedores maior competitividade no mercado (Kunda e Brooks, 2000; Meijler e Nierstrasz, 1997; Szyperski et al., 2002).

Como o contexto deste trabalho envolve a construção de um método para o desenvolvimento de software baseado em componentes e aspectos, neste capítulo são abordados alguns temas relevantes sobre o assunto, como os conceitos e princípios básicos de componentes, assim como métodos e tecnologias de desenvolvimento. Na Seção 2.2 é feita uma introdução aos componentes de software, apresentando-se seus conceitos básicos, objetivos e princípios. Na Seção 2.3 são descritos alguns métodos de desenvolvimento com componentes conhecidos na literatura, como o UML Components de Cheesman e Daniels (2000), o Catalysis (D’Souza e Wills, 1999) e o método Kobra (Atkinson et al., 2000). Na Seção 2.4 são apresentadas algumas tecnologias de implementação de componetes, tais como Common Object Request Broker Architecture (CORBA), Component Object Model (COM) e Enterprise Java Beans (EJB), que surgiram como apoio ao desenvolvimento de software baseado em componentes e fomentaram a migração de muitos desenvolvedores para esse novo paradigma de desenvolvimento. Por fim, na Seção 2.5 são apresentadas as considerações finais deste capítulo.

\subsection{Introdução ao conceito de componentes de software}

Inicialmente, quando o conceito de componentes de software começou a surgir, houve uma grande tendência em se fazer analogias com os componentes utilizados em áreas como hardware, engenharias em geral, brinquedos, enfim, com muitos elementos que estão presentes no cotidiano das pessoas e que lembram o uso de componentes. Nas áreas citadas anteriormente, os componentes geralmente são vistos como elementos que possuem uma função específica e que quando são ligados uns aos outros podem formar uma estrutura maior para realizar uma determinada tarefa. Como esse conceito simples de componente está presente no cotidiano das pessoas, a impressão que se tinha era que o mundo todo já era orientado a componentes, com exceção das tecnologias de software (Szyperski, 1998).

Esse fato fez com que a tecnologia de componentes começasse a ser divulgada e vendida para as empresas, pois existia a idéia de que os componentes de software funcionariam da mesma maneira que nas outras áreas. Entretanto os componentes não tiveram grande aceitação por parte da maioria das indústrias, em razão da natureza do software ser diferente dos produtos de todas as outras áreas comparadas e o seu conceito não estar claramente definido (Szyperski et al., 2002).

Desde as primeiras pesquisas com componentes, passando pelo primeiro workshop de DSBC em 1998, em Kyoto, até o CBSE (Component-Based Software Engineering) de 2005 em St. Louis, Missouri-EUA, e outras conferências mais específicas como o ICSR (International Conference on Software Reuse) e WCOP (Workshop on Component-Oriented Programming), diversas definições para componentes têm sido apresentadas. Cada conceito apresentado varia de acordo com o 
contexto no qual o componente é utilizado, mas as características básicas e fundamentais para a definição de um componente são compartilhadas entre as conceituações.

Brown e Wallnau (1998) apresentam algumas visões do que é um componente, definindo-o como um elemento arquitetural, que deve prover e estar em conformidade com um conjunto de interfaces, preenchendo uma função clara no contexto de uma arquitetura (Brown e Wallnau, 1996); um elemento implementacional, que faz parte de um contexto arquitetural específico e que deve ser acessado por meio de interfaces bem documentadas, que podem ser descobertas em tempo de execução; e um elemento de negócio, que representa a implementação de um conceito autônomo de negócio ou processo, consistindo dos artefatos de software necessários para expressar, implementar e executar o conceito como um elemento reutilizável de um grande sistema de negócio.

Fuentes e Troya (2000) caracterizam conceitualmente um componente como uma unidade independente e coesa de um projeto lógico, contendo classes, funções e enumerações que são entidades lógicas, sendo o encapsulamento das informações o princípio básico para a construção do seu núcleo. Os componentes de software em geral funcionam como caixa-preta, escondendo os detalhes de implementação, em que o usuário do componente apenas precisa conhecer suas interfaces oferecidas e requeridas para usá-lo.

Segundo Szyperski et al. (2002), um componente de software é uma unidade de composição claramente identificável, com interfaces contratualmente especificadas e com dependências de contexto explícitas; uma unidade de instalação independente que está sujeita a composição com outros componentes; e uma unidade que não possui estado observável externamente. Além disso, um um componente precisa ter uma documentação apropriada e um grau de reutilização definido (Sametinger, 1997).

Para ser um elemento de composição com outros componentes, o componente precisa ser suficientemente auto-contido, ter uma função específica bem definida e interfaces claramente especificadas quanto às propriedades requeridas e oferecidas (Sametinger, 1997; D’Souza e Wills, 1999; Werner e Braga, 2000). Para um componente poder ser uma entidade de instalação independente é necessário poder separar claramente o componente de seu ambiente, de seu contexto de utilização e dos outros componentes (Sametinger, 1997).

Ser auto-contido significa que a função que o componente desempenha deve ser realizada por ele, de forma completa. Um componente também deve ser claramente identificável em um determinado contexto, de forma que possa ser facilmente definido. Um determinado componente não é completamente independente dos outros componentes e do ambiente e o que determina como se dá essa dependência em relação aos demais e ao ambiente que o cerca são suas interfaces. As interfaces de um componente determinam como o componente pode ser reutilizado e interconectado com outros componentes.

Szyperski (1998) define uma interface como um conjunto de assinaturas de operações que podem ser usadas por um cliente. Segundo Councill e Heineman (2001), a interface define o comportamento que pode ser executado externamente ao componente, que é obtido por considerar 
somente as interações de suas interfaces e por ocultar todas as demais interações. A conexão entre os componentes é realizada por meio de suas interfaces, podendo ser de maneira direta ou por meio de conectores que são componentes projetados exclusivamente para intermediar a conexão (Wills, 2001).

A documentação é também indispensável para o reúso dos componentes. Esta deve ser suficiente para que se possa recuperar um componente, avaliar sua adequabilidade para o contexto da reutilização, fazer adaptações (se for o caso) e integrar o componente ao seu novo ambiente. Outro conceito importante é o quê os pesquisadores chamam de grau de reutilização do componente, que contém informações de reúso, tais como: quantas vezes e onde o componente foi reutilizado, quem é responsável pela manutenção do componente e quem é o proprietário (Sametinger, 1997). Além disso, as garantias de alguns atributos de qualidade pelas certificações, como a quantidade de memória utilizada, desempenho e restrições, são muito importantes para a escolha do componente a ser reusado.

Um componente de software, de forma análoga a outras formas de reúso, impõe diferentes técnicas de utilização dependentes da disponibilidade do código fonte. A reutilização do componente de software que independe de sua implementação é denominada caixa preta, em oposição à reutilização caixa branca, que depende de como o componente de software é implementado.

No reúso caixa branca, os componentes são reusados após terem sido modificados para necessidades específicas. No reúso caixa preta, um componente é reusado diretamente, sem modificação ou então por herança, de forma que classes sejam especializadas a partir do componente. No reúso caixa de vidro, o componente não é diretamente usado, ao invés disso, ele se torna um exemplo de solução a ser seguido e, a partir dele, uma implementação é feita para resolver um problema semelhante (Meijler e Nierstrasz, 1997; Fellner e Turowski, 2000).

Segundo Cheesman e Daniels (2000), embora o reúso dos componentes seja um objetivo importante, a meta principal e um dos maiores desafios na construção de sistemas baseados em componentes é o gerenciamento de mudanças. Isto significa que, durante a construção dos componentes, deve haver uma atenção especial ao projeto e à arquitetura das dependências entre os componentes e o gerenciamento destas dependências. Deseja-se que os componentes sejam facilmente substituíveis, ou por uma implementação completamente diferente ou por uma versão nova da mesma implementação, permitindo assim que os sistemas possam evoluir sem grande impacto de mudanças.

No contexto deste trabalho, componente é definido como um elemento de construção e composição formado por classes e construções logicamente relacionadas que implementam um certo interesse de um sistema. O ocultamento das informações e detalhes de implementação são a base para a construção e utilização do componente, com exceção dos componentes que possuem pontos de variação e/ou precisem ser estendidos para serem reusados. Os serviços oferecidos pelos componentes podem apenas ser acessados por meio de interfaces claramente definidas e especificadas. 


\subsubsection{Princípios}

Os componentes de software são unidades estruturadas de acordo com alguns princípios específicos estendidos dos princípios fundamentais que dão suporte à tecnologia de objetos. Esses princípios, segundo Cheesman e Daniels (2000), são:

- Unificação entre dados e funções: um objeto de software encapsula dados e funções que processam esses dados, o que aumenta a coesão do objeto.

- Encapsulamento: os clientes dos objetos de software não precisam conhecer como os dados são armazenados e como as funções processam estes dados, ou seja, precisam conhecer a especificação, não a implementação. Esse princípio aumenta a separação de interesses e é a chave para o gerenciamento das dependências e redução do acoplamento no software.

- Identidade: Cada componente de software tem uma única identidade, sem considerar o estado do objeto.

Os componentes estendem esses princípios, mas diferem pelo fato de separar implementação e especificação, em que as especificações são divididas em interfaces. Isso significa que as dependências entre componentes podem ser restringidas por interfaces individuais, fazendo com que o impacto de mudanças seja reduzido, pois um componente em uso pode ser substituído por outro que até mesmo tenha uma especificação diferente, desde que suas especificações incluam as mesmas interfaces que o cliente do componente requer.

Um exemplo de como os componentes podem ser substituídos com um impacto mínimo é mostrado na Figura 2.1. No exemplo, o cliente utiliza interfaces estáveis e não será afetado pela substituição do componente utilizado (existente), pois o novo componente oferece a interface antiga utilizada (IX). Além disso, o novo componente pode oferecer novas funcionalidades $(\mathrm{IX}+)$ para os clientes antigos ou novos.

\subsubsection{Benefícios}

Segundo Meijler e Nierstrasz (1997), os motivos para o uso de componentes no desenvolvimento de software são:

- Tempo de desenvolvimento reduzido: aplicações construídas com o uso de componentes reusáveis podem ser entregues em prazos mais curtos e atender às pressões de mercado com preço competitivo.

- Confiabilidade: componentes reusados em muitas aplicações podem ser mais confiáveis que componentes novos. 


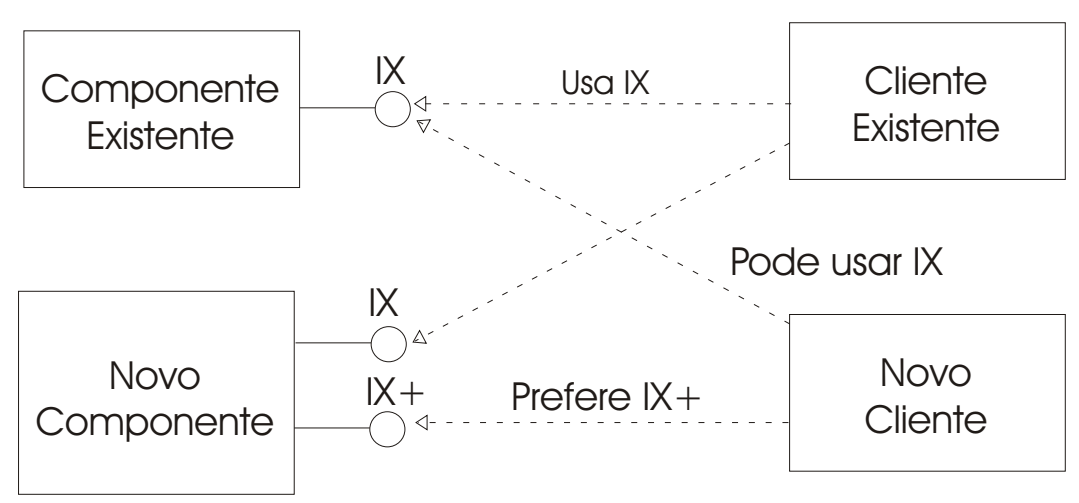

Figura 2.1: Substituição de componentes com baixo impacto (Cheesman e Daniels, 2000)

- Divisão de trabalho: componentes com interfaces bem definidas são unidades que podem ser distribuídas para serem desenvolvidas entre várias equipes de trabalho.

- Variabilidade: componentes oferecem variabilidade às aplicações porque permitem parametrização, que representa variações nas funcionalidades a serem fornecidas aos clientes do componente.

- Adaptabilidade: a utilização de componentes melhora o gerenciamento das mudanças que podem ocorrer no software e, assim, faz com que os componentes possam ser substituíveis graças à separação entre interface e implementação, bem como ao gerenciamento das dependências dos componentes (Cheesman e Daniels, 2000).

- Distribuição e Concorrência: componentes oferecem uma maneira natural de distribuir serviços e otimizar a utilização de recursos de hardware.

- Heterogeneidade: componentes de sistemas distribuídos podem ser desenvolvidos em diferentes plataformas e linguagens de programação e serem utilizados apenas pela sua interface, como por exemplo, por meio do uso de CORBA e de COM.

Uma característica essencial da arquitetura de componentes é a separação clara entre a definição das interfaces dos componentes de software e suas implementações. O benefício aqui alcançado é o ideal de poder utilizar um componente de software conhecendo-se apenas a definição de sua interface, tornando o sistema construído totalmente independente de qualquer implementação particular de algum componente de software (Szyperski, 1998).

A separação da especificação em diferentes interfaces permite que as dependências entre os componentes sejam restritas às interfaces especificadas e não a todo o componente. Com a separação, essa forma de reúso de software sustenta a possibilidade de que adaptações possam estar 
disponíveis pela simples troca de componentes, sem impacto sobre os clientes desses componentes, desde que esses novos componentes especifiquem, no mínimo, as mesmas interfaces dos componentes originais (Pree, 1997).

\subsection{Métodos para o Desenvolvimento de Software Baseado em Componentes}

O desenvolvimento de software baseado em componentes consiste não somente no uso ou desenvolvimento de componentes em si, mas na construção de sistemas pela composição de componentes, de acordo com um processo de desenvolvimento específico. Encontram-se na literatura alguns processos de desenvolvimento, como o o método UML Components de Cheesman e Daniels (2000), o Catalysis (D’Souza e Wills, 1999) e o método KobrA (Atkinson et al., 2000). Uma visão geral de cada método citado é apresentada nas subseções seguintes, com destaque para o método de Cheesman e Daniels (2000) que constitui a base para este trabalho.

\subsubsection{O Método UML Components}

O método UML Components é um método proposto por Cheesman e Daniels (2000) que possui um processo bem definido para o desenvolvimento de software baseado em componentes e utiliza a UML como notação para os elementos de projeto.

O método tem o objetivo de, a partir dos requisitos de negócio de um sistema, produzir uma arquitetura de componentes e suas especificações, conforme o processo mostrado na Figura 2.2. No processo, as caixas representam as etapas de trabalho (workflows) e as setas representam os fluxos dos artefatos produzidos e consumidos pelas etapas.

O processo global tem como entrada os requisitos de negócio de um sistema que é usado pela etapa de requisitos para produzir um modelo conceitual de negócio e modelos de casos de uso. Esses modelos, juntamente com os recursos existentes no sistema (sistemas legados, pacotes, base de dados) e as restrições técnicas do projeto (arquiteturas e ferramentas a serem usadas), formam as entradas necessárias para que a etapa de especificação produza as especificações dos componentes, das interfaces requeridas/oferecidas e a arquitetura de componentes, que mostra como os componentes interagem entre si.

Essas saídas (especificações e arquitetura) serão usadas na etapa de provisionamento para definir quais componentes serão reutilizados e quais precisam ser comprados ou construídos. A etapa de provisionamento também inclui os testes de unidade para os componentes, para que possam ser utilizados na etapa de montagem.

A etapa de montagem recebe como entrada os recursos existentes, os modelos de casos de uso e os componentes, para poder juntá-los e formar uma nova aplicação ou integrá-los em uma apli- 


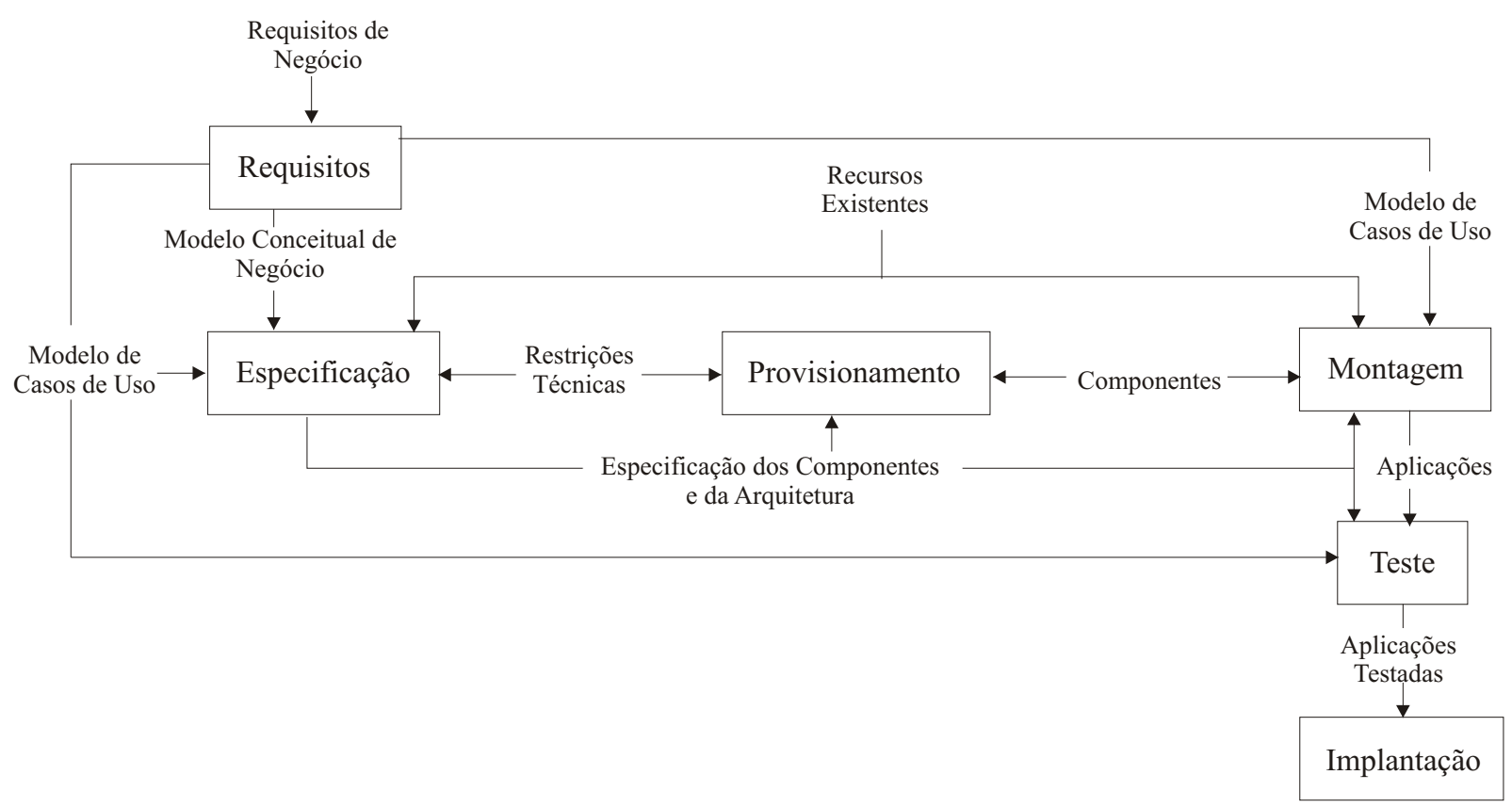

Figura 2.2: Etapas do método de desenvolvimento com componentes (Cheesman e Daniels, 2000).

cação já existente. Após a etapa de montagem, a aplicação é testada e em seguida disponibilizada para operação.

A etapa de especificação dos componentes é o foco principal do método de Cheesman e Daniels (2000) e é dividida em três sub-etapas: identificação, interação e especificação dos componentes. Os objetivos destas sub-etapas, artefatos produzidos e consumidos são ilustrados pela Figura 2.3 e detalhados nos tópicos a seguir.

\subsubsection{1 - Identificação dos Componentes}

A ênfase desta etapa é a descoberta de quais informações precisam ser gerenciadas pelos componentes, quais interfaces são necessárias para gerir essas informações, quais componentes são necessários para prover as funcionalidades e como tudo pode ser integrado. O objetivo principal é identificar um conjunto inicial de interfaces de negócio para os componentes de negócio, um conjunto inicial de interfaces do sistema e operações para os componentes do sistema. As interfaces de negócio possuem operações que fazem a gestão de dados do sistema e as interfaces de sistema possuem operações que implementam os as regras de negócio.

Após a identificação, as interfaces de negócio e de sistema devem compor uma arquitetura de componentes inicial. Outro artefato produzido nesta etapa é o modelo de tipos de negócio, que representa a visão do sistema sobre o modelo conceitual de negócios e é utilizado em um estágio posterior da etapa de especificação dos componentes. 


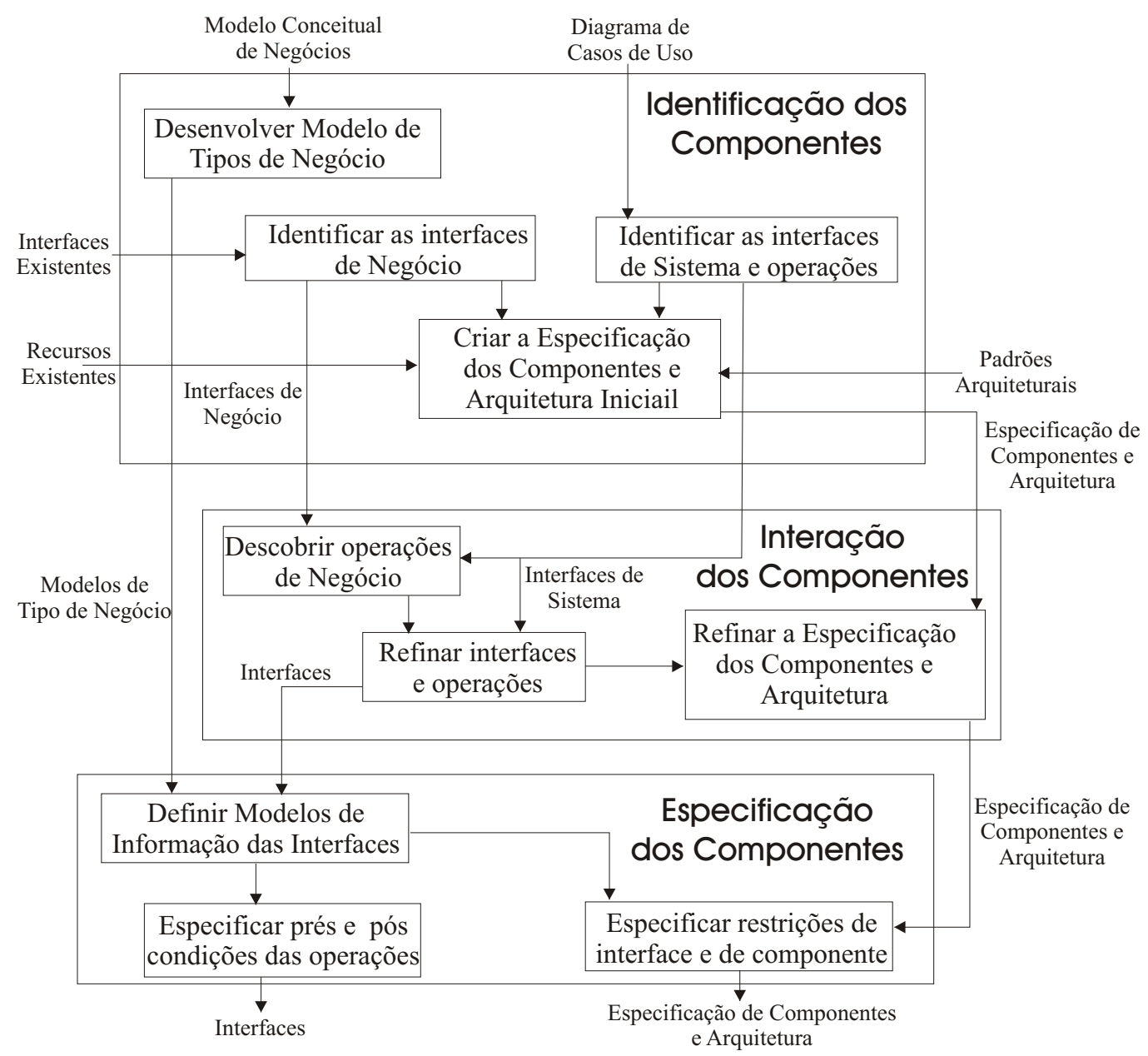

Figura 2.3: Refinamento da Etapa de Especificação (Cheesman e Daniels, 2000)

As interfaces e operações do sistema são descobertas por meio de casos de uso. Para cada passo de um caso de uso deve-se considerar se há ou não responsabilidades do sistema que precisam ser modeladas e representá-las como uma ou mais operações de uma interface apropriada do sistema. Isso permite a criação de um conjunto inicial de interfaces e operações que serão utilizadas na próxima etapa. As interfaces do sistema podem ser ampliadas por interfaces que são parte do ambiente no qual o sistema será implantado, como, por exemplo, um sistema de faturamento. Um modelo de tipos de negócio é desenvolvido e as regras de negócio devem ser capturadas e utilizadas como restrições no modelo.

As interfaces de negócio são abstrações das informações que devem ser geridas pelo sistema, como informações de um Cliente, por exemplo, e descobertas pela identificação dos tipos principais ou básicos do modelo de tipos de negócio, que são os tipos de informações que podem ser geridas independentemente das outras informações. Para isso deve-se refinar o modelo de tipos de negócio e identificar os tipos de negócio básicos, os quais dão origem às interfaces de negócio. Por fim, deve-se refinar o modelo de tipos básicos para indicar as responsabilidades das interfaces de negócio. 
Após a identificação das interfaces de negócio e de sistema, um conjunto inicial de especificações de componentes é criado, tendo-se uma visão de como eles são integrados para formar a arquitetura inicial dos componentes. Um exemplo de uma arquitetura inicial de um sistema pode ser visto na Figura 2.4, em que a arquitetura inicial de componentes para um sistema de controle de reserva de hotel (Cheesman e Daniels, 2000), com as interfaces de sistema IF a zerReserva e IOcuparReserva, e as interfaces de negócio IGes Hotel e IGesCliente. Já IFaturamento refere-se à interface de um sistema existente. O estereótipo de classe «comp spec» é utilizado para indicar a especificação de um componente.

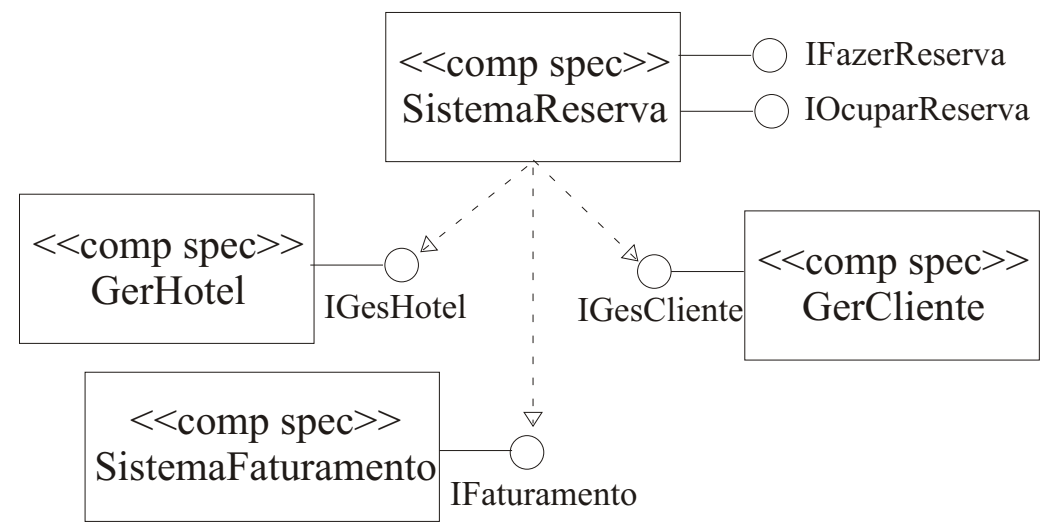

Figura 2.4: Um arquitetura de componentes inicial para um sistema de reserva para hotéis

(Cheesman e Daniels, 2000)

\subsubsection{2 - Interação dos Componentes}

A etapa de identificação dos componentes fornece um conjunto inicial de interfaces e componentes a serem utilizados na aplicação. Na etapa de interação dos componentes, decide-se como os componentes vão interagir para implementar os requisitos do sistema. Cada operação do sistema é modelada com o uso dos diagramas de interação (como o da UML, por exemplo) para descobrir operações nas interfaces de negócio e suas assinaturas.

Após a descoberta das operações das interfaces de negócio é necessário refinar as responsabilidades das interfaces e quebrar as dependências entre os componentes. Pode-se fatorar as interfaces com generalizações ou até mesmo investigar agrupamentos de interfaces alternativos, além de fatorar as operações para se tornar mais genéricas. Um exemplo de especificação de interfaces de sistema e de negócio com as assinaturas de suas operações pode ser visto na Figura 2.5 e 2.6, respectivamente. Para representar a especificação das interfaces é utilizado o estereótipo de classe «interface type». 


\begin{tabular}{|c|}
\hline $\begin{array}{c}<<\text { interface type }>> \\
\text { IFazerReserva }\end{array}$ \\
\hline \begin{tabular}{c}
\hline obterDetalhesHotel(in match: string): DetalhesHotel[] \\
obterInfoQuarto(in res:DetalhesReserva, out disponibilidade:Boolean, out preco: Currency) \\
fazerReserva (in res:DetalhesReserva, in cli:DetalhesCliente, out resRef:String):Integer
\end{tabular} \\
\hline \\
\hline$<<$ interface type $>>$ \\
IOcuparReserva \\
\hline $\begin{array}{l}\text { obterReserva (in resRef:String, out rd:DetalhesReserva, out cli:DetalhesCliente):Boolean } \\
\text { iniciarEstadia(in resRef:String, out NumeroQuarto:String):Boolean }\end{array}$ \\
\hline
\end{tabular}

\begin{tabular}{|c|}
\hline $\begin{array}{c}<\text { interface type }>> \\
\text { Ifaturamento }\end{array}$ \\
\hline abrirConta(in res:DetalhesReserva, in cli:DetalhesCliente) \\
\hline
\end{tabular}

Figura 2.5: Interfaces do Sistema e assinaturas de suas operações

\begin{tabular}{|c|}
\hline \multicolumn{1}{|c|}{$<<$ interface type $>>$} \\
IGesHotel
\end{tabular}

\begin{tabular}{|c|}
\hline $\begin{array}{c}<<\text { interface type }>> \\
\text { IGesCliente }\end{array}$ \\
\hline $\begin{array}{l}\text { obterClienteCorrespondente(in cliD:DetalhesCliente, out cliId:CliId):Integer } \\
\text { criarCliente(in cliD: DetalhesCliente, out cliId:CliId):Boolean } \\
\text { obterDetalhesCliente (in cli:CliId):DetalhesCliente } \\
\text { notificarCliente (in cli:cliId, in msg:String) }\end{array}$ \\
\hline
\end{tabular}

Figura 2.6: Interfaces de Negócio e assinaturas de suas operações

\subsubsection{3 - Especificação dos Componentes}

O objetivo geral desta etapa é especificar os contratos de uso e os contratos de realização dos componentes e interfaces. O contrato de uso é definido pela especificação de interface e o contrato de realização pela especificação do componente.

Deve-se fazer a especificação detalhada das interfaces de negócio e de sistema, que são o conjunto de operações que definem serviços e funções do objeto componente. Por meio das interfaces pode-se saber como gerenciar as dependências entre componentes, pois elas são unidades de contrato. A primeira tarefa para isso é descrever o estado dos objetos componente e assim especificar 
pré e pós-condições para as operações. Cada interface deve possuir um modelo de informação que especifica as operações das interfaces. O modelo de informação da interface é derivado do modelo de tipos de negócio e mostra os possíveis estados de um objeto componente e descreve as mudanças de estado dos objetos componente causados pelas operações. Esse modelo deve conter os parâmetros de entrada, os parâmetros de saída, os resultados da mudança de estado dos objetos componentes e as restrições aplicáveis. Um exemplo da especificação de uma interface pode ser visto na Figura 2.7. O estereótipo de classe «data type» é utilizado para representar tipos de dados estruturados como classes da UML.

\begin{tabular}{|c|c|}
\hline \multicolumn{2}{|c|}{$\begin{array}{c}<<\text { Interface type }>> \\
\text { IGesCliente }\end{array}$} \\
\hline \multicolumn{2}{|c|}{$\begin{array}{l}\text { obterClienteCorrespondente(in cliD:DetalhesCliente, out cliId:CliId):Integer } \\
\text { criarCliente(in cliD: DetalhesCliente, out cliId:CliId):Boolean } \\
\text { obterDetalhesCliente (in cli:CliId):DetalhesCliente } \\
\text { notificarCliente (in cli:cliId, in msg:String) }\end{array}$} \\
\hline $\begin{array}{c}<<\text { type }>> \\
\text { Cliente }\end{array}$ & $\begin{array}{l}<<\text { data type }>> \\
\text { DetalhesCliente }\end{array}$ \\
\hline $\begin{array}{l}\text { Id: CliID } \\
\text { nome: String } \\
\text { codPostal: String } \\
\text { email: String }\end{array}$ & $\begin{array}{l}\text { nome: String } \\
\text { codPosta[0..1]:String } \\
\text { email[0..1]:String }\end{array}$ \\
\hline
\end{tabular}

Figura 2.7: Especificação da Interface IGesCliente

Após a especificação das interfaces, a especificação dos componentes é realizada. Para cada especificação de componentes é necessário estabelecer a quais interfaces sua realização apóia. Um diagrama de especificação de componentes mostra a dependência de interfaces de objetos componentes e as interfaces oferecidas, como é mostrado na Figura 2.8. O componente Si stemaReserva oferece as interfaces IFazerReserva e IOcuparReserva e deve usar as interfaces IFaturamento, IGesHotel e IGescliente.

Por fim, uma análise das restrições entre interfaces deve ser feita. Essa análise trata dos relacionamentos entre os modelos de informação de interface, de como as interfaces oferecidas se relacionam entre si e com as interfaces usadas. Diferentes interfaces de uma especificação de componente podem fazer referência a um mesmo tipo e, portanto, deve-se definir explicitamente quais tipos são usados por quais interfaces, deixando explícito quando uma interface utiliza um tipo que pertence à outra.

O método UML Components (Cheesman e Daniels, 2000) não oferece mecanismos e diretrizes para o projeto de requisitos não-funcionais do sistema que tendem a ficar espalhados e entrelaçados pelo projeto e implementação do sistema. 


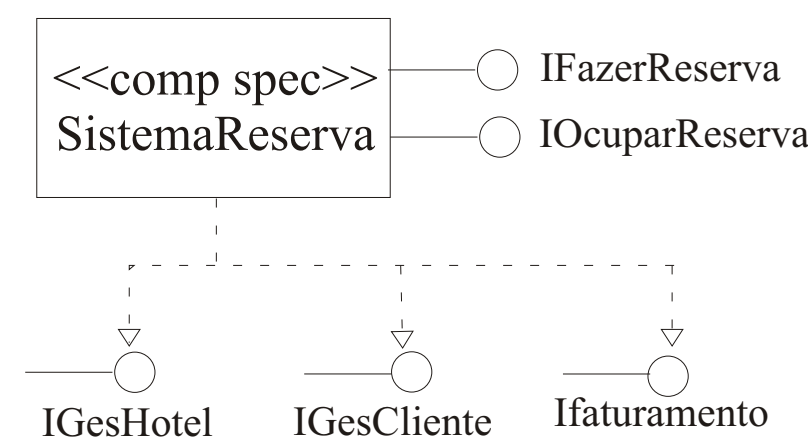

Figura 2.8: Especificação do componente SistemaReserva

\subsubsection{Catalysis}

O método Catalysis tem foco em prover um processo de desenvolvimento baseado em componentes que usa como estratégia a combinação de características dos métodos de análise e projeto nas fases iniciais de desenvolvimento, utilizando um tratamento sistemático de refinamentos contínuos até chegar a um projeto arquitetural bem definido e mapeá-lo para uma linguagem de programação (D’Souza e Wills, 1999).

Catalysis usa um processo iterativo e incremental baseado na definição abstrata de conceitos e mecanismos de refinamentos que são aplicados no decorrer do desenvolvimento do sistema, desde estágios iniciais como a análise até estágios finais como a implementação. Dessa forma, o desenvolvimento do sistema é visto como uma série de refinamentos dos conceitos, princípios e abstrações para níveis mais baixo de implementação, até chegar ao código.

\subsubsection{O Método KobrA}

O método KobrA foi desenvolvido no Instituto Fraunhofer e patrocinado pelo ministério alemão de pesquisa e tecnologia com o objetivo de dar apoio ao desenvolvimento dirigido por modelos (model-driven development); à representação de componentes com a UML para descrever a estrutura e comportamento essencial dos componentes, independentemente da tecnologia de implementação; e a uma abordagem de linhas de produto para o desenvolvimento e evolução de aplicações. Isso permite que os benefícios do desenvolvimento baseado em componentes possam ser obtidos em todo ciclo de vida do software e que a reusabilidade dos componentes possa aumentar significativamente (Atkinson et al., 2000).

O desenvolvimento dirigido por modelos para componentes busca desenvolver uma arquitetura dirigida por modelos em que as funcionalidades principais do sistema sejam descritas independentes de plataformas específicas de implementação, em que os modelos possam ser eficientemente transformados em componentes reusáveis, de forma verificável e aumentando a qualidade dos componentes e dos sistemas formados por eles. 
O objetivo principal do método é fornecer apoio concreto para o desenvolvimento e aplicação de framewoks de domínio específico baseado em componentes para desenvolver de linhas de produto de software. Para desenvolver uma aplicação concreta, o framework genérico, que é o artefato principal produzido pelo método, é instanciado pela tomada de decisões sobre quais funcionalidades farão parte da aplicação a ser gerada.

No KobrA, cada Komponente (componente KobrA) do framework é descrito por um diagrama UML adequado, como se fosse um sistema independente, feita em duas partes principais: a especificação, que descreve as características externas e visíveis do componente e especifica os requisitos; e a realização, que define como o componente satisfaz os requisitos. A especificação do Komponente consiste em quatro diagramas: estrutural, comportamental, funcional e de decisão, que descrevem as diferentes variações do Komponente.

\subsection{Tecnologias de Implementação}

Como apoio ao desenvolvimento de software baseado em componentes, algumas tecnologias de integração de componentes têm surgido ao longo do tempo, resultando em modelos de componentes que oferecem mecanismos com os quais os engenheiros de software podem desenvolver aplicações pela composição de componentes, definindo formas e interfaces padronizadas entre os componentes (Emmerich e Kaveh, 2001). Se os componentes de um sistema forem desenvolvidos isoladamente uns dos outros, objetivos primários como a instalação independente e montagem dos componentes são difíceis de ser alcançados, por causa de conflitos de interfaces, formas de comunicação, etc. Para evitar esses conflitos, os modelos forçam os componentes a aderirem a certos padrões, como, por exemplo, a forma de construir as interfaces requeridas ou oferecidas pelo componente (Crnkovic e Larsson, 2001).

As tecnologias de desenvolvimento possuem contêineres nos quais os componentes são implantados. Os contêineres implementam serviços para os componentes como registro de operações, distribuição, controle de acesso e persistência, por exemplo, que são interesses geralmente provenientes de requisitos não-funcionais do sistema. Esses interesses são chamados de interesses transversais por não poder ser encapsulados adequadamente pelos componentes de um sistema e serem geralmente implementados de forma espalhada (um interesse implementado em vários componentes) e entrelaçada (um componente implementando mais de um interesse) pelos componentes do sistema.

Como os contêineres dos componentes implementam alguns interesses transversais, alguns dos problemas de entrelaçamento e espalhamento de código são amenizados mas não resolvidos. As chamadas aos serviços oferecidos pelos contêineres continuam espalhadas pelos componentes do sistema que desejam usar os serviços, além dos serviços oferecidos serem fixos (Duclos et al., 2002). 
Atualmente, os três maiores modelos de componentes usados são o COM (Component Object Model), JavaBeans (Java) com o EJB e o CORBA (Common Object Request Broker Architecture), sendo que todos eles oferecem diferentes níveis de serviços (distribuição, por exemplo) para o desenvolvimento das aplicações.

As tecnologias COM, Java e CORBA oferecem os componentes COM, os JavaBeans e objetos CORBA como componentes básicos, respectivamente. A distribuição é fornecida por um protocolo que foi adicionado ao modelo de componentes básicos, em que o COM usa o COM distribuído (DCOM), o Java usa o RMI (Remote Method Invocation) e CORBA usa o protocolo Inter-ORB (IIOP). Já o apoio para componentes de negócio são encontrados no COM+, EJB e serviços CORBA.

O surgimento dessas tecnologias fomentou a migração de muitos desenvolvedores para esse novo paradigma de desenvolvimento, pois o desenvolvimento de software com componentes se tornou mais simples com os serviços que os modelos de componentes oferecem.

\subsubsection{Componente Object Model (COM)}

A tecnologia COM foi desenvolvida primeiramente para a plataforma Microsoft Windows, mas é um padrão aberto e tem sido implementado em outras plataformas. Essa tecnologia fornece um modelo para o projeto de componentes que possui múltiplas interfaces com vinculação dinâmica com outros componentes. As interfaces são binárias, o que torna possível implementar os componentes em uma variedade de linguagens de programação, como $\mathrm{C}++$, Visual Basic e Java. Para acessar as interfaces necessárias, um componente utiliza o modelo COM para localizar o servidor de componentes e então procurar a interface desejada. O COM+ é uma extensão do COM com tecnologias que apóiam transações, serviços de diretório, load balancing e fila de mensagens (Crnkovic e Larsson, 2001).

O DCOM é um protocolo utilizado para tornar transparente a comunicação entre os componentes, de maneira que se tenha a impressão de que um componente que está em outro servidor esteja sendo acessado localmente. Para isso, um cliente se comunica com um procurador (proxy) que localiza o servidor com o componente requisitado e gerencia a comunicação real entre eles.

\subsubsection{Java Beans}

No coração da arquitetura J2EE (Java 2 Enterprise Edition) está um grupo de três modelos de componentes usados nas camadas do cliente, web e servidor. Na camada do servidor encontra-se o EJB, que é a arquitetura servidora de componentes que permite o desenvolvimento rápido e simples de aplicações baseadas na tecnologia Java. O EJB provê suporte para transações e segurança sobre um protocolo neutro de comunicação de objetos, o que dá ao usuário o benefício de implementar a aplicação sobre um protocolo de sua escolha. 
Uma arquitetura EJB típica consiste de um servidor EJB; um contêiner de componentes EJB que rode nesses servidores; componentes EJB que rodem nesses contêineres; clientes EJB e outros sistemas e tecnologias auxiliares como Java Naming (JN), Directory Interface (JNDI), Java Transaction Service (JTS), Java Data Base Connection (JDBC), JSPs, RMI (Remote Method Invocation), etc.

Um contêiner EJB age como uma interface entre um componente EJB e o ambiente externo, pois um cliente EJB nunca acessa um componente diretamente, sendo que qualquer acesso é feito por meio de métodos gerados pelo contêiner para acessar os métodos dos componentes requisitados. Esses contêineres podem ser de dois tipos: contêineres de sessão (session containers), que podem conter componentes EJB transientes (não persistentes) cujos estados não são salvos; e contêineres de entidade (entity containers) que contém componentes EJB persistentes cujos estados são salvos entre as invocações.

Os clientes EJB fazem uso dos componentes EJB para suas operações, encontrando os contêineres EJB que contém o componente desejado por meio do Java Naming (JN) e Directory Interface (JNDI). Quando o contêiner com o componente requerido é encontrado, os clientes fazem uso do contêiner EJB para invocar métodos dos componentes EJB.

Existem componentes EJB de dois tipos: os de sessão (Session Beans) e os de entidade (Entity Beans). Cada componente EJB de sessão pode realizar um tipo de tarefa em um dado local remoto, e seus clientes serão outros programas Java que se conectam quando precisam efetuar suas tarefas. Um componente EJB de sessão pode ter ou não um estado, mas não sobrevive à finalização do sistema. Um componente EJB de entidade é um objeto com propriedades especiais, pois é um objeto permanente que sempre tem estados e sua existência permanece mesmo após o programa ser finalizado.

Cada componente EJB de entidade pode ser compartilhado por múltiplos clientes EJB e pode ser acessado remotamente, sendo que seus métodos são executados em um servidor. Uma outra característica desse tipo de componente é que ele deve ser unicamente identificado por uma chave primária, ou seja, só se pode usar componente EJB de entidade quando os objetos que o compõem tem uma chave de identificação única.

Para um JavaBean (componente do modelo de componentes do Java - Java Component Model) se tornar um EJB, o JavaBean precisa satisfazer às especificações do EJB, implementando alguns métodos que são requeridos. Esses métodos permitem que o contêiner do EJB gerencie os componentes de maneira uniforme para criação, transação, segurança, etc. Um cliente de um componente EJB pode virtualmente ser qualquer coisa nesse contexto, como, por exemplo, um servlet, um applet ou outro componente EJB.

\subsubsection{Commom Object Request Broker Architecture (CORBA)}

No início da década de 90, a OMG (Object Management Group) criou a tecnologia CORBA com o intuito de criar um framework comum para integrar e permitir interconexão entre apli- 
cações desenvolvidas com diferentes linguagens, implementações e plataformas, buscando alcançar reusabilidade, portabilidade e interoperabilidade de componentes de software em um ambiente distribuído (Szyperski et al., 2002; Crnkovic e Larsson, 2001).

O CORBA tem essencialmente três partes: um conjunto de interfaces de invocação, o ORB (object request broker) e um conjunto de adaptadores para objetos. Para realizar a invocação de métodos com essa tecnologia, é necessário que algumas vinculações de implementações sejam feitas tardiamente e, para isso, as interfaces de invocação permitem vários graus de vinculação tardia. O ORB possui um registro de objetos disponíveis e oferece mecanismos de transparência de localidade, fazendo requisições e recebendo respostas de objetos locais ou remotos. Os programas que precisam funcionar como objetos que oferecem serviços precisam se registrar no ORB por meio dos adaptadores de objetos.

Quando um componente precisa invocar um método de outro componente, as interfaces de invocação enfileiram os argumentos da invocação e o ORB localiza o objeto receptor da mensagem e sua máquina hospedeira. Tendo feito isso, o ORB invoca o método requisitado e transporta os argumentos da mensagem para o adaptador de objetos que recebe os argumentos e invoca o método do objeto receptor da mensagem.

Para que as invocações de interfaces e os adaptadores dos objetos funcionem, é necessário que todas as interfaces dos objetos estejam descritas em uma linguagem comum e as linguagens de implementação dos objetos tenham vinculação para essa linguagem. Essa linguagem comum é chamada de IDL (Interface Definition Language) e é utilizada para especificar as interfaces dos objetos ou componentes e gerar os esqueletos (stubs) de código necessários.

A tecnologia CORBA é parte da arquitetura OMA (Object Management Architecture), que oferece serviços para os objetos, como, por exemplo, serviço de nomeação de objetos, persistência, controle de eventos, notificação, transações, relacionamentos, segurança, concorrência, etc.

\subsection{Considerações Finais}

Neste capítulo foram abordados os principais conceitos relacionados com o desenvolvimento de software baseado em componentes, seus princípios, objetivos, métodos de implementação e tecnologias.

O desenvolvimento com componentes permite a diminuição do tempo de desenvolvimento de sistemas de software em razão do reúso dos componentes e facilita a gestão das mudanças que os sistemas sofrem no decorrer do tempo. Os métodos de desenvolvimento auxiliam a modelagem com componentes e o seu processo de desenvolvimento estabelece atividades necessárias para criar as especificações e arquiteturas de componentes.

Quanto à implementação, as tecnologias de desenvolvimento como COM, EJB e CORBA oferecem serviços e padronizações que facilitam o desenvolvimento com componentes. Alguns dos 
serviços oferecidos são implementações de interesses transversais que ficaram espalhados e entrelaçados pelos componentes do sistema, o que causava o aumento do acoplamento entre os componentes e diminuição da coesão, prejudicando a manutenção, a evolução e o reúso do sistema.

A solução de implementar os interesses transversais nos contêineres, entretanto, é paliativa, pois a chamada aos serviços dos contêineres permanece espalhada pelos componentes, além dos serviços implementados serem fixos. Se houver a necessidade de implementar interesses transversais não implementados nos contêineres, os mesmos problemas de espalhamento e entrelaçamento de código aparecerão no sistema (Duclos et al., 2002). 


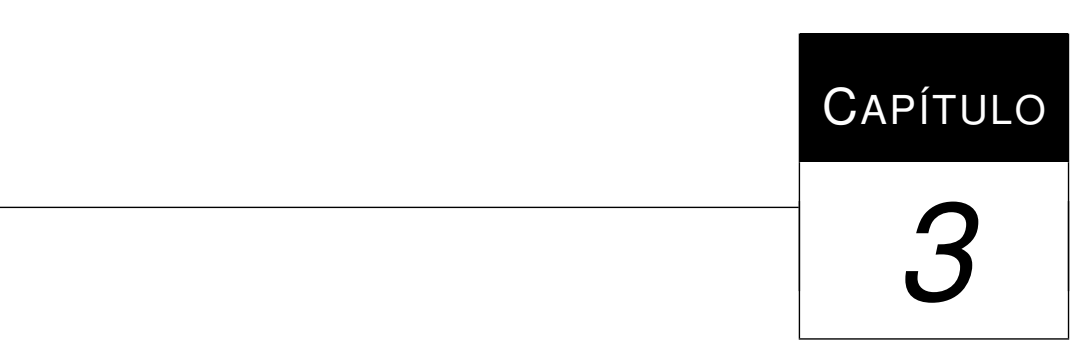

\section{Componentes e Aspectos}

\subsection{Considerações Iniciais}

O princípio de separar interesses está no núcleo da Engenharia de Software e das tecnologias de programação, e refere-se à habilidade de identificar, encapsular e manipular partes do software que são relevantes para um interesse em particular. Um interesse (do inglês, concern) pode ser entendido como uma funcionalidade, característica ou preocupação do sistema, como, por exemplo, as regras de negócio e as entidades de dados (Ossher e Tarr, 2001).

O conceito de separação de interesses foi a motivação inicial para se organizar e dividir o software em partes gerenciáveis e compreensíveis, o que fez com que as linguagens de programação evoluíssem com o objetivo de implementar mecanismos que permitam aos desenvolvedores modularizar claramente cada interesse do sistema. Apesar da evolução das linguagens, existem interesses que não são claramente modularizados pelos módulos de linguagens como as orientadas a objetos (OO), por exemplo.

Nas linguagens OO, uma clara separação de interesses é alcançada quando se decompõe os programas em classes que encapsulam dados e operações sobre esses dados, mas quando se trata da implementação de interesses, como, por exemplo, o controle de concorrência, sua implementação fica espalhada e entrelaçada nas unidades de decomposição do sistema. O espalhamento de código corresponde a um interesse implementado em várias unidades do sistema e o entrelaçamento corresponde a unidades do sistema implementando mais do que um interesse. Esses problemas prejudicam a legibilidade e a compreensibilidade do sistema, o que dificulta o projeto, a evolução, a manutenção e o reúso (Kiczales et al., 1997; Ossher e Tarr, 2001). 
Os interesses que não são adequadamente encapsulados pelas unidades de decomposição das linguagens como a OO, por exemplo, são chamados de interesses transversais, pois afetam vários módulos do sistema. Em geral, os interesses transversais são provenientes de requisitos nãofuncionais, mas também existem interesses transversais provenientes de requisitos funcionais do sistema. Alguns exemplos clássicos de interesses transversais descritos na literatura são o controle de concorrência, registro de operações, distribuição, autenticação de usuários, persistência, rastreamento e tratamento de exceção.

Diante dos problemas causados pelo espalhamento e entrelaçamento dos interesses transversais nos módulos dos sistemas, Kiczales et al. (1997) propuseram a programação orientada a aspectos, que fornece mecanismos para o encapsulamento adequado dos interesses transversais, o que evita problemas de entrelaçamento e espalhamento de código e aumenta a separação de interesses no sistema.

Além das linguagens de programação, como as estruturadas e orientadas a objetos, o paradigma de desenvolvimento de software baseado em componentes também sofre com os problemas de entrelaçamento e espalhamento de código de interesses transversais nos componentes do sistema. Isso aumenta o acoplamento, diminui a coesão e a reusabilidade dos componentes. Para resolver ou amenizar alguns desses problemas, as tecnologias de desenvolvimento de componentes passaram a implementar interesses transversais em seus contêineres, como autenticação e distribuição, por exemplo, e oferecê-los como serviços aos componentes. Entretanto, a chamada aos serviços dos contêineres continua espalhada pelos componentes, além dos serviços oferecidos serem fixos e permitirem pouca extensão (Duclos et al., 2002).

Com isso, como proposta de solução dos problemas de espalhamento e entrelaçamento de código nos sistemas baseados em componentes, alguns trabalhos têm sido realizados com o intuito de introduzir os conceitos de aspectos no desenvolvimento com componentes, com a criação de métodos de desenvolvimento e linguagens de programação específicas para implementar componentes combinados com aspectos.

Neste capítulo são investigados os conceitos relativos à programação orientada a aspectos e sua integração aos conceitos de desenvolvimento baseado em componentes. Na Seção 3.2 são apresentados os conceitos de desenvolvimento orientado a aspectos e a linguagem de aspectos de propósito geral mais amplamente utilizada pelos pesquisadores, o AspectJ. Algumas abordagens para o desenvolvimento de software orientado a aspectos são apresentadas na Seção 3.3. Na Seção 3.4 são apresentadas as idéias e desafios na integração de componentes e aspectos e as abordagens (métodos e linguagens) que se propõe a fazer isso. Na Seção 3.5, por fim, são apresentadas as considerações finais. 


\subsection{Desenvolvimento de Software Orientado a Aspectos}

As linguagens de programação têm a capacidade de decompor os programas em partes gerenciáveis para aumentar a flexibilidade e compreensibilidade dos sistemas, dividindo os programas em diferentes unidades de decomposição, dependendo do tipo de linguagem. Nas linguagens estruturadas, por exemplo, os programas são divididos em unidades, procedimentos e funções, enquanto que nas linguagens orientadas a objetos a unidade de decomposição dominante é a classe. $\mathrm{O}$ que há em comum nas linguagens de programação, independente do tipo de unidade de decomposição, é que apenas apóiam a decomposição do sistema em uma dimensão. A OO, por exemplo, apóia a decomposição do sistema apenas em classes; o desenvolvimento baseado em componentes apenas em componentes e o paradigma funcional em funções. A dimensão representa a combinação das unidades e o meio de combiná-las para formar um programa completo (Robillard, 2000).

Essa limitação das linguagens de programação faz com que consigam encapsular adequadamente somente interesses para os quais foram criadas, enquanto que os interesses de outros tipos, como os transversais, por exemplo, são implementados de maneira arbitrária, o que causa problemas como o espalhamento e entrelaçamento de código que prejudica o entendimento, projeto, desenvolvimento, reúso e manutenção dos sistemas. Em geral os interesses transversais representam os requisitos não-funcionais do sistema e alguns exemplos típicos são: rastreamento, sincronização, distribuição, controle de acesso e persistência de dados.

Um exemplo clássico de interesse transversal é o rastreamento, em que se deseja saber, por exemplo, quais métodos foram acessados durante a execução de um determinado programa. Uma maneira simples de implementar o rastreamento com linguagens orientadas a objetos é introduzir uma linha de código que imprime uma indicação de que o método foi executado. Essa implementação faz com que o interesse rastreamento fique entrelaçado no sistema, pois os módulos, além de implementar o interesse desejado, também implementam código para o rastreamento. O interesse também fica espalhado pelo sistema, pois está implementado em vários módulos.

Uma implementação do interesse rastreamento pode ser vista na Figura 3.1, em que a linha de código System. out.println (". . " ) é responsável por implementar o interesse em cada método das classes do modelo. No modelo de classes à direita do código fonte, as faixas pretas dentro das classes indicam a implementação do rastreamento espalhado pelas classes do sistema (dentro de cada método).

A limitação das linguagens em decompor o sistema em apenas uma dimensão recebe o nome de tirania da decomposição dominante (Tarr et al., 1999). Diante desse problema, um grupo de pesquisadores do centro de pesquisa da Xerox, em Palo Alto, propôs uma abordagem chamada de programação orientada a aspectos que procura fornecer conceitos e mecanismos de programação para separar e encapsular interesses transversais e eliminar o espalhamento e entrelaçamento de código, resultando em sistemas mais legíveis, fáceis de entender, implementar, integrar, reusar, personalizar, evoluir e manter (Kiczales et al., 1997). 


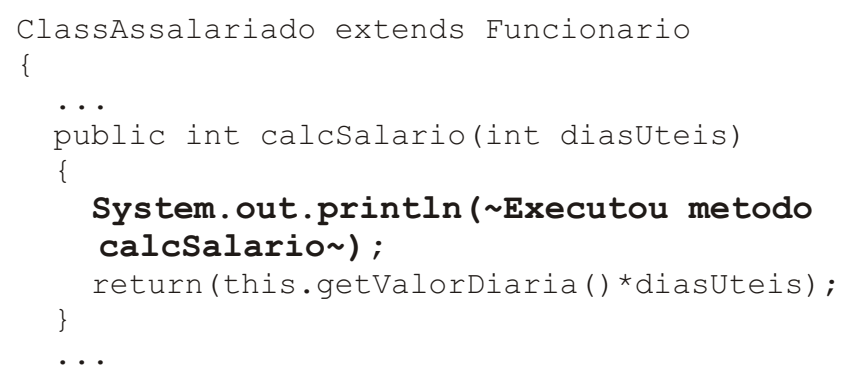

Figura 3.1: Implementação de rastreamento - espalhamento e entrelaçamento de código.

No desenvolvimento de software orientado a aspectos os interesses transversais são modularizados por meio de construções chamadas de aspectos. Os aspectos implementam os interesses transversais e são capazes de entrecortar pontos bem definidos no fluxo de execução de um programa. No entrecorte, os aspectos são capazes de executar algum comportamento antes, depois ou no lugar de algum ponto entrecortado, como, por exemplo, chamadas de métodos, construtores, modificação de valores de atributos, etc. No último caso, quando o aspecto executa um comportamento no lugar do ponto entrecortado, o aspecto pode ou não devolver o fluxo de controle para que o ponto entrecortado seja executado.

Os pontos bem definidos na execução de um programa capazes de serem entrecortados são chamados de conjuntos de pontos de junção e são determinados pelo aspecto de acordo com regras da linguagem utilizada.

Como os aspectos são desenvolvidos em módulos separados dos módulos da aplicação base, há a necessidade de um processo de combinação dos aspectos com o programa base para poder gerar o sistema final com todas os interesses implementados. O processo de combinação pode ser realizado tanto em tempo de compilação, também chamada de combinação estática, quanto em tempo de execução, também chamada de combinação dinâmica, de acordo com a abordagem adotada pela linguagem AspectJ (Kiczales et al., 2001a).

Existem abordagens de programação orientada a aspectos que não possuem construções como os aspectos do AspectJ. Todos os interesses do sistema são desenvolvidos em módulos como as classes, por exemplo, e o entrecorte é definido apenas na composição entre os módulos por meio de conectores específicos da linguagem. Exemplos de trabalhos que usam essa abordagem são o FuseJ (Suvée et al., 2004) e o JAML (Lopes e Ngo, 2005).

A implementação do interesse de rastreamento mostrado na Figura $3.1 \mathrm{com}$ a programação orientada a aspectos é ilustrado pela Figura 3.2. Pode-se notar que o rastreamento que estava espalhado pelas classes do sistema está agora localizado em uma unidade denominada de aspecto. Maiores detalhes sobre a sintaxe dos aspectos está na subseção sobre a linguagem AspectJ.

Um dos primeiros passos para a concretização do paradigma de programação orientada a aspectos foi a construção de linguagens de propósitos específicos para a implementação de in- 

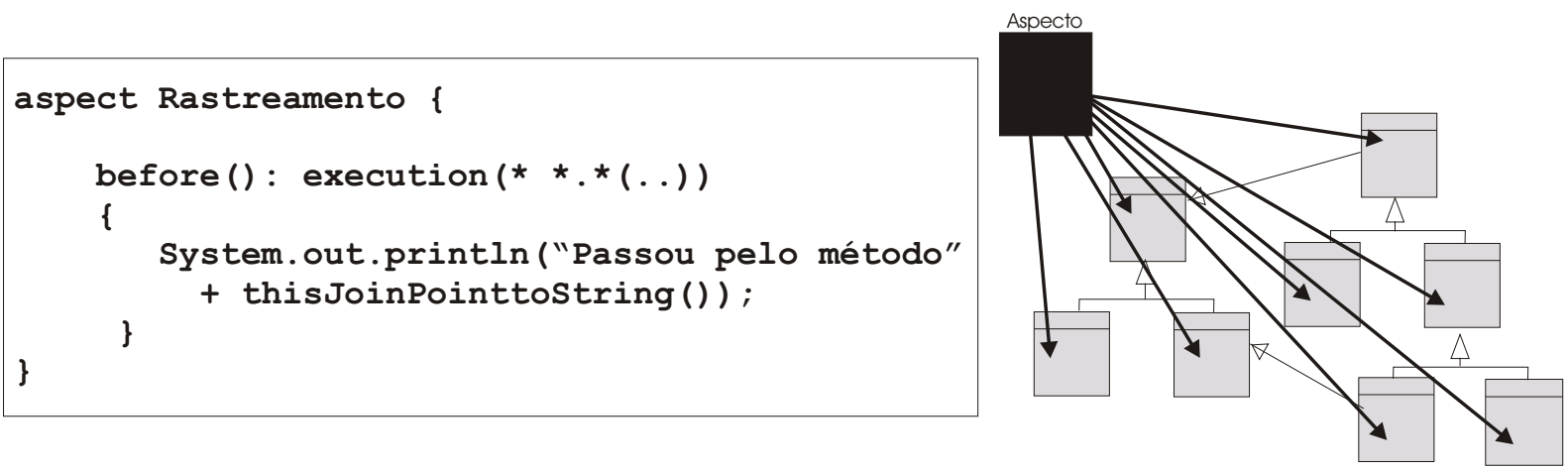

Figura 3.2: Implementação de rastreamento com aspectos.

teresses transversais de domínios específicos, como a COOL (Lopes, 1997), para interesses de locking/exclusão mútua, por exemplo, e a criação de linguagens de propósito geral para a implementação de interesses transversais de domínios gerais, como a AspectJ. Além disso, pesquisas têm sido realizadas com o intuito de identificar os aspectos de um sistema desde as fases iniciais do desenvolvimento de software.

As linguagens de programação orientadas a aspectos contém propriedades interessantes que as distinguem das diversas linguagens de programação. De acordo com Filman e Friedman (2000), tais propriedades se resumem na capacidade de alterar o comportamento de um programa utilizando blocos de código, sem que o programador dos módulos básicos tenha conhecimento dessas modificações. Em outras palavras, com a Pogramação Orientada a Aspectos é possível fazer com que uma determinada ação A seja executada em um programa $\mathrm{P}$, todas as vezes que uma certa condição $\mathrm{C}$ for satisfeita, sem que o desenvolvedor de $\mathrm{P}$ esteja preocupado com essas modificações. A partir daí, de acordo com Lieberherr (Elrad et al., 2001), uma linguagem orientada a aspectos deve determinar:

- Um modelo de pontos de junção que descrevam os ganchos onde os entrecortes podem ocorrer, ou seja, como as condições $\mathrm{C}$ podem ser especificadas;

- Um mecanismo de identificação dos pontos de junção, ou seja, como saber quando as condições C são satisfeitas;

- Unidades que encapsulem tanto especificações de pontos de junção quanto mudanças de comportamento desejadas;

- Um processo para combinar as unidades em um programa (o weaver).

Na subseção a seguir são apresentadas as características, mecanismos, sintaxe e alguns detalhes da linguagem AspectJ, linguagem que têm sido amplamente utilizada na programação orientada a aspectos. 


\subsubsection{AspectJ}

A linguagem AspectJ é uma extensão da linguagem Java para apoiar a programação orientada a aspectos e é, portanto, uma linguagem de propósitos gerais. A linguagem foi desenvolvida no centro de Pesquisa da Xerox (Kiczales et al., 1997, 2001a), em Palo Alto, e posteriormente foi agregada ao projeto Eclipse da IBM.

$\mathrm{Na}$ programação orientada a aspectos é introduzido o conceito de aspectos, que implementam os interesses transversais do sistema e adicionam comportamento ao código-base (classes, por exemplo) do sistema. Para permitir a implementação de aspectos, o AspectJ introduz novas construções, tais como: os aspectos (aspect); os conjuntos de pontos de junção (pointcut) que identificam pontos de junção (join points); e os adendos (advices) que implementam o comportamento a ser adicionado ao ponto de junção. Além disso, pode-se definir atributos e métodos que alteram a estrutura estática das classes afetadas pelo aspecto, e por isso chamadas de declarações inter-tipos (intertype declarations). Aspect J também permite a alteração da hierarquia das classes afetadas pelo aspecto e a declaração de hierarquias entre os aspectos, por meio de aspectos especializados.

Um exemplo da implementação de um aspecto de rastreamento pode ser visto na Figura 3.3. As construções introduzidas pelo AspectJ são detalhadas e exemplificadas nos tópicos a seguir, bem como a descrição sucinta de como os aspectos e classes são combinados para formar o programa final.

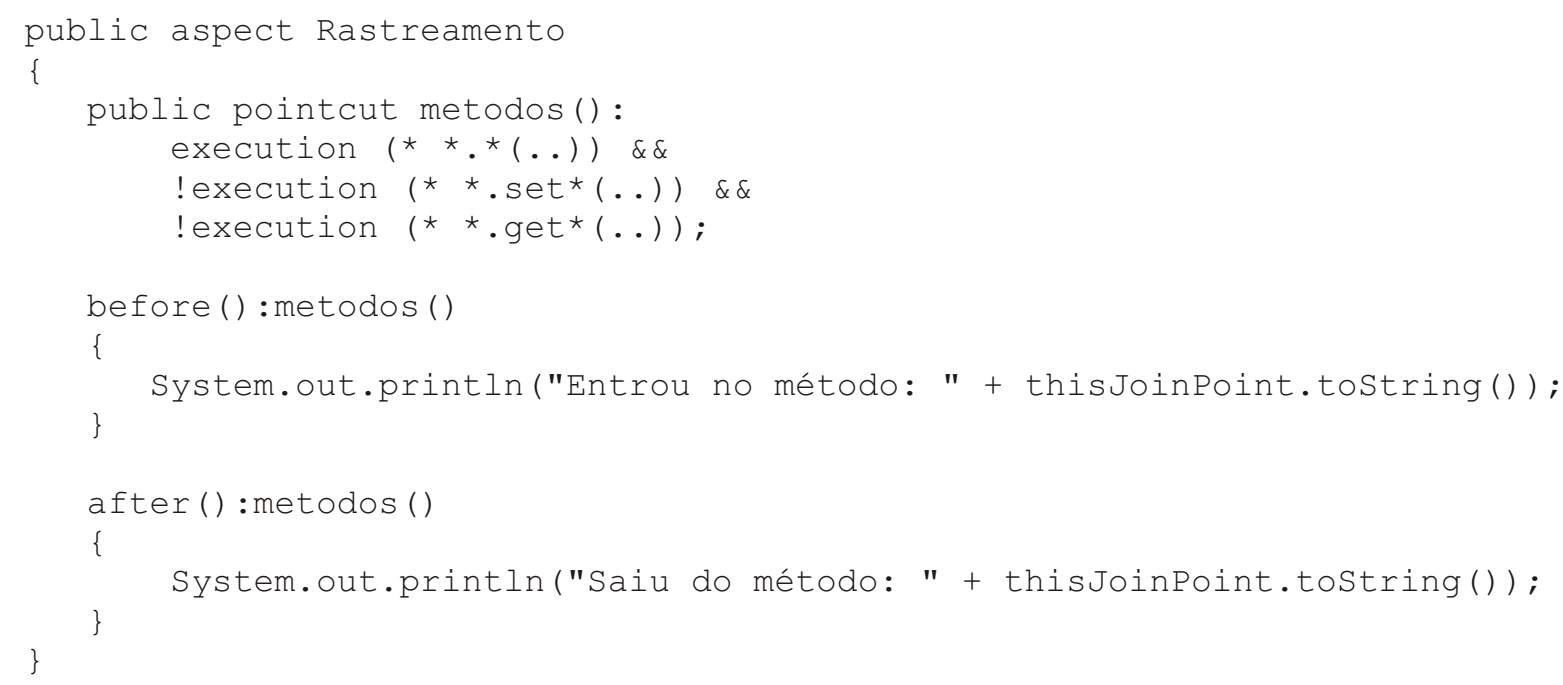

Figura 3.3: Implementação de Rastreamento em AspectJ

\subsubsection{1 - Conjunto de Pontos de Junção}

Os conjuntos de ponto de junção são utilizados para identificar um conjunto de pontos bem definidos no fluxo de execução de um programa, em que os comportamentos adicionais inseridos 
pelos aspectos serão executados. Esses pontos bem definidos no fluxo de execução do programa são chamados de pontos de junção e podem ser construtores de classes, chamadas e execução de métodos, acesso a atributos, etc. Na Tabela 3.1 são mostrados os tipos de pontos de junção do AspectJ e suas respectivas sintaxes.

\begin{tabular}{|c|c|}
\hline Tipo & Sintaxe \\
\hline \hline Execução de método & execution(AssinaturaDeMétodo) \\
\hline Chamada a método & call(AssinaturaDeMétodo) \\
\hline Execução de construtor & execution(AssinaturaDeConstrutor) \\
\hline Chamada a construtor & call(AssinaturaDeConstrutor) \\
\hline Iniciação de classe & staticinicialization(AssinaturaDeTipo) \\
\hline Acesso de leitura de atributo & get(AssinaturaDeAtributo) \\
\hline Acesso de modificação de atributo & set(AssinaturaDeAtributo) \\
\hline Execução de tratador de exceção & handler(AssinaturaDeTipo) \\
\hline Iniciação de objeto & initialization(AssinaturaDeConstrutor) \\
\hline Pré-iniciação de objeto & preinitialization(AssinaturaDeConstrutor) \\
\hline Execução de advices & adviceexecution() \\
\hline
\end{tabular}

Tabela 3.1: Tipos de pontos de junção do AspectJ e suas respectivas sintaxes (adaptado de Laddad (2003))

Os conjuntos de pontos de junção podem identificar um único ponto de junção ou a composição de vários deles, usando operadores lógicos como \&\& (e), II (ou), além de operadores unários como o ! (negação). Os conjuntos de junção podem ser identificados na própria declaração dos adendos ou serem identificados por um nome e posteriormente podem ser referidos por esse mesmo nome na declaração dos adendos.

No código mostrado na Figura 3.3, o conjunto de pontos de junção recebe o nome de metodos e identifica os pontos de junção a serem entrecortados. O ponto de junção execution ( * $\star \star \star(.)$.$) determina que quando qualquer método, com qualquer parâmetro, de qualquer classe$ e de qualquer tipo for executado (execution), esses métodos serão entrecortados e um comportamento adicional será executado. Os pontos de junção ! execution $(* \star$. set $\star$ ( . . ) ) e ! execution $(* \star . g e t *(.)$.$) definem que os métodos que começam com get e set de$ qualquer tipo, de qualquer classe e de qualquer parâmetro não serão entrecortados. Mais detalhes sobre como designar os conjuntos de ponto de junção podem ser encontrados nos manuais do AspectJ (Team, 2003).

\subsubsection{2 - Adendos}

Os adendos são implementações de comportamento que são executados quando o aspecto entrecortar a classe nos pontos de junção determinados pelo designador dos conjuntos de ponto de junção. Os adendos podem ser de três tipos básicos: anteriores (before), que são executados antes do ponto de junção ser executado; os posteriores (after), que são executados depois do ponto de 
junção ser executado; e os de contorno (around), que são executados no lugar do ponto de junção, sendo que após serem executados podem ou não chamar a execução do ponto de junção por um método denominado de proceed ( ) .

Os adendos são construções semelhantes aos métodos, entretanto não podem ser chamados diretamente pela aplicação base e nem pelo próprio aspecto, pois sua execução é feita automaticamente após o entrecorte no ponto de junção. Uma outra diferença em relação aos métodos é que os adendos não possuem nome, não têm especificadores de acesso (public, private, etc) e tem acesso a variáveis especiais das execuções dos pontos de junção, como assinatura dos métodos entrecortados, etc.

No código do exemplo da Figura 3.3, os adendos be fore e a fter simplesmente implementam uma linha de código que escreve uma indicação de que o fluxo de execução do programa está iniciando ou finalizando a execução do método entrecortado. Os adendos adicionam comportamento aos pontos de junção identificados em metodos (), pois o conjunto de ponto de junção foi nomeado e está referenciado na declaração do adendo. Outra maneira de se identificar os pontos de junção que serão entrecortados é mostrado na Figura 3.4, em que os pontos de junção são identificados na própria declaração do adendo.

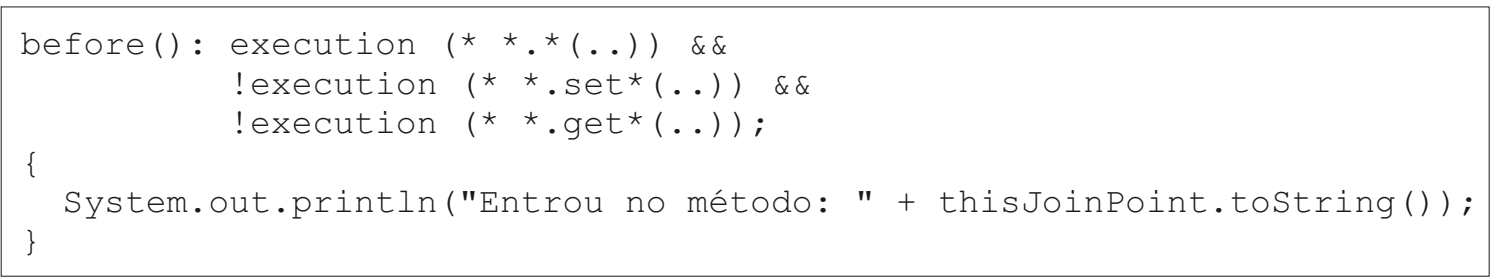

Figura 3.4: Implementação de um adendo identificando os pontos de junção a entrecortar

\subsubsection{3 - Declarações inter-tipos}

As declarações inter-tipo permitem a introdução de novos atributos e métodos nas classes básicas do programa. Isso é feito simplesmente pela declaração de atributos e métodos no próprio aspecto, com esses novos métodos podendo ser acessados diretamente pelas classes afetadas. O aspecto mostrado na Figura 3.5, introduz na classe Servidor o atributo enable que é ativado e desativado dependendo do método executado em Servidor..

\subsubsection{4 - Processo de Combinação}

No processo de combinação entre aspectos e classes, o compilador AspectJ transforma os aspectos em implementações semelhantes às classes, com os adendos se tornando semelhantes aos métodos e os aspectos às classes. Diante disso, o combinador identifica os possíveis pontos de junção das classes afetadas pelos aspectos e insere uma chamada ao método do aspecto (adendo) 


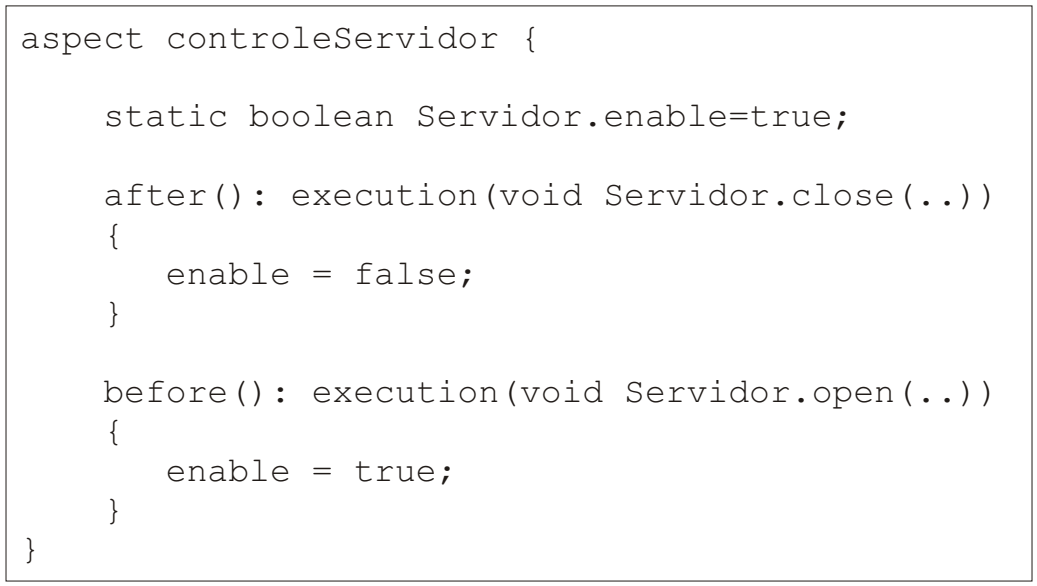

Figura 3.5: Exemplo de declaração inter-tipos

antes, depois ou no lugar do ponto de junção, de acordo com o adendo. Esse processo é feito diretamente no bytecode.

\subsection{Métodos de Desenvolvimento de Software Orientado a Aspectos}

Para auxiliar na investigação sobre como construir um método para desenvolver software com componentes e aspectos, métodos de desenvolvimento com aspectos não específicos para componentes foram considerados, como os trabalhos de de Clarke e Baniassad (2005), de Chavez (2004) e de Jacobson e $\mathrm{Ng}$ (2004).

\subsubsection{Análise e Projeto Orientado a Aspectos: a Abordagem Tema}

A abordagem Tema (Clarke e Baniassad, 2005) propõe o desenvolvimento de software pela composição de temas, que são unidades que encapsulam os interesse de um sistema. Os temas que compõem o sistema são identificados a partir dos requisitos e, para isso, é estabelecida uma relação de cada requisito (ou conjunto de requisitos) a um tema que o encapsule.

A partir dos artefatos que relacionam temas e requisitos, Clarke e Baniassad (2005) estabelecem critérios para identificar temas que encapsulam interesses transversais e são candidatos a serem implementados como aspectos. Os temas que encapsulam interesses transversais são chamados de temas transversais e em geral são relacionados a mais de um requisito, enquanto que os outros temas, denominados de temas-base, geralmente são relacionados a um único requisito.

Após a identificação dos temas-base e transversais, os temas são projetados separadamente. Tanto os temas-base quanto os transversais podem ser compostos por uma ou mais classes com atributos e métodos relacionados ao interesse encapsulado. No projeto de um tema transversal, 
diagramas de interação são especificados para mostrar o comportamento-padrão do tema quando combinado com algum tema-base da aplicação. Para isso, são adotados templates em que as operações entrecortadas são representadas genericamente nos diagramas e são substituídas pelas operações dos temas-base na composição.

\subsubsection{Um Enfoque Baseado em Modelos para o Projeto Orientado a Aspectos}

Chavez (2004), em sua tese de doutorado, trata do projeto e modelagem de sistemas orientados a aspectos, em que aborda a modelagem de aspectos e apresenta a aSideML, uma linguagem de modelagem que define uma notação gráfica, a semântica e regras para a especificação e a comunicação de projetos orientados a aspectos.

O trabalho de Chavez (2004) apresenta artefatos para o projeto orientado a aspectos, como diagramas de classes, de seqüência e de colaboração em que os elementos-base da aplicação são combinados com os aspectos. Adicionalmente, o trabalho apresenta o conceito de interface transversal (crosscutting interface) como um conjunto de características transversais com nome associado, que caracterizam o comportamento transversal de aspectos.

\subsubsection{Desenvolvimento de Software Orientado a Aspectos com Ca- sos de Uso}

Jacobson e $\mathrm{Ng}$ (2004) propõem uma abordagem de desenvolvimento de software orientado a aspectos com base em casos de uso. A proposta é identificar interesses transversais a partir dos casos de uso de um sistema e implementá-los em módulos separados.

$\mathrm{Na}$ abordagem de Jacobson e $\mathrm{Ng}$ (2004) os casos de uso que implementam interesses transversais são identificados principalmente pelos relacionamentos (include ou extends) que estabelecem com os outros casos de uso. Diante disso, foram estabelecidos critérios que orientam os desenvolvedores na decisão de quais tipos de relacionamentos os casos de uso têm entre si.

Cada interesse do sistema é descrito por um caso de uso e o sistema completo pode ser obtido pela composição dos casos de uso base e transversais. Na implementação, cada caso de uso pode ser composto por uma ou mais classes que possuem métodos e atributos relacionados ao interesse descrito. Jacobson e Ng (2004) propõem a codificação de todos os casos de uso com linguagens orientadas a aspectos e que a composição para produzir o sistema completo seja feita por meio de introduções (declarações inter-tipos) em entidades vazias previamente criadas. 


\subsection{Desenvolvimento de Software Baseado em Compo- nentes e Aspectos}

O desenvolvimento de software baseado em componentes também sofre com os problemas causados pela tirania da decomposição dominante, em que os interesses transversais ficam espalhados e entrelaçados pelos componentes do sistema, com aumento do acoplamento entre os componentes, diminui sua coesão e conseqüentemente dificulta sua evolução, manutenção e reúso (Ossher e Tarr, 2000).

Para resolver ou amenizar os problemas de espalhamento e entrelaçamento de código nos componentes do sistema, as tecnologias de implementação de componentes passaram a implementar alguns interesses transversais, como distribuição, por exemplo, e a oferecer esses serviços para os componentes. Essa foi uma grande evolução para modularizar e reusar os interesses transversais, entretanto as chamadas aos serviços dos contêineres permanecem espalhadas pelos componentes. Além disso, os serviços oferecidos pelos contêineres são fixos e quando há a necessidade de implementar um novo interesse transversal, este é implementado espalhado e entrelaçado nos componentes do sistema Duclos et al. (2002).

Como solução dos problemas citados anteriormente, alguns trabalhos de integração entre os conceitos do desenvolvimento com componentes e orientado a aspectos têm sido desenvolvidos com o objetivo de criar mecanismos para modularizar os interesses transversais que afetam os componentes e atacar os problemas relacionados ao entrelaçamento e espalhamento de código. A integração entre aspectos e componentes não é uma tarefa simples, pois os componentes possuem certos princípios e objetivos que devem ser respeitados nesse processo, tais como o conceito de encapsulamento do componente, certificação de qualidade e a previsibilidade de composição dos componentes (Cottenier e Elrad, 2004).

O primeiro desafio de colocar componentes na presença de aspectos é a política de encapsulamento dos componentes. Um aspecto, em razão do poder de expressividade das linguagens, como no AspectJ, por exemplo, pode facilmente acessar a estrutura interna do componente, quebrando assim a política de encapsulamento do componente.

Um outro desafio é a questão da previsibilidade de composição dos componentes. Quando se faz a composição entre componentes, sabe-se, em termos gerais, qual o resultado da composição. Com o poder de expressividade dos aspectos, pode-se acessar mais do que se deseja e ter efeitos colaterais indesejados. Além disso, um aspecto pode mudar o fluxo de execução de um programa, mudar a hierarquia de classes, introduzir métodos e atributos no componente afetado, etc. Com todo esse poder, a composição dos componentes não tem resultados previsíveis, pois não há garantia de que o aspecto não está alterando o comportamento para o qual o componente foi criado.

O terceiro desafio está relacionado à certificação de qualidade dos componentes. Quando se adquiri um componente de terceiros, os componentes são entregues com especificações e com garantia de qualidade do componente, indicando a função oferecida, desempenho, gasto de memória, 
etc. Se um aspecto é utilizado e acessa o interior de um componente, essas garantias podem ser perdidas, pois não se pode garantir que o componente atende às especificações originais de fabricação e o comprador ou re-utilizador do componente não pode exigir que o fornecedor garanta os atributos de qualidade descritos na especificação.

Tendo em vista que os problemas de quebra de encapsulamento, previsibilidade e certificação dos componentes são efeitos colaterais por se acessar e modificar o interior dos componentes, mesmo que de maneira não invasiva, as propostas de integração entre componentes e aspectos variam em termos de expressividade dos aspectos, inconsciência e transparência dos componentes (Cottenier e Elrad, 2004). A expressividade dos aspectos diz respeito ao poder que a linguagem de aspectos tem para acessar os elementos dos componentes base, fazer entrecorte, modificar hierarquias, introduzir elementos, etc. A inconsciência diz respeito a quanto os desenvolvedores devem levar os aspectos em conta quando desenvolvem os componentes. A transparência dos aspectos diz respeito à política de encapsulamento dos componentes.

Se existem dificuldades em unir os conceitos dos aspectos nos componentes, também há dificuldades na integração dos conceitos de componentes nos aspectos. Isso acontece porque os componentes são independentes de contexto, dinâmicos e interagem entre si e, em geral, a instalação dos aspectos é estática e os aspectos são dependentes de contexto (Suvée et al., 2003).

Nas abordagens de integração entre componentes e aspectos pesquisadas, foram encontrados métodos para desenvolver software com componentes e aspectos; abordagens para construir componentes com aspectos; e linguagens de propósito específico para implementar componentes transversais, que são componentes com características dos aspectos, com capacidade para entrecortar outros componentes.

Nas subseções a seguir são apresentados os métodos de Grundy e Patel (2001) que propõe um processo, uma notação e tecnologias de implementação, como modelos de componentes e ferramentas para construir software com componentes e aspectos, e o de Clemente et al. (2002); Clemente e Hernández (2003), que mostra o uso da UML para modelar componentes e aspectos nas fases genéricas do desenvolvimento baseado em componentes. Em seguida é mostrada uma abordagem para a construção de componentes com aspectos, de Almeida et al. (2005). E, por fim, são apresentadas algumas linguagens de propósito específico para implementar componentes transversais.

\subsubsection{A abordagem de Grundy: Aspect-Oriented Component Engi- neering(AOCE)}

O grupo de pesquisa em desenvolvimento liderado por Grundy, após algumas experiências com o desenvolvimento de software baseado em componentes, identificou que, em geral, os métodos tradicionais de desenvolvimento enfocam o projeto e a implementação de componentes que representam funcionalidades verticais dos sistemas, que são as funcionalidades que agrupam dados e operações sobre os dados. Essas decomposições podem ser encapsuladas adequadamente por 
componentes regulares, mas há funcionalidades que afetam todos os componentes e representam decomposições horizontais do sistema que não podem ser encapsuladas de maneira apropriada por componentes regulares (Grundy et al., 2000; Grundy, 2000; Grundy e Patel, 2001; Filman et al., 2004; D’Souza e Wills, 1999).

Para o projeto e desenvolvimento de sistemas com componentes, em que tanto as funcionalidades transversais (horizontais) quanto as verticais sejam encapsuladas, Grundy e Patel (2001) propõem uma abordagem chamada de Aspect Oriented Component Engineering (AOCE). Esta abordagem concentra-se no desenvolvimento de componentes cujos serviços são transversais (oferecem serviços a vários componentes) e procura fatorá-los cuidadosamente nas interfaces dos módulos aspectuais, evitando técnicas como combinação de código e uso de mecanismos de reflexão (Grundy e Patel, 2001).

\subsubsection{1 - O Processo}

O processo de desenvolvimento proposto pela abordagem AOCE é composto pelas seguintes etapas: Engenharia de Requisitos, Especificação, Projeto e Implementação dos Componentes.

A etapa de Engenharia de Requisitos dos Componentes tem o objetivo de analisar os requisitos do sistema ou dos componentes, construir diagramas de classe e modelos conceituais OO e a partir daí identificar possíveis componentes a serem construídos. Em seguida, deve-se identificar restrições não funcionais e serviços requeridos para cada componente e identificar os aspectos e detalhes aspectuais do sistema. Os detalhes aspectuais descrevem características do componente relacionadas ao aspecto, como, por exemplo, as funções requeridas e oferecidas pelo componente transversal.

A etapa de Especificação e Projeto dos Componentes inclui o refinamento dos requisitos de componentes para o projeto de componentes, em que os aspectos refinam os requisitos do sistema em detalhes aspectuais e propriedades dos detalhes aspectuais, que são informações adicionais e específicas para a implementação dos componentes. São utilizados diagramas de interação e colaboração da UML para identificar funções e operações do sistema. Conclui-se a etapa com a atribuição de funções e responsabilidades de dados aos componentes.

Para a etapa de projeto dos componentes, Grundy e Patel (2001) propuseram diagramas que representam os componentes do sistema e seus aspectos, além de terem proposto extensões ao meta-modelo e à notação visual da UML para incluir componentes transversais (implementações dos interesses transversais) para apoiar a modelagem com componentes e aspectos.

Na Figura 3.6 pode ser visto um diagrama em que são mostrados os componentes regulares de um sistema de Vídeo Locadora (Reviews UI, Tree Viewer, MW Communications, Customers, Products, On-line Reviews e Database Access) e seus componentes transversais (User Interface, Persistency, Distribuition, Collaboration e Security). 
Cada componente regular oferece algum serviço para vários outros componentes da aplicação, como, por exemplo, os componentes Tree Viewer e Reviews oferecem serviços de interface com usuário (aspecto User Interface); o componente Database Access oferece gerenciamento de persistência (aspecto Persistency) e distribuição (aspecto Distribuition). Além de oferecer serviços, a maioria dos componentes do sistema também requer serviços de outros componentes e aspectos para realizar suas funções, como, por exemplo, o componente Tree Viewer requer apoio para a distribuição (Distribuition) e persistência (Persistency).

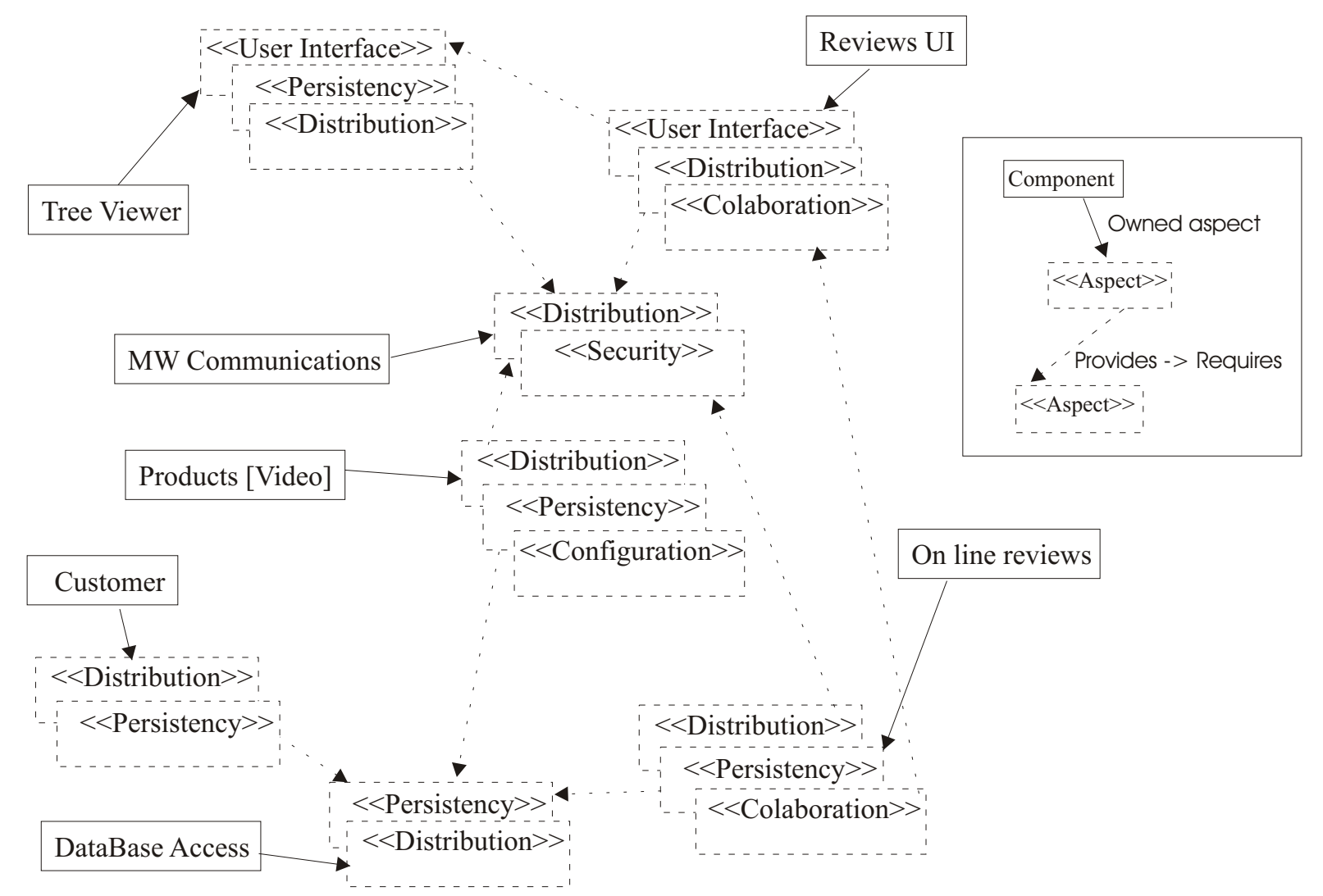

Figura 3.6: Componentes do Sistema de Vídeo e alguns de seus aspectos (Grundy e Patel, 2001)

As extensões na notação visual da UML oferecem representações concretas para os pontos de junção dos aspectos nos componentes bases do sistema, deixando explícito os detalhes aspectuais requeridos e oferecidos pelo componente, tanto nos diagramas de classe, quanto nos de sequência e de colaboração, como pode ser visto no diagrama da Figura 3.7. Os contêineres que representam as classes foram estendidos para adicionar compartimentos para cada tipo de aspecto e cada compartimento contém um rótulo que identifica o aspecto e seus detalhes, indicando se oferece (+) ou requer (-) características funcionais ou não funcionais.

Os detalhes aspectuais têm uma ou mais propriedades que podem estar representadas ou não no modelo visual. No exemplo, o componente VideoStoreClient contém os aspectos User Interface, Security e Distribuition que descrevem os serviços que oferecem ou que necessitam de outros componentes. Esse componente é composto de outros componentes 
menores que são requeridos do componente javax. swing e oferece serviços básicos de interface com o usuário, como janelas e máscaras de senha. Outros componentes da aplicação (CustomerApp, StaffApp e VideoApp) requerem serviços oferecidos pelos componentes Middleware (transferência de dados), Data Store (armazenamento de dados) e Appli cation Manager (gerenciamento de transações, autenticação de usuários).

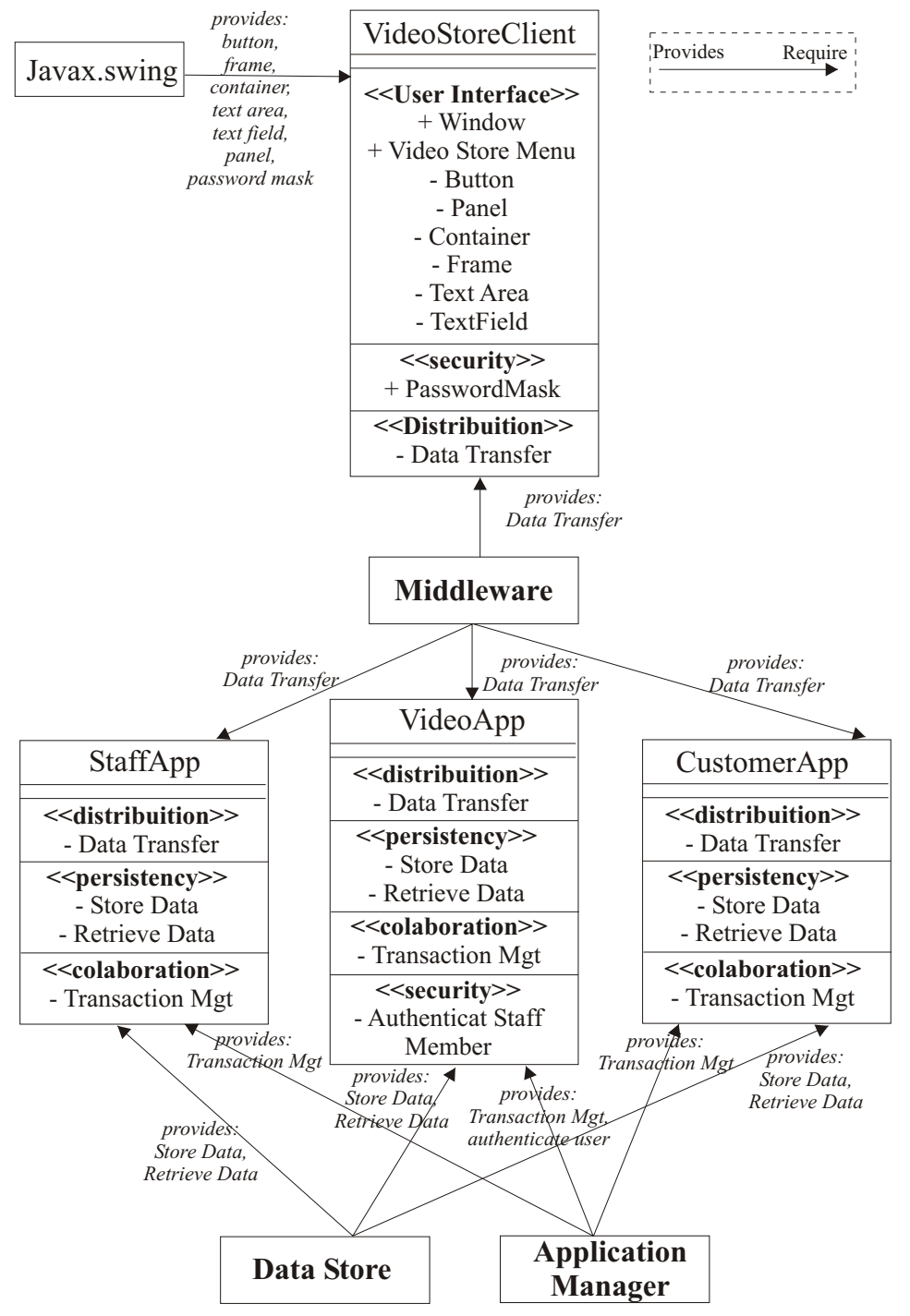

Figura 3.7: Projeto orientado a aspectos de uma parte do sistema de vídeo locadora (Grundy e Patel, 2001)

A Implementação dos componentes abrange o uso de modelos e frameworks de composição de componentes e ferramentas próprias desenvolvidas pelo grupo, como o JViews, a linguagem Perceval e o JComposer, para a codificação de aspectos. Essas tecnologias estão descritas na subseção a seguir. 


\subsubsection{2 - A tecnologia de implementação}

O JViews é uma extensão do modelo de componentes JavaBeans e foi modificado para incorporar informações aspectuais, em que um gerenciador de aspectos permite que os detalhes aspectuais e suas propriedades sejam incorporados ao modelo. Além disso, foi criado um gerador de eventos que controla as chamadas dos serviços dos componentes e o comportamento dos aspectos em tempo de execução. Os componentes JViews implementam suas funcionalidades e os aspectos que os compõem e notificam o modelo dos serviços oferecidos e requeridos, para que em tempo de execução os componentes possam descobrir em que componente encontrar os serviços necessários para seu pleno funcionamento.

Embora o JViews seja uma implementação poderosa para os mecanismos da AOCE, essa tecnologia sofre por não ser padronizada e somente componentes JViews podem ser facilmente usados no framework. Diante disso, os pesquisadores do grupo resolveram utilizar também componentes desenvolvidos com a arquitetura EJB para o desenvolvimento de suas aplicações.

O JComposer foi estendido para oferecer mecanismos de modelagem de componentes transversais com as extensões ao meta-modelo da UML realizado. Outra extensão ao JComposer foi a de adicionar a funcionalidade de gerar a codificação de informações do projeto dos componentes transversais do sistema na linguagem Perceval, que é baseada em XML (Extensible Markup Language) e foi estendida para apoiar a codificação de informações sobre aspectos. Por ser baseada em XML, a linguagem permite aos desenvolvedores gerar este tipo de formato de codificação em varias ferramentas CASE (Computer Aided Software Engineering) e gerar uma variedade de implementações de componentes diretamente da especificação.

Além das ferramentas citadas, foi desenvolvido um repositório de componentes JViews, cujos componentes são indexados de acordo com suas informações aspectuais. Esse repositório também foi estendido para armazenar componentes EJB.

O AOCE é um método complexo e extenso, que não explica clara e explicitamente como os componentes e aspectos do sistema devem ser identificados e como interagem. Além disso, na interação certas características dos componentes, como o encapsulamento, não são levadas em consideração.

A notação utilizada pelo método não deixa explícito como os aspectos são implementados no sistema. É difícil perceber se os aspectos são implementados dentro dos componentes ou em módulos separados, ou se até mesmo são implementados em vários módulos. Além disso, a implementação é dependente de ferramentas e tecnologias específicas, como o JViews, por exemplo, e a linguagem Perceval.

\subsubsection{Componentes e Aspectos com UML}

Clemente et al. (2002) apresenta um processo em que a programação orientada a aspectos é utilizada para descrever e implementar as dependências entre componentes. Segundo o autor, a 
contribuição maior de seu trabalho é o uso da UML para representar os aspectos em todas as fases genéricas de desenvolvimento com componentes.

As fases genéricas do desenvolvimento com componentes identificadas por Clemente et al. (2002) são a fase de Especificação, Interação, Montagem e Implantação dos Componentes. Essas etapas são descritas em mais detalhes nas subseções seguintes.

\subsubsection{1 - Especificação}

$\mathrm{Na}$ especificação, as interfaces oferecidas e requeridas pelos componentes devem ser identificadas, bem como as dependências entre os componentes. As dependências entre os componentes são identificadas como não-intrínsecas e intrínsecas. A dependência não-intrínseca é aquela em que o componente depende de um serviço que pode ser oferecido pelo contêiner ou contexto onde o componente será usado, e intrínseca uma dependência da qual o componente precisa para funcionar plenamente.

Nos diagramas de componentes da fase de especificação, os relacionamentos intrínsecos são representados pelo estereótipo «uses» e os não-intrínsecos pelo estereótipo «uses_aspect». Na Figura 3.8 pode ser visto um diagrama de componentes em que as dependências entre os componentes é mostrada. Pode-se notar que o relacionamento entre ServerBank e a interface Autentication é do tipo «uses_aspect», pois o serviço de autenticação pode ser fornecido pelo contêiner ou contexto onde o componente será implantado. Já o relacionamento entre ClientBank e a interface AccountManager é do tipo «uses», pois ClientBank precisa das operações de AccountManager para realizar sua função.
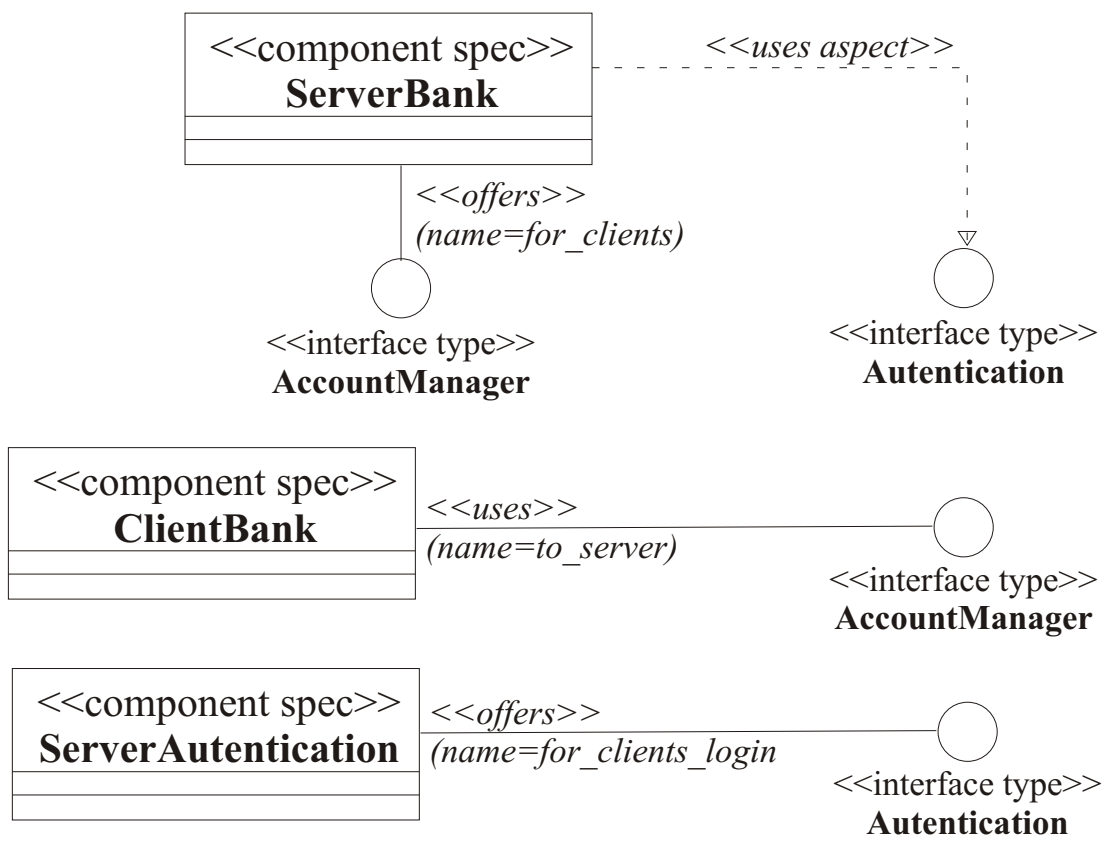

Figura 3.8: Diagrama de componentes na fase de especificação (Clemente et al., 2002) 


\subsubsection{2 - Interação}

$\mathrm{Na}$ fase de interação, o comportamento dos componentes para realizar suas operações oferecidas são modelados por meio de diagramas de colaboração. Na Figura 3.9 é mostrado um diagrama de colaboração em que a operação Balance é invocada de AccountManager, o que implica a chamada à operação CheckLogin de Autentication, por meio de uma relação não-intrínseca, ou seja, aspectual.

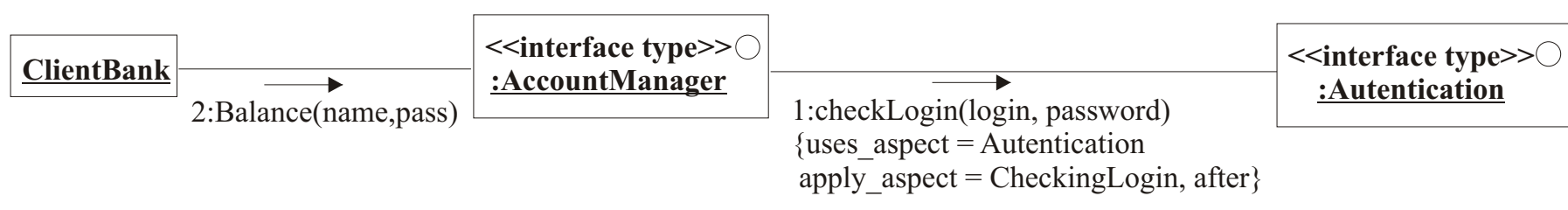

Figura 3.9: Interação entre componentes na fase de interação (Clemente et al., 2002)

\subsubsection{3 - Montagem e Implantação}

Depois de ter identificado as interfaces dos componentes, suas dependências e como os componentes interagem, o diagrama de implantação do sistema é especificado. Como a aplicação exemplo é de um sistema distribuído de contas bancárias, deve-se mostrar no diagrama o computador físico (host) em que cada componente será implantado, como pode ser visto na Figura 3.10. Na figura, um novo estereótipo é criado, «connect_aspects», que mostra a interação aspectual entre CompServerBank e CompServerAutentication.

A abordagem de Clemente et al. (2002) apresenta o uso da UML no projeto de componentes que possuem interações aspectuais com outros componentes e/ou aspectos. Entretanto, não apresenta um processo para o desenvolvimento de software com componentes e aspectos, partindo das etapas iniciais de Requisitos, com diretrizes e recomendações para identificar os componentes suas dependências aspectuais, bem como não apresenta com mais profundidade os tipos de interações dos componentes com os aspectos. Além disso, as etapas de montagem e implementação não são abordadas com muita ênfase.

Outro ponto a ser considerado na abordagem de Clemente et al. (2002) é o fato de não estar claro se a interação entre os componentes regulares (ou base) e os aspectos é feita por meio de entrecorte ou por meio de chamadas a métodos ou operações que estão implementados nos aspectos do sistema ou nos contêineres.

\subsubsection{Desenvolvimento de Componentes com Aspectos}

No contexto do desenvolvimento de componentes de prateleira, Almeida et al. (2005) propõe a utilização de aspectos na implementação de componentes. A idéia é implementar requisitos 


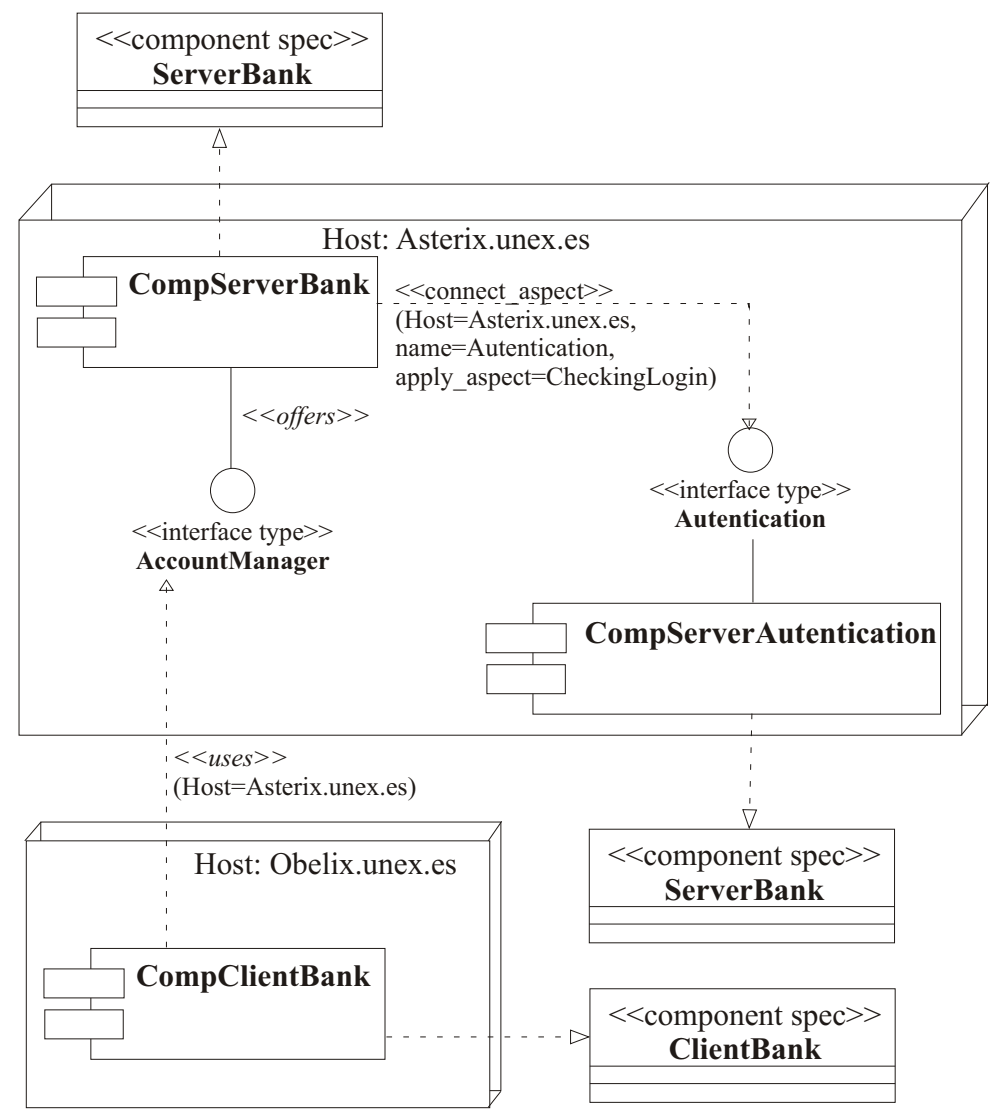

Figura 3.10: Interação entre componentes na fase de interação (Clemente et al., 2002)

não funcionais como registro de operações e controle de acesso como aspectos, em que esses aspectos atuam internamente ao componente. Cada componente de prateleira possue requisitos não funcionais implementados como aspectos e podem ser ligados ou desligados pelo desenvolvedor que utiliza os componentes.

As limitações dessa abordagem são que todos os componentes de prateleira terão que possuir vários interesses transversais implementados internamente como aspectos e interfaces serem oferecidas para cada um deles serem ativados ou desativados no sistema. Outro problema é que não se pode prever a quais requisitos não-funcionais o componente vai estar sujeito, pois em geral são reusáveis em várias aplicações e em diferentes contextos, ficando difícil implementar todos os requisitos não-funcionais possíveis.

Além disso, os componentes perdem sua coesão, sendo mais difíceis de manter e evoluir. Outro problema é a necessidade que surge de componentes serem usados na aplicação para orquestrarem a ativação e desativação dos aspectos dentro de cada componente de prateleira adquirido.

\subsubsection{Abordagens baseadas em linguagens}

Como apoio ao desenvolvimento de software baseado em componentes e aspectos, surgiram linguagens específicas para o desenvolvimento de componentes transversais, que são compo- 
nentes com características de aspectos. A seguir são apresentadas algumas dessas linguagens, com destaque para a linguagem JAsCO, utilizada para implementar o sistema apresentado no Capítulo 4 deste trabalho, e para a FuseJ, que tem uma abordagem simétrica para implementar interesses transversais com componentes. No Capítulo 4 é apresentado sucintamente uma forma de mapear o projeto com componentes e aspectos para a linguagem FuseJ.

\subsubsection{1 - JAsCo}

JAsCo é uma linguagem orientada a aspectos para o desenvolvimento específico de componentes que contém mecanismos da programação orientada a aspectos. A linguagem busca, por um lado, incluir conceitos da programação orientada a aspectos nos componentes, fazendo com que os interesses transversais sejam modularizados adequadamente. Por outro lado, pretende incluir na programação orientada a aspectos os princípios dos componentes, com o objetivo de construir aspectos que sejam reusáveis e tenham instalação fácil e flexível (Suvée et al., 2003).

A linguagem JAsCo foi construída baseada nas linguagens AspectJ (Kiczales et al., 1997) e Aspectual Components (Lieberherr et al., 1999). Do AspectJ usou a expressividade de sua linguagem de conjuntos de pontos de junção e do Aspectual Components aproveitou a idéia de declarar aspectos como um conjunto de pontos de junção abstratos e usar conectores para ligá-los aos pontos de junção concretos na aplicação alvo, deixando os aspectos independentes de contexto. Dessa forma, em JAsCo os aspectos são declarados como um conjunto de pontos de junção abstratos e são determinados quando combinados com os módulos base. Esta abordagem compromete a expressividade dos aspectos para preservar o encapsulamento do componente, pois os aspectos só têm permissão para operar nas interfaces do componente e não podem estendê-las por meio de introduções.

JAsCo possui sintaxe próxima à de Java e somente introduziu um pequeno número de novas palavras-chave e construções. Dois novos conceitos foram introduzidos: aspect beans e conectores. Um aspect bean é um componente que é capaz de declarar um ou mais ganchos (hooks) relacionados. Os ganchos geralmente são entidades genéricas e reusáveis que podem ser consideradas como a combinação de conjuntos de ponto de junção abstratos e adendos. Os conectores têm o propósito de instalar o aspect bean abstrato em um contexto concreto e ligar os conjuntos de ponto de junção abstratos a conjuntos de pontos de junção concretos.

Para tornar a linguagem JAsCo operacional, foi introduzido um novo modelo de componentes denominado Modelo de Componentes JAsCo Beans (JAsCo Beans Component Model), uma extensão retro-compatível com o modelo de componentes Java Beans, que já possui armadilhas (traps) construídas. Essas armadilhas são usadas para adicionar e remover os aspectos na aplicação.

Para ilustrar o uso das novas construções introduzidas pelo modelo JAsCo beans, é mostrado na Figura 3.11 o código fonte de um aspect bean que implementa o interesse de controle de acesso (Access Manager). Algumas propriedades da linguagem, as novas construções e o novo modelo de componentes criado são apresentados com maiores detalhes nas subseções a seguir. 


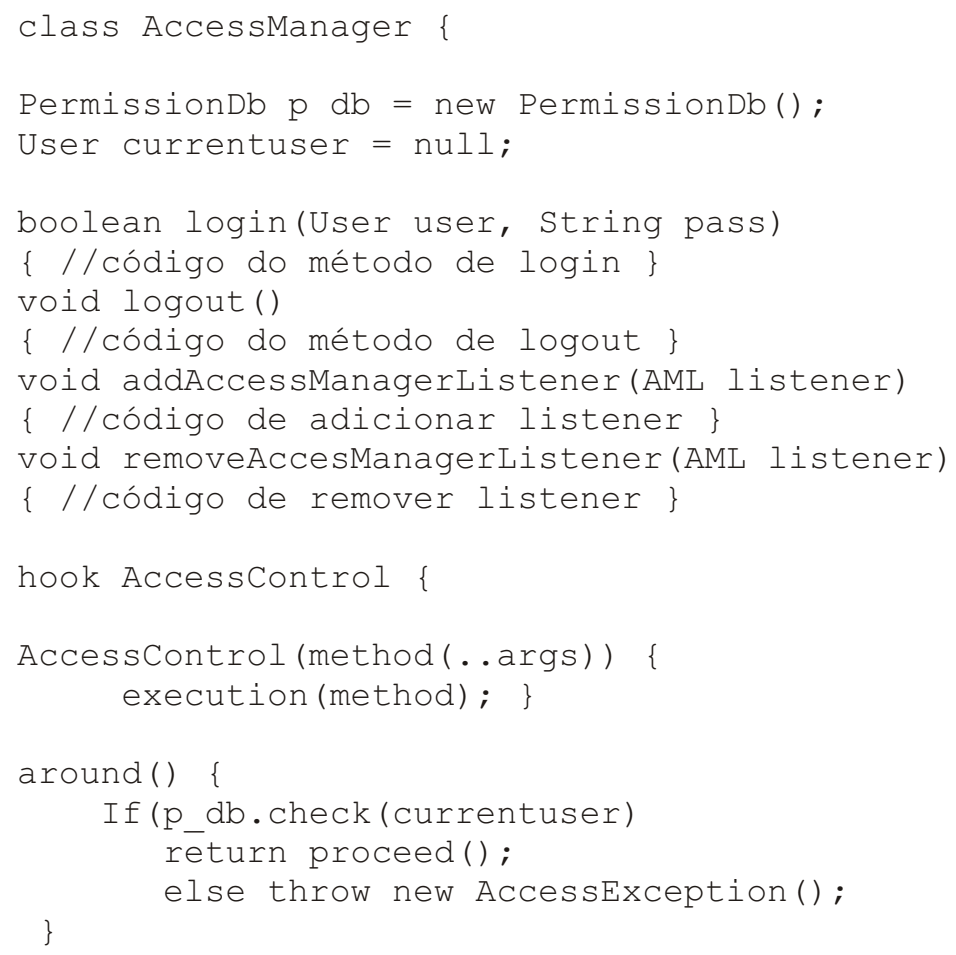

Figura 3.11: aspect bean implementando controle de acesso (adaptado de Suvée et al. (2003)

\section{Aspect Bean}

Os aspect beans são usados para descrever as funcionalidades que normalmente entrecortam vários componentes do sistema, como os interesses transversais. Podem ter implementações semelhantes às classes Java, como métodos e atributos, por exemplo. O comportamento transversal em si é especificado com construções chamadas de hook (gancho), que é um tipo especial de classe interna. Os ganchos são usados para especificar quando um programa base deve ser entrecortado e o que fazer nesse momento.

O construtor do gancho (linha 17 e 18) é responsável por especificar quando seu comportamento deve ser utilizado. Dessa forma, o construtor é semelhante aos conjuntos de pontos de junção abstratos, pois o construtor contém um ou mais métodos abstratos como parâmetro (linha 17) e determinam o contexto em que o gancho será instanciado. O método abstrato é concretizado quando o gancho for instanciado por um conector.

O construtor especifica, por meio dos caracteres especiais "..", que qualquer método pode ser usado como parâmetro para concretizar o método abstrato declarado no construtor. O construtor também pode especificar a necessidade de instanciar os ganchos com métodos com parâmetros de tipos específicos como valores iniciais.

No corpo do construtor do gancho, a declaração execution determina que o gancho será ativado quando o método passado por parâmetro na instanciação do gancho for executado. Outras palavras chaves para determinar essas condições são o cflow (X), que avalia se o método en- 
trecortado está no fluxo de controle do método X passado como parâmetro, o withincod (X), que avalia se o método X como parâmetro é o chamador do método entrecortado e o X, que avalia se o objeto que chamou o método entrecortado é do tipo do parâmetro X.

Os adendos (linha 20 a 24) são usados para especificar as várias ações que um gancho deve executar quando é ativado, especificando o que o gancho deve fazer. Pelo menos um adendo deve ser especificado, caso contrário o gancho não será ativado. Cinco tipos de adendos são possíveis: before, around, after, after throwing e after returning. O adendo before é executado antes do entrecorte da aplicação (ativação do gancho). O adendo around é executado no lugar do método entrecortado, podendo devolver ou não o controle para a aplicação base, por meio do comando proceed ( ) (linha 22), como no AspectJ. O adendo after é executado após a execução do método entrecortado, o adendo after throwing é executado também quando o método entrecortado finaliza sua execução, mas somente se uma exceção foi lançada e o adendo after returning é executado quando o método é executado com sucesso.

JAsCo também dá apoio à herança de aspect beans e de ganchos. Um aspect bean filho herda todos os ganchos declarados no aspect bean pai e pode declarar novos ganchos. É possível substituir um gancho definido no aspect bean pai especificando um gancho com o mesmo nome no aspect bean filho. Da mesma maneira, os ganchos filhos herdam os adendos dos ganchos pais e podem substitui-los ou adicionar novos adendos.

A linguagem oferece outros recursos de apoio, como o de acessar o objeto correspondente ao ponto de junção executado; mecanismos de reflexão; a definição de métodos que determinam se o gancho deve ser aplicado ou não, como o isApplicable; etc. Informações mais específicas e completas sobre outros recursos dos aspect beans podem ser encontradas no manual de referência da linguagem (Suvée, 2005).

\section{Conectores}

Os conectores são responsáveis por implantar um conjunto de ganchos relacionados em um contexto específico concreto e determinar ordens de precedência e estratégias de combinação entre os ganchos. Na Figura 3.12 é mostrada a implementação de um conector que instala os ganchos do aspect bean de controle de acesso nos componentes Printer e Fax. Os ganchos dos aspect beans são instanciados nos conectores (linha 2 e 3) e os parâmetros da instanciação atribuem valores iniciais aos ganchos e concretizam os métodos abstratos de seus construtores.

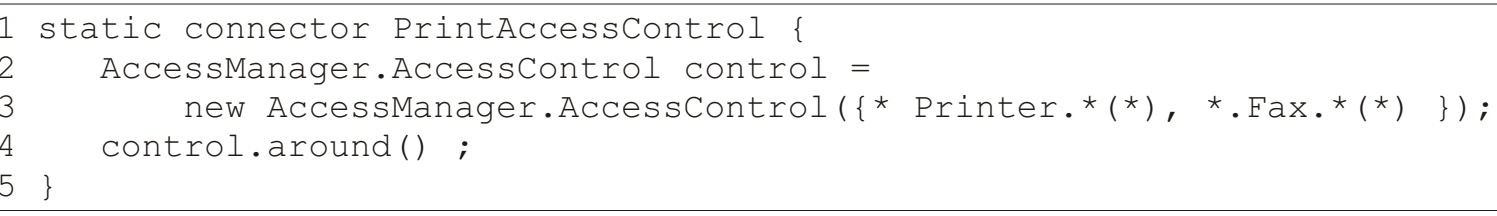

Figura 3.12: Um Conector que instala um gancho nos componentes Printer e Fax

No conector apresentado na Figura 3.12 são passados como parâmetros todos os métodos dos componentes Printer e Fax. Dessa forma, todas as vezes que esses componentes forem aces- 
sados será executado o código descrito pelo gancho do aspect bean, que verifica se o usuário tem permissão de acesso e executa o método requisitado caso tenha autorização e emite uma mensagem de erro caso contrário. Os conectores também podem especificar explicitamente qual adendo deve ser executado quando o gancho for ativado (linha 4).

Apesar de usar caracteres curinga, como o $\star$, a linguagem JAsCO possui mecanismos que faz com que apenas os métodos da interface dos componentes (públicos) sejam passados como parâmetro e posteriormente entrecortados.

Além de instanciar os ganchos em contextos concretos, os conectores também podem estabelecer estratégias de precedência e combinação. As estratégias de precedência são implementadas com a declaração explícita da ordem em que os adendos dos ganchos instalados para um mesmo componente devem ser executados, como pode ser visto na Figura 3.13. A ordem de chamada dos adendos no conector estabelece a ordem de precedência, pois primeiro se deve registrar que a impressora vai ser usada (linha 12), depois bloqueá-la para outros usuários (linha 13), executar o adendo que verifica se o usuário tem permissão para a operação e realizar a tarefa designada (linha 14), liberar o acesso para outros usuários (linha 15) e por último registrar o fim da utilização da impressora para aquela tarefa (linha 16).

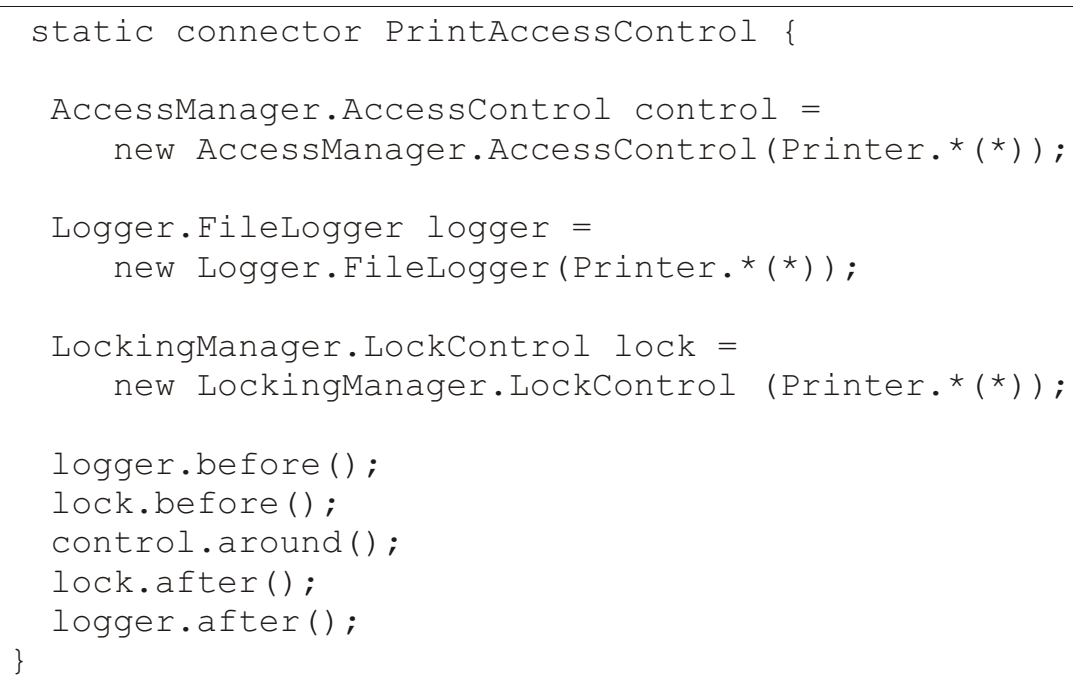

Figura 3.13: Estratégias de Precedência (Suvée, 2005)

As estratégias de combinação permitem que regras de relacionamento entre aspectos sejam respeitadas em tempo de execução, como, por exemplo, aspectos mutuamente exclusivos, em que um aspecto A deve ser removido da aplicação caso um aspecto B esteja presente.

Outros detalhes sobre como implementar um conector, instanciar ganchos, implementar estratégias de precedência e combinação, e utilizar outros recursos oferecidos na implementação dos conectores podem ser encontrados no manual de referência da linguagem (Suvée, 2005).

\section{O modelo JAsCo Beans}


O modelo de componentes JAsCo Beans Component Model pode ser visto na Figura 3.14. O modelo possui um registro de conectores que contém um banco de dados de conectores e serve como o principal ponto de endereçamento para as entidades do JAsCo, o qual é notificado sempre que uma armadilha (sinalizadores inseridos nos métodos traps) foi alcançada ou quando um conector foi carregado.

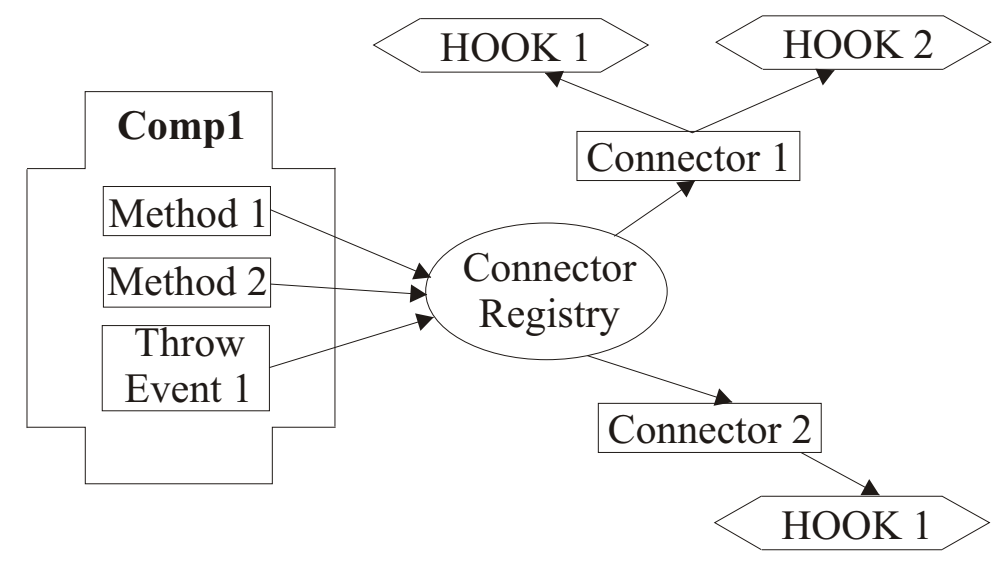

Figura 3.14: Modelo de Componentes JAsCo Beans (Suvée et al., 2003)

Todos os métodos do componente COMP 1 (à esquerda) são equipados com armadilhas e sempre que um método é chamado a execução é passada para o registro de conectores. Quando uma armadilha é disparada, ou seja, um método entrecortado é executado, o registro de conectores verifica todos os conectores registrados para aquele método ou evento e transfere a execução para os ganchos que foram instanciados com o correspondente método ou evento, os quais executam o comportamento apropriado. Esse modelo é flexível em relação a mudanças em tempo de execução, pois os conectores registrados para os métodos e eventos podem ser facilmente carregados e retirados em tempo de execução.

\section{Características do Modelo JAsCo Beans}

Algumas características do modelo JAsCo Beans, segundo seus criadores, estão listadas a seguir:

- O modelo permite a instalação e desinstalação de aspectos em tempo de execução, por meio da compilação e remoção dos conectores.

- Não há necessidade de uma máquina virtual Java especializada para rodar o JAsCo.

- JAsCo oferece o Java HotSwap, em que somente os métodos afetados pelos aspectos são equipados com armadilhas. Quando os aspectos são adicionados ou removidos, os métodos correspondentes são respectivamente mudados para um com armadilhas, ou para o original (sem armadilhas).

- JAsCo introduz um combinador em tempo real, permitindo a AOP dinâmica. 
- Os componentes são entrecortados somente nas operações de suas interfaces.

Uma das desvantagens do modelo é o alto custo de desempenho causado pela flexibilidade e dinamicidade das inserções e remoções dos aspectos no sistema, além do modo de funcionamento dos entrecortes, em que as execuções de métodos e eventos são redirecionadas para o registro de conectores para verificar se há ganchos instalados para tal método ou evento.

\section{Ferramentas de Apoio}

Além de um modelo de componentes, algumas ferramentas foram desenvolvidas para o pleno funcionamento da linguagem. Elas são:

- Transformation Tool: transforma um Java Bean normal em um JAsCo bean. Recebe como entrada um Java Bean em formato binário e insere armadilhas em cada método que o componente implementa.

- Compile Connector: compila um conector para sua representação como uma classe em Java.

- Remove Connector: permite a remoção de um certo conector do registro de conectores.

- Compile Aspect: compila um aspecto do JAsCo (aspect bean) para um Java Bean normal. O componente gerado também é equipado com armadilhas, para que um aspecto possa ser aplicado em um outro aspecto.

- Introspect: uma ferramenta visual que permite ver quais conectores estão carregados, além de mostrar os vários ganchos (hooks) instanciados pelos conectores e onde estão aplicados.

\section{Benefícios da linguagem JAsCo}

Alguns dos principais benefícios do uso da linguagem JAsCo estão listados a seguir:

- Independência e reusabilidade dos aspect beans, que não possuem um contexto concreto em que os adendos devem ser aplicados.

- Possibilidade de instalar aspectos para a disparada de eventos de um Java bean (modelo de comunicação do modelo de componentes utilizado).

- Possibilidade de definir explicitamente estratégias de precedência dos aspectos em um conector.

- Possibilidade de definir explicitamente estratégias de combinação em um conector, o que permite o gerenciamento de aspectos colaborativos.

- Possibilidade de aplicar aspectos em outros aspectos.

- Apoio à programação adaptativa usando conectores transversais. 


\subsubsection{2 - FuseJ}

FuseJ é uma abordagem que propõe tanto um nova arquitetura de componentes quanto uma linguagem que promova a unificação entre aspectos e componentes. O FuseJ foi proposto com o objetivo de implementar os interesses de um sistema como componentes regulares e introduzir mecanismos de composição de componentes que permitam especificar tanto interações regulares quanto aspectuais entre eles. A abordagem propõe uma Arquitetura de Componentes Unificada (Unified Component Architecture) que não faz distinção entre componentes regulares e aspectuais (Suvee, 2003; Suvée et al., 2004; Suvée et al., 2005), e uma linguagem de programação chamada FuseJ.

A arquitetura unificada de componentes proposta possui três elementos principais: componentes, portões (gates) e conectores. Uma ilustração do modelo de componentes do FuseJ pode ser vista na Figura 3.15. Os interesses do sistema são implementados com componentes ( $C 1$, C2 e C3) que ficam na camada de componentes da arquitetura. Não há construções específicas para a implementação de comportamentos transversais, pois todos os interesses do sistema devem ser implementados como componentes regulares.

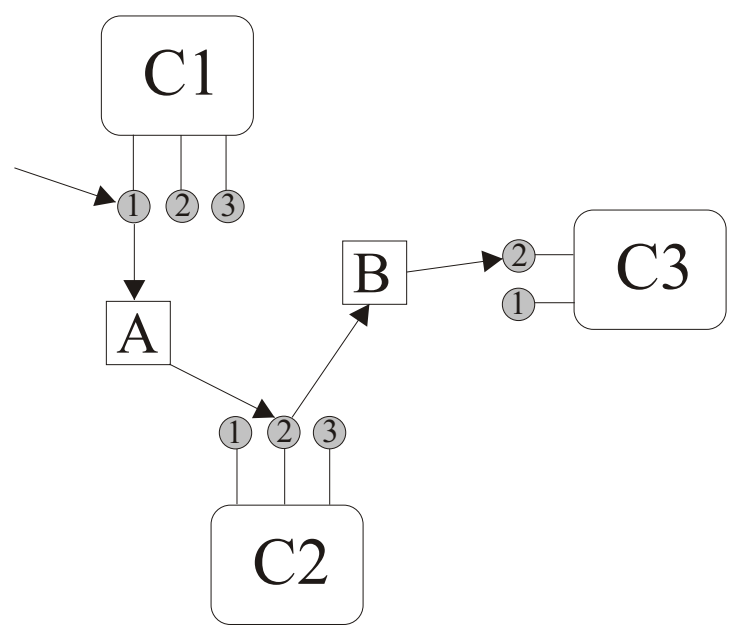

Figura 3.15: Arquitetura de Componentes Unificada (adaptado de Suvée et al. (2005))

Cada componente oferece serviços que não podem ser acessados diretamente, pois toda comunicação com ou do componente deve ser feita por meio dos portões. Portões são pontos de entrada e de saída de um componente que oferecem acesso aos serviços oferecidos pelos componentes e são mapeadas em um ou mais métodos internos do componente. Há dois canais de comunicação em um portão: o de entrada, que corresponde à solicitação do serviço oferecido pelo componente, e o de saída, que corresponde a um comportamento adicional que ocorre quando o serviço acessado pelo portão for executado. O comportamento adicional depende do serviço do portão ao qual o portão do serviço executado está conectado. O conceito de entrada e saída no portão permite que as portões estejam envolvidas tanto em interações regulares quanto aspectuais com os outros componentes (Suvée et al., 2004). 
As interações entre os portões são feitas por conectores (connectors) ( $\mathrm{A}$ e B) que ligam a saída de comunicação de um ou mais portões com a entrada de um ou mais portões e são responsáveis por descrever as composições regulares e aspectuais entre componentes. Os conectores são usados para construir o código de junção ( glue code) dos componentes, resolvendo problemas como nome de métodos ou tipos de argumentos.

Segundo Suvée et al. (2004), transferir a especificação das interações orientadas a aspectos para os portões e conectores tem algumas vantagens: o componente torna-se mais reusável, pois o desenvolvedor não precisa se preocupar se um componente vai interagir de maneira regular ou de forma aspectual; todos os interesses são implementados como componentes regulares, deixando os conectores responsáveis por especificar como as interações entre os componentes ocorrem; e os serviços de um componente podem ser reusados tanto de maneira regular quanto como um aspecto ao mesmo tempo.

\section{A linguagem Fuse J}

Para apresentar o uso da linguagem FuseJ, é apresentado um estudo de caso de um sistema de reserva de hotel que possui três componentes: BookingService, Payment Service e Discount Service. O componente BookingService oferece o serviço de reserva de hotel, o componente PaymentService oferece o serviço de registrar o pagamento de uma conta com um cartão de crédito de um cliente e o componente Di scount Service implementa regras de negócio que oferece desconto de N\% a um cliente dependendo das condições específicas do negócio.

Os componentes da aplicação são implementados como JavaBeans regulares e possuem interfaces (gate-interface) que especificam os portões que descrevem os serviços oferecidos pelo componente. Nas Figuras 3.16, 3.17 e 3.18 são mostradas as implementações das interfaces dos componentes Booking Service, Discount Service e Payment Service, respectivamente.

A especificação de um portão consiste de duas partes: binds, que descreve o mapeamento do portão sobre os métodos internos do componente, e exposes, que descreve as propriedades do portão (argumentos de entrada, valor de retorno, etc.).

A interface BookingService agrupa dois portões: BookHotel e ChargeForHotel. O portão BookHotel (linha 3 a 9) permite iniciar a execução de funcionalidades internas do componente Booking Service invocando-as de fora. Já o portão ChargeForHotel (linha 11 a 16) é um portão de saída (outputgate) e não pode ser executado de fora do componente. Este portão apenas dispara um evento interno que cobra um cliente quando faz uma reserva em um hotel. $\mathrm{O}$ binds do primeiro portão (linha 4 e 5) mapeia o portão sobre o método bookHotel (linha 5). O portão bookHotel descreve a propriedade input HotelName (linha 7) que representa o nome do hotel que é dado como entrada. A propriedade outputPrice (linha 8) descreve o valor de retorno (palavra chave returnvalue) do método bookHotel sobre o qual o portão é mapeado. 


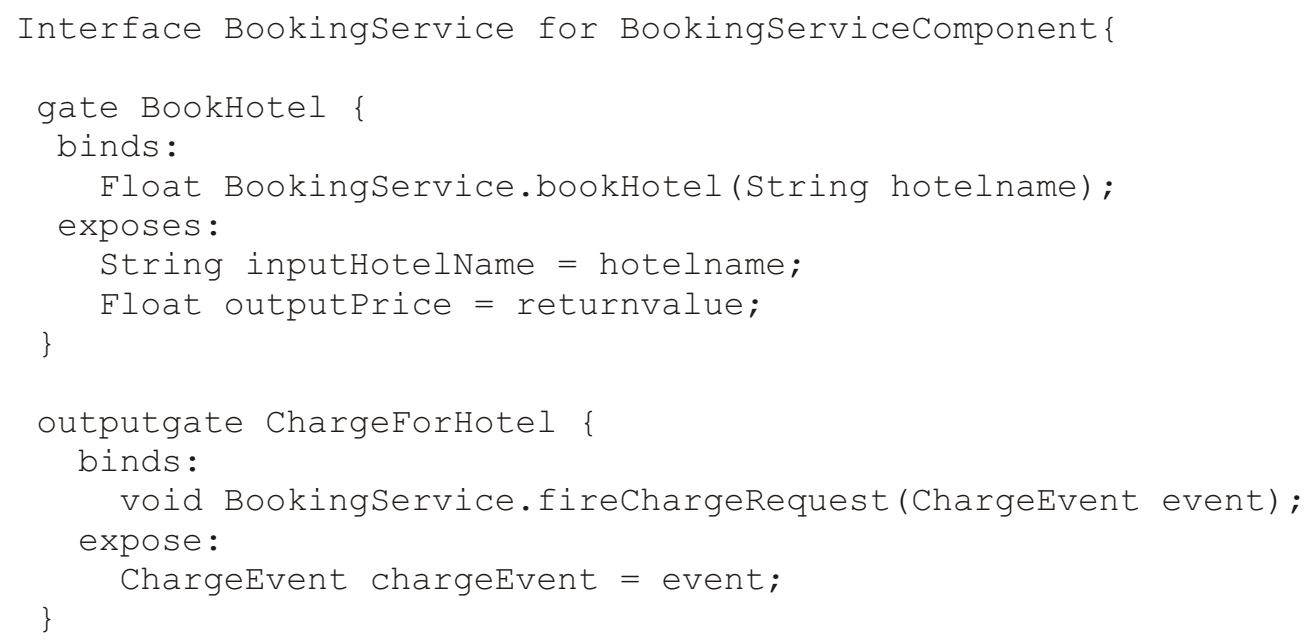

Figura 3.16: Interface do Componente BookingService (Suvée et al., 2005)

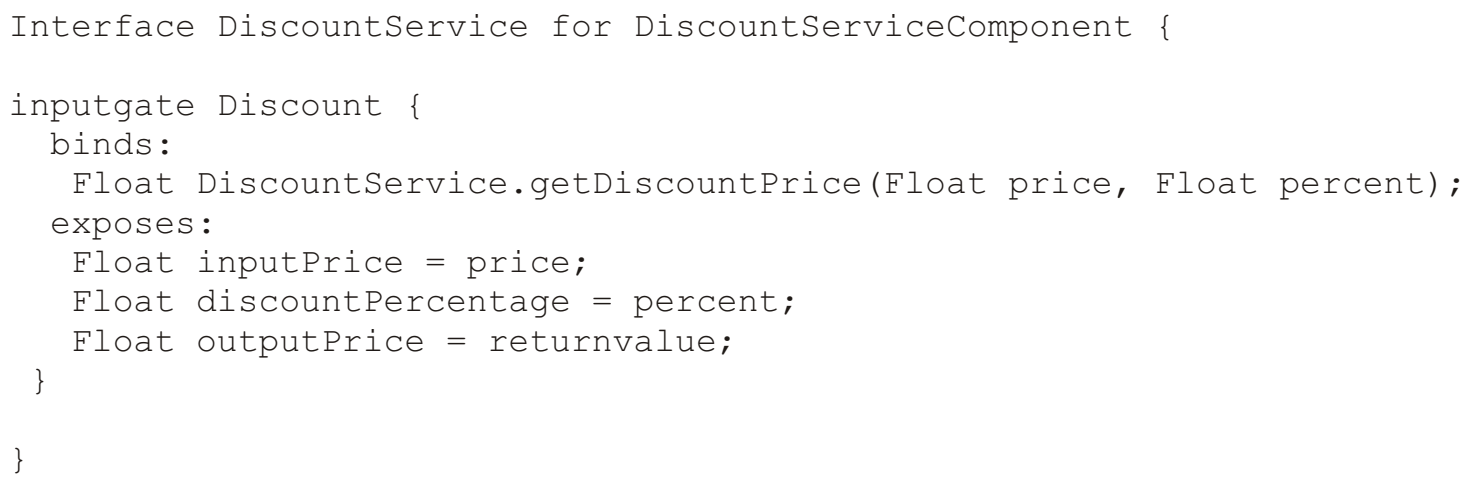

Figura 3.17: Interface do Componente Discount Service (Suvée et al., 2005)

Os conectores são utilizados para combinar os componentes do sistema, sendo responsáveis por conectar um ou mais portões e descrever como os componentes devem ser compostos (de forma regular ou aspectual). Um conector especifica uma ou mais composições de portões, possuindo duas partes típicas: a parte de conexão, que interconecta dois portões, e a de mapeamento, que é responsável por especificar o mapeamento entre as propriedades dos portões.

No exemplo do hotel, há a necessidade de dois conectores, um para realizar o pagamento da conta de um cliente com cartão de crédito quando uma reserva é feita e outro para fazer o cálculo de desconto do cliente de acordo com algumas condições.

A implementação do conector que faz a ligação regular do serviço de reserva de hotel com o pagamento pode ser visto na Figura 3.19. Na parte de conexão do conector (linha 3 a 6), o portão ChargeAmount do componente Payment Service é conectado ao portão ChargeForHotel do componente BookingService. O mapeamento (linha 7 a 11) é responsável por especificar 


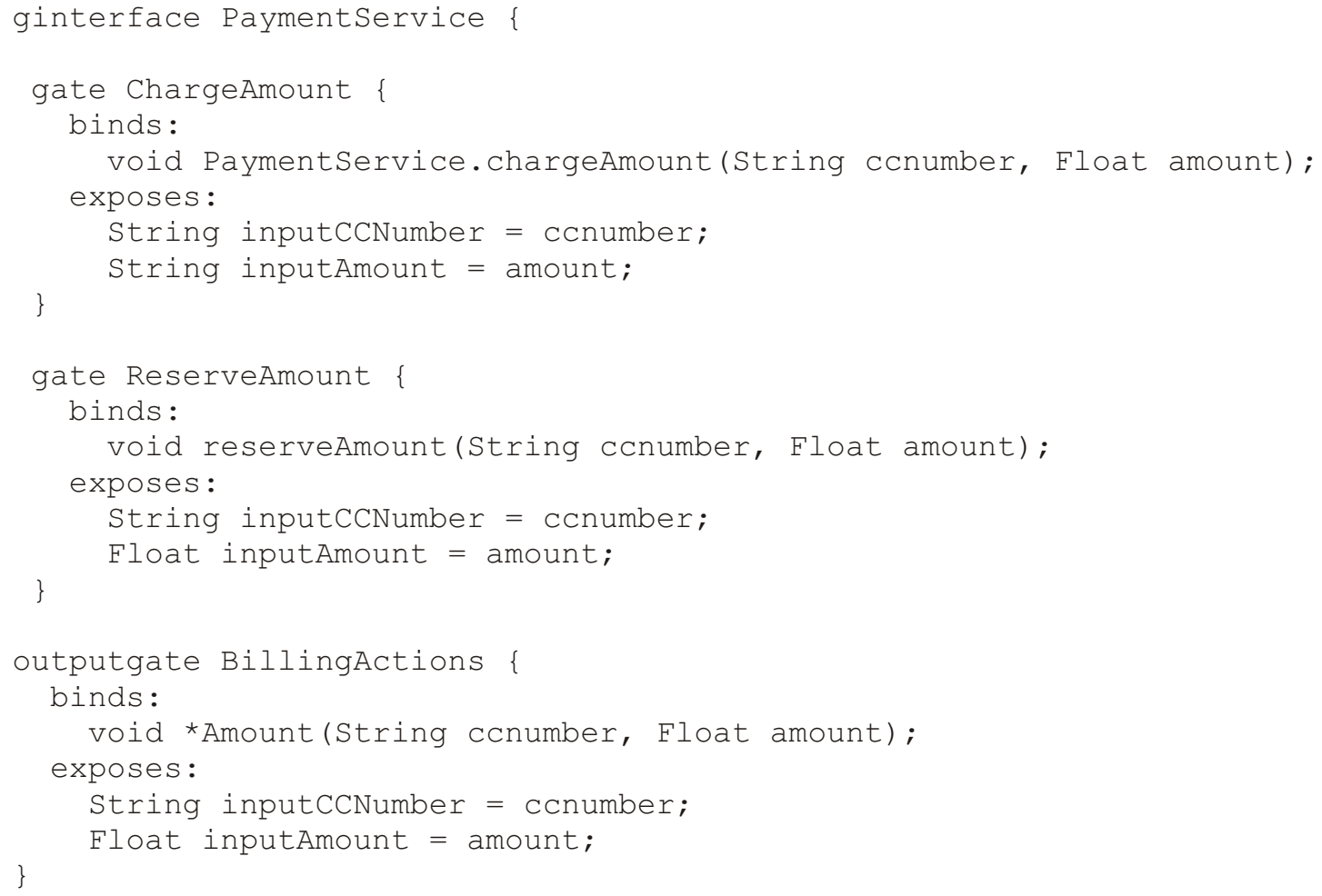

Figura 3.18: Interface do Componente Payment Service (Suvée et al., 2005)

as traduções de algumas propriedades do portão, e, nesse caso, o mapeamento da propriedade chargeEvent do portão ChargeForHotel sobre inputCCNumber e o inputAmount do portão ChargeAmount. O efeito resultante deste conector é que o sempre que um cliente faz reserva no hotel, o componente Payment Service é empregado para realizar a cobrança.

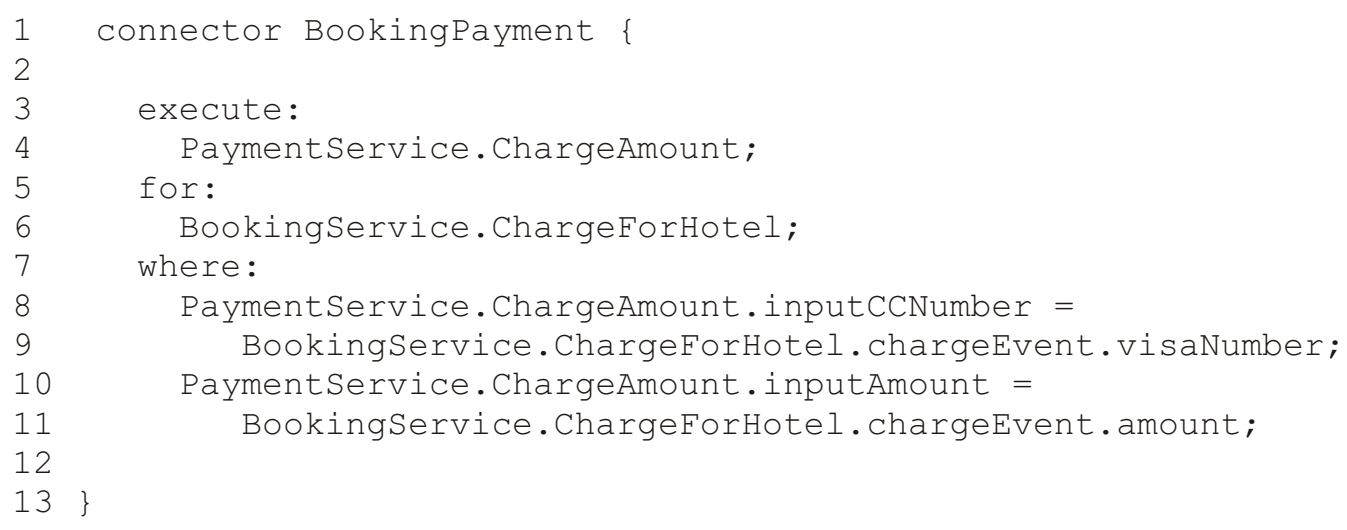

Figura 3.19: Conector que descreve uma composição regular entre componentes (Suvée et al., 2005) 
O conector BookingDiscount mostrado na Figura 3.20 tem o propósito de realizar uma interação aspectual entre os componentes BookingService e PaymentService, concedendo um disconto de $15 \%$ aos clientes por reservas efetuadas no natal. Para isso, o conector liga o portão BookHotel do componente BookingService ao portão Discount do componente Discount Service. A interação especifica que o comportamento do portão Di scount deve ser executado no lugar do comportamento do portão Book Hotel. A especificação do a round determina que o valor de retorno do portão Book Hotel será substituído pelo valor do portão Discount. A condição do desconto ser dado no natal é introduzida pela cláusula when (linha 11 e 12).

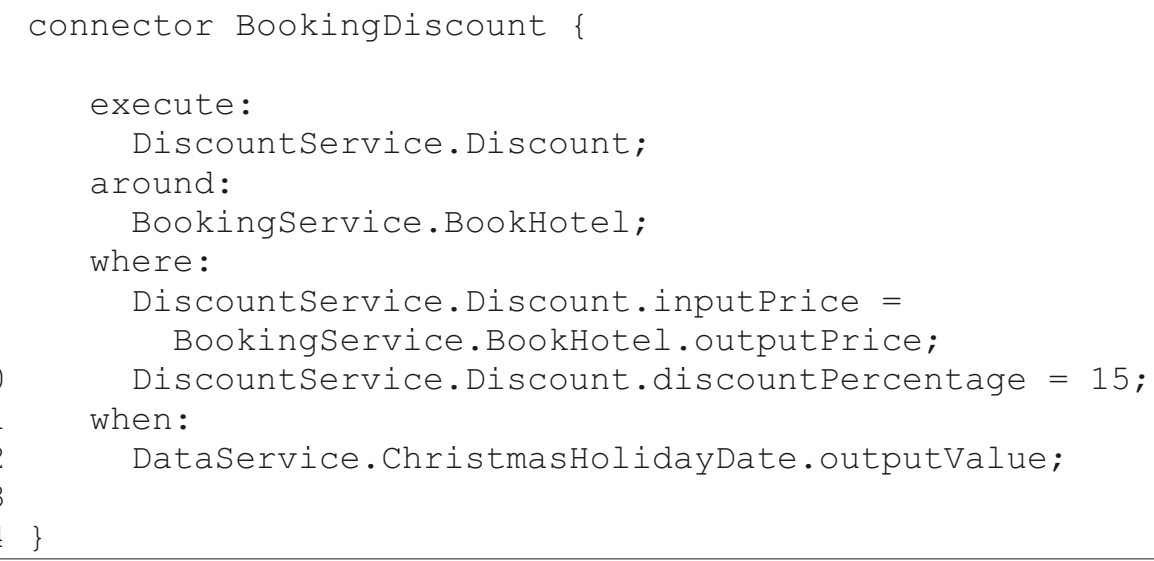

Figura 3.20: Conector que descreve uma composição aspectual entre componentes (Suvée et al., 2005)

\subsubsection{3 - Open Modules}

Open Modules foi proposto para preservar a expressividade das técnicas de programação orientada a aspectos, como o AspectJ, por exemplo, e ao mesmo tempo oferecer garantias do encapsulamento dos componentes (open modules) mesmo na presença de aspectos. Nessa abordagem os aspectos podem entrecortar todos os métodos disponíveis na interface do módulo e os módulos têm a possibilidade de exportar os conjuntos de junção que deseja tornar disponíveis em suas interfaces, para que os aspectos possam usá-los. Por meio de operadores com o de negação (!), os Open Modules deixam explícito quais funções internas dos módulos, com exceção das que estão na interface, não podem ser acessadas externamente pelos aspectos, preservando assim o encapsulamento dos módulos (Aldrich, 2004).

Os Open Modules garantem o encapsulamento dos componentes, preservando a expressividade dos aspectos. Entretanto, o fator inconsciência fica comprometido parcialmente, pois os desenvolvedores precisam antecipar quais aspectos vão entrecortar o componente e quais conjuntos de junção criar e exportar nas interfaces.

Segundo Aldrich (2004), a abordagem permite maior compreensão do sistema e dos aspectos e permite que as composições de seus componentes tenham resultados previsíveis, uma vez que 
o encapsulamento dos componentes é garantido; a evolução dos componentes e dos sistemas é facilitada; e as interações entre aspectos são vistas de maneira mais compreensível.

\subsection{Considerações Finais}

Neste capítulo foram abordados os principais conceitos relacionados com a programação orientada a aspectos, a linguagem AspectJ e as abordagens que buscam integrar os conceitos dos aspectos e do desenvolvimento com componentes.

Foram apresentados problemas que ocorrem com o desenvolvimento baseado em componentes quando interesses transversais precisam ser desenvolvidos. Os interesses transversais são geralmente implementados de forma arbitrária, causando problemas como o espalhamento e entrelaçamento de código, o que dificulta a manutenção, a evolução e o reúso dos componentes. A evolução dos componentes nessa questão foi a implementação de alguns interesses transversais nos contêineres dos componentes. Entretanto, os serviços oferecidos são fixos e as chamadas aos serviços permanecem espalhadas nos componentes do sistema.

Para resolver esses problemas foram apresentadas propostas de utilização de programação orientada a aspectos, tanto para o desenvolvimento de componentes quanto para o desenvolvimento com componentes. A programação orientada a aspectos fornece mecanismos para a aumentar a separação de interesses no sistema, separando os interesses transversais em módulos independentes

Os componentes possuem princípios que podem ser desrespeitados quando colocados na presença dos aspectos, e, por isso, as abordagens de componentes e aspectos discutem os desafios de como preservar o encapsulamento dos componentes, as certificações de qualidade e a previsibilidade das composições para formar um sistema. Além disso, deseja-se implementar aspectos que sejam independentes de contexto, flexíveis, dinâmicos e reusáveis em outros sistemas.

Identificou-se que embora as tecnologias de desenvolvimento de componentes transversais já estejam em um estágio mais amadurecido, os métodos e processos para o desenvolvimento com componentes e aspectos está em um estágio inicial. Os métodos encontrados na literatura não apresentam de forma clara e objetiva diretrizes para identificar os componentes transversais em potencial desde as fases iniciais de desenvolvimento, relacionando de uma forma simples os requisitos com os componentes do sistema. A interação dos componentes e aspectos no sistema não é apresentada com detalhes e por vezes a interação mostrada viola princípios dos componentes como o encapsulamento.

Os métodos pesquisados também não possuem diretrizes e recomendações mais específicas e detalhadas para o provisionamento, generalização, documentação, implementação e reúso dos componentes transversais. Além disso, as especificações dos componentes apresentados não são traduzidas de forma direta e objetiva para as linguagens orientadas a aspectos, nem para as de propósito geral ou para as específicas, para a construção de componenentes transversais. 
Com vistas a preencher essa lacuna, é apresentado no próximo capítulo um método proposto para o desenvolvimento de software baseado em componentes e aspectos, em que as etapas de desenvolvimento são apresentadas em detalhes, com diretrizes e recomendações para a identificação dos componentes transversais em potencial desde a fase de requisitos do sistema. Além disso, a UML é utilizada com algumas alterações e adaptações na construção dos artefatos necessários para cada atividade. 


\section{Proposta de um Método Para o Desenvolvimento de Software Baseado em Componentes e Aspectos (DSBC/A)}

\subsection{Considerações Iniciais}

Neste capítulo é apresentada a proposta de um método para o Desenvolvimento de Software Baseado em Componentes e Aspectos (DSBC/A). O método é uma adaptação do método UML Components com modificações e inclusões de algumas atividades para considerar aspectos no desenvolvimento. Essas modificações levaram em conta os trabalhos de Clarke e Baniassad (2005), Araujo e Moreira (2003, 2004), Jacobson e Ng (2004) e Suvée et al. (2003).

O método UML Components foi escolhido para ser adaptado por ser um método prático, simples, conciso e objetivo, em que os componentes são identificados e especificados de forma direta a partir dos requisitos do sistema. Além disso, o método utiliza a UML como notação e há um livro publicado que o apresenta didaticamente.

No método para o DSBC/A, os componentes são considerados como caixa preta e a interação entre os componentes e os aspectos é projetada com o objetivo de preservar o encapsulamento dos componentes, permitindo que os aspectos apenas operem nas interfaces dos componentes, evitando problemas como os discutidos na seção 3.3 deste trabalho.

Para ilustrar a apresentação do método proposto, é usado o exemplo de um Sistema de Reservas de Hotel extraído e adaptado do livro de Cheesman e Daniels (2000), em que os artefatos principais 
de cada etapa do processo são apresentados. O Documento de requisitos deste sistema é descrito no Apêndice A deste trabalho.

Este capítulo está organizado da seguinte maneira. Na Seção 4.2 são apresentadas as atividades realizadas para especificar o método proposto. Na Seção 4.3, uma visão geral com algumas características do método é mostrada. Nas Seções 4.4, 4.5, 4.6, 4.7 são apresentadas as etapas do método para o DSBC/A em detalhes, como a Análise de Requisitos, Especificação, Provisionamento e Montagem dos Componentes, respectivamente. Por fim, as considerações finais do capítulo são apresentadas na Seção 4.8 .

\subsection{O processo de construção do método}

A especificação do método para o DSBC/A envolveu a realização de algumas atividades projetadas para alcançar esse objetivo. Primeiramente, o método UML Components foi estudado em detalhes, com o objetivo da familiarização com os conceitos, atividades, artefatos e notação utilizados pelo método.

Além de métodos de desenvolvimento com componentes, métodos que usam conceitos da programação orientada a aspectos foram estudados, como o método Theme, de Clarke e Baniassad (2005); o método Aspect-Oriented Component Engineering, de Grundy et al. (2000); o método Aspect-Oriented Use Case Driven Devolopment de Jacobson e Ng (2004); e os trabalhos de Araújo e Moreira (2003, 2004).

Após a familiarização com esses métodos de desenvolvimento, foi realizado um projeto baseado em componentes do Sistema de Reservas de Hotel descrito no livro de Cheesman e Daniels. A especificação do sistema foi estendida com requisitos funcionais e não-funcionais para adicionar interesses transversais aos requisitos do sistema. Algumas atividades do método UML Components foram modificadas e outras introduzidas para considerar aspectos no desenvolvimento do sistema. Com isso, foram especificados tanto componentes regulares, os quais são chamados de componentes-base, quanto componentes transversais, os quais possuem comportamento semelhante a um aspecto e podem entrecortar outros componentes. A documentação completa do projeto desse exemplo encontra-se em um documento de trabalho (Eler e Masiero, 2006b).

As anotações sobre as atividades modificadas e introduzidas no método UML Components e a documentação do projeto realizado foram utilizadas para escrever um processo com atividades para especificar componentes transversais (aspectos). As atividades novas foram especificadas e introduzidas de forma a manter a homogeneidade e a compatibilidade entre as etapas, atividades, conceitos, artefatos e notação do método UML Components. Uma versão preliminar e parcial desse processo foi publicada (Eler e Masiero, 2005).

Depois que o processo foi elaborado, um outro sistema foi escolhido para ser projetado e com isso validar a utilização e refinar o método proposto. Um Sistema de Locação de Carros, extraído do trabalho de Sass (2003) foi escolhido, por ser um sistema relativamente simples e já haver um 
projeto baseado em componentes realizado, o que permite a comparação dos resultados obtidos pelos dois métodos. Durante o projeto do Sistema de Locação de Carros, o método para o DSBC/A foi refinado, pois identificou-se a necessidade de mudar a ordem de execução de algumas atividades, detalhar e descrever melhor algumas atividades que não haviam sido previstas mas haviam sido de fato realizadas no projeto do Sistema de Reservas de Hotel. A documentação completa deste exemplo (Sistema de Locação de Carros) encontra-se em um documento de trabalho (Eler e Masiero, 2006a).

\subsection{Visão Geral do Método}

O método proposto tem o objetivo de, a partir do documento de requisitos de um sistema, produzir uma arquitetura de componentes que contenha componentes-base (regulares) e transversais (aspectuais), bem como suas especificações. Os componentes-base são como os EJB's, componentes CORBA e COM, e possuem comportamento semelhante a um objeto dentro de uma aplicação. Já os componentes transversais são componentes que possuem o comportamento de um aspecto, tendo a capacidade de entrecortar outros componentes nas operações de suas interfaces e adicionar ou substituir algum comportamento. Mais detalhes sobre esses dois tipos de componentes, como suas características e comportamento, são apresentados juntamente com o método.

Em seu nível mais alto, o método proposto mantém as mesmas etapas do método UML Components - Requisitos, Especificação, Provisionamento, Montagem, Teste e Implantação. Apesar dos processos do método UML Components e do método proposto serem os mesmos, algumas atividades internas às etapas gerais são incluídas e outras são modificadas para considerar e modularizar interesses transversais (aspectos) ${ }^{1}$. Além disso, alguns artefatos que passam de uma etapa para outra do processo também são alterados e outros incluídos. As etapas gerais do método proposto podem ser vistas na Figura 4.1.

Em relação aos artefatos que transitam entre as etapas do processo geral original, os que mudam no método proposto são os artefatos que passam da Análise de Requisitos para a Especificação dos Componentes, em que um Modelo Conceitual de Negócio Não-Funcional e uma lista de casos de uso transversais são incluídos, além do Modelo de Casos de Uso que também inclui os casos de uso não-funcionais. Da Especificação dos Componentes para o Provisionamento, também deve haver um artefato com a especificação dos componentes transversais. Entre o Provisionamento e Montagem dos Componentes, deve transitar os artefatos que mostram a arquitetura e especificação dos componentes transversais, além dos componentes-base.

O processo, em linhas gerais, tem como entrada os requisitos de um sistema, que são usados pela etapa de requisitos para produzir um modelo conceitual de negócios (funcional e nãofuncional), um modelo de casos de uso (funcionais e não-funcionais) e uma lista de casos de uso

\footnotetext{
${ }^{1}$ Neste trabalho, interesses transversais referem-se aos interesses que afetam várias partes de um sistema, sejam funcionais ou não-funcionais. Aspectos são unidades que modularizam os interesses transversais em termos de projeto e implementação, principalmente quando se usa a linguagem AspectJ. Aqui é usado de forma geral.
} 


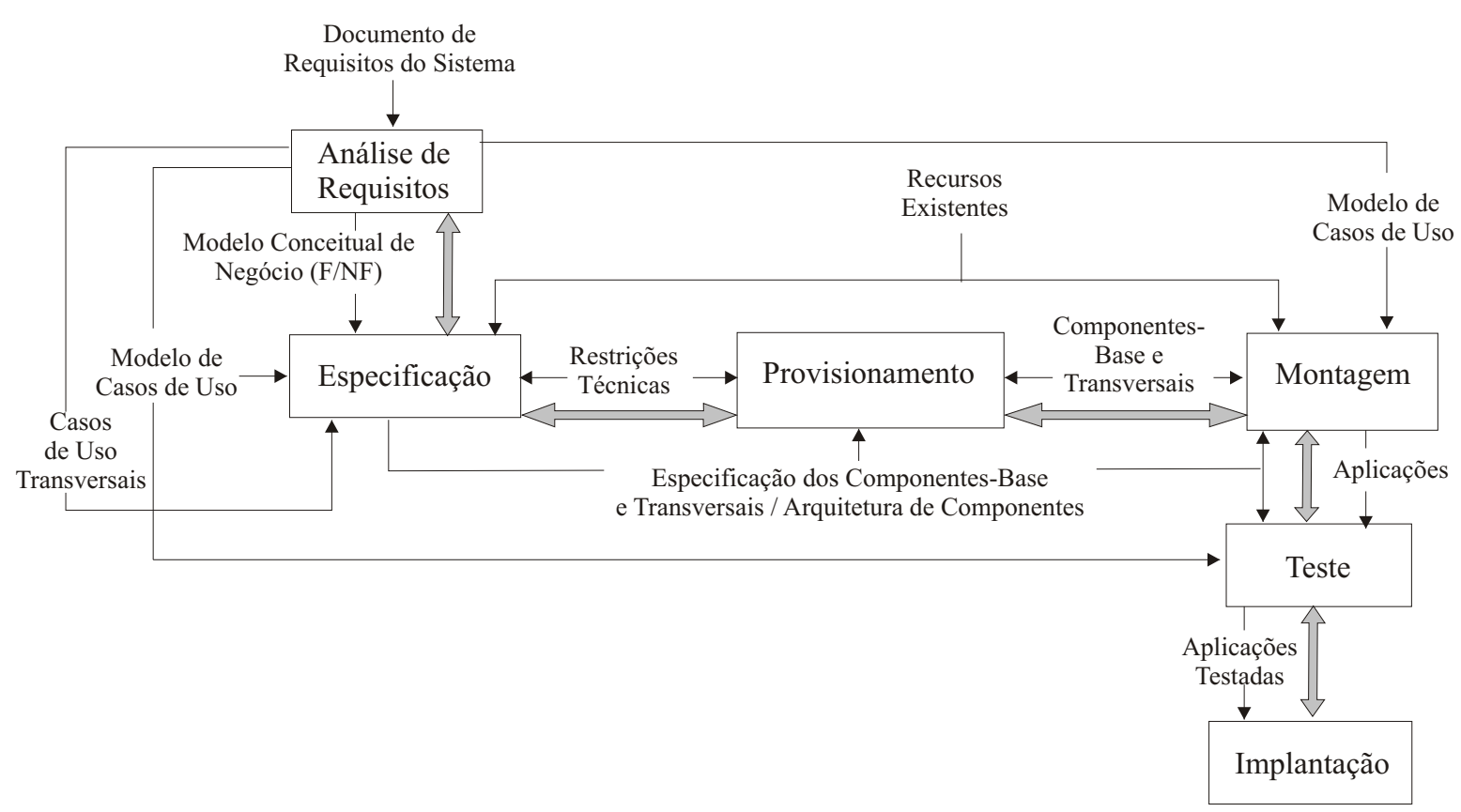

Figura 4.1: Processo do Método UML Components (Cheesman e Daniels, 2000) com pequenas adaptações

transversais. Esses modelos, juntamente com os recursos existentes no sistema (sistemas existentes, pacotes, sistema de banco de dados) e as restrições técnicas do projeto (arquiteturas e ferramentas a serem usadas), formam as entradas necessárias para que na etapa de especificação sejam produzidas as especificações dos componentes-base e transversais, assim como de suas interfaces requeridas e oferecidas.

Além disso, é produzida a arquitetura de componentes que mostra como os componentes-base e transversais interagem entre si. As saídas (especificações e arquitetura) são usadas na etapa de provisionamento para definir quais componentes serão reusados e quais precisarão ser adquiridos de terceiros. A etapa de provisionamento também inclui os testes de unidade para os dois tipos de componentes, para que possam ser utilizados na etapa de montagem.

As etapas de Requisitos e Especificação foram as que mais sofreram mudanças e são abordadas em mais detalhes neste trabalho, enquanto que as etapas de Provisionamento, Montagem, Implantação e Teste de componentes mudaram pouco. Neste trabalho as etapas de Provisionamento e Montagem não são apresentadas detalhadamente e as etapas de Implantação e Teste não foram consideradas no trabalho e por isso não serão apresentadas.

Cada etapa do método proposto é apresentada em detalhes nas seções a seguir e para ilustrar sua execução é utilizado o exemplo de um Sistema de Reservas de Hotel (SRH), extraído e adaptado do livro de Cheesman e Daniels (2000), cujo documento de requisitos pode ser visto no Apêndice A deste trabalho. 


\subsection{Análise de Requisitos}

A etapa de requisitos tem o objetivo de fazer a análise dos requisitos do sistema para definir o escopo e identificar os interesses do sistema. Uma abordagem baseada em casos de uso é utilizada com diretrizes e atividades reutilizadas da etapa de Requisitos do UML Components. Outras abordagens que auxiliam na identificação de interesses transversais do sistema são utilizadas e incorporadas ao método proposto, como os trabalhos de Jacobson e Ng (2004), de Araújo e Moreira (2003); Moreira e Araújo (2004), de Chavez (2004) e de Clarke e Baniassad (2005).

Esta etapa possui as seguintes atividades: 1) Criar Modelo de Processo de Negócio; 2) Identificar casos de uso funcionais; 3) Identificar atores do sistema; 4) Construir diagrama de casos de uso funcionais; 5) Descrever casos de uso funcionais; 6) Identificar casos de uso não-funcionais; 7) Descrever casos de uso não-funcionais; 8) Integrar casos de uso não-funcionais aos casos de uso funcionais; 9) Criar Modelo Conceitual de Negócio (Funcional e Não-Funcional); e 10) Identificar Casos de Uso transversais.

As atividades desta etapa podem ser vistas na Figura 4.2 e são apresentadas em detalhes nas subseções a seguir. Em relação à etapa de análise requisitos do UML Components, as atividades 2, 3, 4, 5 e 9 foram alteradas e as atividades 6, 7, 8 e 10 são novas. Nota-se que algumas atividades estão agrupadas por objetivos, como as atividades 2, 3, 4 e 5 para Modelo de Casos de Uso, e as atividades 6, 7 e 8 para Modelo de Casos de Uso Não-Funcional. A ordem das atividades é especificada pela sua numeração no diagrama.

\section{Modelo de Processo: Cascata x Incremental}

O método para o DSBC/A é apresentado neste trabalho de modo sequencial, em que é feita a análise de todos os requisitos do sistema na fase inicial, em seguida o projeto dos componentes na fase de Especificação e posteriormente a implementação na etapa de provisionamento e montagem, tudo em uma única iteração. A sequência de apresentação do processo dá a impressão de que o método adapta-se apenas ao modelo de processo em cascata. Deve-se considerar que o Sistema de Reservas de Hotel apresentado é relativamente simples e não houve necessidade de construí-lo em várias iterações. Entretanto, o processo cascata não é o único ao qual o método se adapta, pois quando o sistema a ser desenvolvido é relativamente grande e complexo, o método pode adaptar-se ao modelo de desenvolvimento iterativo e incremental.

O método apresentado é dirigido por casos de uso, assim como o método de Larman (Larman, 2001). Dessa forma, diretrizes sobre como desenvolver o software de modo iterativo e incremental devem ser utilizadas, como a recomendação de se escolher inicialmente os casos de uso mais complexos e críticos e desenvolvê-los logo nos primeiros ciclos e dividir os ciclos de maneira uniforme levando em conta o tempo de desenvolvimento. A recomendação adicional em relação ao método para o DSBC/A é que os casos de uso funcionais sejam desenvolvidos nas primeiras etapas, e os requisitos não-funcionais que não influem diretamente na funcionalidade do sistema, 


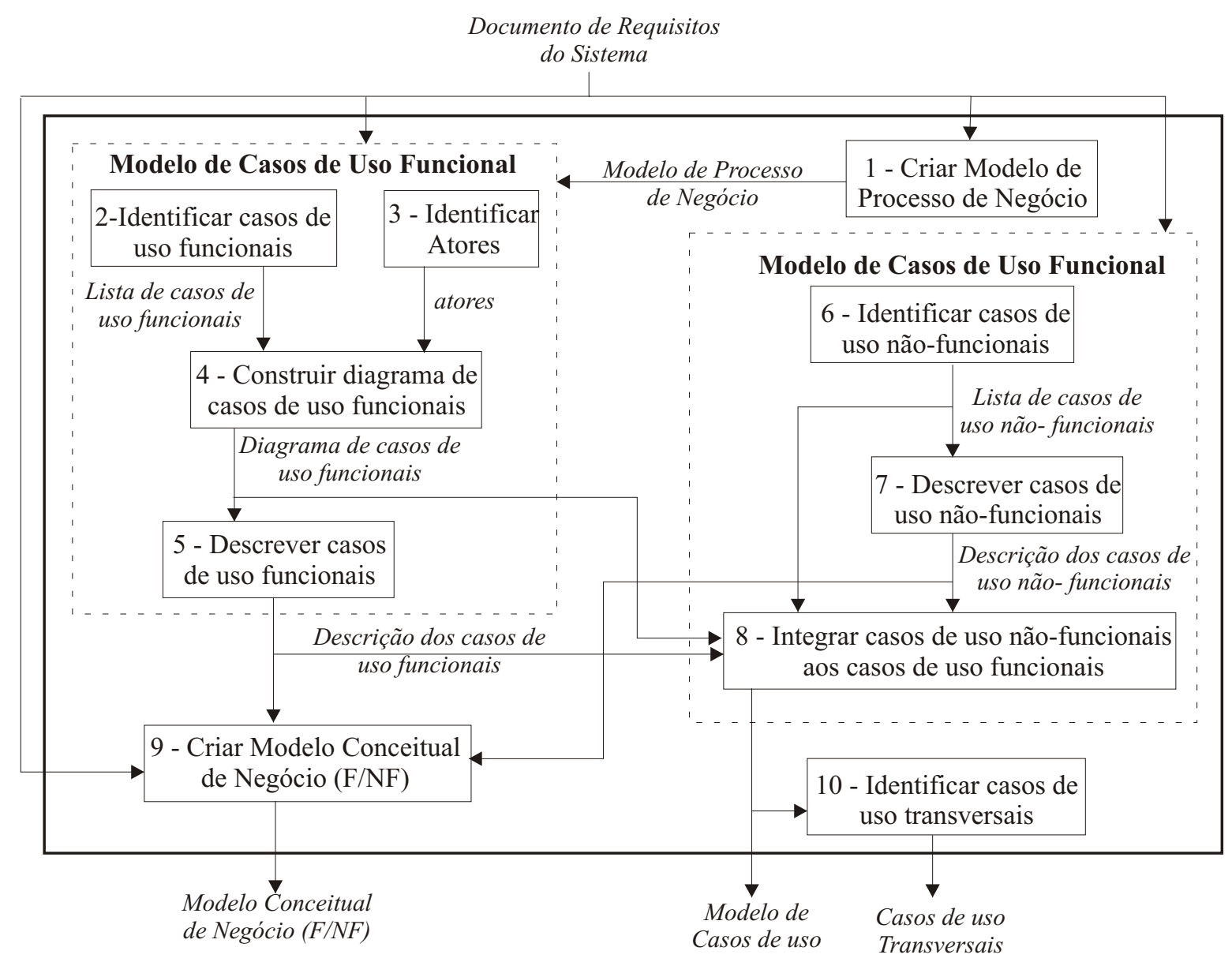

Figura 4.2: Atividades da Análise de Requisitos

como requisitos de registro, controle de acesso e autenticação, sejam analisados e implementados nos últimos ciclos. Já a persistência, por exemplo, que influi na funcionalidade por ser responsável por armazenar e recuperar os dados da aplicação, deve ser considerada nas primeiras iterações.

A etapa de requisitos do método agrupa as atividades para facilitar a visão da etapa por objetivos, como, por exemplo, as atividades 2 a 5 que são responsáveis por construir os casos de uso funcionais do sistema, enquanto que as atividades 6 a 8 são responsáveis por construir os casos de uso não-funcionais do sistema.

\subsubsection{Criar Modelos de Processos de Negócio}

Nesta atividade deve-se criar o Modelo de Processos de Negócio (MPN) para os processos mais importantes do sistema com a utilização de um diagrama como o de atividades da UML. Esta atividade é útil para que se possa melhor entender o funcionamento do sistema e facilitar a análise dos requisitos e a identificação dos casos de uso. É uma atividade opcional, seguindo o que é recomendado pelo método UML Components. 
O MPN do sistema é composto por um conjunto de diagramas de atividades que são criadas para os objetivos mais relevantes do sistema e/ou para seus processos mais complexos. No Sistema de Reservas de Hotel, o processo mais importante a ser representado é o de reserva de tipo de acomodação, cujo diagrama de atividades pode ser visto na Figura 4.3.

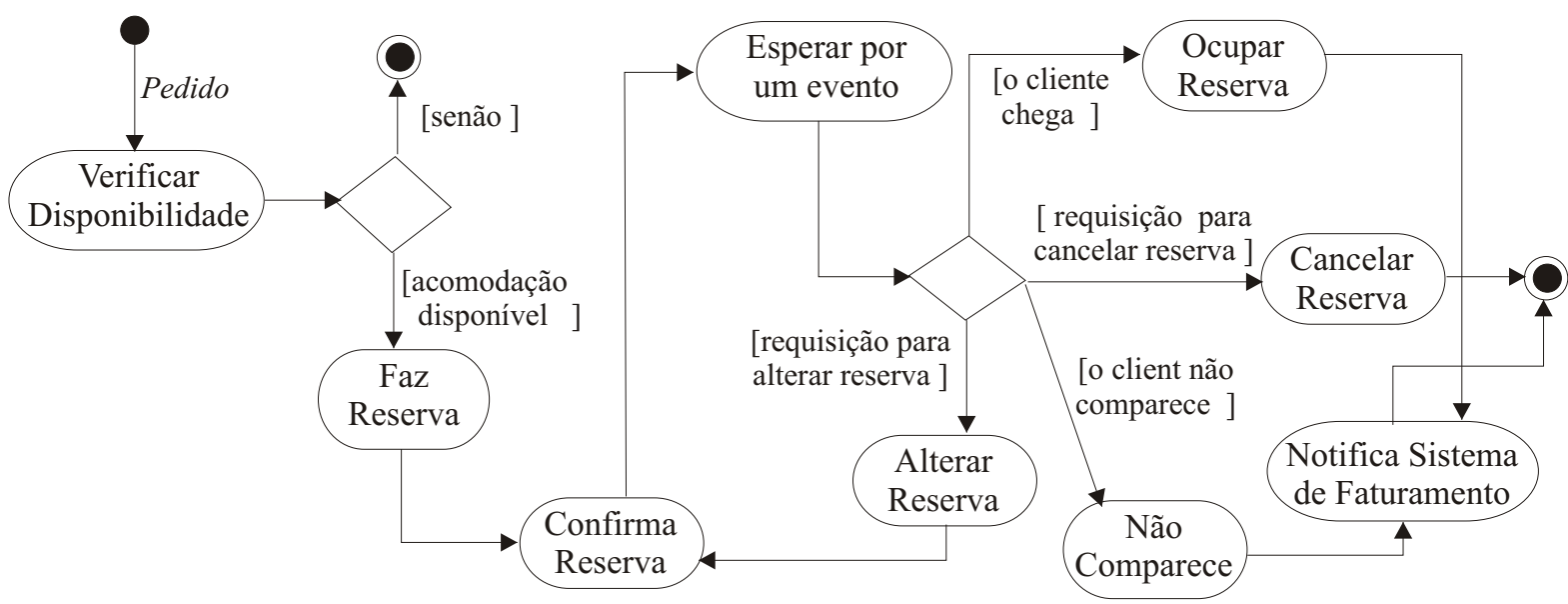

Figura 4.3: Diagrama de Atividades do Sistema de Reservas de Hotel

\subsubsection{Identificar casos de uso funcionais}

Nesta atividade, deve-se representar os requisitos funcionais do sistema em um diagrama de casos de uso. Para facilitar a rastreabilidade entre os elementos do diagrama e os requisitos representados, aconselha-se a construção de uma tabela que relacione os requisitos funcionais e os casos de uso identificados. Um modelo para relacionar requisitos e casos de uso pode ser visto na Tabela 4.1. Por meio dessa tabela, pode-se também verificar se todos os requisitos foram cobertos com os casos de uso identificados.

\begin{tabular}{|l|l|}
\hline Requisito Coberto & Caso de Uso \\
\hline & \\
\hline
\end{tabular}

Tabela 4.1: Modelo de Tabela que relaciona requisitos e casos de uso

Os casos de uso identificados no Sistema de Reservas de Hotel e os requisitos cobertos podem ser vistos na Tabela 4.2. Os requisitos do sistema de reservas de hotel podem ser vistos no Apêndice A desta dissertação. Alguns casos de uso são muito simples e repetitivos e não estão representados no diagrama de casos de uso, por isso uma nova coluna foi acrescentada em relação ao modelo para indicar quais casos de uso são apresentados no diagrama. 


\begin{tabular}{|c|c|c|}
\hline Requisito Coberto & Caso de Uso & D.C.U. \\
\hline Req. 1 & Incluir/Alterar/Excluir Hotel & \\
\hline Req. 2 & Incluir/Alterar/Excluir Acomodação & \\
\hline Req. 2 & Incluir/Alterar/Excluir Tipo de Acomodação & \\
\hline Req. 3 & Incluir/Alterar/Excluir Clientes & \\
\hline Req. $4,5,10$ & Incluir/Alterar/Excluir Empresas & \\
\hline Req. 6 & Fazer Reserva & $*$ \\
\hline Req. 6 & Verificar Disponibilidade de Acomodação por Período & $*$ \\
\hline Req. 7 & Enviar e-mail & \\
\hline Req. 8 & Cancelar Reserva & $*$ \\
\hline Req. 8 & Alterar Reserva & $*$ \\
\hline Req. 9 & Ocupar Reserva & $*$ \\
\hline Req. 10 & Gerar dados para faturamento & $*$ \\
\hline Req. 10 & Não Comparecer & $*$ \\
\hline Req. 5,10 & Calcular Desconto & \\
\hline Req. 11 & Consultar se uma acomodação está disponível no momento & \\
\hline Req. 12 & Consultar número de reservas de um tipo de acomodação & \\
\hline Req. 13 & Listar Reservas por período & $*$ \\
\hline Req. $6,8,9,10$ & Identificar Reserva & \\
\hline
\end{tabular}

Tabela 4.2: Casos de Uso Funcionais do Sistema de Reservas de Hotel

\subsubsection{Identificar atores}

Nesta atividade, deve-se identificar os atores do sistema, conforme as diretrizes do método UML Components. Para cada caso de uso identificado deve haver um ator que o dispare, com exceção dos casos de uso incluídos, os casos de uso de extensão e de restrição. No Sistema de Reservas de Hotel, os atores identificados foram: Administrador, Gerente de Hotel, Operador de Reservas, Auxiliar de Reservas, Recepcionista eliente. O Sistema de Faturamento existente também foi identificado como um ator do sistema.

\subsubsection{Construir o diagrama de casos de uso funcionais}

Nesta atividade, deve-se construir o diagrama de casos de uso do sistema contendo os atores, os casos de uso funcionais identificados e os relacionamentos entre eles, como recomendado pelo método UML Components. A definição do tipo de relacionamento entre os casos de uso é uma tarefa muito importante, pois a partir dos relacionamentos são definidos critérios para selecionar os casos de uso que representam interesses transversais e são candidatos a serem implementados como aspectos.

Os casos de uso possuem comportamentos que são comuns entre si. Os comportamentos em comum devem ser fatorados dos casos de uso e deve-se criar um novo caso de uso que descreva esse comportamento e definir seu relacionamento com os casos de uso dos quais foram extraídos. Esse relacionamento pode ser do tipo «include» ou «extends». O tipo de relacionamento é 
definido de acordo com o seguinte critério: se o caso de uso fatorado é parte integrante do caso de uso do qual foi extraído e não faz sentido sem ele, deve-se estabelecer um relacionamento «include». Se o caso de uso fatorado pode ser tirado do caso de uso do qual foi extraído, sem que este perca o sentido, continuando a funcionar perfeitamente mesmo sem a funcionalidade retirada, o relacionamento é do tipo «extends»(Jacobson e $\mathrm{Ng}$, 2004). Um caso de uso para calcular o preço de um produto, por exemplo, pode considerar uma regra para calcular desconto ou não.

Além dos relacionamentos «include»e «extends», dois outros tipos de relacionamento são possíveis: «generalize»e «constrain». Usa-se o relacionamento «generalize» quando um caso de uso é uma generalização de dois ou mais casos de uso presentes no sistema. $\mathrm{O}$ relacionamento «constrain» é usado quando existe algum caso de uso que restringe o comportamento de outro caso de uso, como ocorre com restrições de tempo, de desempenho, etc. Pode-se citar, como exemplo, um caso de uso que impõe a restrição de que o caso de uso de cálculo de folha de pagamento não deva exceder 15 minutos. No caso do Sistema de Reservas de Hotel, só são mostrados no diagrama exemplos de casos de uso que contêm relacionamentos «include»e «extends».

O diagrama de casos de uso funcionais do Sistema de Reservas de Hotel pode ser visto na Figura 4.4. Nesse diagrama, nota-se que o casos de uso identificar reserva foi fatorado dos casos de uso cancelar reserva, alterar reserva e ocupar reserva e estabeleceu um relacionamento «include», enquanto que o caso de uso calcular desconto foi fatorado dos casos de uso fazer reserva e alterar reserva, por exemplo, e estabelece um relacionamento «extends».

Em relação à notação dos relacionamentos no diagrama de casos de uso, algumas indicações são feitas: no relacionamento «include» a direção da seta é do caso de que inclui para o caso de uso incluído; no relacionamento «extends» a direção da seta é do caso de uso que estende para o caso de uso estendido; no relacionamento «Constrain» a direção da seta é do caso de uso que restringe para o caso de uso restringido; e no relacionamento «general i ze» é do caso de uso geral para o específico.

\subsubsection{Descrever os casos de uso funcionais}

Nesta atividade, deve-se descrever cada caso de uso funcional usando o modelo apresentado na Figura 4.5. Quando o caso de uso descrito é uma extensão de outro caso de uso, os casos de uso por ele estendidos devem ser listados como casos de uso relacionados, como, por exemplo, o caso de uso calcular desconto deve ter os casos de uso fazer reserva, ocupar reserva, alterar reserva e nao comparecer como casos de uso relacionados. O mesmo deve ocorrer para os casos de uso de restrição e generalização.

É apresentado na Figura 4.6 a descrição do caso de uso Fazer Reserva do Sistema de Reservas de Hotel. 


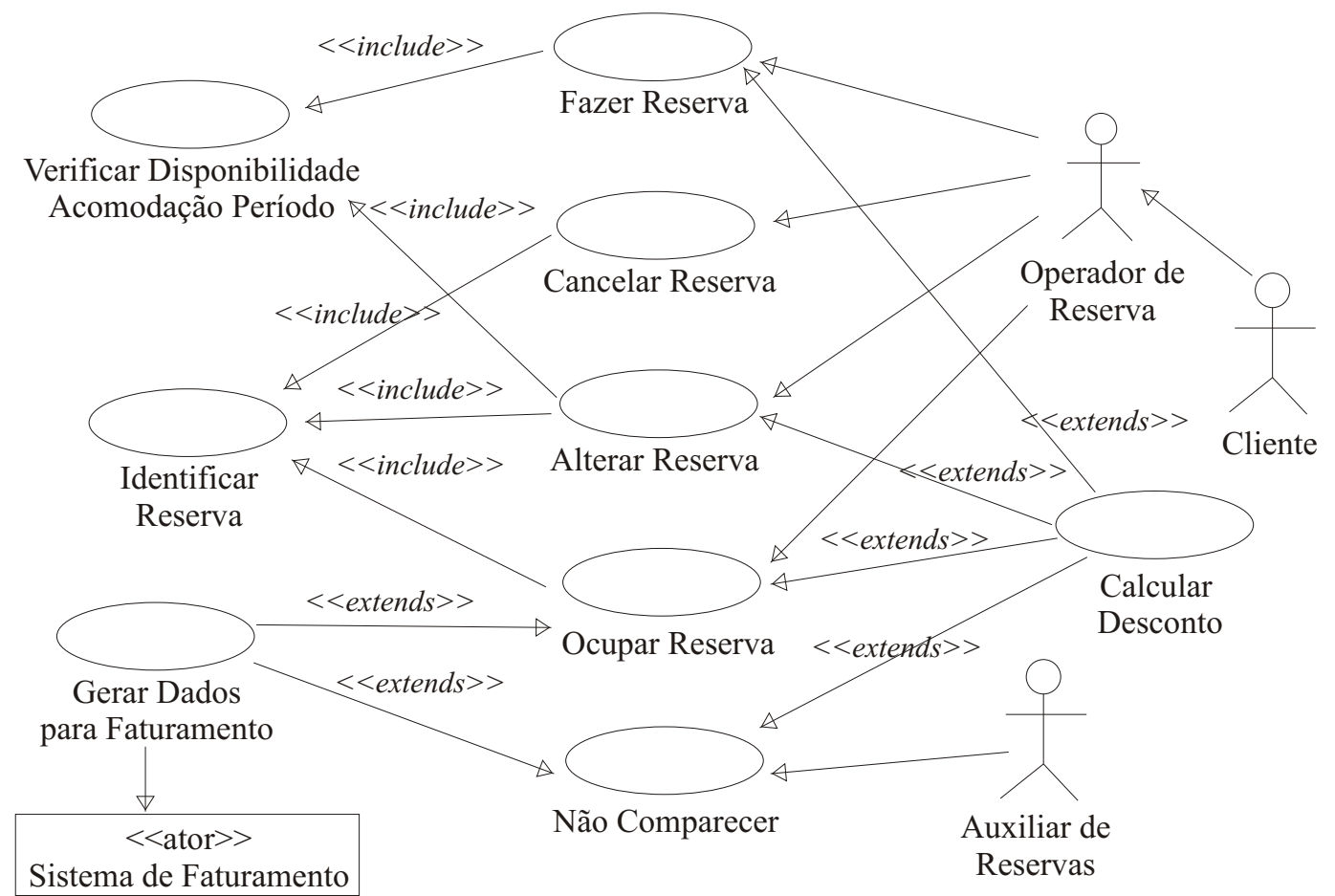

Figura 4.4: Diagrama de Casos de Uso Funcionais do Sistema de Reservas de Hotel

\begin{tabular}{|ll|}
\hline Nome: & Nome do caso de uso \\
\hline Atores: & Atores que interagem com o caso de uso \\
\hline Objetivo: & Objetivo do caso de uso \\
\hline Casos de Uso: & Casos de uso relacionados \\
\hline \multicolumn{3}{|c|}{ Cenário de Sucesso Principal } \\
$\ldots$ \\
\hline \\
Fluxo Alternativo \\
\hline
\end{tabular}

Figura 4.5: Gabarito para descrição de casos de uso funcionais

Usando-se um processo iterativo e incremental, neste momento os casos de uso seriam descritos de forma sucinta e um subconjunto deles seria escolhido para ser tratado no primeiro ciclo.

\subsubsection{Identificar casos de uso não-funcionais}

Nesta atividade, deve-se identificar os casos de uso com base nos requisitos não-funcionais do sistema e construir uma tabela relacionando cada caso de uso não-funcional com os requisitos cobertos por ele. Um modelo para relacionar requisitos e casos de uso pode ser visto na Tabela 4.1. Por meio desta tabela, pode-se rastrear os requisitos não-funcionais no ciclo de vida do software e verificar se todos os requisitos foram cobertos com os casos de uso identificados. 


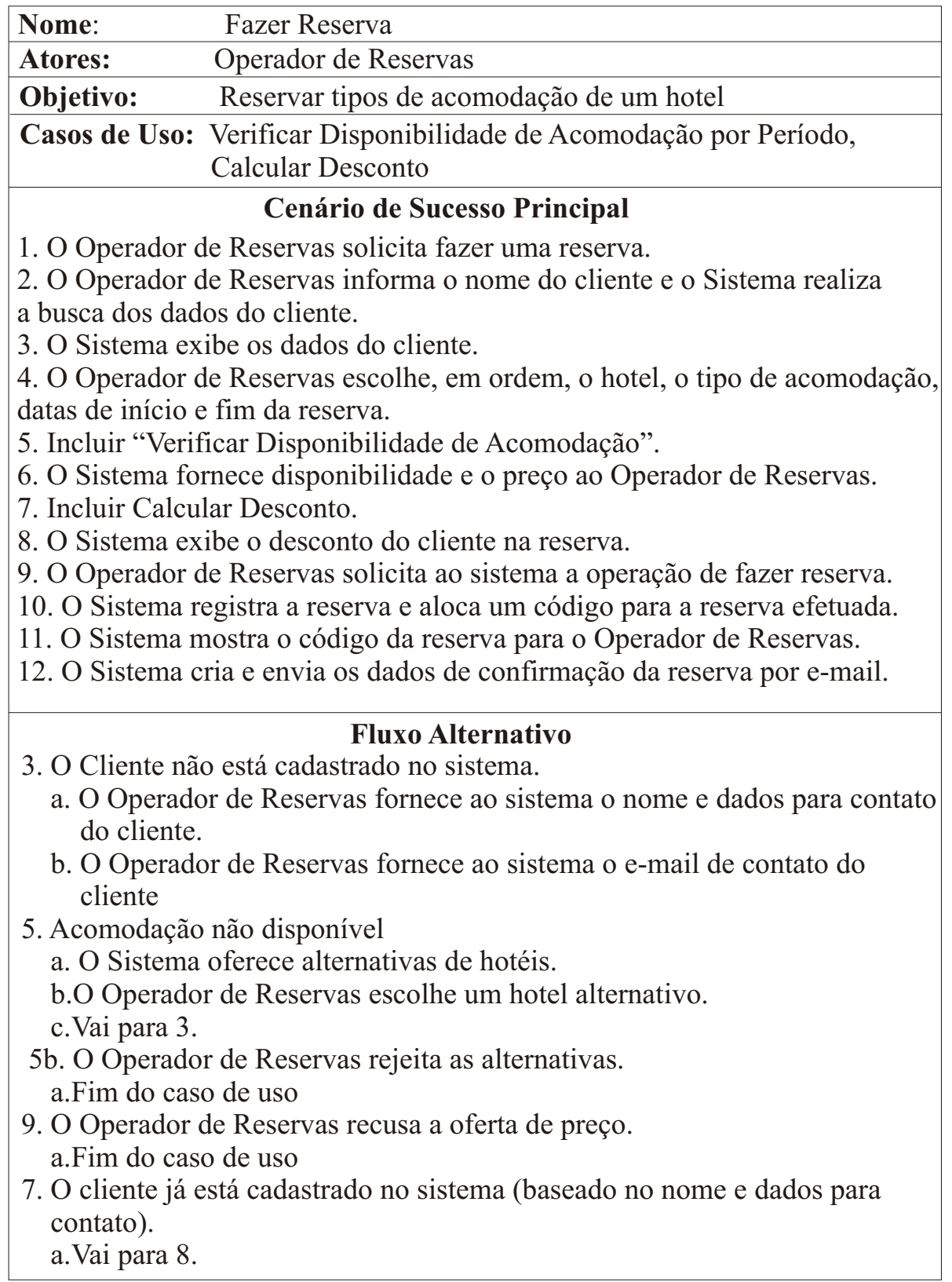

Figura 4.6: Descrição do caso de uso funcional Fazer Reserva

Os casos de uso não-funcionais identificados no Sistema de Reservas de Hotel e os requisitos cobertos podem ser vistos na Tabela 4.3. Uma nova coluna foi acrescentada em relação ao modelo para indicar quais casos de uso serão representados no diagrama de casos de uso.

\subsubsection{Descrever os casos de uso não-funcionais}

Nesta atividade, deve-se descrever cada caso de uso não-funcional usando o modelo apresentado na Figura 4.5. Os casos de uso funcionais afetados pelos casos de uso não-funcionais devem 


\begin{tabular}{|c|c|c|}
\hline Requisito Coberto & Caso de Uso & D.C.U. \\
\hline Req. 14 & Incluir/Alterar/Remover (Gerenciar) Usuários do Sistema & $*$ \\
\hline Req. 15 & Autenticar Usuário & $*$ \\
\hline Req. 16 & Criptografar Dados & $*$ \\
\hline Req. 17 & Registrar Operações (log) & $*$ \\
\hline Req. 18 & Controlar Acesso de Usuários & $*$ \\
\hline Req. 18 & Incluir/Alterar/Remover (Gerenciar) Papéis & $*$ \\
\hline Req. 18 & Incluir/Alterar/Remover (Gerenciar) Operações & $*$ \\
\hline Req. 19 & Persistir Dados & $*$ \\
\hline Req. 20 & Controlar Tempo de Reserva & \\
\hline
\end{tabular}

Tabela 4.3: Casos de Uso Não-Funcionais do Sistema de Reservas de Hotel

ser listados na seção de casos de uso relacionados da tabela, como pode ser visto na descrição apresentada na Figura 4.7.

\begin{tabular}{|lc|}
\hline Nome: & Registrar Operações \\
\hline Atores: & Registrar execução de operações e entrada do sistema \\
\hline Objetivo: & $\begin{array}{l}\text { Cazer Reserva, Cancelar Reserva, Alterar Reserva, } \\
\text { Ocupar Reserva, Não Comparecer, Gerenciar Usuário, } \\
\text { Gerenciar Papeis, Gerenciar Operacoes }\end{array}$ \\
\hline $\begin{array}{l}\text { Cenário de Sucesso Principal } \\
\text { 2. O Sistema executa alguma operação de entrada do sistema. }\end{array}$ \\
\hline Fluxo Alternativo \\
$\ldots$
\end{tabular}

Figura 4.7: Descrição do caso de uso não-funcional Registrar Operação

Alguns casos de uso não-funcionais possuem atores que interagem com eles, como os casos de uso de Gerenciar Operações e Gerenciar Usuário, que descrevem a inclusão, alteração, remoção e consulta de operações e usuários do sistema, respectivamente, e por isso precisam de um ator que seja responsável por eles. Outros casos de uso são processos, algoritmos ou funções que são disparadas quando algum evento acontece internamente ao sistema. Nesta situação, não há atores para interagir com esses casos de uso.

O exemplo do caso de uso não-funcional Registrar Operações integrado aos casos de uso funcionais pode ser visto na Figura 4.8. No diagrama apresentado, os casos de uso responsáveis pela gerência de operações, papéis e usuários possuem atores responsáveis, já o caso de uso Registrar Operações, que é disparado por um determinado evento no sistema, não possui ator responsável. 


\subsubsection{Integrar casos de uso não-funcionais no diagrama de casos de uso funcional}

Nesta atividade, deve-se integrar os casos de uso não-funcionais ao diagrama de casos de uso funcionais. Caso haja muitos casos de uso não-funcionais que se relacionem com muitos casos de uso funcionais, não é recomendado mostrar os casos de uso funcionais e todos os não-funcionais em um único diagrama, por questões de legibilidade do diagrama. A orientação é que sejam criadas visões separadas para cada caso de uso não-funcional, em que é feito um diagrama mostrando seu relacionamento com os casos de uso funcionais.

Um exemplo de um diagrama de casos de uso parcial contendo casos de uso funcionais e o caso de uso não-funcional relacionado ao registro de operações pode ser visto na Figura 4.8.

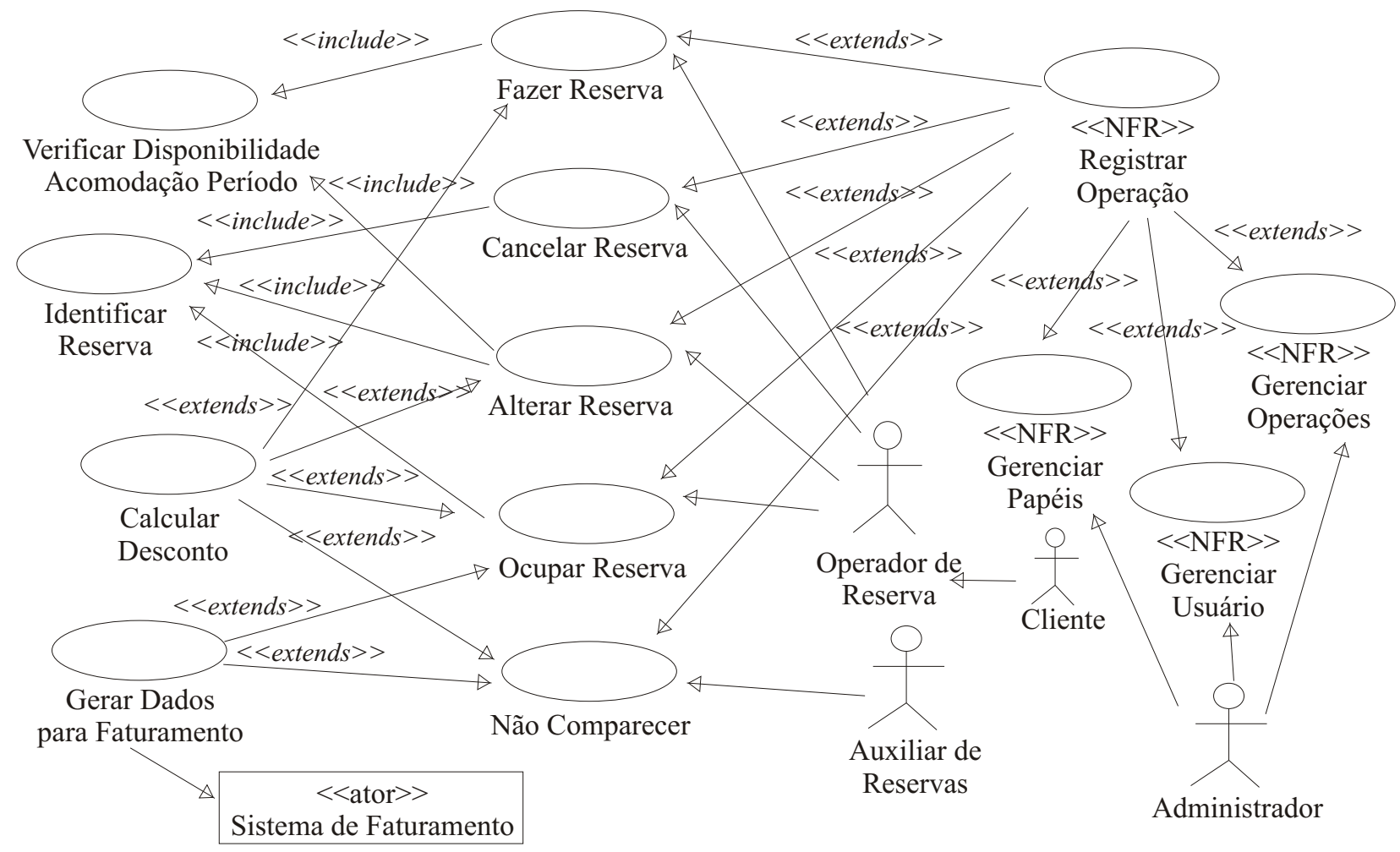

Figura 4.8: Diagrama Parcial de Casos de Uso Funcionais e Não-Funcionais

Os casos de uso não-funcionais devem ser identificados no diagrama com o estereótipo «NER». O relacionamento entre o caso de uso não funcional e os casos de uso funcionais devem ser do tipo «extends» ou «constrain», segundo os critérios citados na atividade de construção do diagrama de casos de uso funcional. O caso de uso Registrar Operação, por exemplo, tem um relacionamento de «extends» com alguns casos de uso funcionais, pois estende seus comportamentos.

Um caso de uso não-funcional também pode se relacionar com outro caso de uso não-funcional por meio de um relacionamento «constrain», «extends», «includes»ou «gereralize». 
Pode-se citar como exemplo o caso de uso Registrar Operação que possui um relacionamento «extends» com o caso de uso Gerenciar Usuário (ver Figura 4.8), pois deve-se registrar as operações de inclusão, alteração e remoção dos usuários do sistema, que, apesar de serem não-funcionais, são operações de entrada do sistema.

\subsubsection{Criar Modelo Conceitual de Negócio (F / NF)}

O objetivo desta atividade é construir o Modelo Conceitual de Negócio Funcional (F) e NãoFuncional (NF) do Sistema. Cada modelo deve ser criado separadamente, pois são utilizados em etapas diferentes do processo. O Modelo Conceitual de Negócio Funcional (MCN-F) deve ser construído como recomendado pelo método UML Components, apenas com base nos requisitos funcionais. O MCN-F do Sistema de Reservas de Hotel pode ser visto na Figura 4.9.

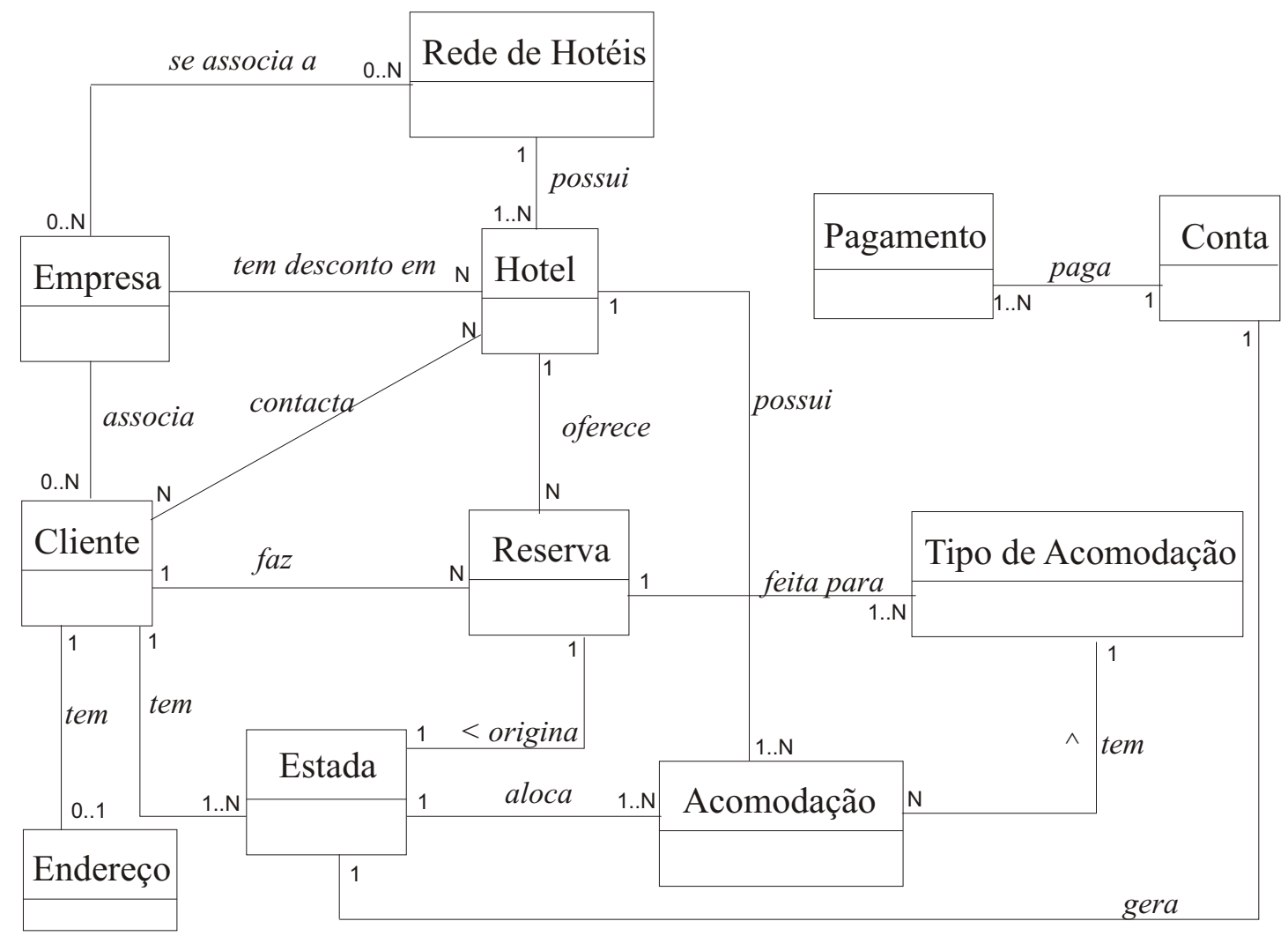

Figura 4.9: Modelo Conceitual de Negócio Funcional

As estratégias para identificar as classes conceituais do sistema podem ser extraídas de métodos tradicionais de desenvolvimento orientado a objetos, como o método de Larman (2001), por exemplo, que recomenda fazer uma lista de conceitos candidatos, identificar substantivos (ou expressões nominais) nas descrições textuais do domínio do problema e nas descrições dos casos de uso, e considerá-los como conceitos ou atributos do modelo.

O Modelo Conceitual de Negócio Não-Funcional (MCN-NF) deve ser criado com base nos requisitos não-funcionais do sistema. A criação desse modelo é uma atividade nova e foi introduzida 
pelo autor deste trabalho porque a representação de conceitos de alguns interesses não-funcionais auxilia em sua compreensão e implementação. O requisito número 18 do Apêndice A, por exemplo, diz respeito ao interesse de Controle de Acesso e gera conceitos como Usuário, Papel e Operação. Já o requisito número 20, por exemplo, diz respeito ao interesse de desempenho e não gera conceitos no sistema.

Pode haver mais de um MCN-NF para o mesmo sistema, pois se procura criar modelos para subconjuntos de requisitos não-funcionais relacionados entre si. No caso do Sistema de Reservas de Hotel, os interesses não-funcionais que geram conceitos são os relacionados à autenticação dos usuários, ao controle de acesso às operações e aos de registro de execução das operações de entrada do sistema. Como esses interesses estão relacionados entre si, só foi gerado um MC-NF para o sistema, que pode ser visto na Figura 4.10.

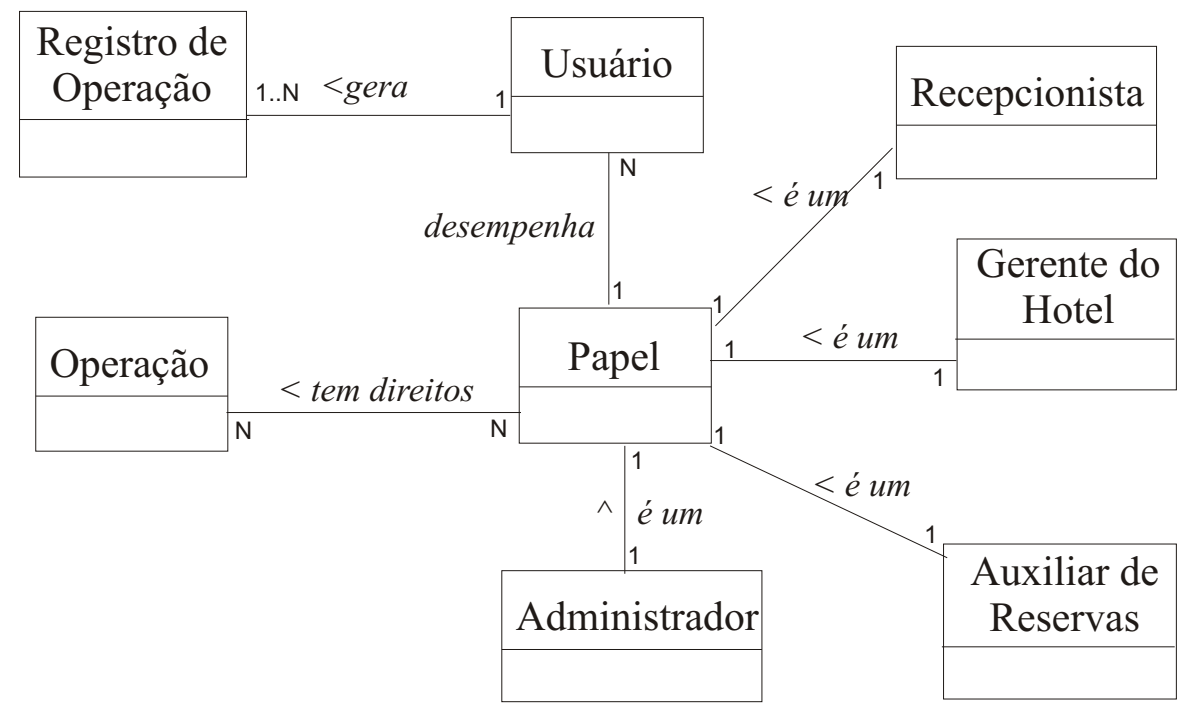

Figura 4.10: Modelo Conceitual de Negócio Não-Funcional

\subsubsection{Identificar Casos de Uso Transversais}

Após a elaboração dos diagramas de casos de uso funcionais relacionados com cada caso de uso não-funcional, deve-se identificar os casos de uso transversais, que são os casos de uso candidatos a serem implementados como aspectos. Os casos de uso transversais são casos de uso que implementam interesses transversais e conseqüentemente possuem relacionamento com mais de um caso de uso do sistema.

Como o objetivo principal da etapa de Requisitos é analisar os requisitos, definir o escopo e entender as funcionalidades e objetivos do sistema, ainda é muito cedo para se decidir como o caso de uso vai ser implementado e qual a tecnologia a ser usada. Por isso os casos de uso transversais do sistema são identificados como candidatos a aspectos, estabelecendo indícios de que posteriormente possam ser implementados como um aspecto no sistema. 
O critério para decidir se um caso de uso é transversal é o critério de quantidade de relacionamentos, que especifica que os casos de uso que possuem relacionamento com mais de um caso de uso são considerados transversais e conseqüentemente são candidatos a serem implementados como aspectos. Segundo o critério de quantidade de relacionamento, são casos de uso transversais:

- os casos de uso incluídos por dois ou mais casos de uso;

- os casos de uso que estendem dois ou mais casos de uso;

- os casos de uso que restringem dois ou mais casos de uso.

De acordo com os critérios estabelecidos, os casos de uso transversais identificados no Sistema de Reservas de Hotel estão listados na Tabela 4.4.

\begin{tabular}{|c|c|c|}
\hline Caso de Uso & Tipo & Critério \\
\hline Verificar Disp. de Acomodacao P/ Período & Funcional & Incluído por mais de dois casos de uso \\
\hline Identificar Reserva & Funcional & Incluído por mais de dois casos de uso \\
\hline Gerar Dados Para Faturamento & Funcional & Estende mais de dois casos de uso \\
\hline Calcular Desconto & Funcional & Estende mais de dois casos de uso \\
\hline Autenticar Usuário & Não-Funcional & Estende mais de dois casos de uso \\
\hline Controlar Acesso & Não-Funcional & Estende mais de dois casos de uso \\
\hline Criptografar Dados & Não-Funcional & Estende mais de dois casos de uso \\
\hline Registrar Operacoes & Não-Funcional & Estende mais de dois casos de uso \\
\hline Persistir Dados & Não-Funcional & Estende mais de dois casos de uso \\
\hline
\end{tabular}

Tabela 4.4: Casos de Uso Transversais do Sistema de Reservas de Hotel

\subsection{Especificação}

A etapa de especificação dos componentes é uma das principais do processo, pois é nesta etapa que os componentes do sistema são identificados e especificados para que se possa construir a arquitetura do sistema e em etapas posteriores selecionar os componentes a serem reusados e/ou implementados. As atividades desta etapa compreendem a: 1) identificação dos componentesbase; 2) interação entre os componentes-base; 3) identificação dos componentes transversais; 4) interação entre os componentes-base e transversais; e 5) especificação dos componentes-base e transversais. Estas atividades podem ser vistas na Figura 4.11.

Em relação ao método UML Components, as atividades 3 e 4 são novas, e a atividade 5 é modificada para também especificar componentes transversais, e não só componentes-base, como no método UML Components. As atividades desta etapa são apresentadas a seguir. As atividades que são iguais às do método UML Components (1 e 2) serão apresentadas de forma resumida, apenas mostrando seus artefatos principais, enquanto que as atividades novas ( 3 e 4 ) e modificadas (5) são apresentadas em mais detalhes. 


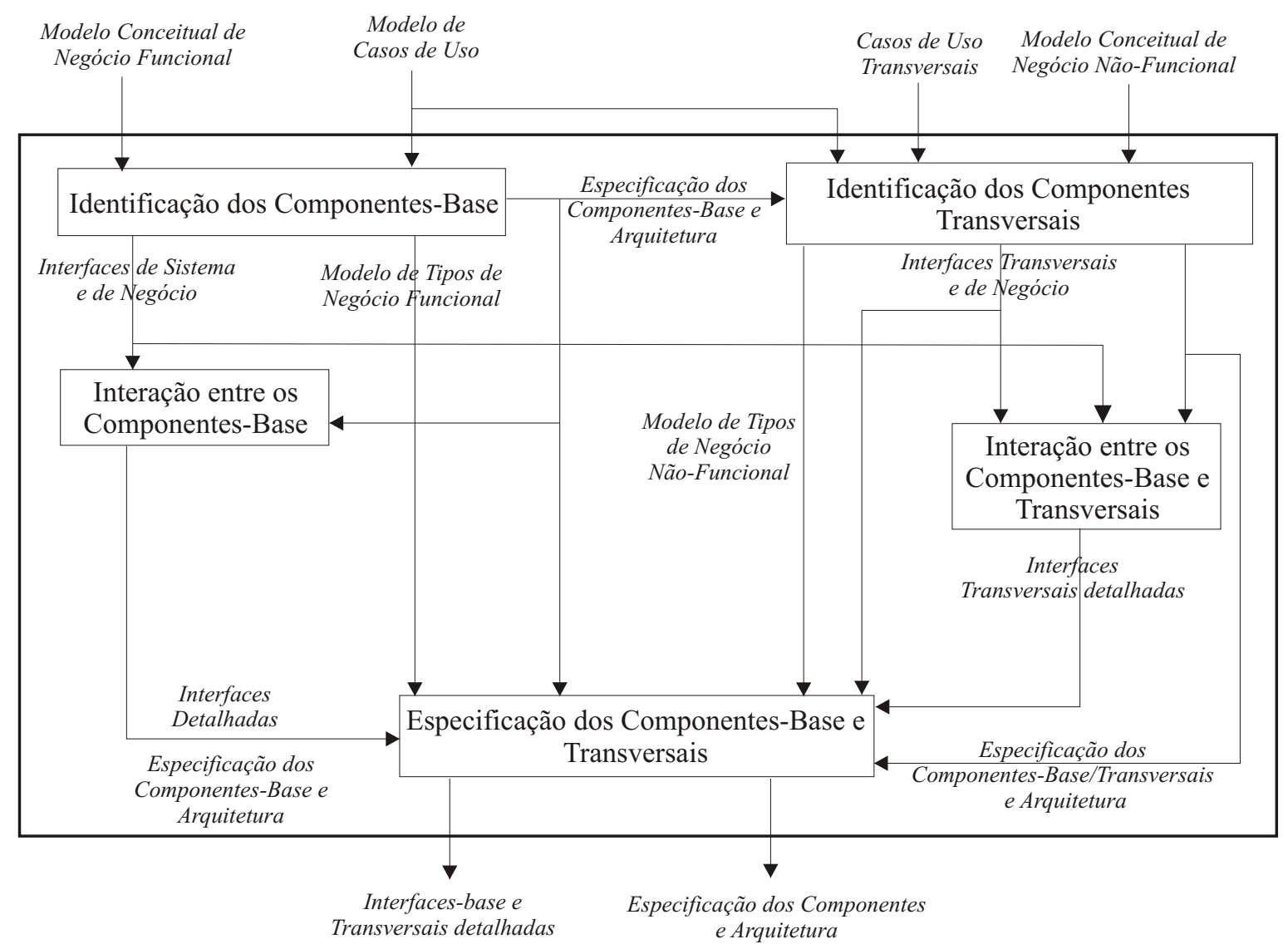

Figura 4.11: Etapa de Especificacao dos Componentes

\subsubsection{Identificação dos Componentes-Base}

Esta etapa segue exatamente as mesmas diretrizes do método UML Components, conforme o Capítulo 5 do livro de Cheesman e Daniels (2000) e tem o objetivo de identificar as interfaces de negócio e de sistema, assim como os componentes que as oferecem. As interfaces de sistema contém as operações responsáveis por executar as funcionalidades relativas às regras de negócio da aplicação e as interfaces de negócio contêm as operações que fazem a gestão dos dados utilizados pelas operações das interfaces de sistema.

Nesta etapa também são identificadas as operações das interfaces de sistema e é criada uma arquitetura inicial de componentes. As atividades desta etapa são mostradas na Figura 4.12.

A execução da atividade de "Desenvolver Modelo de Tipos de Negócio"produziu como resultado o Modelo de Tipos de Negócio apresentado na Figura 4.13. O modelo apresentado é um refinamento do Modelo Conceitual de Negócio em que são identificados os tipos básicos (core types) do sistema. Cheesman e Daniels (2000) definem tipos básicos como tipos que possuem um identificador de negócio único e independente de outros identificadores e que possuem existên- 


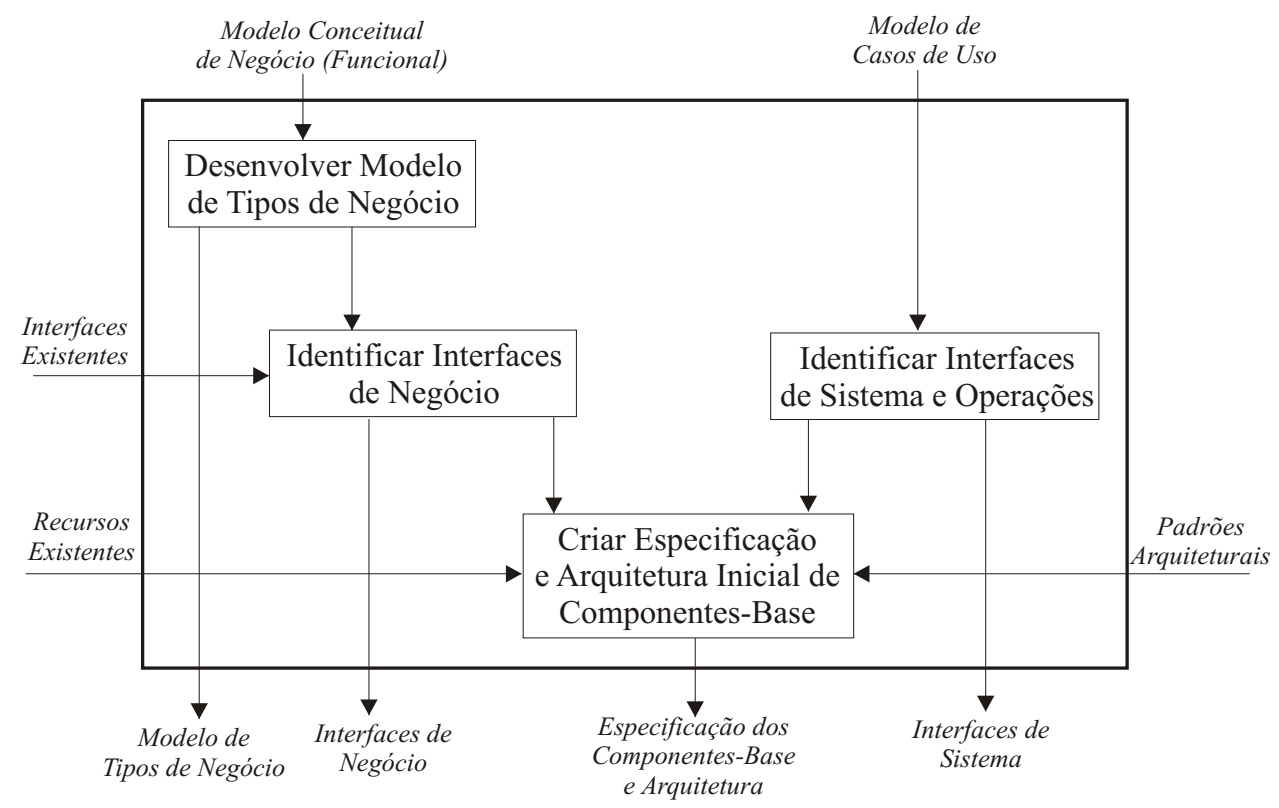

Figura 4.12: Etapa de Identificação dos Componentes-Base

cia independente, ou seja, não precisam de relacionamentos obrigatórios com outros tipos para existirem, com exceção das associações com tipos classificadores.

No Sistema de Reservas de Hotel, por exemplo, o tipo Acomodação possui uma associação obrigatória com Tipo de Acomodação, mas Tipo de Acomodação apenas classifica Acomodacao. Isso caracterizaria Acomodação como um tipo básico, mas Acomodação também precisa de uma associação obrigatória com Hotel, que não é um classificador, portanto Acomodação não é um tipo básico. Já Hotel, por exemplo, é um tipo básico, pois existe independentemente dos outros tipos e possui um identificador de negócio único. Maiores detalhes sobre a definição e critérios para se construir um modelo de tipos básicos pode ser visto no livro UML Components (Cheesman e Daniels, 2000), no Capítulo 5, seção 5.3.4.

Com o Modelo de Tipos de Negócio construído, foi possível identificar as interfaces de negócio do sistema, pois cada tipo básico dá origem a uma interface de negócio que agrega os tipos relacionados. As interfaces de negócio identificadas no Sistema de Reservas de Hotel foram IGesHotel, IGesCliente e IGesEmpresa.

Para identificar as interfaces de sistema, o modelo de casos de uso produzido na etapa de Requisitos é utilizado. Segundo as diretrizes do método de Cheesman e Daniels (2000), cada caso de uso dá origem a uma interface de sistema e pela análise dos passos da descrição dos casos de uso identifica-se as operações de cada interface de sistema. No Sistema de Reservas de Hotel, as interfaces de sistema são: IFazerReserva, IOcuparReserva, ICancelarReserva, INaoComparecer e IAlterarReserva. 


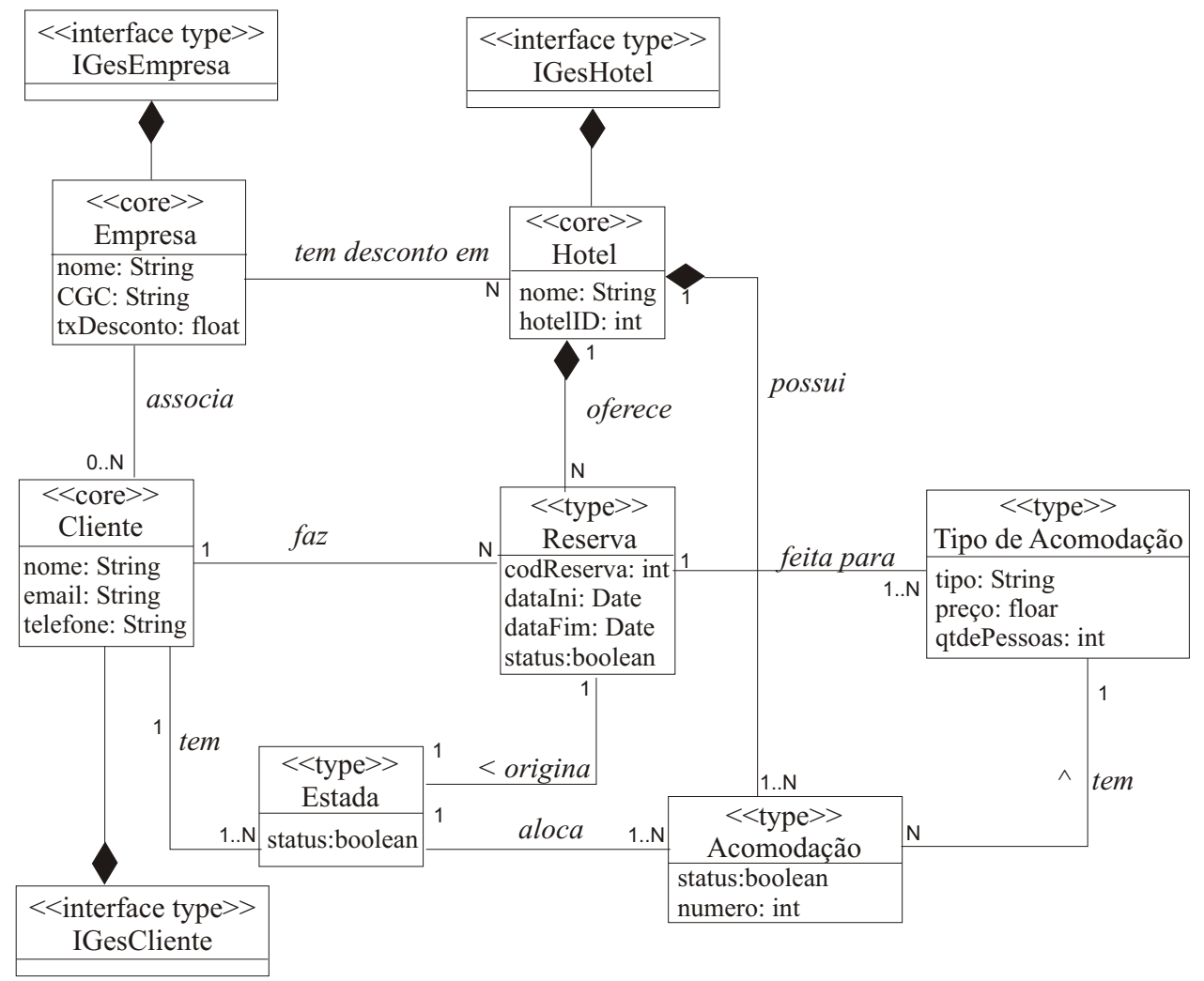

Figura 4.13: Modelo de Tipos Básicos Funcional

Como recurso existente no sistema foi identificado um Sistema de Faturamento que deve ser utilizado. O Sistema de Faturamento oferece a interface IFaturamente para que outros sistemas tenham acesso aos seus serviços oferecidos.

Para montar a arquitetura dos componentes, deve-se observar as dependências oferecidas e requeridas pelos componentes de negócio e sistema identificados e os padrões arquiteturais do sistema. A arquitetura parcial dos componentes do Sistema de Reservas de Hotel é mostrada na Figura 4.14. Nota-se na arquitetura os componentes de sistema (GerReserva), os de negócio(GerCliente, GerHotel e GerEmpresa) e o componente existente (Sistema de Faturamento). A própria arquitetura de componentes contêm as especificações dos componentes, pois é possível, por meio dela, identificar as interfaces oferecidas e requeridas pelos componentes. O componente de sistema GerReserva, por exemplo, oferece as interfaces IFazerReserva, IOcuparReserva, ICancelarReserva, INaoComparecer IAlterarReser va, e requer as interfaces IFaturamento, IGesCliente, IGesHotel e IGesEmpresa. Já o componente GerHotel oferece a interface IGesHotel e não requer nenhuma interface.

Recomenda-se que os nomes dos componentes e suas interfaces se adeqüem a um padrão. No caso do UML Components, os componentes de negócio possuem nomes com o prefixo Ger e suas interfaces com o prefixo I + Ges + nome da interface. Os componentes de sistema devem ter seus nomes com o prefixo Ger e suas interfaces nomes relativos aos casos de uso cujas operações são oferecidas na interface. 


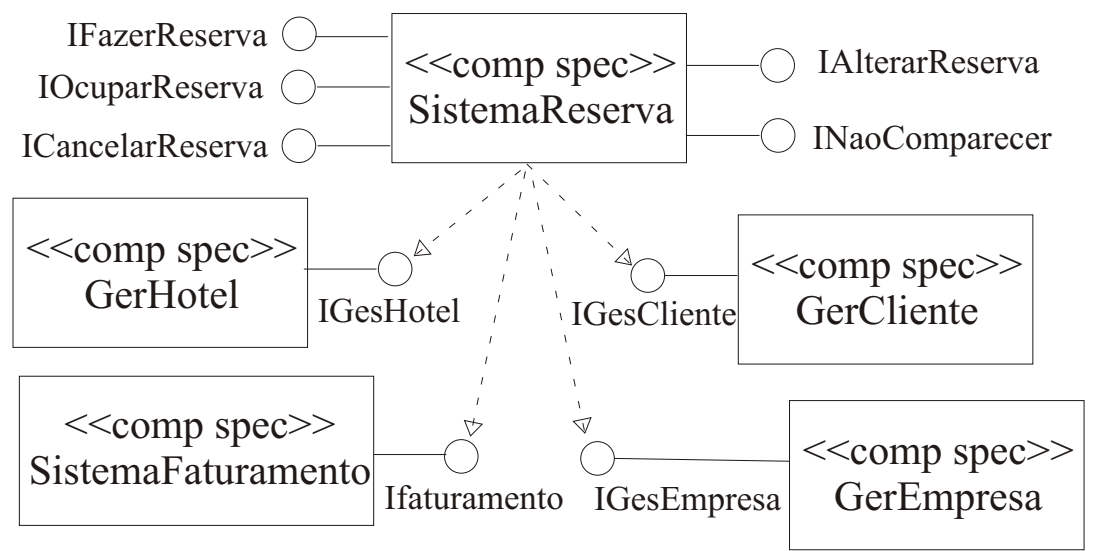

Figura 4.14: Arquitetura Inicial de Componentes-Base

\subsubsection{Interação dos Componentes-base}

O objetivo geral desta etapa é mostrar como os componentes-base da aplicação devem interagir entre si para alcançar as funcionalidades oferecidas pelas interfaces de sistema. Isso é feito por meio de diagramas de comportamento da UML, como, por exemplo, o diagrama de colaboração. Como são mostradas as interações entre componentes de sistema e de negócio, é possível também nesta etapa identificar as operações das interfaces de negócio.

Esta etapa não muda em relação ao método UML Components e segue exatamente as diretrizes definidas no Capítulo 6 do livro de Cheesman e Daniels (2000) para ser realizada. Suas atividades podem ser vistas na Figura 4.15.

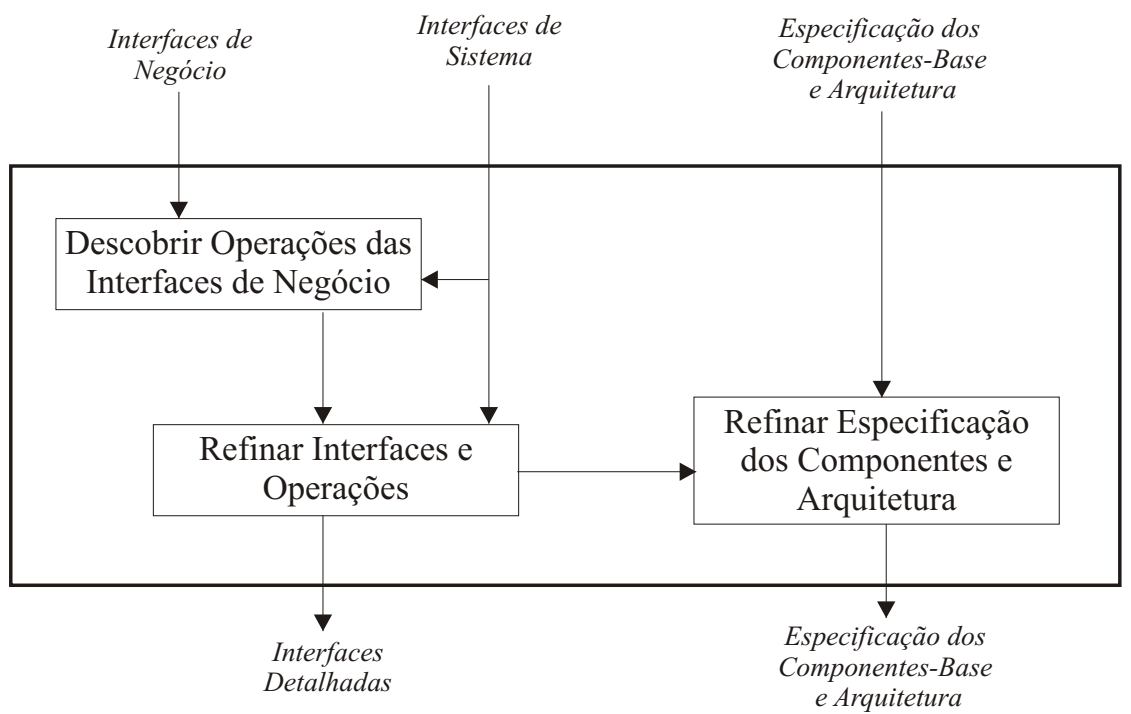

Figura 4.15: Atividades da etapa de Interação de Componentes-Base

Nas atividades desta etapa, é especificada a interação dos componentes-base para a realização de cada operação identificada nas interfaces de sistema. Com isso é possível especificar a 
assinatura da operação modelada e identificar as operações das interfaces de negócio necessárias para que as operações de sistema possam realizar sua função. Na Figura 4.16 é apresentada a interação entre os componentes-base para a realização da operação fazer reserva da interface IFazerReserva.

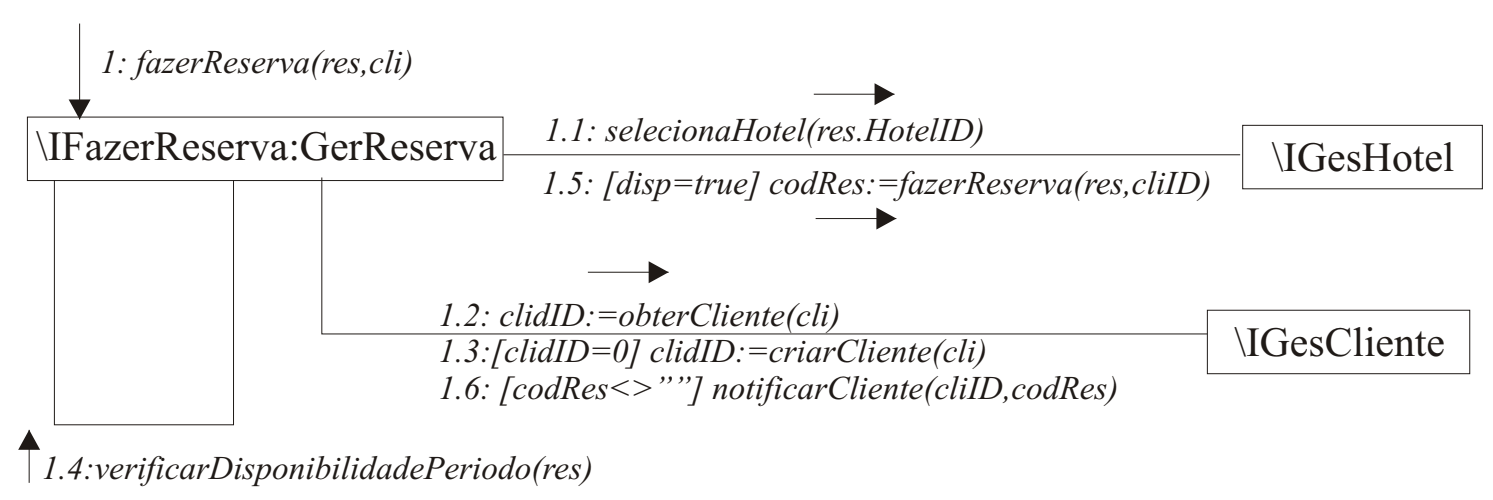

Figura 4.16: Diagrama de colaboração para a operação fazer reserva

Após todos os diagramas de colaboração terem sido construídos e as assinaturas das operações de sistema definidas, as interfaces de negócio são detalhadas com suas operações e assinaturas identificadas. Os detalhes da interface de negócio IGesCliente pode ser visto na Figura 4.17. Algumas operações canônicas da interface não são mostradas.

\begin{tabular}{|l|}
\multicolumn{1}{|c|}{$\quad$ ¿<interface $>>$} \\
IGesCliente
\end{tabular}

Figura 4.17: Interface IGesCliente detalhada

\subsubsection{Identificação dos Componentes Transversais}

O objetivo desta atividade é identificar os componentes transversais que implementam os interesses transversais do sistema. Para isso são definidas algumas atividades que auxiliam a identificar as interfaces transversais de sistema. A definição de interfaces transversais aqui utilizada assemelha-se à definição de Chavez (2004) e refere-se às interfaces pertencentes a componentes transversais e possuem operações que entrecortam ou são executadas no entrecorte de outros com- 
ponentes. As interfaces de negócio que são responsáveis pela gestão dos dados utilizados pelos componentes transversais de sistema também são identificadas nesta etapa.

As interfaces transversais são assim denominadas pois contém operações responsáveis por implementar um determinado interesse transversal do sistema. São interfaces de componentes transversais, que possuem características de um aspecto da programação orientada a aspectos, pois são capazes de entrecortar as operações das interfaces de outros componentes e adicionar ou substituir seu comportamento.

Assim como as interfaces de negócio dos componentes-base de negócio oferecem operações para gerir os dados dos componentes-base de sistema, existem interfaces de negócio que fazem a gestão de dados para os componentes transversais. Em geral, esses componentes de negócio podem ser funcionais quando os componentes transversais que o utilizam são funcionais e não-funcionais quando os componentes transversais que o utilizam são não-funcionais.

Além de identificar os componentes transversais, também é objetivo desta atividade fornecer diretrizes para a construção de uma arquitetura de componentes-base e transversais, e mostrar quais interfaces dos componentes-base são entrecortadas por quais interfaces dos componentes transversais de sistema.

As atividades desta etapa são mostradas na Figura 4.18 e apresentadas nas subseções seguintes.

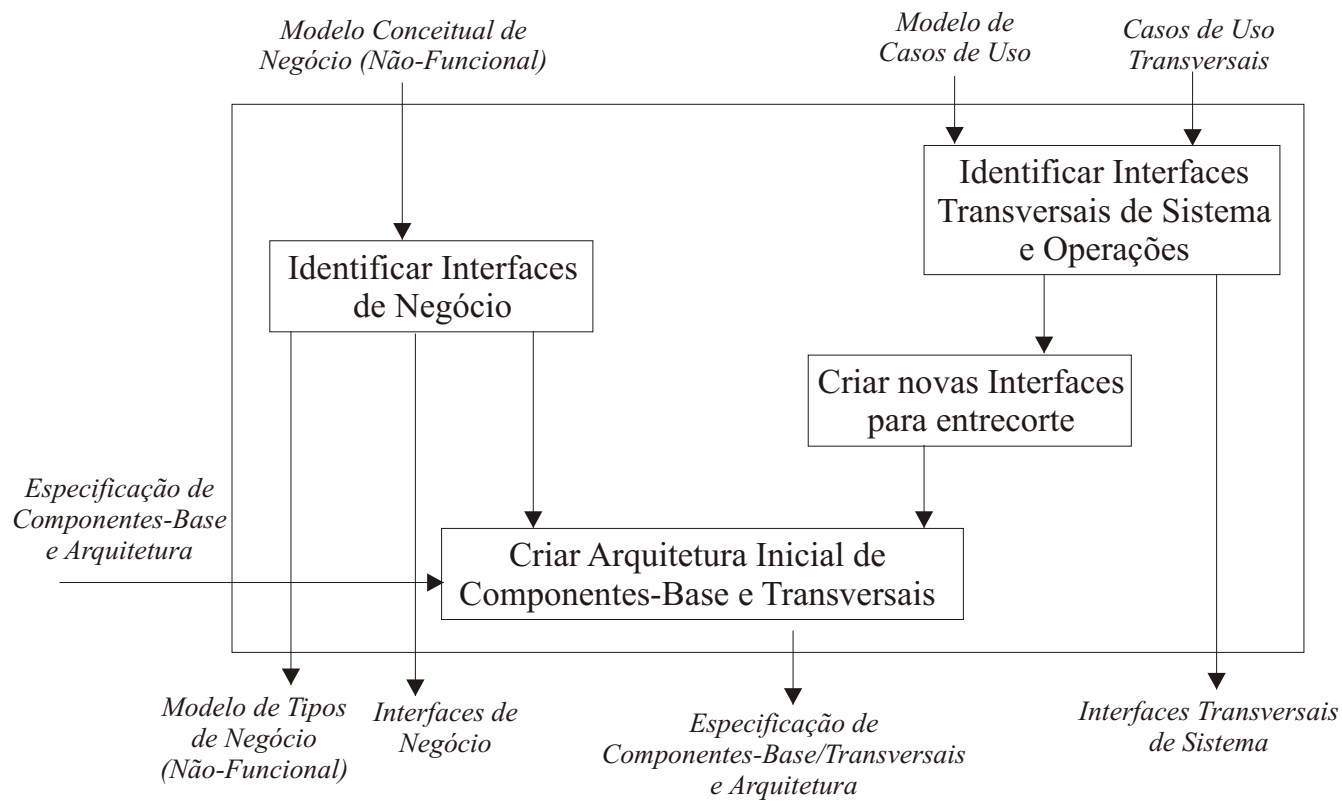

Figura 4.18: Etapa de Identificação dos Componentes Transversais

\section{Identificar interfaces transversais de sistema e operações}

Para identificar as interfaces transversais de sistema, que são as interfaces que contêm as operações que entrecortam as operações de outros componentes, deve-se analisar os casos de usos 
transversais obtidos da etapa de Análise de Requisitos e decidir se o caso de uso será representado e implementado como um aspecto.

Decidir quais casos de usos transversais devem de fato se tornar um aspecto e quais não devem não é uma tarefa simples. Para auxiliar o desenvolvedor do sistema nesta tarefa foram estabelecidos alguns critérios de decisão. São eles: critério de atomicidade, critério de disparo, critério de integridade, critério de variabilidade/volatilidade e de custo/benefício. Cada caso de uso transversal deve ser analisado de acordo com os critérios estabelecidos e deve-se decidir se de fato serão representados e implementados como um aspecto.

É importante lembrar que os critérios estabelecem diretrizes e orientações na decisão, mas cabe ao desenvolvedor julgar qual a melhor maneira de implementar os casos de uso dependendo da situação. Os critérios de decisão são apresentados em detalhes a seguir.

\section{Critério de atomicidade}

O critério da atomicidade foi extraído e adaptado do trabalho de Clarke e Baniassad (2005). Este critério estabelece que se deve tentar separar o caso de uso transversal em outros casos de uso para que sejam estabelecidos relacionamentos de um-para-um entre os casos de uso. Se o caso de uso não puder ser dividido em outros casos de uso (caso de uso atômico) e conseqüentemente continuar transversal, ele tem a possibilidade de ser implementado como um aspecto.

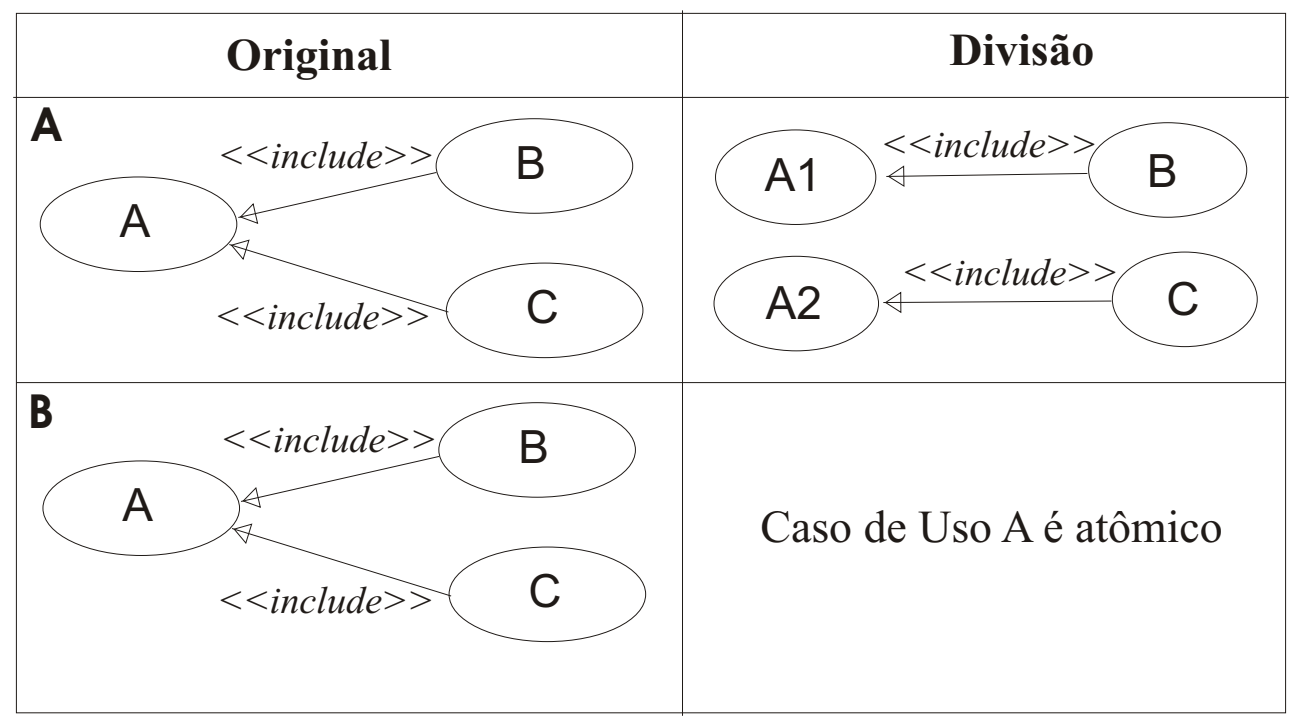

Figura 4.19: Exemplo da aplicação do critério de atomicidade

Na Figura 4.19 é mostrada uma situação que exemplifica a aplicação deste critério. Na parte A da figura, o caso de uso A é incluído pelos casos de uso B e C e, portanto, é transversal. Com o critério de atomicidade, o caso de uso A foi analisado e dividido em A1 e A2, o que fez com que o caso de uso $A$ não existisse mais e fosse estabelecido relacionamentos um-para-um de $A 1$ com B e A2 com C, eliminando o comportamento transversal. Na parte $\mathbf{B}$ da figura, o caso de uso A não pôde ser dividido em outros casos de uso por ser um caso de uso atômico. O comportamento 
transversal continuou existindo, o que indica que o caso de uso A pode ser implementado como um aspecto se os outros critérios de decisão estabelecidos confirmarem essa decisão.

O caso de uso Calcular Desconto, por exemplo, descreve apenas a funcionalidade de calcular a taxa de desconto que um cliente tem para fazer reservas no hotel, e não faz sentido que ele seja dividido em casos de uso com funcionalidades mais detalhadas. Isso faz com que o caso de uso Calcular Desconto seja realmente caracterizado como um caso de uso transversal e com tendência a ser implementado como um aspecto.

\section{Critério de disparo}

O critério de disparo também é um critério de identificação de aspectos extraído e adaptado do trabalho de Clarke e Baniassad (2005). O critério consiste em verificar se o caso de uso transversal é disparado pelos casos de uso que por eles são estendidos, restringidos ou que os incluem. Disparar o caso de uso transversal significa que o comportamento do caso de uso transversal deve ser executado em algum momento da execução de outro caso de uso.

Se o caso de uso transversal é disparado mais de uma vez em um momento específico da execução de outros casos de uso, também é possível que seja implementado como um aspecto, pois, antecipando ou pensando em aspectos em termos de implementação, já há indício da presença de pontos de junção.

O caso de uso Registrar Operações, por exemplo, deve ser executado todas as vezes que uma ação descrita no caso de uso por ele estendido alterar o estado do sistema. Isso faz com que haja pontos bem definidos em que o caso de uso Registrar Operacões deva ser executado, fazendo com que, explícita ou implicitamente o caso de uso estendido dispara o caso de uso Registrar Operações.

\section{Critério de integridade}

O critério da integridade consiste em verificar se os caso de usos transversais são parte integrante dos casos de uso por ele estendidos, restringidos ou que os incluem. Dizer que um caso de uso transversal é parte integrante de outro caso de uso significa que se o caso de uso transversal for retirado o caso de uso com o qual faz relacionamento fica sem sentido, ou seja, perde sua integridade e não funciona plenamente conforme os requisitos do sistema.

Pelos critérios estabelecidos na atividade de identificação de casos de uso transversais, os casos de uso transversais incluídos são funcionalidades integrantes dos que os incluíram e estes perdem o sentido se os transversais forem retirados, como, por exemplo, o caso de uso cancelar reserva não pode ser implementado se não houver uma rotina de identificação da reserva que se deseja cancelar. Isso implica a recomendação de que os casos de usos transversais que sejam incluídos por outros casos de uso não sejam implementados como aspectos, pois é desejável que os aspectos e os módulos base de uma aplicação sejam ortogonais entre si, em que se for retirado um aspecto que afeta um módulo, ele continua a executar suas funcionalidades sem problemas (Jacobson e $\mathrm{Ng}$, 2004; Colyer et al., 2004). 
Os casos de uso transversais que são extensões de outros casos de uso não são parte integrante do caso de uso, e por isso já foram relacionados com outros casos de uso como extensões. Se o caso de uso Registrar Operação for retirado da implementação do sistema, os casos de uso por ele estendidos continuariam a funcionar plena e integralmente, sem ferir sua integridade. Por esses motivos, a recomendação é que os casos de uso transversais que são extensões sejam implementados como aspectos.

Quanto aos casos de uso que restringem outros casos de uso deve-se fazer uma análise como a citada anteriormente e avaliar os custos benefícios de implementá-lo como um aspecto. Em geral, os casos de uso de restrição são restrições quanto a tempo, desempenho e disponibilidade, por exemplo, e são implementados a partir de decisões sobre mudança de processos do negócio, arquitetura e algoritmos diferenciados, quantidade de servidores, etc (Kazman et al., 2000; Rashid et al., 2003).

O caso de uso Controlar Acesso, por exemplo, é um caso de uso de extensão e não é parte integrante dos casos de uso por ele estendidos e se ele for retirado do sistema os caso de usos por ele estendidos continuam funcionando plenamente, não perdem sua integridade. Isso faz com que o caso de uso Controlar Acesso seja ortogonal aos outros casos de uso, o que torna justificável sua implementação como um aspecto.

\section{Critério de variabilidade/volatilidade ${ }^{2}$}

O critério da variabilidade consiste em verificar se o caso de uso transversal tem tendências a ser um ponto de variabilidade que afete vários pontos do sistema ou a descrição de requisitos voláteis, que têm chances de mudar durante o ciclo de vida do software (Moreira e Araújo, 2004).

Em uma aplicação muito complexa em que as variabilidades de um interesse afetem várias pontos do sistema, é justificável sua implementação como aspectos, independentemente dos outros critérios de decisão.

Em um seminário com a Profa. Cristina Lopes, da Universidade da Califórnia, foi citado como exemplo um jogo em que pessoas interagem com o ambiente onde estão utilizando um palm-top. O jogador pode entrar em vários ambientes cujo mecanismo de localização dos jogadores pode variar (GPS, laser, etc.). O sistema de localização é, portanto, um ponto de variabilidade que impacta vários pontos da aplicação, pois, dependendo do tipo de sistema de localização utilizado, será diferente a maneira de posicionamento do jogador, como ele interage com os objetos do ambiente, etc. Dessa forma, por impactar vários pontos da aplicação e ser um interesse complexo, é justificável que o interesse de localização do jogador seja implementado como um aspecto.

Em outros tipos de sistemas, como em linhas de produtos de software, alguns autores identificaram que é benéfica a utilização de aspectos na implementação de variabilidades para compor várias funcionalidades e gerar produtos de uma determinada família.

\section{Critério de custo/benefício}

\footnotetext{
${ }^{2}$ Alguns fundamentos para o uso deste critério foram estabelecidos após discussões a respeito do assunto com a Profa. Cristina Videira Lopes, da Universidade da Califórnia - Irvine, em seminários realizados durante uma visita ao ICMC-USP (Outubro de 2005, visita ao ICMC na ocasião do SBES de 2006)
} 
Após analisar os casos de uso transversais com todos os critérios citados anteriormente, concluise que os casos de uso transversais que podem ser implementados com aspectos são os casos de uso que são extensões ou restrições, são atômicos e são disparados pelos casos de uso por ele estendidos ou incluídos, ou são pontos de variabilidade no sistema. Apesar destas conclusões a partir dos critérios relacionados, há outras considerações a serem feitas, que estão expostas a seguir.

Os casos de uso que são extensões podem ser de dois tipos: funcionais e não-funcionais. Em relação aos não-funcionais, a recomendação geral é que sejam implementados como aspectos e os motivos para isso são:

- Os requisitos não-funcionais não fazem parte da funcionalidade básica do sistema e é interessante que sejam implementados em módulos separados e independentes da aplicação básica, o que pode ser feito adequadamente por um aspecto.

- Os requisitos não-funcionais geralmente são recorrentes em muitas aplicações e possuem características comuns, o que possibilita a generalização e maior facilidade de reúso e justifica sua implementação como um aspecto que pode ser reusado em várias aplicações.

- A separação da implementação não-funcional da funcional permite que as funcionalidades básicas do sistema sejam testadas independentemente e/ou em conjunto com a parte não funcional.

Já em relação aos casos de uso transversais funcionais, existem alguns motivos para implementálos como aspectos e outros motivos para implementá-los como entidades regulares. Entre os motivos para implementá-los como aspectos está o fato de serem extensões, adicionarem comportamentos a outros casos de uso em pontos específicos(critério do disparo) e serem independentes, o que caracteriza uma possível implementação como um aspecto.

Além disso, os casos de uso em questão podem ser variabilidades, pontos de extensão, implementação de requisitos voláteis, que são requisitos que se sabe previamente que podem mudar durante o ciclo de vida do software, o que também justificaria sua implementação como um aspecto (Moreira e Araújo, 2004).

Dentre os motivos para implementar os casos de uso transversais funcionais como uma entidade regular está o fato de que este caso de uso pode ter características de negócio específicas para uma aplicação, não haver possibilidades de generalização e reúso e a implementação como aspecto ser mais complexa do que simplesmente criar módulos internos aos componentes e implementar o comportamento com simples chamadas a operações.

Além disso, separar funcionalidades fortemente acopladas em componentes distintos aumenta a necessidade de comunicação entre os componentes, e, consequientemente, a complexidade da composição. É necessário que se avalie as vantagens e desvantagens em implementar um determinado caso de uso como aspecto ou não, se realmente é mais fácil, se auxilia no melhor entendimento do sistema, na manutenção e na evolução. 
O resultado das decisões citadas anteriormente deve ser uma lista dos casos de uso que serão representados e implementados como aspectos e dos que não serão.

\section{Análise dos casos de uso transversais}

Pelos critérios apresentados anteriormente, decidiu-se que os casos de uso transversais nãofuncionais e que são extensões devem ser implementados como aspectos. Isso foi decidido porque, com exceção do caso de uso Persistir Dados, todos os demais são atômicos; são disparados pelos casos de uso por eles estendidos; se forem retirados do sistema mantêm a integridade dos casos de uso por eles estendidos, o que faz com que sejam ortogonais às funcionalidades básicas do sistema; e justifica-se também pelo critério de custo/benefício.

O caso de uso Persistir Dados é um caso especial, pois ele não é totalmente ortogonal em relação à funcionalidade básica do sistema (Colyer et al., 2004). Primeiramente porque deve haver chamadas explícitas a funções de persistência para que possa funcionar. Em segundo lugar porque sem a persistência o sistema não funciona plenamente, contrariando o critério de integridade. Entretanto é vantajoso implementá-lo como aspecto pois é uma funcionalidade que pode ser parcialmente extraída dos componentes e pode ser isolada em um aspecto, facilitando a manutenção, evolução e o reúso.

Já os casos de uso transversais funcionais que são extensões, como o Calcular Desconto e Gerar Dados Para Faturamento, também serão implementados como aspectos. A justificativa para isso é que atendem aos critérios de atomicidade, de disparo e de integridade. Pela conclusão dos critérios, deve-se julgar se, apesar de atender aos outros critérios, é benéfico a implementação de um caso de uso funcional como um aspecto.

Quanto ao caso de uso Calcular Desconto, a justificativa adicional é que esse caso de uso descreve um requisito volátil do sistema (Moreira e Araújo, 2004) que pode mudar no decorrer do ciclo de vida do software, pois as regras de desconto, a forma como aplicá-lo e outros requisitos podem mudar. Como se trata da implementação de componentes transversais (aspectos) que podem ser inseridos e retirados no sistema dinamicamente, fica fácil realizar a manutenção e evolução da funcionalidade de desconto. Além disso, não há complexidade adicional na implementação dessa funcionalidade como um aspecto.

Em relação aos casos de uso transversais Verificar Disponibilidade de Acomodação por Período e Identificar Reservas, decidiu-se que não devem ser implementados como aspectos. Isto porque ferem o princípio de integridade e seria oneroso implementá-los como aspectos, pois são parte integrante dos casos de uso que os incluem.

São apresentadas na Tabela 4.5 os casos de uso transversais e os critérios analisados para decidir se realmente devem ser implementados como aspectos e qual a opção final de implementação.

Para cada caso de uso a ser implementado como um aspecto, deve-se criar uma interface transversal de sistema com um nome relacionado. As operações da interface transversal de sistema são descobertas seguindo-se os passos dos casos de uso a partir de sua descrição textual, ou a partir de um diagrama de sequiência/colaboração da UML. Para cada uma dessas interfaces 


\begin{tabular}{|c|c|c|c|c|c|c|}
\hline C.U. Transv. & Atom. & Disparo & Integr. & Variab. & Custo/Benef. & Implementação \\
\hline Verif. Disp. Período & $\mathrm{X}$ & $\mathrm{X}$ & - & - & - & Outro \\
\hline Identificar Reserva & $\mathrm{X}$ & $\mathrm{X}$ & - & - & - & Outro \\
\hline Gerar Dados Fatur. & $\mathrm{X}$ & $\mathrm{X}$ & $\mathrm{X}$ & - & - & Aspecto \\
\hline Calcular Desconto & $\mathrm{X}$ & $\mathrm{X}$ & $\mathrm{X}$ & $\mathrm{X}$ & $\mathrm{X}$ & Aspecto \\
\hline Autenticar Usuário & $\mathrm{X}$ & $\mathrm{X}$ & $\mathrm{X}$ & - & $\mathrm{X}$ & Aspecto \\
\hline Controlar Acesso & $\mathrm{X}$ & $\mathrm{X}$ & $\mathrm{X}$ & - & $\mathrm{X}$ & Aspecto \\
\hline Criptografar Dados & $\mathrm{X}$ & $\mathrm{X}$ & $\mathrm{X}$ & - & $\mathrm{X}$ & Aspecto \\
\hline Registrar Operacoes & $\mathrm{X}$ & $\mathrm{X}$ & $\mathrm{X}$ & - & $\mathrm{X}$ & Aspecto \\
\hline Persistir Dados & $\mathrm{X}$ & $\mathrm{X}$ & - & - & $\mathrm{X}$ & Aspecto \\
\hline
\end{tabular}

Tabela 4.5: Análise dos casos de uso transversais

deve-se utilizar a seguinte convenção de nome: IT + Ger + nome da interface. Por exemplo, para um caso de uso transversal que calcula o desconto de alguma transação tem-se a interface ITGerCalcularDesconto.

O componente transversal de sistema criado para oferecer a interface deve também seguir a convenção de ter o prefixo Ger antes do nome, como, por exemplo, o componente GerDesconto. É apresentada na Figura 4.20 a interface transversal criada para o caso de uso transversal Regi st rar Operação. As interfaces transversais devem ser rotuladas com o estereótipo «crosscuting interface» e suas operações devem ser identificadas.

\begin{tabular}{|c|}
\hline $\begin{array}{c}<<\text { crosscutting interface }>> \\
\text { ITRegistrarOperacao }\end{array}$ \\
\hline registrarOperacaoExecutada () \\
\hline
\end{tabular}

Figura 4.20: Interface Transversal de Sistema ITRegistrarOperacao

\section{Casos de Uso transversais que não são implementados como aspectos}

Os casos de uso transversais que não são implementados com aspectos devem ser implementados de acordo com o critério apresentado a seguir:

- Se o caso de uso tem relacionamento com casos de uso que vão gerar interfaces de um mesmo componente, então deve ser implementado como uma interface ou até mesmo uma função interna ao componente.

- Se o caso de uso tem relacionamento com casos de uso que vão gerar interfaces de mais de um componente, então deve ser implementado como um componente do qual os que têm relacionamento com ele dependem.

Seguindo os critérios apresentados anteriormente, o caso de uso Identificar Reserva, por exemplo, tem relacionamento com casos de uso que geram interfaces de um mesmo compo- 
nente, e, por isso, é implementado como uma função interna do componente que é chamada explicitamente quando necessário. Ocorre o mesmo com o caso de uso Verificar Disponibilidade de Acomodação por Período.

É importante notar que, em geral, os casos de uso transversais que são restrições (const rain) quanto a tempo, desempenho, disponibilidade, segurança, etc., são implementados com decisões de arquitetura, algoritmos mais eficientes, mudança de processos de negócio, dentre outras soluções (Kazman et al., 2000; Colyer et al., 2004).

\section{Identificar Interfaces de Negócio}

Esta atividade tem o objetivo de identificar as interfaces de negócio, que são as interfaces dos componentes de negócio, os quais fazem a gestão de dados para os componentes transversais de sistema. Para identificar essas interfaces, deve-se refinar o modelo conceitual de negócios nãofuncional em um modelo de tipos de negócios não-funcional e logo após em um modelo de tipos básicos (core types) não-funcionais, como recomendado pelo método UML Components para o modelo de tipos básicos funcionais.

Deve-se criar uma interface de negócio para cada tipo básico identificado no Modelo de Tipos Básicos Não-Funcionais e criar um componente de negócio que ofereça a interface criada. O componente de negócio compreende o tipo básico e seus agregados. O nome da interface de negócio deve conter o prefixo I de interface e o termo Ges de Gestão de Dados, e o nome do componente que o oferece deve conter o prefixo Ger. Exemplo: a interface IGesAcesso é oferecida pelo componente GerAcesso.

O Modelo de Tipos Básicos Não-Funcionais (MTB-NF) do Sistema de Reservas de Hotel pode ser visto na Figura 4.21. De acordo com o MTB-NF apresentado, deve ser criada uma interface para os tipos básicos (core) Registro de Operações e Usuário que, no caso, são as interfaces IGesRegistroOperacoes e IGesAcesso, respectivamente.

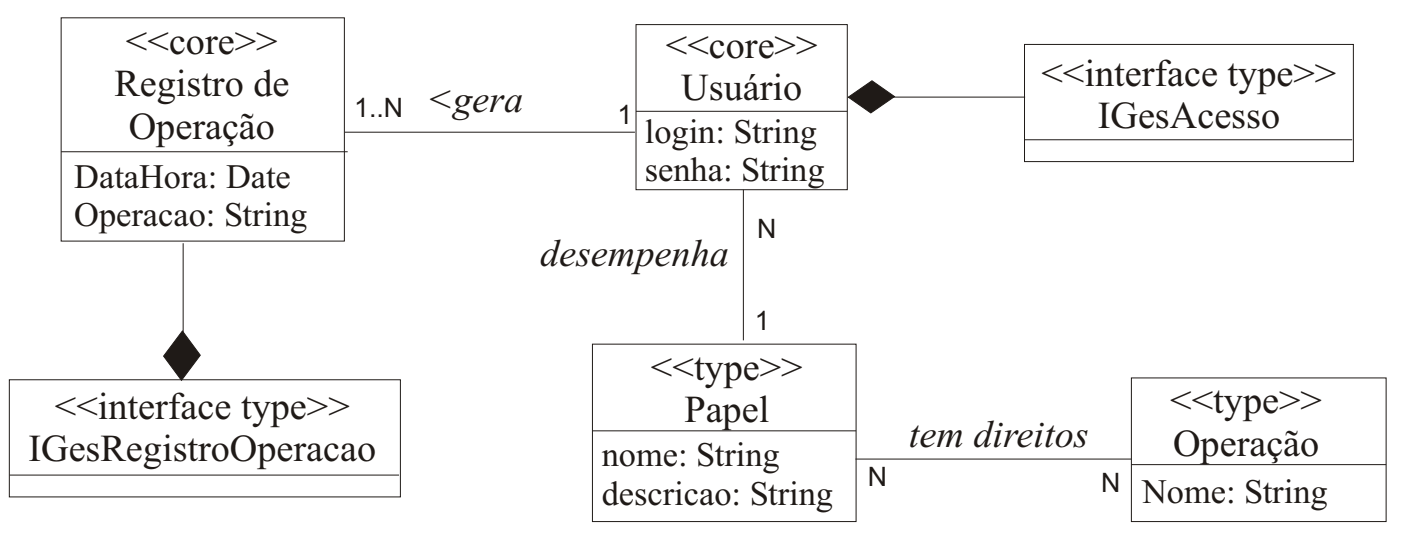

Figura 4.21: Modelo de Tipos Básicos Não-Funcionais 
Adicionalmente, as operações das interfaces transversais de negócio são identificadas na etapa de Interação dos Componentes-Base e Transversais, uma das etapas posteriores deste processo. As atribuições de responsabilidades às associações entre componentes devem ser feitas segundo a orientação do método UML Components.

\section{Elaborar interfaces para as operações entrecortadas}

A arquitetura de componentes do sistema tem o objetivo de mostrar os componentes-base e transversais que compõem o sistema e seus relacionamentos. Além do relacionamento de dependência entre os componentes, introduziu-se, com os componentes transversais, o relacionamento de entrecorte. $\mathrm{O}$ entrecorte dá-se pelo relacionamento entre uma interface transversal de sistema e a interface de outro componente.

No relacionamento de dependência mostrado na arquitetura do sistema, se um componente é dependente de uma interface, sabe-se que isto significa que o componente necessita das operações daquela interface para funcionar plenamente. Já no relacionamento de entrecorte, se considerar apenas as interfaces identificadas até o momento, nem todas as operações da interface serão entrecortadas pelo componente transversal relacionado. Há casos em que todas as operações da interface são entrecortadas, mas também há casos em que apenas um subconjunto de operações da interface é entrecortado.

Para facilitar a representação de quais operações das interfaces são entrecortadas, introduziuse a atividade de elaborar interfaces para as operações entrecortadas com o objetivo de reagrupar logicamente as operações das interfaces e construir interfaces que contenham somente operações entrecortadas por um determinado componente transversal.

Com a criação dessas novas interfaces reagrupadas logicamente, a legibilidade do diagrama de componentes é facilitada, pois os componentes-base são apresentados com as interfaces logicamente criadas e quando é representado um entrecorte nessa interface por um componente transversal, sabe-se que todas as suas operações são entrecortadas. Do contrário teria que ser mostrado o relacionamento de entrecorte com várias interfaces e indicar quais operações das interfaces são entrecortadas, podendo, em alguns casos, poluir o diagrama.

Para facilitar a elaboração das interfaces com operações logicamente reagrupadas, recomendase a construção de tabelas que indiquem quais operações e quais interfaces dos componentes são entrecortadas pelos componentes transversais de sistema. Deve-se criar uma tabela indicando o componente transversal de sistema (CompTransvSist), a interface (ITSist) e a operação transversal (operacaoTransversal), bem como o componente entrecortado, com suas interfaces e operações entrecortadas, conforme o modelo mostrado na Tabela 4.6.

A tabela anterior deve ser construída para cada operação das interfaces transversais de sistema. Para cada tabela criada deve-se elaborar uma interface agrupando as operações entrecortadas. Esse processo é realizado segundo o algoritmo mostrado na Figura 4.22. 


\begin{tabular}{||c|c|c|}
\hline \multicolumn{3}{|c|}{ CompTransvSist.ITSist.operacaoTransversal } \\
\hline Componente Entrecortado & Interface Entrecortada & Operação Entrecortada \\
\hline & & \\
\hline
\end{tabular}

Tabela 4.6: Tabela de entrecorte

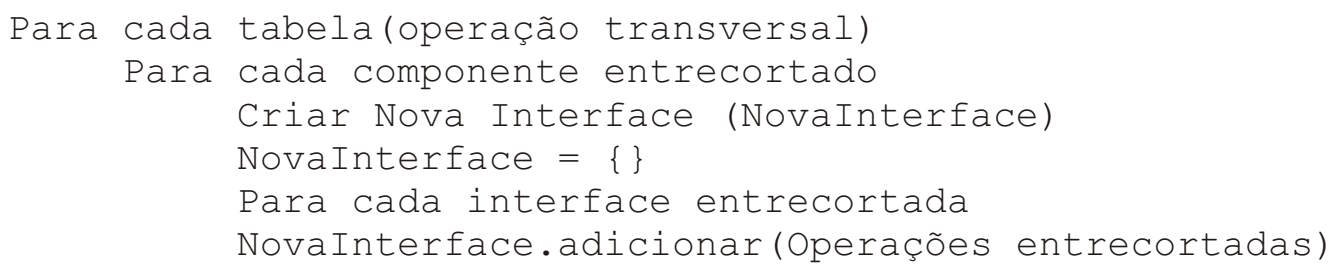

Figura 4.22: Algoritmo de criação de novas interfaces para entrecorte

Para exemplificar o resultado do algoritmo, supõe-se que todas as operações de entrada do componente GerReserva devem ser entrecortadas pelo componente transversal GerRegistroOp. A tabela irá conter o componente GerReserva, suas interfaces, e em cada interface suas operações de entrada, como é mostrado na Tabela 4.7:

\begin{tabular}{|c|c|c|}
\hline \multicolumn{3}{|c|}{ GerRegistroOp.ITRegistrarOperacao.registrarOperacaoExecutada() } \\
\hline Componente Entrecortado & Interface Entrecortada & Operação Entrecortada \\
\hline GerReserva & IFazerReserva & fazerReserva() \\
\hline & & adicionarCliente() \\
\hline & IOcuparReserva & iniciarEstada() \\
\hline & ICancelarReserva & cancelarReserva() \\
\hline & IAlterarReserva & alterarReserva() \\
\hline & INaoComparecer & cancelarReservasVencidas() \\
\hline
\end{tabular}

Tabela 4.7: Operações do Componente-Base GerReserva entrecortadas pelo Componente Transveral GerRegistroOp

$\mathrm{Na}$ execução do algoritmo, será criada uma nova interface de nome IGerEntrada para o componente GerReserva. A interface IGerEntrada recebe as operações listadas na tabela para cada interface. O resultado do algoritmo na tabela será uma única interface IGerEntrada contendo todas as operações de entrada do componente GerReserva, como é mostrado na Figura 4.23 .

Com essa nova interface, é mais fácil indicar quais operações do componente são entrecortadas por qual componente transversal, como, por exemplo, se em um diagrama aparecer a indicação de que o componente GerRegistroOp entrecorta a interface IGerEntrada, sabe-se que o componente GerRegistroop entrecorta todas as operações contidas na interface IGerEntrada. Além disso, as novas interfaces também são úteis na etapa de Interação dos Componentes-base e transversais. 


\begin{tabular}{|l|}
\hline \multicolumn{1}{|c|}{$\begin{array}{c}\text { | } \text { interface }>> \\
\text { IGerEntrada }\end{array}$} \\
\hline fazerReserva() \\
adicionarCliente() \\
iniciarEstada() \\
cancelarReserva( $)$ \\
alterarReserva() \\
cancelarReservasVencidas () \\
\hline
\end{tabular}

Figura 4.23: Nova Interface IGerEntrada

Deve-se notar que as interfaces elaboradas são usadas na etapa de projeto para facilitar a legibilidade dos diagramas e a indicação de quais operações do componente-base são entrecortados por um determinado componente transversal de sistema. Na implementação, recomenda-se que as interfaces originais dos componentes-base identificadas na etapa de Identificação dos Componentesbase sejam utilizadas, para que não seja perdido o mapeamento entre os casos de uso e as interfaces de sistema.

Apesar de ser um boa estratégia elaborar novas interfaces agrupando somente as operações entrecortadas por um determinado componente transversal, pode haver situações em que isso não é possível, ou o esforço em fazê-lo pode ser grande ou até mesmo o projetista do sistema não querer introduzir estas novas interfaces só para mostrar o entrecorte. Nesses casos, uma solução possível é criar uma notação para representar quais operações de uma determinada interface estão sendo entrecortadas.

A notação proposta usa uma nota da UML para identificar as operações entrecortadas. A indicação das interfaces entrecortadas podem ser de três formas. A primeira utiliza o termo exceto seguido das operações da interface que não devem ser entrecortadas, como pode ser visto na Figura 4.24, parte A. A outra forma é a listagem direta das operações da interface que devem ser entrecortadas, como pode ser visto na parte $\mathbf{B}$ da figura. Por fim, pode-se usar caracteres coringa $(\star$, . . ) quando operações que possuem aproximação léxica devem ser entrecortadas, como, por exemplo, todos os get e set de uma interface, como pode ser visto na parte $\mathrm{C}$ da figura. A notação para este último caso é semelhante à linguagem de expressão de conjuntos de ponto de junção das linguagens orientadas a aspectos em geral. Adicionalmente, o uso destes recursos pode ser feito em conjunto e com o uso de operadores unários tais como o ! (negação), e binários, como \&\& (e) e II (ou).

\section{Criar Arquitetura de Componentes-base e Transversais}

Após identificar os componentes transversais e conhecendo os componentes-base do sistema, deve-se criar uma arquitetura de componentes contendo tanto os componentes-base quanto os 


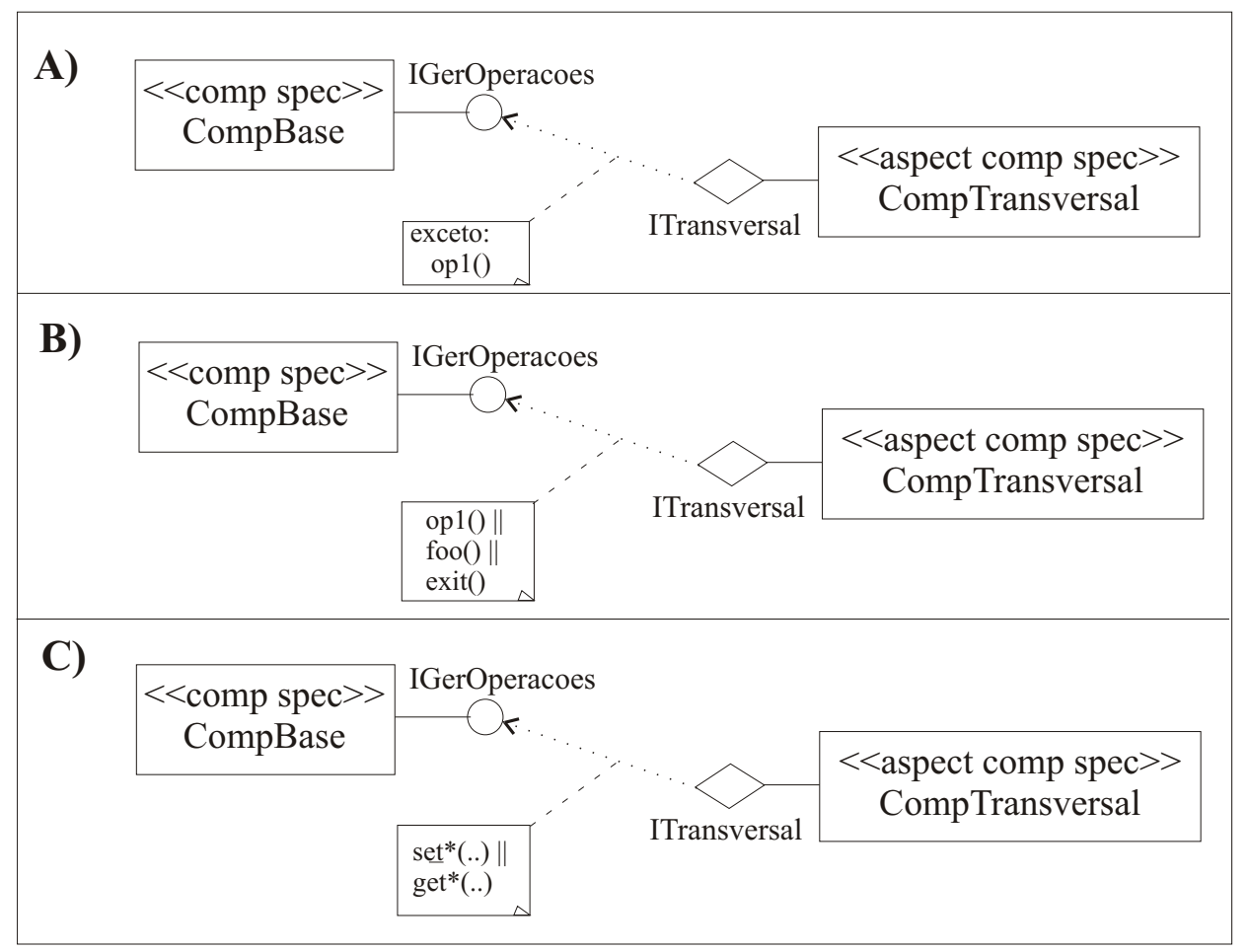

Figura 4.24: Notação para indicar operações entrecortadas

transversais. Essa arquitetura tem o objetivo de mostrar os relacionamentos de dependência e os de entrecorte.

$\mathrm{Na}$ construção da arquitetura de componentes, recomenda-se, por questões de legibilidade do diagrama, que não seja mostrada a arquitetura contendo todos os componentes-base e transversais juntos. Essa recomendação é feita porque em algumas situações os componentes transversais entrecortam os mesmos componentes base e pode ser que a grande quantidade de setas indicando o entrecorte e dependência entre os componentes prejudique a legibilidade do diagrama. Por isso, aconselha-se que apenas arquiteturas parciais sejam mostradas, contendo um ou mais componentes transversais de sistema, os componentes de negócio necessários e os componentes-base com as novas interfaces para entrecorte.

Uma arquitetura parcial de componentes do sistema de reservas de hotel pode ser vista na Figura 4.25 .

No diagrama de componentes, os componentes-base devem ser rotulados com o estereótipo «comp spec», os componentes transversais de sistema com o estereótipo «aspect comp spec»e os componentes de negócio dos componentes transversais também com o estereótipo «comp spec». As interfaces transversais de sistema não são representadas com a notação de pirulito utilizada para as interfaces dos componentes-base. Ao invés disso, é utilizado um segmento de reta com um losango na ponta (Chavez, 2004).

Para expressar o entrecorte das interfaces, é utilizada uma seta com direção componente transversal para componente-base. Essa direção foi escolhida para manter a semântica da dependência 


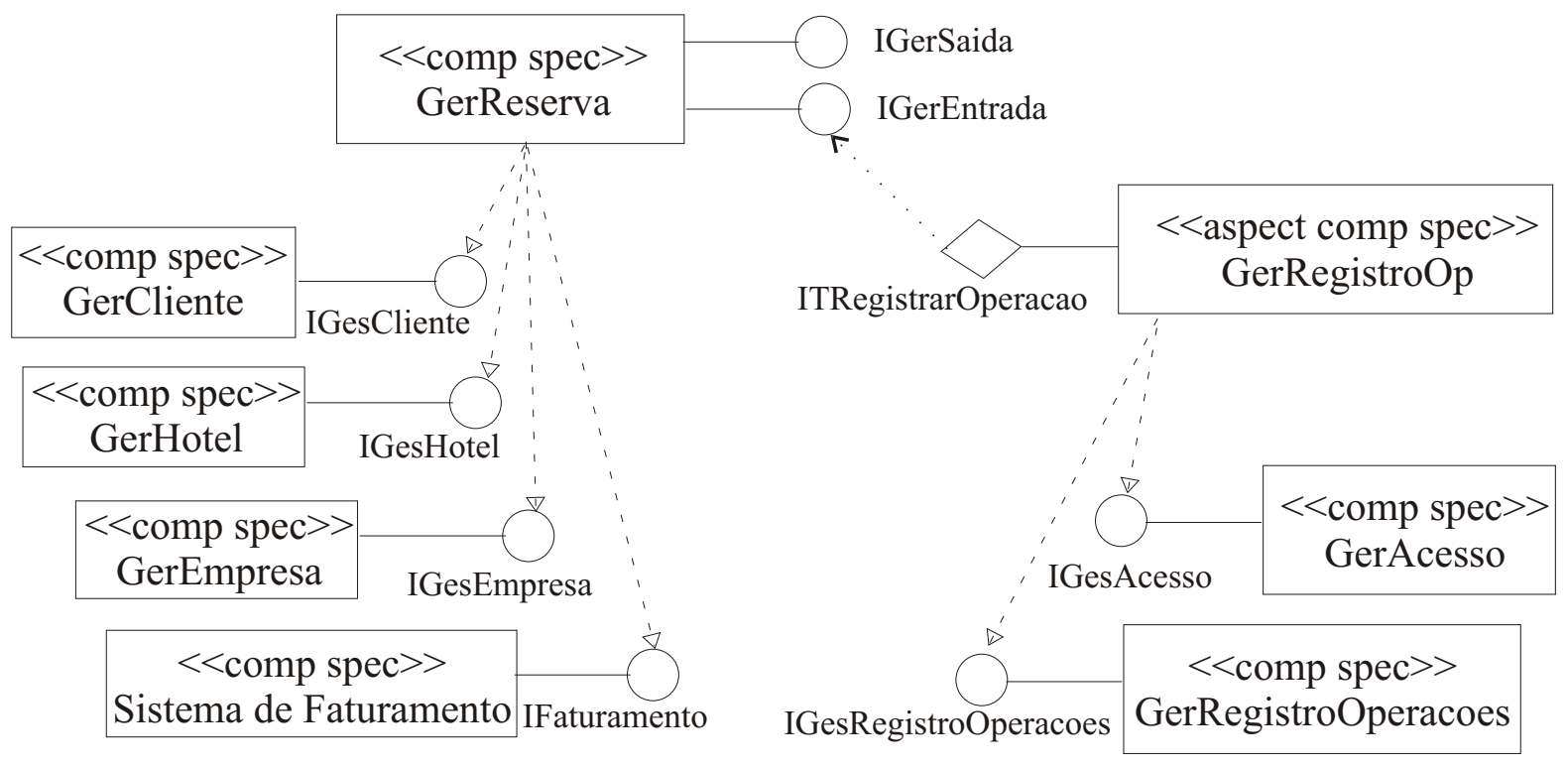

Figura 4.25: Arquitetura Parcial de Componentes-Base e Transversais - Registrar Operação

entre componentes, uma vez que os componentes transversais são dependentes dos componentesbase para executar seu comportamento.

No diagrama apresentado na Figura 4.25, nota-se que o componente GerReserva (componente de sistema) é dependente das interfaces dos componentes de negócio (Sistema de Faturamento, Gercliente, GerHotel e GerEmpresa). GerReserva oferece duas interfaces: IGerSaida, que contém operações de consulta, e IGerEntrada (interface reelaborada para entrecorte - ver Figura 4.23), que contém operações que modificam o estado das entidades do sistema. As operações de entrada do sistema foram agrupadas em uma nova interface que é entrecortada pelo componente transversal de sistema GerRegistroOp, para atender o requisito 17 do Apêndice A, que especifica que deve ser feito o registro de execução de todas as operações de entrada do sistema.

O Componente Transversal de Sistema GerRegistroop é dependente das operações das interfaces dos componentes de negócio GerAcesso e GerRegistroOperacoes (ver Figura 4.25), os quais fornecem dados necessários ao seu funcionamento. O relacionamento de entrecorte entre a interface ITRegistraroperacao de GerRegistroop e IGerEntrada de GerReserva indica que qualquer operação da interface IGerEntrada é entrecortada pela(s) operação(ões) presentes na interface transversal de sistema ITRegistraroperacao. O comportamento resultante do entrecorte é mostrado na etapa de interação entre componentes-base e transversais. 


\subsubsection{Interação entre os Componentes-base e transversais}

Após construir a arquitetura de componentes-base e transversais e mostrar seus relacionamentos de dependência e entrecorte, é necessário mostrar como os componentes-base e transversais interagem entre si para que os interesses transversais sejam implementados no sistema, que é o objetivo principal desta etapa.

Para conseguir este objetivo, duas atividades principais são necessárias: modelar a interação entre os componentes transversais de sistema e seus componentes de negócio, e com isso identificar as operações das interfaces transversais de negócio; e modelar a interação de entrecorte entre os componentes transversais e componentes-base.

As atividades desta etapa podem ser vistas na Figura 4.26 e são apresentadas com mais detalhes a seguir.

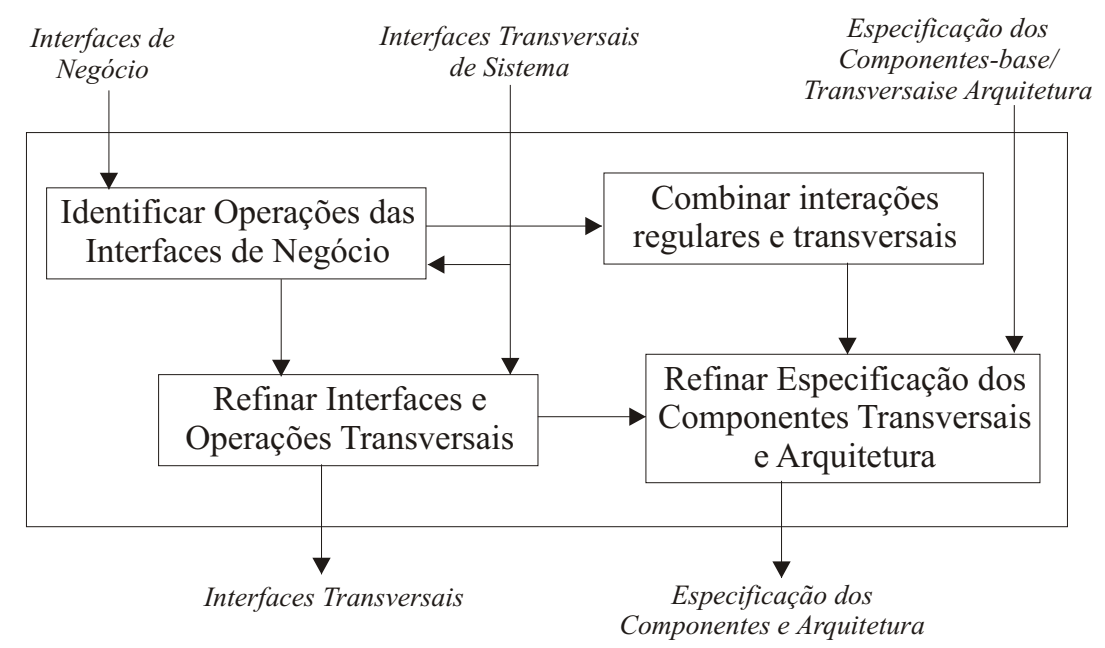

Figura 4.26: Atividades da etapa de Interação de Componentes-Base e Transversais

\section{Identificar Operações das Interfaces de Negócio}

Esta atividade consiste em identificar as operações das interfaces de negócio e apresentar o comportamento das operações transversais de sistema. Para isso deve-se construir um diagrama de colaboração da UML que mostre a interação entre os componentes transversais de sistema e seus componentes de negócio. Isso deve ser feito para cada operação das interfaces transversais de sistema.

É mostrado na Figura 4.27 o diagrama de colaboração de uma operação de uma interface transversal de sistema. As operações dos componentes transversais são identificadas pela letra $\mathrm{A}$ antes de sua numeração. No diagrama, o componente transversal de sistema GerRegi stroop interage com os componentes Date, GerAcesso por IGesAcesso e GerRegistrooperacoes por IGesRegistrooperacoes para realizar sua função. 


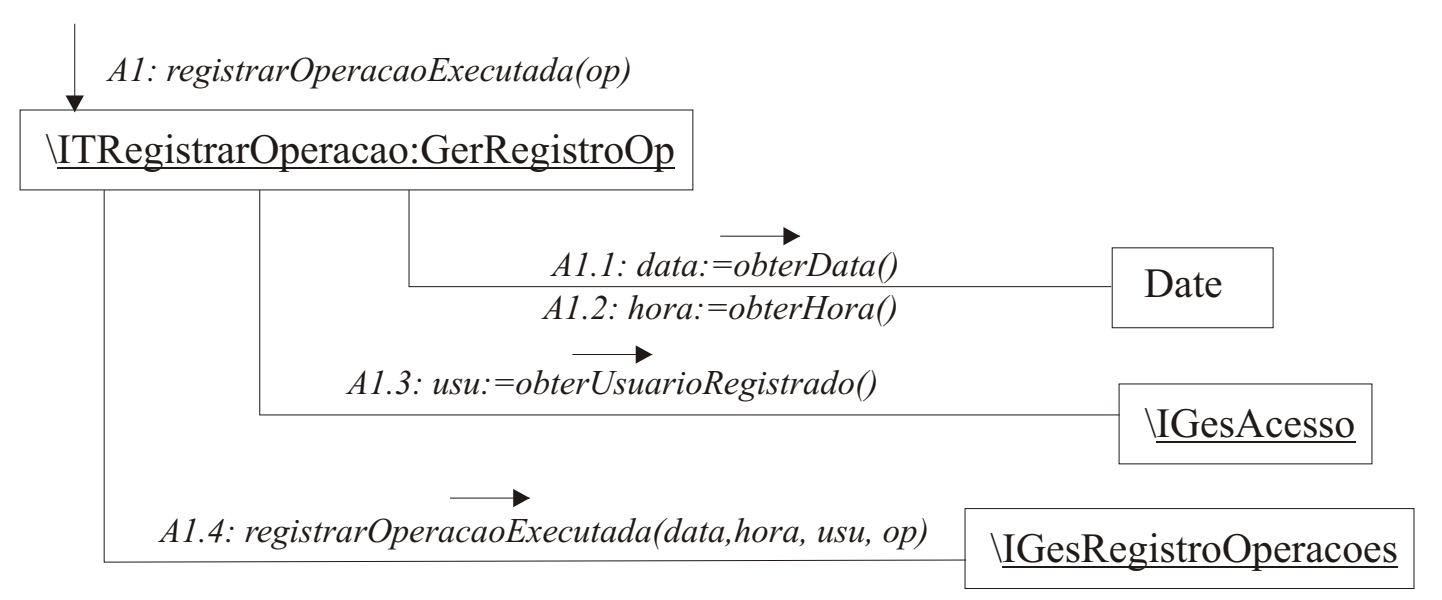

Figura 4.27: Diagrama de Colaboração da operação registrarOperacaoExecutada(op)

Após a construção dos diagramas de colaboração, deve-se especificar as assinaturas das operações das interfaces de negócio identificadas. A interface de negócio IGesAcesso e suas operações pode ser vista na Figura 4.28.

\begin{tabular}{|l|}
\hline \multicolumn{1}{|c|}{$<<$ interface $>>$} \\
IGesAcesso: GerAcesso \\
\hline $\begin{array}{l}\text { obterUsuarios(): String[] } \\
\text { obterSenhaUsuario(in login: String): String } \\
\text { obterUsuarioRegistrado():String } \\
\text { obterPapelUsuario(in login:String): String } \\
\text { obterOperacoesPapel(in papel:String): String[] }\end{array}$ \\
\hline
\end{tabular}

Figura 4.28: Interface de Negócio IGesAcesso

\section{Refinar interfaces e Operações Transversais}

Esta atividade segue as mesmas diretrizes das atividades de refinamento das interfaces e operações de sistema e de negócio do método UML Components. Entretanto é executada para interfaces e operações transversais, com o objetivo de torná-las mais genéricas e reusáveis.

\section{Combinar Interações Regulares e Transversais}

O objetivo desta atividade é modelar o comportamento do entrecorte de um componente transversal de sistema em uma operação de um componente-base. Isso é feito por meio do diagrama de colaboração da UML e consiste em mostrar uma operação genérica invocada de uma interface sendo entrecortada por um componente transversal, sem, contudo, mostrar detalhadamente a execução do componente-base e nem do componente transversal, pois ambos já foram especificados 
em atividades anteriores. O objetivo é apenas estabelecer e mostrar quais operações são entrecortadas e de acordo com quais critério de composição (before, after, around).

O diagrama de colaboração deve ser feito para cada interface logicamente reelaborada ou que contenha operações entrecortadas por um componente transversal de sistema. No diagrama, a operação chamada da interface deve ser genérica, denotando que qualquer operação entrecortada daquela interface resultará na mesma interação com um componente transversal.

O entrecorte de um componente transversal em um componente-base é modelado como se fosse uma chamada de uma operação do componente transversal pelo componente-base. Para mostrar o tipo de entrecorte são utilizados os estereótipos «before», «after» ou «around», cujos exemplos de utilização são apresentados a seguir.

Os exemplos de diagramas de colaboração que são mostrados a seguir são genéricos e as operações chamadas dos componentes-base representam operações entrecortadas pelos componentes transversais. Para saber as operações entrecortadas da interface chamada basta verificar as novas interfaces elaboradas para o entrecorte ou a notação que indica quais operações das interfaces são entrecortadas.

O estereótipo «before» é usado quando a operação do componente transversal de sistema deve ser executada antes da operação do componente-base entrecortado. Um diagrama do entrecorte do tipo «before» é apresentado na Figura 4.29, em que uma operação op ( ) é chamada da interface IGerEntrada e é entrecortada por uma operação da interface ITRegistrarOperacao do componente transversal de sistema GerRegistroop.

Além do estereótipo «before», a numeração das operações mostra a ordem em que as operações devem ser executadas: primeiramente a operação regi straroperacaoExecutada (op) da interface ITRegistraroperacao e em seguida a operação do_op(), que representa a operação op ( ) originalmente invocada de IGerEntrada (Clarke e Baniassad, 2005).

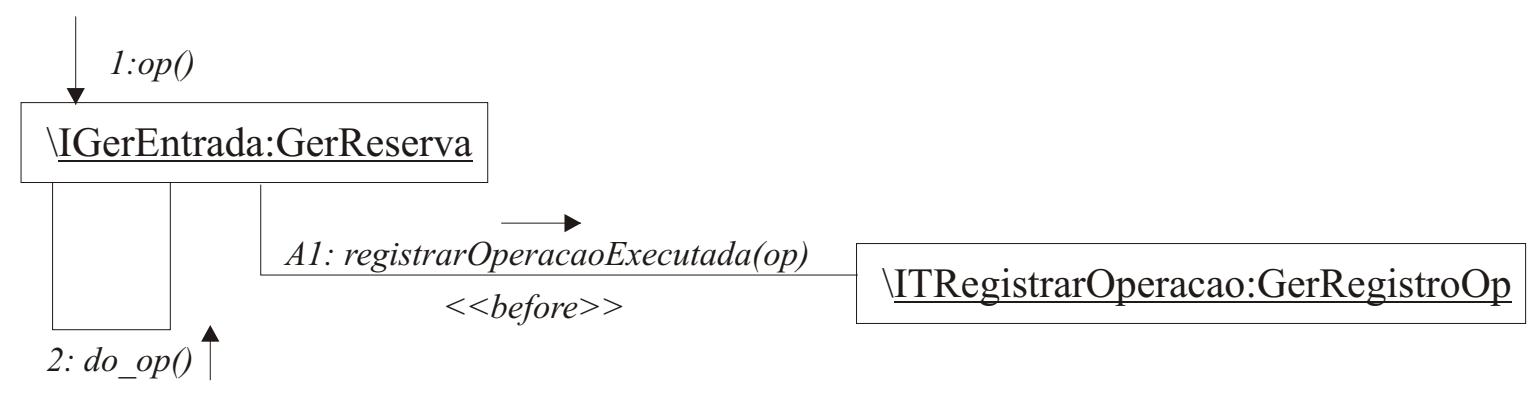

Figura 4.29: Diagrama de Colaboração de um entrecorte do tipo before

O estereótipo «after» é usado quando a operação do componente transversal de sistema deve ser executada depois da operação do componente-base entrecortada. Um diagrama do entrecorte do tipo «after» é apresentado na Figura 4.30, em que uma operação qualquer (op ( ) ) é chamada da interface IGerEnt rada e é entrecortada por uma operação da interface ITReg i straroperacao do componente transversal de sistema GerRegistroop. 
Além do estereótipo «after», a numeração das operações mostra a ordem em que as operações devem ser executadas: primeiramente a operação do_op ( ), que representa a interface originalmente invocada de IGerEnt rada e em seguida a operação registraroperacaoExecutada (op) da interface ITRegistraroperacao (Clarke e Baniassad, 2005).

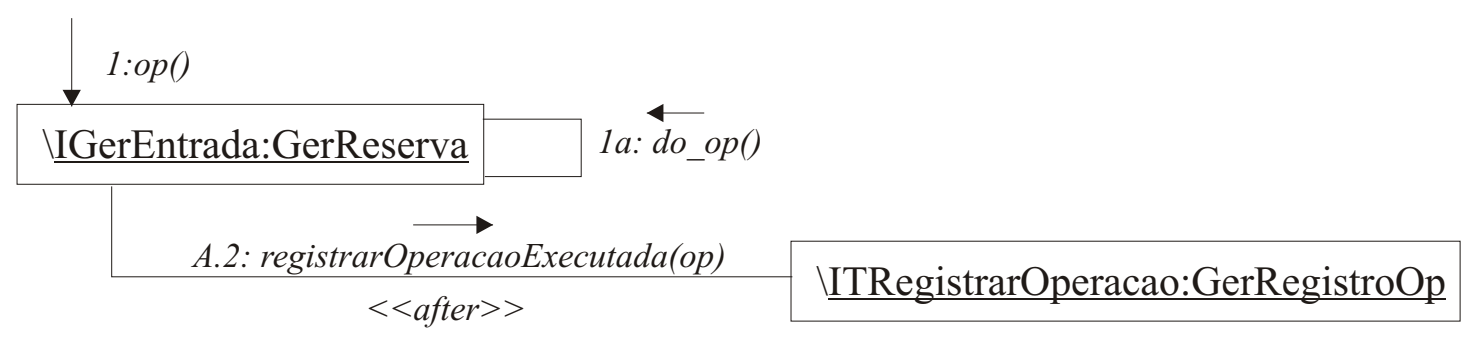

Figura 4.30: Diagrama de Colaboração de um entrecorte do tipo after

Quando existe um entrecorte do tipo «before» e «after» nas mesmas operações de um componente base por uma mesma operação de um componente transversal, deve-se fazer um diagrama contendo os dois entrecortes, como é mostrado na Figura 4.31.

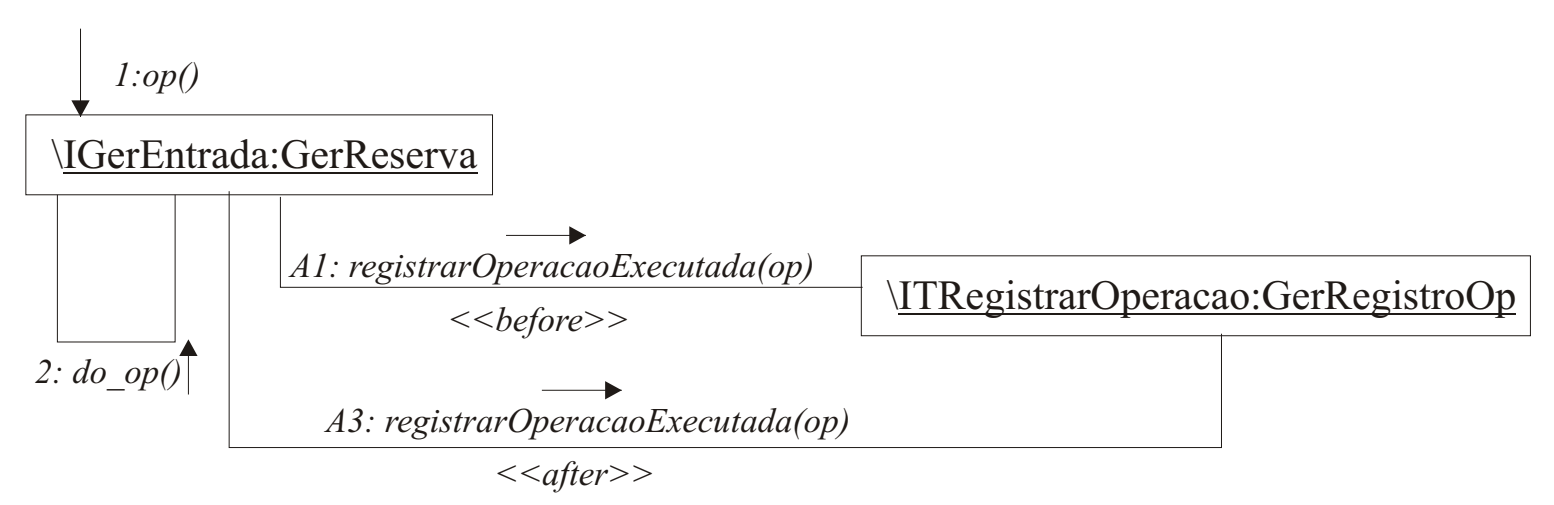

Figura 4.31: Diagrama de Colaboração de um entrecorte do tipo before e after juntos

O estereótipo «around» é utilizado quando a operação da interface transversal de sistema que entrecorta o componente-base deve ser executada em substituição à operação entrecortada. Neste caso, deve-se deixar explícito no diagrama se a operação do componente-base será executada ou não e quais as condições para isso. É mostrado um exemplo deste tipo de entrecorte no diagrama da Figura 4.32, no qual a operação op ( ) é entrecortada e a operação verificarDireitoAcesso (op) é executada no lugar, sendo que do_op ( ), que representa a operação originalmente invocada, só é executada caso o valor de retorno da operação verificarDireitoAcesso(op) seja verdadeiro (true). 
1:op()

\section{$\underline{\text { IGerReserva:GerReserva }}$}

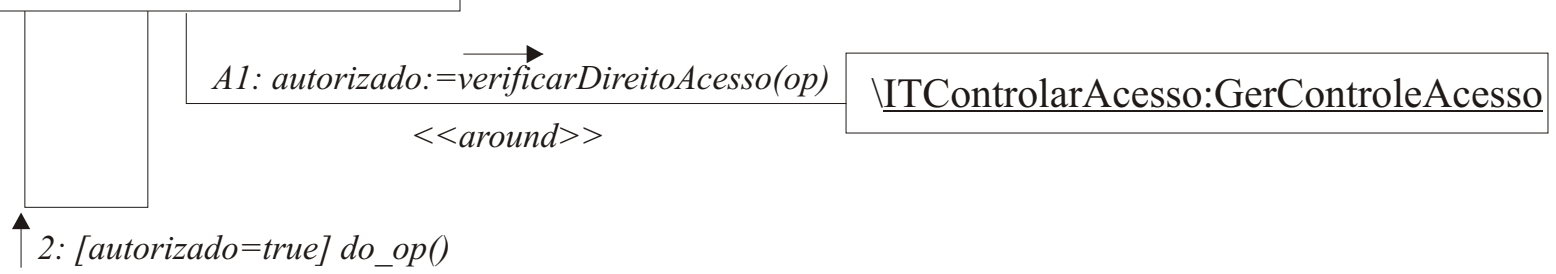

Figura 4.32: Diagrama de Colaboração de um entrecorte do tipo around

\section{Refinar Especificação dos Componentes Transversais e da Arquitetura}

Esta atividade consiste em refinar a especificação dos componentes transversais e da arquitetura criada, seguindo as mesmas diretrizes do método UML Components para o refinamento dos componentes-base e sua arquitetura.

\subsubsection{Especificação dos Componentes-Base e Transversais}

O objetivo geral desta etapa é especificar os contratos de uso e os contratos de realização dos componentes e interfaces. O contrato de uso é definido pela especificação de interface e o contrato de realização pela especificação do componente.

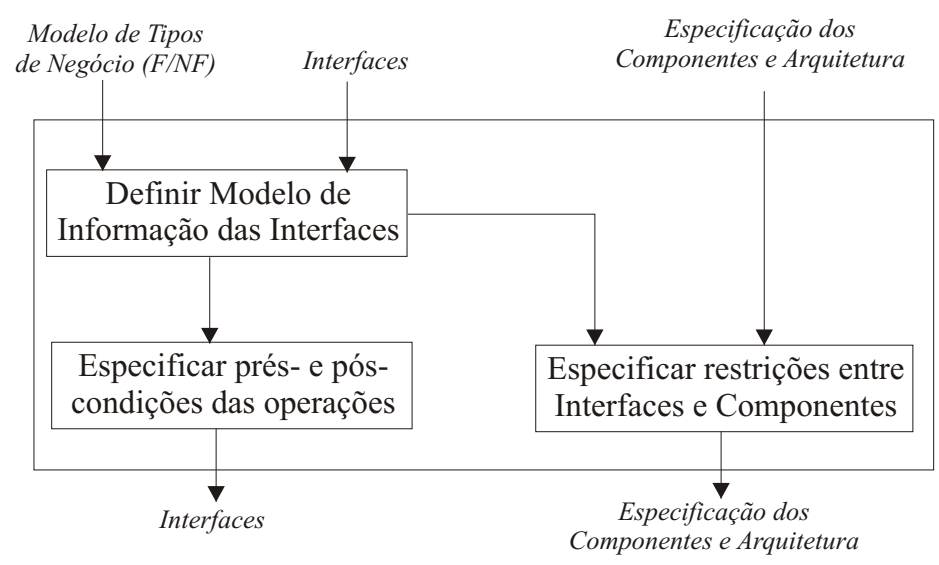

Figura 4.33: Atividades da etapa de Especificação de Componentes Base e Transversais

Deve-se fazer a especificação detalhada das interfaces de negócio e de sistema, pois por meio das interfaces pode-se saber como gerenciar as dependências entre componentes, pois elas são unidades de contrato. Deve-se especificar prés- e pós-condições para as operações e um modelo de informação para cada interface, tanto dos componentes-base quanto transversais. Deve-se também fazer a especificação dos componentes estabelecendo a quais interfaces sua realização dá suporte. 
Esta etapa segue as mesmas diretrizes do método UML Components e não sofreu mudanças, apenas acrescentou-se a necessidade de especificar os componentes transversais e suas interfaces. As atividades desta etapa podem ser vistas na Figura 4.33.

A especificação da interface IGesHotel do componente Sistema de Reservas pode ser vista na Figura 4.34 e a especificação da interface ITRegi strarOperaca o do componente transversal de sistema GerRegistroOp pode ser vista na Figura 4.35.

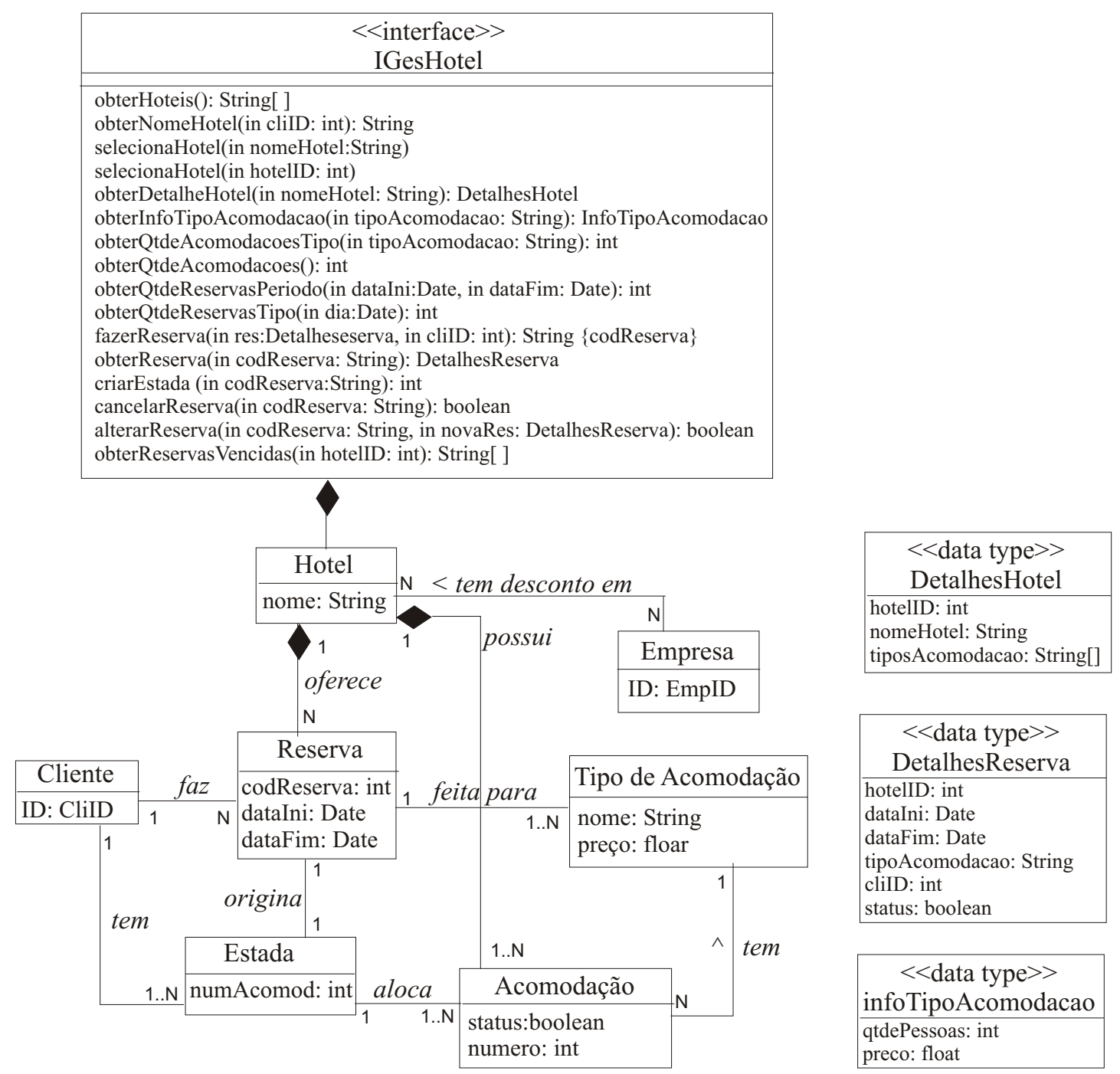

Figura 4.34: Especificação da interface IGesHotel

\subsection{Provisionamento}

O propósito da etapa de Provisionamento é encontrar componentes que satisfaçam os requisitos do sistema e o projeto realizado. Para isso existem três alternativas: reutilizar componentes existentes; adquirir componentes de terceiros; ou implementar novos componentes. 


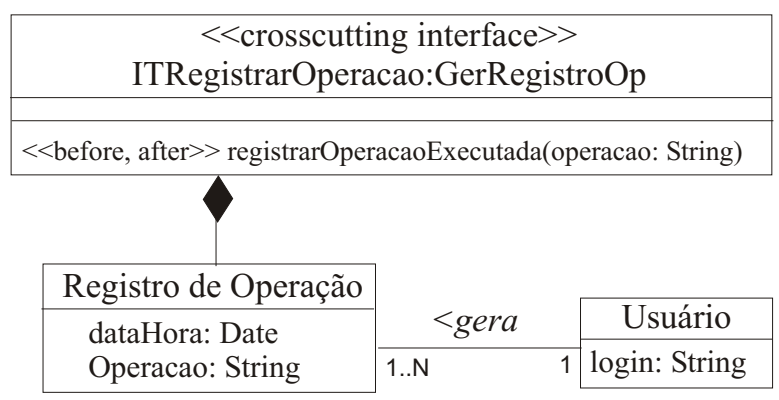

Figura 4.35: Especificação da interface ITRegistrarOperacao

Para atingir os objetivos desta etapa, algumas atividades são recomendadas. Primeiramente deve-se procurar componentes que atendam às especificações no repositório/biblioteca de componentes da própria organização que desenvolve a aplicação. Caso algum componente não seja encontrado, deve-se procurar componentes de terceiros e avaliar o custo/benefício de comprar o componente pronto ou implementá-lo.

Os componentes reusados devem ser usados como estão implementados ou devem ser adaptados para que possam atender às especificações do projeto de componentes realizado. Os componentes implementados devem ser generalizados, documentados e armazenados no repositório/biblioteca de componentes da organização desenvolvedora para ser reusado no futuro.

No método proposto, esta etapa praticamente não muda em relação ao UML Components. A diferença é que não se deseja apenas encontrar componentes-base (regulares), mas também componentes transversais (aspectos). Com isso, identifica-se a necessidade da adaptação dos repositórios e mecanismos de busca de componentes para que os componentes transversais também possam ser armazenados e encontrados. Uma outra alternativa é construir repositórios/bibliotecas de componentes que contenham apenas componentes transversais.

No provisionamento dos componentes para o Sistema de Reservas de Hotel, não foi realizada uma busca em repositórios e bibliotecas por componentes que atendessem às especificações dos componentes projetados, pois foi decidido que todos os componentes seriam implementados. Essa decisão foi tomada porque os componentes são relativamente simples e pequenos, por ser um trabalho acadêmico e não haver a necessidade de investir esforço na busca, seleção e adaptação de componentes. Em relação aos componentes transversais, a motivação para implementá-los foi a utilização de novas linguagens de programação e, portanto, a inexistência de bibliotecas de componentes, e o intuito de extrair abstrações das linguagens para refinar o método caso necessário.

Dentre os componentes transversais identificados, apenas o componente transversal de persistência não foi implementado como aspecto. Essa decisão foi tomada devido à complexidade de implementar a persistência como um aspecto sem quebrar o encapsulamento dos componentes afetados devido às introduções necessárias por meio das declarações inter-tipos. Além disso, a persistência é um caso particular de interesse transversal, pois os componentes-base afetados não são totalmente inconscientes de sua existência. 
A linguagem utilizada para a implementação dos componentes-base foi a linguagem Java e por se tratar de uma tecnologia consolidada não serão mostrados os detalhes de implementação neste trabalho.

\subsubsection{Estratégias de implementação dos componentes transversais}

A implementação dos componentes transversais foi feita com o objetivo de ser fiel ao projeto, de maneira que os componentes transversais não invadissem os componentes, operando apenas nas operações definidas nas interfaces dos componentes entrecortados.

Os componentes transversais de sistema do Sistema de Reservas de Hotel foram implementados em duas versões: uma com a linguagem JAsCO e outra com a linguagem AspectJ. A linguagem JAsCO, como descrita na Seção 3.3.4 deste trabalho, é uma linguagem construída com o propósito de integrar os conceitos do desenvolvimento com componentes e com aspectos. Já a linguagem AspectJ é uma linguagem orientada a aspectos de propósito geral. Nas subseções a seguir são mostrados os detalhes de implementação com o uso dessas linguagens.

Destaca-se que na etapa de Provisionamento a implementação dos componentes pode ocorrer de duas formas, independentemente da linguagem utilizada. A primeira forma é a implementação do componente transversal de forma genérica para ser reusado em outras aplicações. Quando essa forma é adotada, os componentes transversais não têm relacionamento de entrecorte com nenhum componente-base e a determinação das operações dos componentes-base entrecortadas são definidas apenas na etapa de Montagem.

A segunda forma é a implementação do componente transversal especificamente para a aplicação em desenvolvimento. Implementam-se os comportamentos do componente e seus conjuntos de junção concretos, definindo antes da etapa de Montagem as operações dos componentes que devem ser entrecortadas. Em um segundo passo, deve-se generalizar o componente e depois o mecanismo de composição pode se tornar abstrato para que o componente possa ser guardado na biblioteca de componentes e ser posteriormente utilizado em outras aplicações.

Algumas linguagens, como JAsCO, por exemplo, não permitem que os conjuntos de pontos de junção sejam determinados no componente e exige que sejam declarados como abstratos e determinados por um conector. Essa restrição da linguagem, entretanto, não implica o fato de todos componentes construídos em JAsCO serem genéricos, pois ser genérico não está relacionado somente ao fato de ter conjuntos de ponto de junção abstrato, mas também em possuir combinações de comportamentos (adendos) que atendam à necessidade de diferentes requisitos de diferentes aplicações. Questões relacionadas à generalização dos componentes são abordadas na Seção de Generalizaçao. 


\section{Implementação com a linguagem JAsCO}

$\mathrm{Na}$ linguagem JAsCO, os componentes transversais são implementados como classes e o comportamento transversal é especificado com construções chamadas de hook (gancho), que é um tipo especial de classe interna. Os ganchos implementam o conjunto de junção e os adendos de um aspecto, em que seu construtor especifica quando os componentes-base devem ser entrecortados e os adendos determinam o que fazer. Os conjuntos de junção definidos no construtor do gancho são sempre abstratos e são determinados apenas na etapa de Montagem por conectores definidos pela linguagem JAsCO.

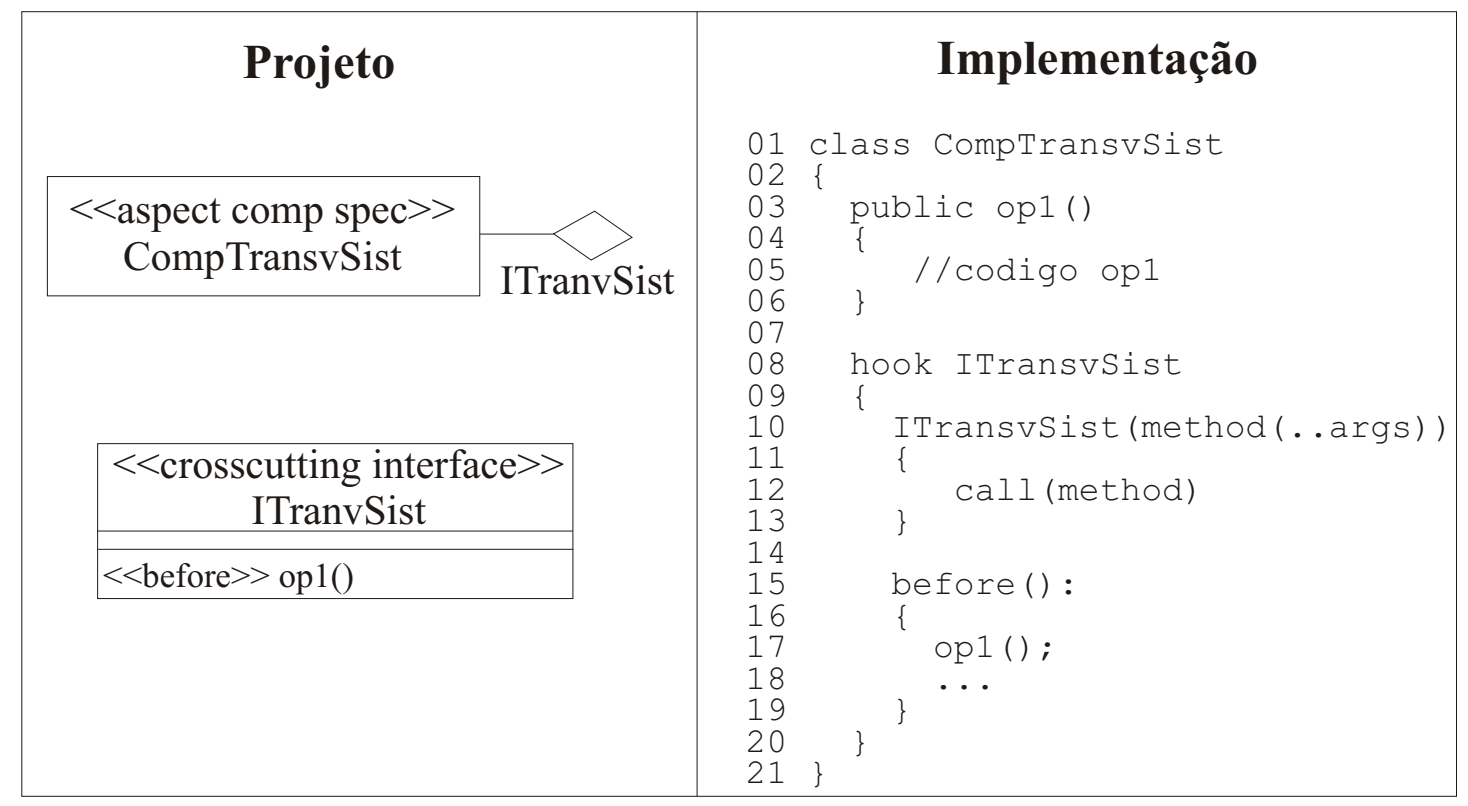

Figura 4.36: Mapeamento do projeto de um componente transversal para a linguagem JAsCO

O mapeamento do projeto dos componentes transversais de sistema é feito de forma direta e objetiva para a linguagem JAsCO. Um mapeamento genérico é mostrado na Figura 4.36. O nome do componente na especificação deve ser usado para dar nome ao componente implementado (linha 1). Como os componentes em JAsCO não implementam interfaces, as interfaces transversais de sistema são definidas como ganchos (linha 8), que descrevem o comportamento entrecortante do componente e fazem as chamadas para as operações definidas nas interfaces do componente (linha 15 a 19) que são implementadas como métodos regulares (linhas 3 a 6).

Para melhor ilustrar o mapeamento do projeto de um componente transversal para a linguagem JAsCO, é apresentado o projeto do componente GerReg i st roOp do Sistema de Reservas de Hotel, que é responsável por registrar a execução de todas as operações de entrada do sistema. O componente possui apenas uma interface transversal de sistema: ITRegistraroperacao. Essa interface também possui apenas uma operação: regi straroperacaoExecutada. O componente depende de duas interfaces transversais de negócio: IGesAcesso e IGesRegistrooperacoes. O projeto desse componente pode ser visto na Figura 4.37. 


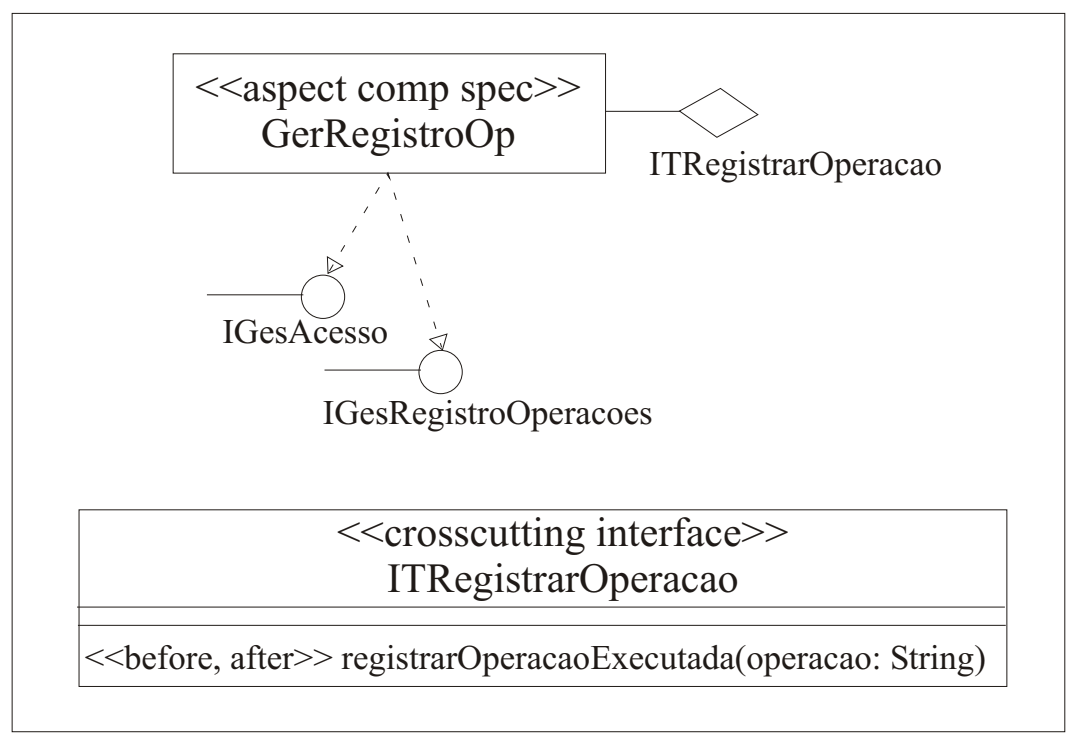

Figura 4.37: Projeto do componente GerRegistroOp

O mapeamento do projeto do componente transversal GerRegistroop para a linguagem JAsCO pode ser visto no código fonte apresentado na Figura 4.38. O componente é implementado de forma semelhante a uma classe (linha 1) e pode ter métodos regulares implementados (linhas 6 a 12). Os componentes JAsCO não implementam interfaces e a interface transversal ITRegistraroperacao do componente GerRegistroop é definida como um gancho (linhas 14 a 31). O gancho implementa o comportamento transversal e seu construtor (linhas 17 a 20) determina que o componente transversal deve executar um comportamento quando o método abstrato method (.. ) for executado. O comportamento executado são os adendos do componente transversal. Nesse caso, foi implementado um adendo anterior (before) e um posterior (after) que definem que quando o método definido no construtor for executado, o método registrarOperacaoExecutada(op) deve ser executado antes e depois dele.

Posteriormente, na etapa de Montagem, o método abstrato do construtor do gancho é concretizado por um conector, determinando os componentes-base e as operações a serem entrecortadas.

É importante notar que o relacionamento do componente transversal de sistema com um componente de negócio ocorre de forma semelhante ao relacionamento entre um componente-base de sistema e um de negócio. Pode-se observar que o relacionamento não é do tipo entrecorte, mas chamadas a operações dos componentes de negócio (linha 10 e 11).

\section{AspectJ}

A linguagem AspectJ é uma linguagem orientada a aspectos de propósito geral. Diferentemente da linguagem JAsCO, não há mecanismos na linguagem que garantam que somente as operações oferecidas pelas interfaces dos componentes sejam entrecortadas. O programador é quem deve 


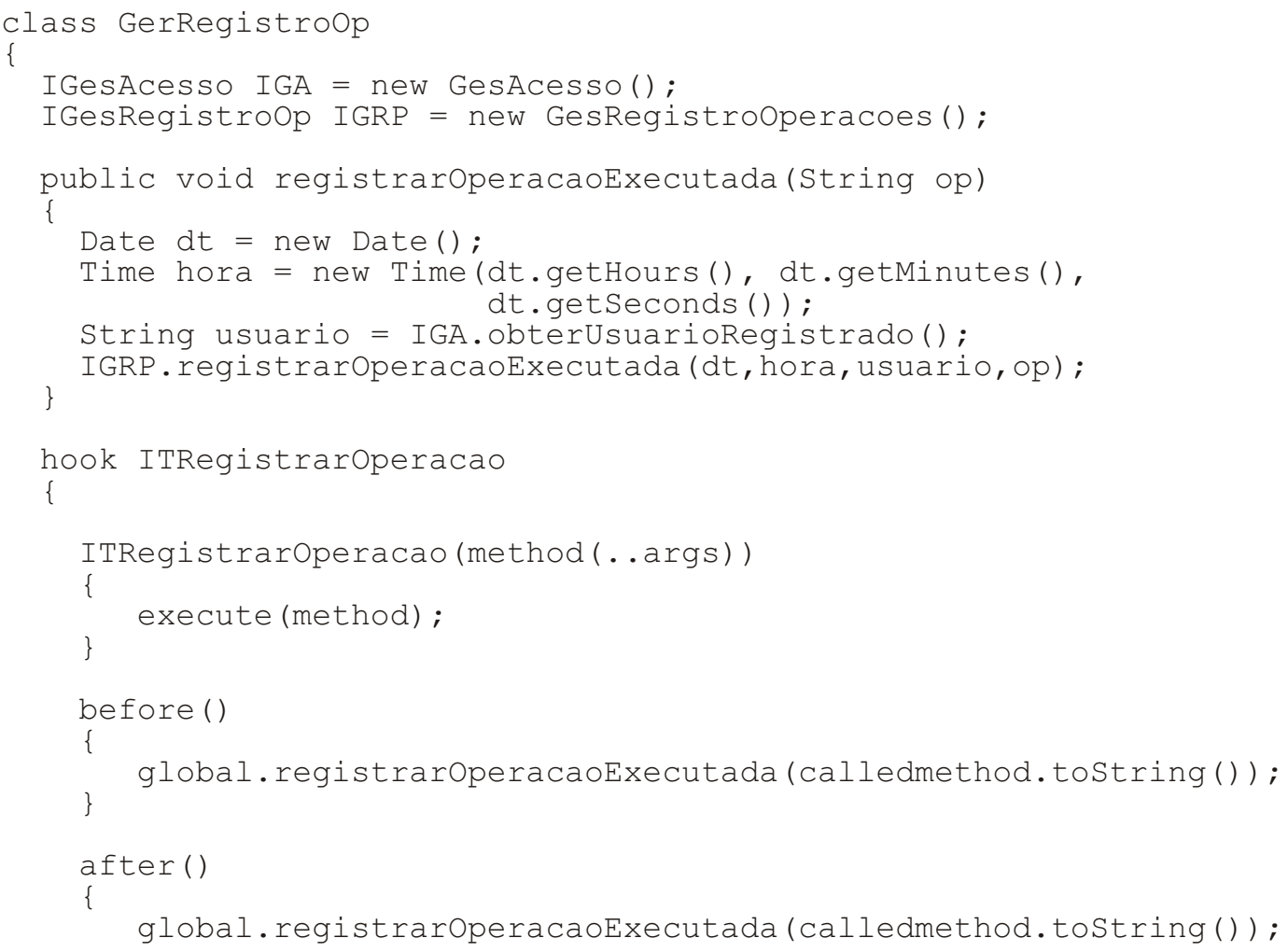

Figura 4.38: Código-fonte do componente transversal GerRegistroOp em JAsCO

usar a linguagem de forma disciplinada para que elementos internos aos componentes não sejam entrecortados por componentes transversais.

O mapeamento genérico do projeto de um componente transversal para a implementação na linguagem AspectJ pode ser visto na Figura 4.39. Nesse exemplo, o componente transversal apesar de não ser genérico, é declarado como um aspecto abstrato, pois a declaração de seus conjuntos de ponto de junção é abstrata. Como os aspectos em AspectJ não implementam interfaces, o nome da interface transversal de sistema do projeto é atribuído ao nome de seu conjunto de ponto de junção abstrato (linhas 04 e 04). As operações definidas na interface transversal são implementadas no corpo do aspecto ou em outra classe ou componente, como ocorre com a operação op1 ( ). No entrecorte, as operações da interface são chamadas pelos adendos do aspecto, como op1 () é chamada do adendo anterior (before) do aspecto Comptransvist.

Para melhor ilustrar o mapeamento do projeto de um componente transversal para a linguagem AspectJ, é apresentada na Figura 4.40 a implementação do componente transversal GerReg i st ro Op, cujo projeto pode ser visto na Figura 4.37. O componente transversal é implementado como um aspecto e a operação da interface é implementada como um método do aspecto (linha 6 a 12), sendo chamado pelos adendos (linha 16 a 24). O conjunto de ponto de junção que determina quais ope- 


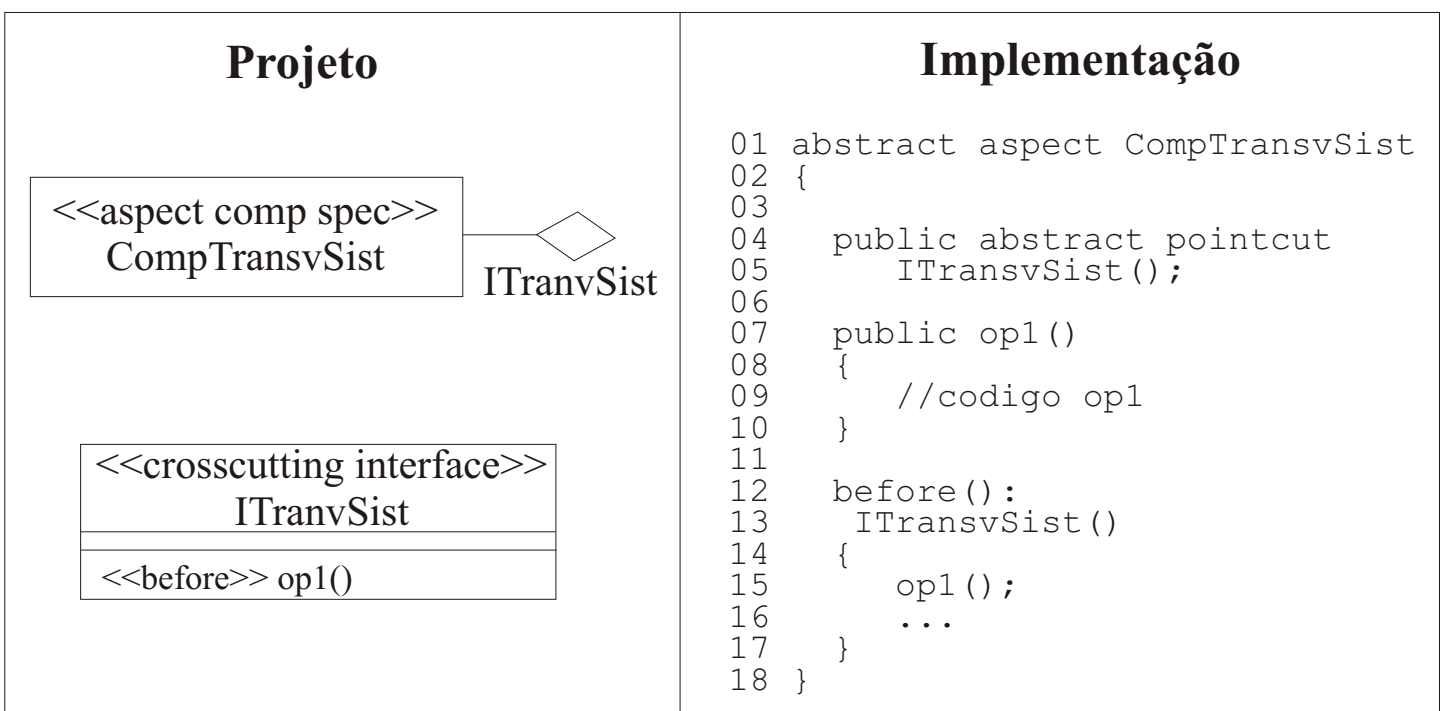

Figura 4.39: Mapeamento do projeto de um componente transversal para a linguagem AspectJ

rações do componente-base devem ser entrecortados são declarados como abstratos (linha 14). O conjunto de pontos de junção que determinam quais operações de quais componentes-base devem ser entrecortados são determinados na montagem do sistema.

\subsubsection{Generalização}

Os componentes implementados na etapa de Provisionamento devem ser generalizados para que possam ser armazenados em um repositório de componentes e posteriormente reusados em outras aplicações. Neste trabalho não é discutida a melhor forma de generalizar componentes em termos de assinatura de operações, variabilidades das funcionalidades, etc, pois o foco do trabalho é explorar as características específicas dos componentes transversais, que, no caso, são as generalizações em termos de conjuntos de ponto de junção e tipos de adendos executados no aspecto.

Para generalizar um componente transversal não é suficiente apenas declarar seus conjuntos de ponto de junção como abstratos, pois o comportamento transversal do componente pode ser específico para a aplicação em desenvolvimento. Isso implica a necessidade de realizar a análise do domínio do interesse implementado no componente transversal e identificar as diferentes variabilidades em termos de tipos de adendos (anteriores, posteriores e de contorno) que podem ser usados para o interesse transversal em questão.

Com a identificação dos comportamentos possíveis que um componente transversal genérico para um determinado interesse deve possuir, o próximo passo é implementar os comportamentos possíveis do componente e criar uma estratégia de escolha dos tipos de adendos que se deseja ativar, pois as aplicações são diferentes e necessitam da ativação de diferentes combinações de adendos para satisfazer seus requisitos. Destaca-se que não é abordada neste trabalho a variabilidade dos 


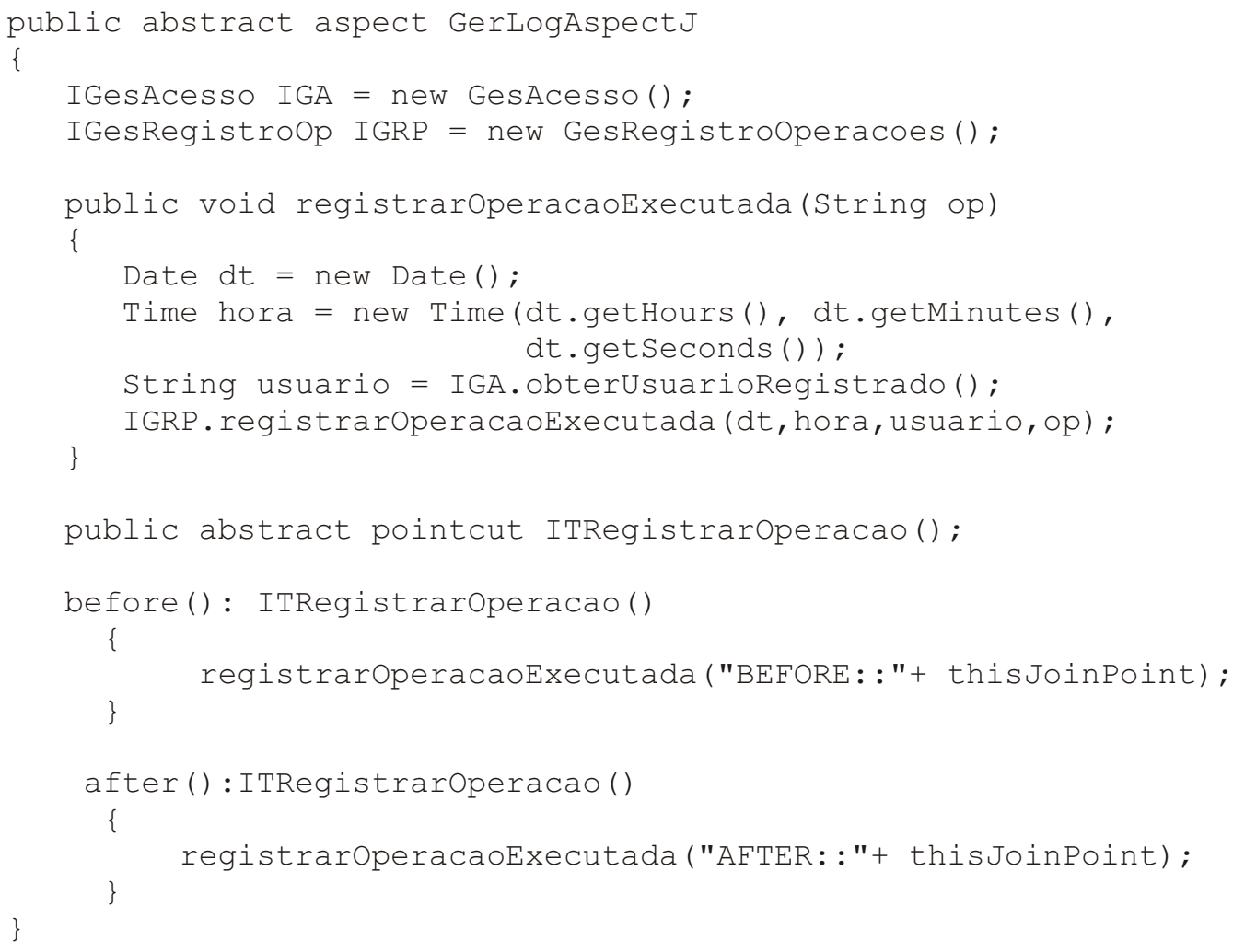

Figura 4.40: Código-fonte do componente transversal GerRegistroOp em AspectJ

componentes em termos de funcionalidades oferecidas, apenas nos tipos de adendos que podem ser ativados.

Em relação aos diferentes tipos de linguagens para implementar componentes transversais, como JAsCO e AspectJ, por exemplo, a implementação dos componentes transversais de modo genérico é relativamente simples. É apenas necessário que os conjuntos de pontos de junção sejam abstratos e os tipos de adendos que serão disponibilizados para reúso sejam implementados. Os adendos utilizados podem ser selecionados na montagem ou o componente transversal pode ser estendido e um novo adendo implementado.

O que diferencia a implementação dos componentes transversais de uma linguagem para outra é a estratégia de implementação e escolha dos adendos que devem ser ativados. A seguir são mostrados exemplos de implementação de componentes transversais genéricos e estratégias de escolha de adendos para as linguagens JAsCO e AspectJ.

\section{Componentes transversais genéricos na linguagem JAsCO}

Na Figura 4.41 é apresentado o código de um componente transversal genérico GerLog que é responsável pelo registro da execução de operações dos componentes de um sistema. Como pode ser observado, há a implementação de um comportamento padrão em que as operações são 
registradas com os dados do usuário, horário e operação executada no sistema. Em relação ao momento de registro da execução da operação, há os dois tipos de adendos implementados: anteriores (before) e posteriores (after).

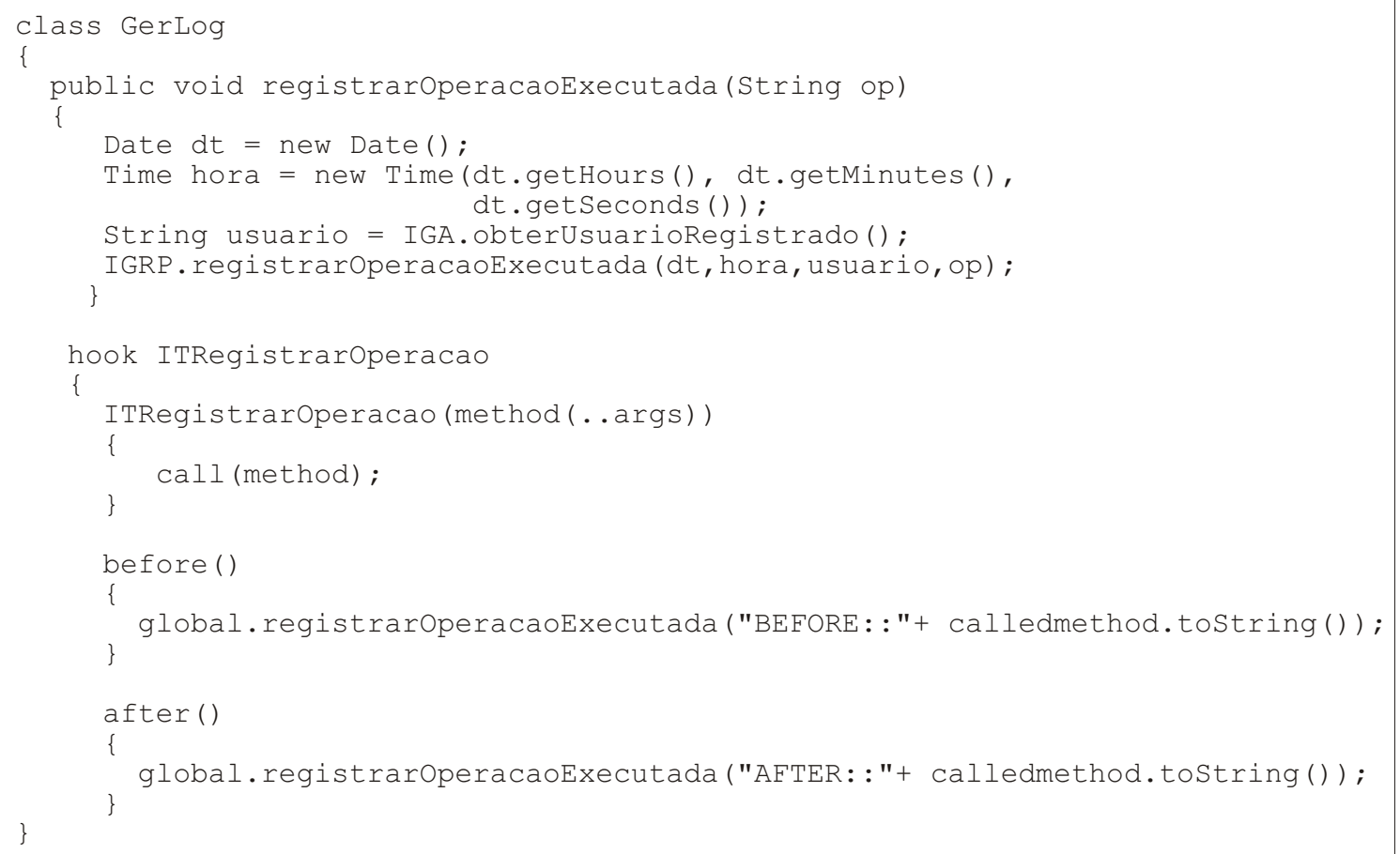

Figura 4.41: Componente Transversal Genérico de Registro de Execução de Operações

Para utilizar o componente GerLog em outras aplicações é necessário que os conjuntos de ponto de junção sejam concretizados e que os adendos a serem ativados sejam escolhidos. No caso da linguagem JAsCO, essas duas escolhas podem ser feitas por um conector.

Para melhor ilustrar a utilização do componente transversal GerLog, supõe-se a necessidade de se fazer o registro de todas as operações de um componente Impressora de uma aplicação qualquer, mas somente após a operação ter sido executada. Na Figura 4.42 é apresentado o conector que determina os pontos de junção do componente GerLog e seleciona os adendos a serem ativados. No caso, os pontos de junção da impressora são todas as operações ( * Impressora . *) e o adendo ativado é apenas o posterior (after).

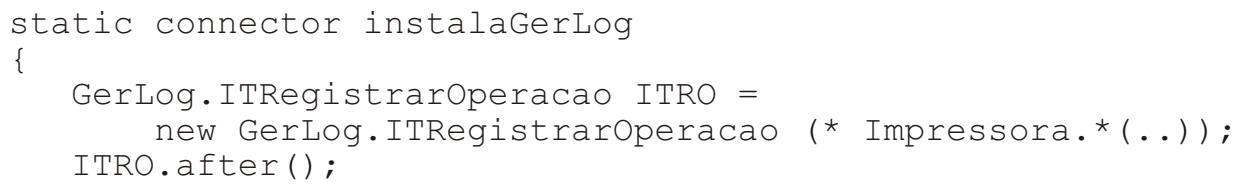

Figura 4.42: Conector que liga o componente GerLog ao componente Impressora 
Se no cenário de reúso do componente houver a necessidade de um adendo do tipo around, o programador deve estender o componente transversal e seu gancho e escrever o código do adendo. Na Figura 4.43 pode ser vista uma situação genérica de reúso com o adendo around, em que o componente transversal CompTransv é estendido pelo componente novoCompTransv, assim como seu gancho ITransv é estendido pelo gancho novoITransv. No adendo implementado, o programador escolheu retornar o controle à aplicação entrecortada por meio do método proceed ( ) após executar algum comportamento.

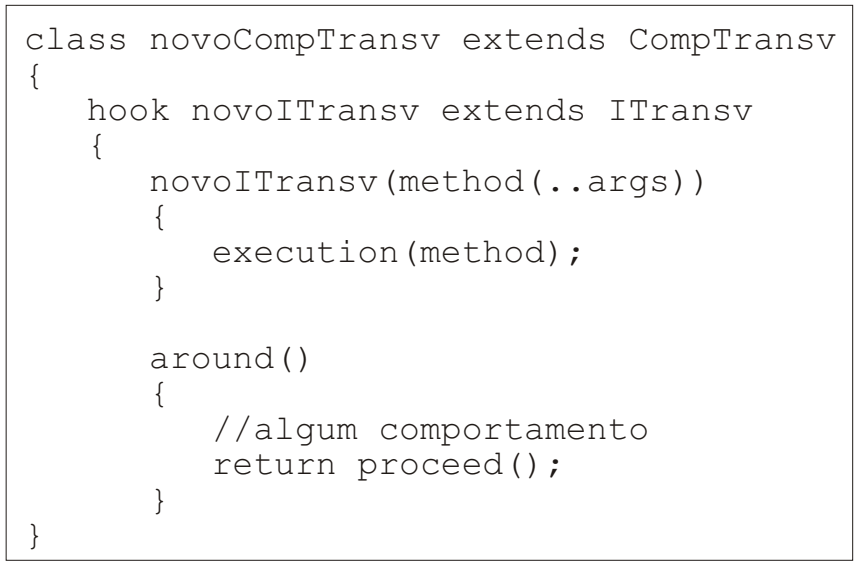

Figura 4.43: Reuso caixa-branca em JAsCO

\section{Componentes transversais genéricos na linguagem AspectJ}

Com a utilização do mesmo exemplo em que um componente transversal foi implementado de forma genérica com a linguagem JAsCO, é apresentado na Figura 4.44 o código da implementação do componente transversal GerLog na linguagem AspectJ. No código apresentado, são implementados dois tipos de adendos (anterior e posterior) e para cada um deles existe um conjunto de ponto de junção associado. Isso é feito para que o desenvolvedor que usar o componente possa selecionar os tipos de adendos que deseja ativar, por meio da extensão dos conjuntos de ponto de junção.

Como pode ser visto na Figura 4.45, o aspecto instalaGerLogAspectJ realiza uma extensão do aspecto GerLogAspect J e o conjunto de ponto de junção ITRegistraroperacaoAfter, indicando que deseja apenas ativar o adendo posterior (after). Quando se deseja utilizar os outros adendos, deve-se estender cada ponto de junção com as operações que devem ser entrecortadas, como é mostrado na Figura 4.46, em que os adendos before e after são ativados pela extensão dos conjuntos de ponto de junção ITRegistraroperacaoBefore e ITRegistrar OperacaoAfter.

A opção de generalização do componente transversal com AspectJ apresentada não é única e pode ser feita de várias maneiras. A solução apresentada foi a mais simples encontrada, em que o desenvolvedor estende apenas os pontos de junção que devem ser ativados e realiza a combinação 


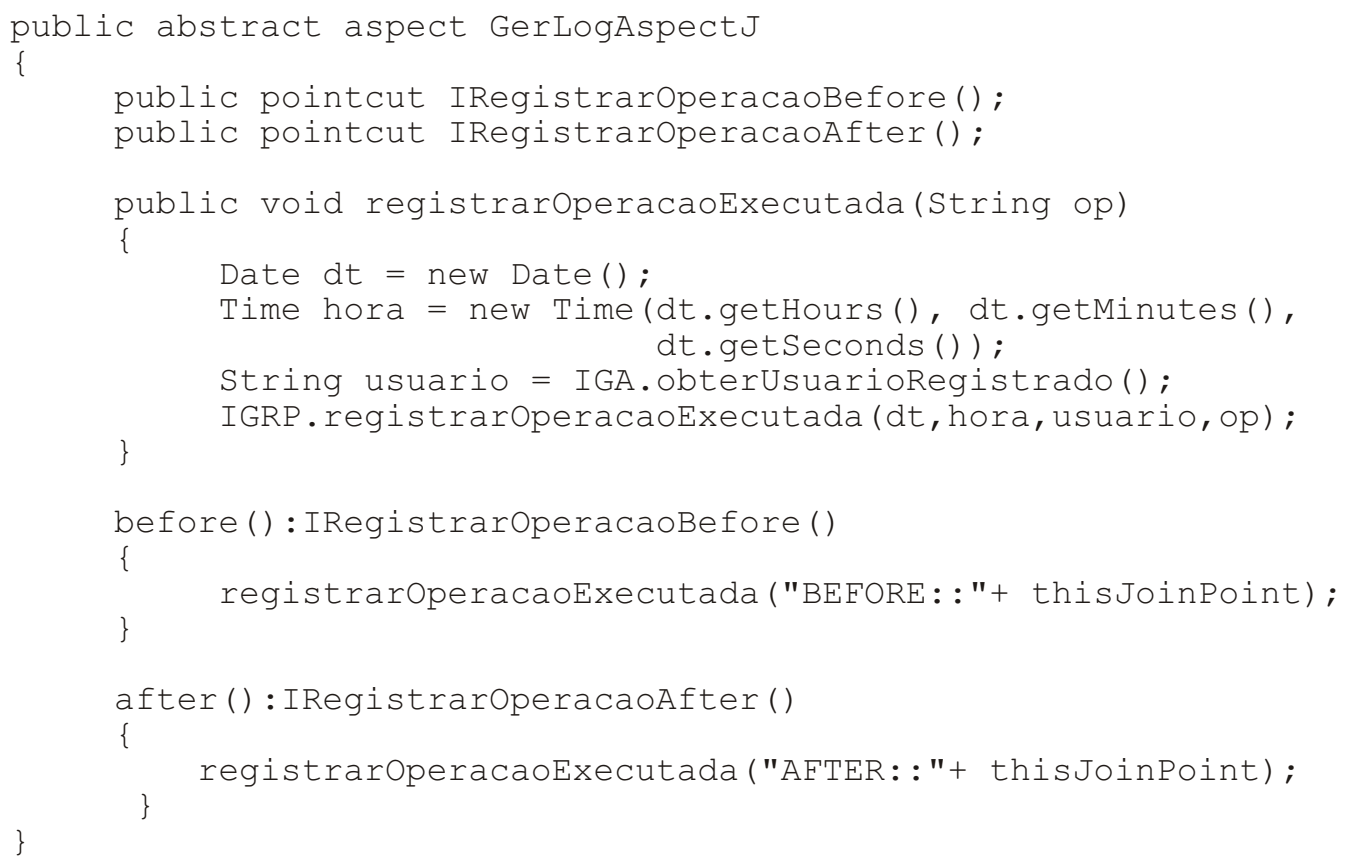

Figura 4.44: Componente Transversal Genérico de Registro de Execução de Operações

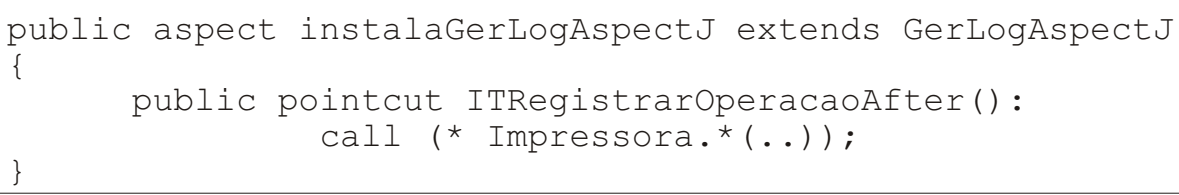

Figura 4.45: Conector que liga o componente GerLog ao componente Impressora (after)

dos adendos da forma como quiser. Outra estratégia de implementação de um aspecto genérico em AspectJ é apresentada na Figura 4.47, em que são previstas combinações de adendos ativados, o que torna a tarefa do desenvolvedor mais simples no momento de escolha de adendos a serem ativados.

Nota-se na Figura 4.47 que há varios conjuntos de ponto de junção definidos para cada adendo: ITRegistraroperacaoBefore, ITRegistraroperacaoAfter, ITRegistraroperacaoBeforeAfter. Esses conjuntos de ponto de junção já prevêem a combinação dos tipos de adendos, ficando a cargo do desenvolvedor estender os conjuntos de ponto de junção de um adendo único ou com a combinação desejada.

$\mathrm{Na}$ Figura 4.48, é apresentado um conector que liga o componente GerLog ao componente Impressora, determinando que todas as operações de Impressora devem ser entrecortados. Os adendos selecionados no conector foram o anterior e o posterior, como pode ser visto pela extensão do conjunto de ponto de junção ITRegistraroperacaoBeforeAfter. Como pode ser observado, não houve a necessidade de se estender dois conjuntos de ponto de junção. 


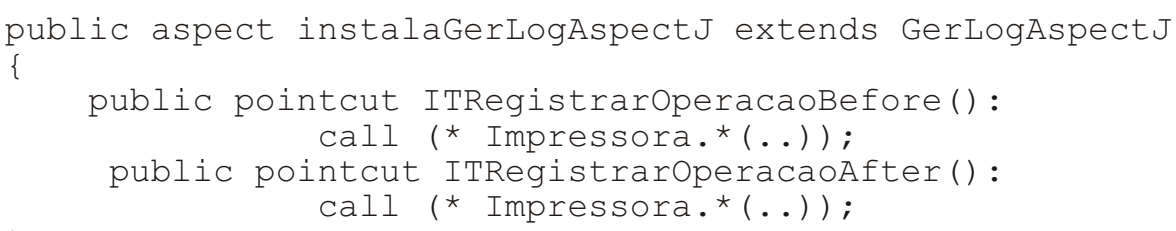

Figura 4.46: Conector que liga o componente GerLog ao componente Impressora (before e after)

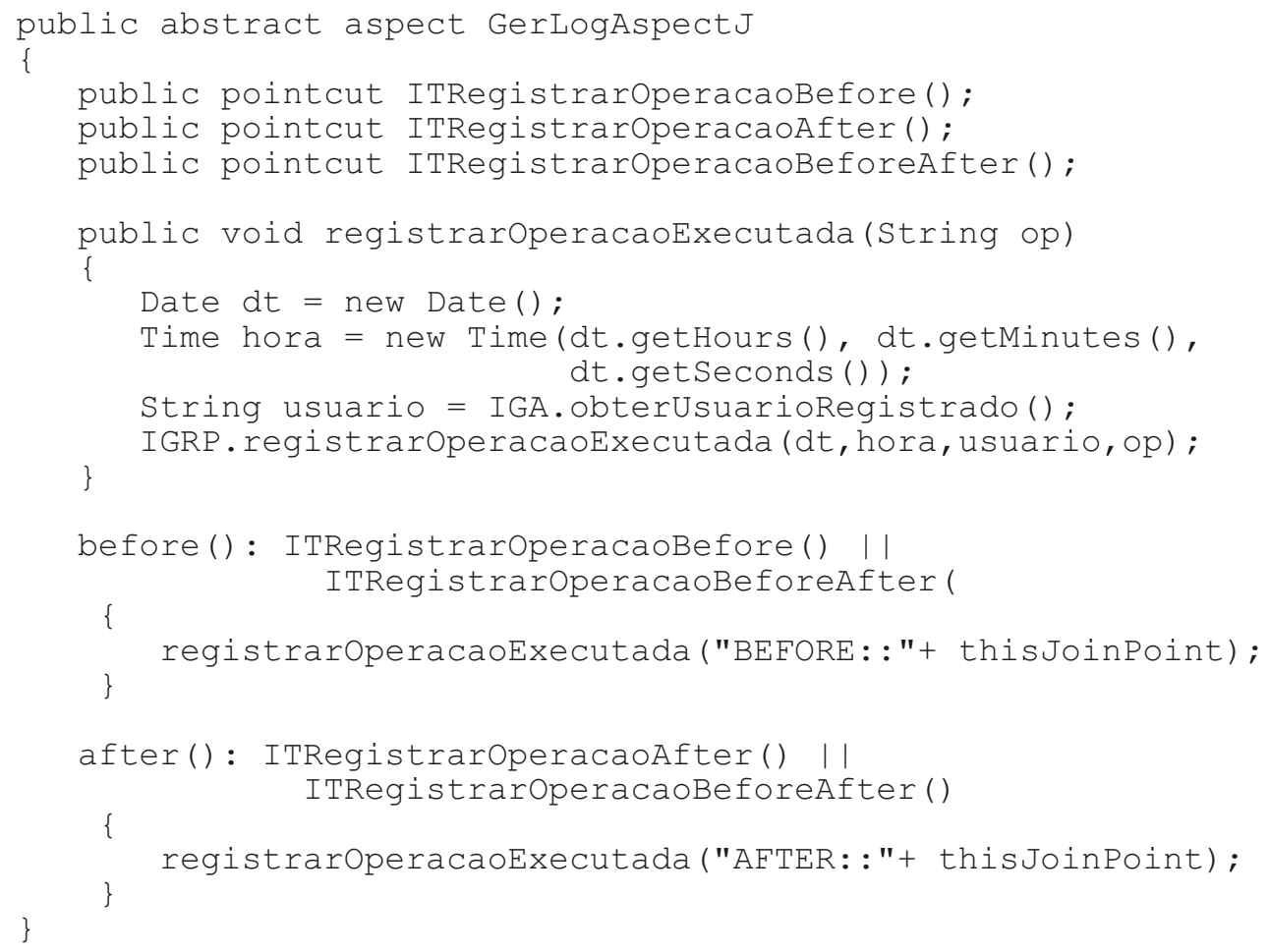

Figura 4.47: Componente Transversal Genérico de Registro de Execução de Operações

Essa forma de generalização facilita a determinação de pontos de junção em comum e específicos para cada tipo de adendo. Como exemplo podemos citar uma situação em que todas as operações de Impressora que começam com set devem ser registradas antes e depois de sua execução e as operações imprime() e esvazia() devem ser registradas apenas após a execução da operação. Isso pode ser facilmente feito pela extensão do conjunto de junção ITRegistraroperacaoBeforeAfter com os pontos de junção set* (. .) e o conjunto de junção ITRegistraroperacaoAfter com as operações imprime() e esvazia(), como pode ser visto no código mostrado na Figura 4.49 


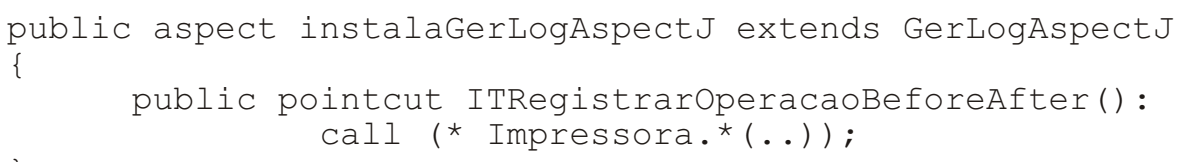

Figura 4.48: Conector que liga o componente GerLog ao componente Impressora

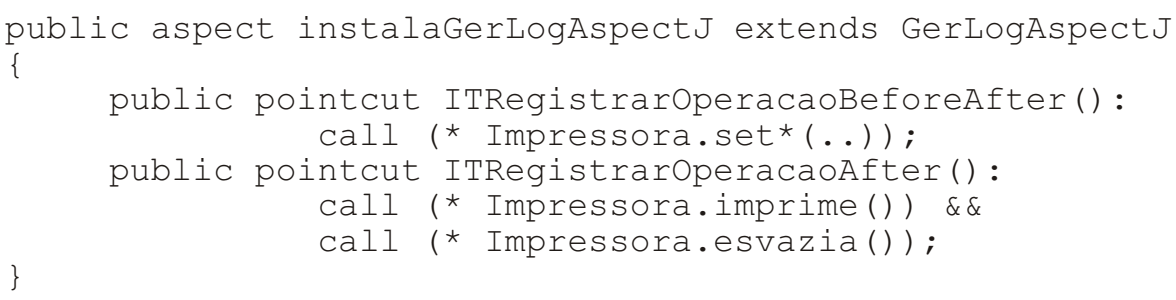

Figura 4.49: Conector que liga o componente GerLog ao componente Impressora

\subsubsection{Documentação}

A documentação de um componente é um fator importante para o seu reúso efetivo, pois é por meio da documentação que é possível conhecer seus serviços oferecidos e requeridos e verificar se um componente satisfaz os requisitos necessários para ser reusado em uma aplicação.

Os componentes transversais de sistema devem ser documentados com o objetivo de mostrar quais são as operações das interfaces transversais e como elas entrecortam os outros componentes do sistema. Sua documentação é feita de forma semelhante à documentação dos componentesbase. Primeiramente deve-se criar um artefato que mostre a especificação do componente com suas interfaces oferecidas e requeridas. Na Figura 4.50 pode ser vista a especificação de um componente transversal de sistema genérico CompTransvSist que oferece uma interface transversal de sistema ITransvSist, e requer uma interface de negócio INeg (de um componente de negócio funcional ou não-funcional). Além disso, é mostrado que o componente transversal de sistema possui uma relação de entrecorte com um componente-base CompBa se 1 que possui seus serviços utilizados por um componente qualquer (CompBase2).

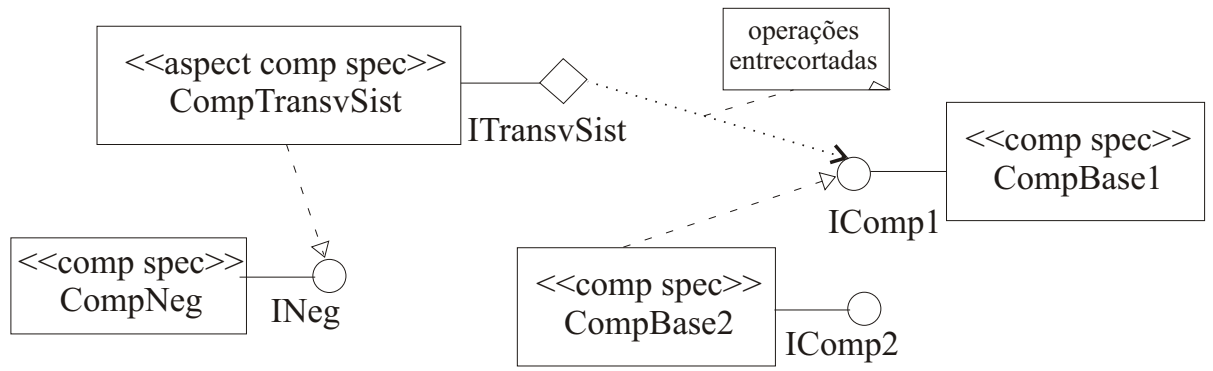

Figura 4.50: Especificação de um componente transversal 
Outro elemento importante da documentação dos componentes transversais de sistema é a especificação das interfaces oferecidas e requeridas pelo componente. No caso, o componente oferece apenas uma interface transversal cuja especificação pode ser vista na Figura 4.51. Observase que a interface possui duas operações: $o p \operatorname{Tr} 1$ ( tipoDado y) e opTr2 (). Na especificação da interface, antes de cada operação é mostrado o tipo de entrecorte da operação (before, after e/ou around).

Uma interface transversal só pode conter mais de uma operação se elas estiverem relacionadas entre si e entrecortarem os mesmos pontos de junção, mesmo que sejam implementadas em tipos de adendos distintos, como ocorre com as operações opTr1 () e opTr2 () de Comptransvist. Se as operações precisam operar em pontos de junção distintos, então deve-se criar uma interface transversal para cada operação.

$\mathrm{Na}$ especificação da interface, também deve-se mostrar os tipos que compõem os componentes e os tipos de dados usados pelo componente, como t ipoDado. Além disso, deve-se mostrar as interfaces e operações requeridas, tal como INeg que possui a operação opNeg1 (y) e opNeg2 ( ) . Adicionalmente, são mostradas as operações da interface IComp1.

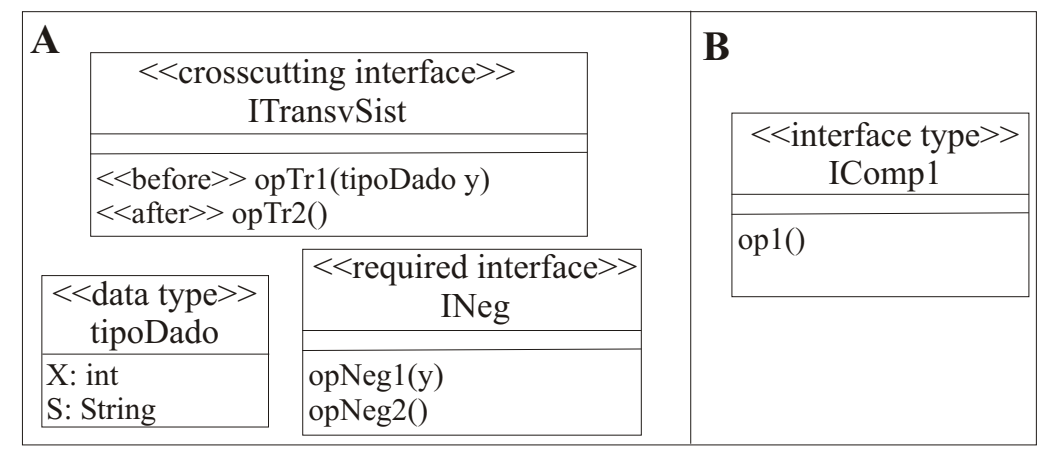

Figura 4.51: Especificação da interface de um componente transversal

Os artefatos apresentados nas Figura 4.50 e 4.51 mostram a estrutura do componente, a qual deve ser acompanhada de descrições textuais das funcionalidades do componente, das responsabilidades de cada operação, suas prés- e pós-condições, etc. Além disso, é necessário que seja mostrado o comportamento do componente, tanto na execução das operações de sua interface quanto na sua interação com os componentes por ele entrecortados. A seguir, na Figura 4.52 é mostrado o comportamento da operação op $\operatorname{Tr} 1$ () da interface ITransvSist por meio de um diagrama de colaboração, em que também é possível identificar as operações das interfaces requeridas.

Tendo sido mostrado o comportamento da operação opTrl () e tendo sido identificadas as operações das interfaces requeridas pelo componente transversal, é necessário que seja mostrado como os componentes transversais de sistema interagem com os componentes entrecortados. Isso pode ser mostrado por diagramas de interação, como o diagrama de colaboração da UML, por exemplo. 


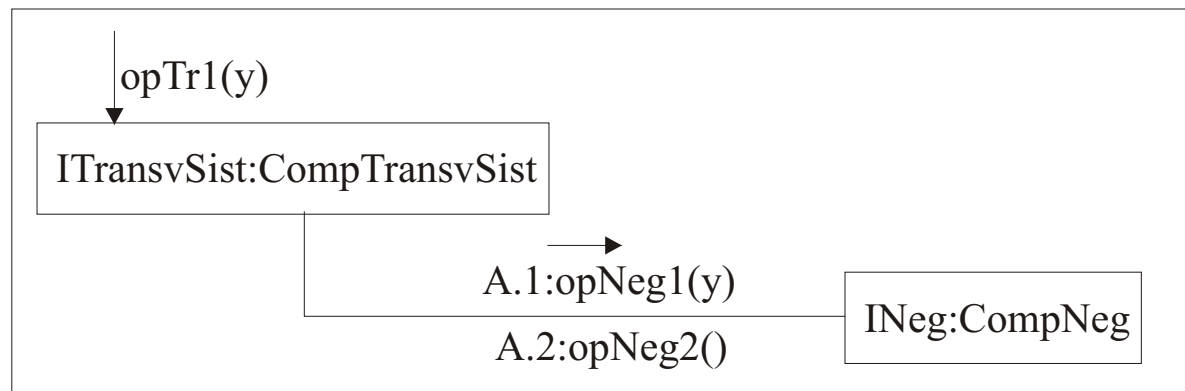

Figura 4.52: Comportamento de uma das operações de um componente transversal

O diagrama que mostra a interação entre os componentes transversais e os componentes entrecortados deve conter a representação de todos os tipos de adendos implementados pelo componente transversal para que o usuário do componente possa selecionar quais adendos deseja utilizar. Na Figura 4.53 é apresentado um diagrama de colaboração que mostra a forma como os componentes são entrecortados pelo componente transversal de sistema e, em particular, pelas operações op $\operatorname{Tr} 1$ (y) e opTr2 ( ) . O componente transversal implementa o adendo anterior (before) para a operação op Tr1 (y) e o adendo posterior (after) para a operação opTr2 ( ), como mostrado na especificação da interface na Figura 4.51.

Observa-se que todas as vezes que uma operação entrecortada da interface IComp1 de CompBase1 é chamada e, no caso, op1 (), o componente Comptransvist entrecorta CompBase1 e executa antes (before) de op1 ( ) a operação op Tr1 (y). Em seguida a operação do_op1 ( ), que representa a operação op1 () original, é executada. Depois da execução de do_op1 (), um novo entrecorte é feito em CompBase1 e a operação opTr2 ( ) é executada.

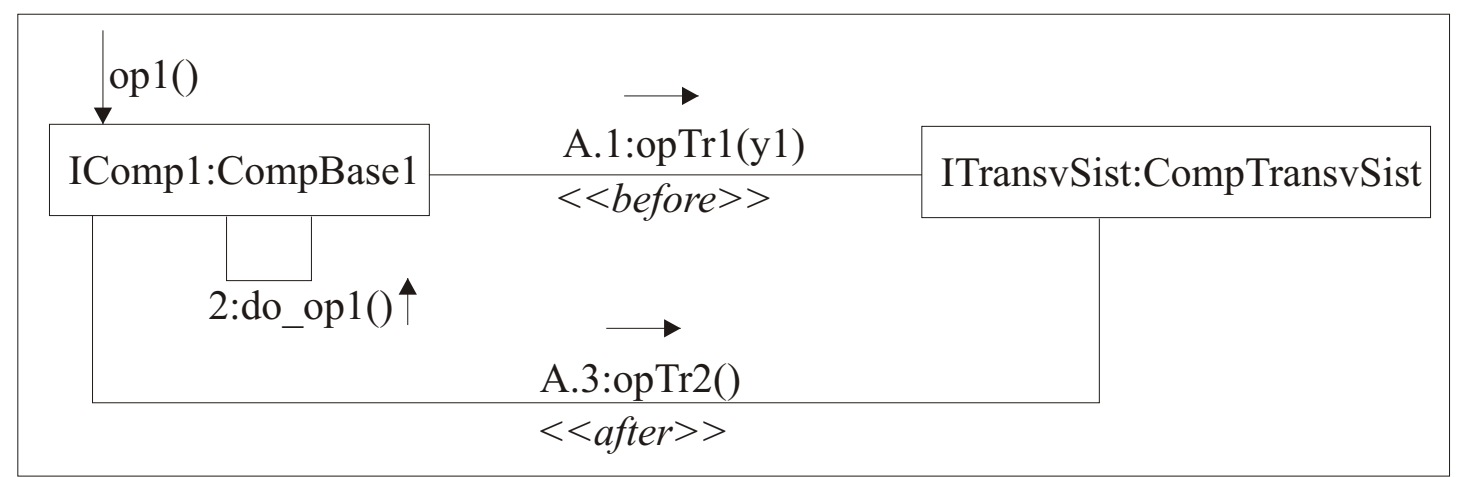

Figura 4.53: Comportamento de entrecorte de um componente transversal

Os artefatos da documentação dos componentes transversais apresentados anteriormente permitem que sejam conhecidas quais são as interfaces oferecidas e requeridas pelos componentes, bem como as operações de suas interfaces transversais; pode-se saber o comportamento das operações e como as operações dos componentes são entrecortadas, bem como os tipos de adendos utilizados pelo componente. Esse conhecimento é o suficiente para que os componentes transver- 
sais possam ser analisados e seja decidido se o componente satisfaz os requisitos necessários para ser usado em uma determinada aplicação.

Nota-se que na documentação não há a identificação das operações entrecortadas pelo componente, pois o componente deve ser construído de forma genérica e independente de contexto, de forma a determinar os pontos de junção a serem entrecortados só no momento da composição dos componentes na etapa de Montagem do sistema.

Para melhor ilustrar a documentação de um componente transversal, é apresentada a documentação do componente GerRegistroop do Sistema de Reservas de Hotel. Na Figura 4.54 é apresentada a especificação do componente GerRegi st roop, em que são mostradas suas interfaces oferecidas e requeridas.

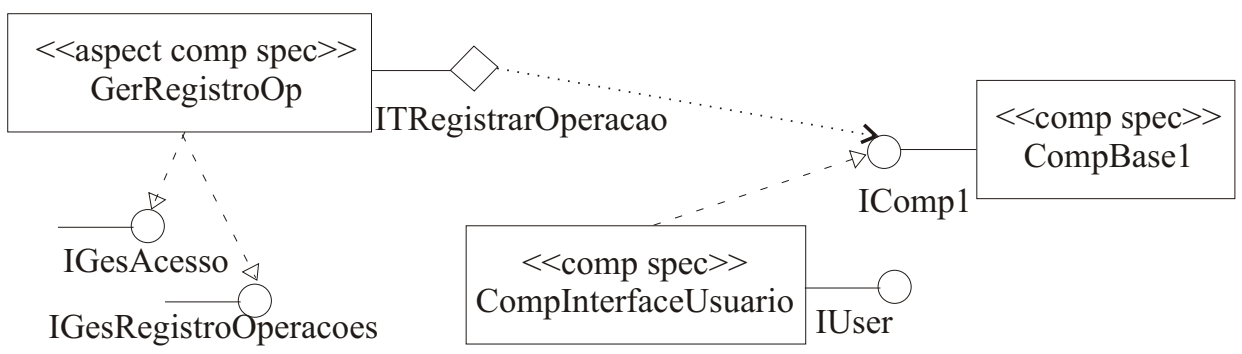

Figura 4.54: Especificação do componente transversal GerRegistroOp

O componente transversal de sistema GerRegist roOp oferece a interface ITRegistrarOperacao e requer as interfaces IGesAcesso e IGesRegistroop, que são interfaces de componentes transversais de negócio. A interface ITRegistrarOperacao possui apenas uma operação, como pode ser visto na especificação da interface mostrada na Figura 4.55. A operação registraroperacaoExecutada (String op) pode entrecortar outros componentes por meio de dois tipos de adendos: anterior ou posterior, como especificado na interface. As operações requeridas de IGesAcesso e IGesRegistrooperacao são mostradas na figura apresentada (required interface).
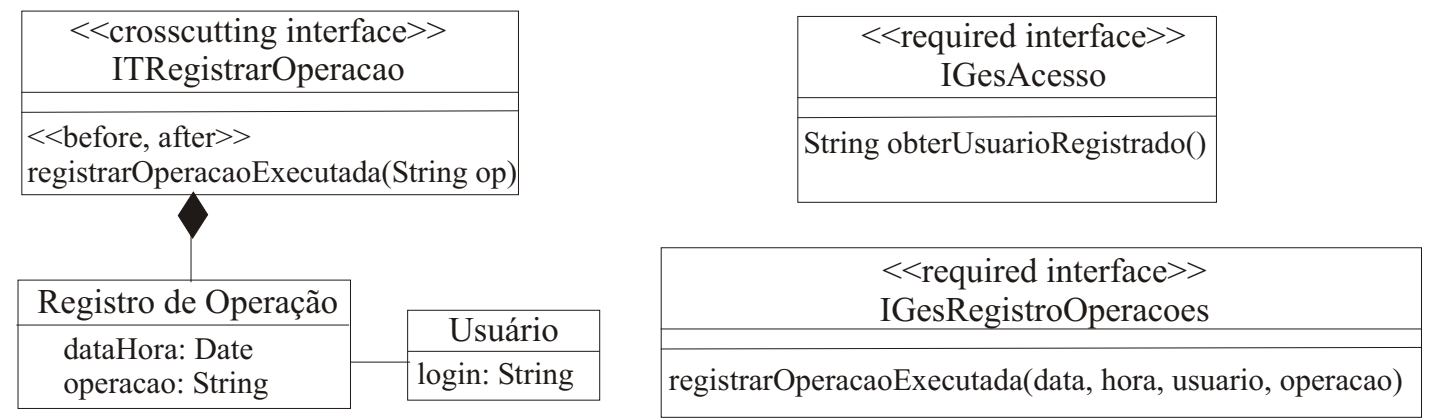

Figura 4.55: Especificação da Interface ITRegistrarOperacao 
O diagrama de colaboração apresentado na Figura 4.56 mostra o comportamento da operação registrarOperacaoExecutada. Pode-se notar que quando a operação é chamada da interface ITRegistrarOperacao, o componente GerRegistroOp interage com outros componentes para executar a operação. A partir desse diagrama pode-se identificar quais operações são utilizadas das interfaces requeridas pelo componente.

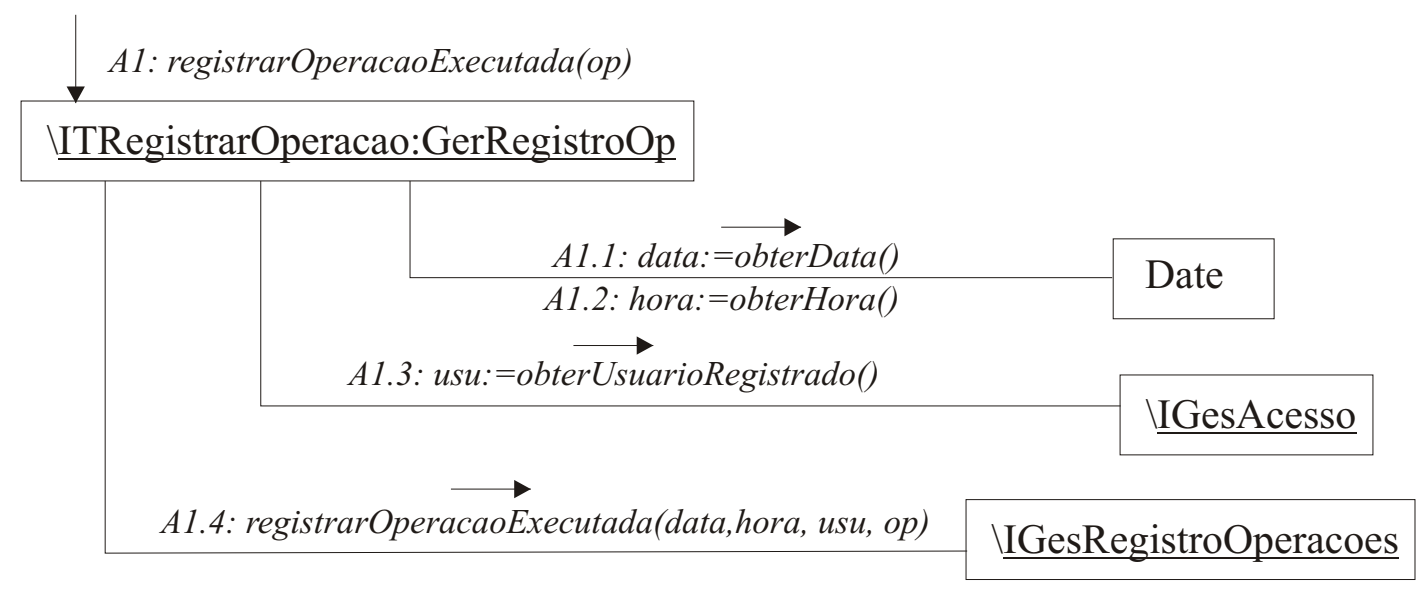

Figura 4.56: Comportamento da operação registrarOperacaoExecutada(op)

Na Figura 4.57 é apresentada a interação entre o componente GerRegistroOp e o componente entrecortado por ele. Nota-se que são representados alguns adendos possíveis de serem ativados. Quando uma operação entrecortada de CompBase é executada, o componente GerRegistroop entrecorta o componente e, antes de op ( ) a operação registraroperaçãoExecutada (op) é executada. Após a execução de do_op ( ), que representa a operação op ( ) originalmente invocada, há um novo entrecorte em que a operação registraroperacaoExecutada (op) de GerRegistroop é executada.

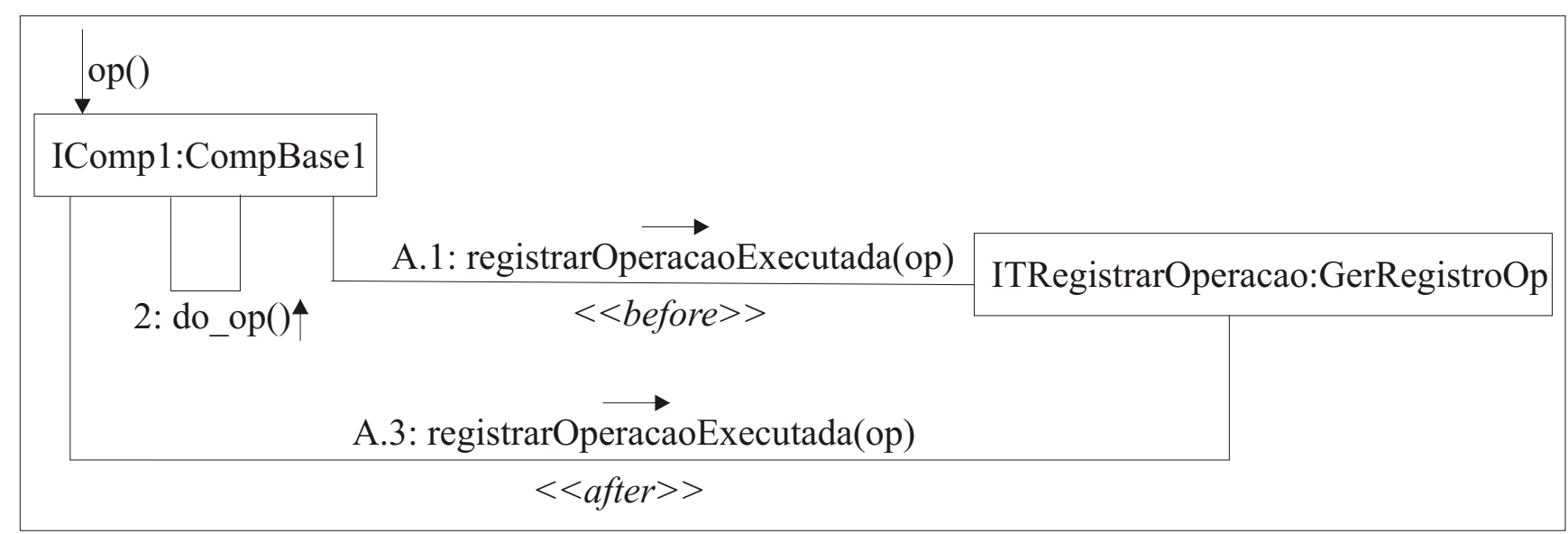

Figura 4.57: Comportamento do entrecorte do componente GerRegistroOp 
Por meio dos artefatos da documentação do componente GerRegistroop, é possível decidir se o componente satisfaz as necessidades para compor uma determinada aplicação, pois os artefatos mostram as interfaces oferecidas pelo componente, com suas operações e tipos de adendos implementados, bem como suas interfaces requeridas e operações. Além disso é mostrada uma descrição textual dos componentes com prés- e pós-condições das operações e o comportamento da interação entre o componente transversal e o componente identificado.

Se é decidido que o componente será reusado, basta compô-lo com a aplicação indicando, por meio de conectores, quais operações dos componentes devem ser entrecortadas e os tipos de adendos que se deseja ativar.

\subsection{Montagem}

A etapa de Montagem tem o objetivo de juntar os componentes e os recursos existentes, projetar e implementar a interface com o usuário com base nos casos de uso, e produzir uma aplicação completa e operacional. Neste trabalho é destacada a atividade de montagem entre os componentesbase e transversais do sistema.

Na etapa de Provisionamento, os componentes transversais foram obtidos, quer seja pelo reúso ou por implementação. A composição entre os componentes transversais de sistema e de negócio é feita de forma semelhante à composição entre os componentes-base de sistema e de negócio. Os componentes transversais de sistema possuem chamadas às operações dos componentes transversais de negócio que fornecem as operações para a gestão de dados necessários. Os componentes transversais de sistema possuem comportamentos entrecortantes implementados sem, contudo, haver a definição de quais operações de quais componentes-base devem ser entrecortados. Diante disso, surge a necessidade de implementar conectores que liguem os componentes transversais de sistema aos componentes-base entrecortados.

Os conectores são construções ou declarações que determinam os pontos em que os componentes são entrecortados pelos componentes transversais de sistema. Os conectores podem ser implementados de formas distintas, dependendo da linguagem de implementação dos componentes transversais de sistema. Com a linguagem JAsCO, por exemplo, existe a necessidade de construir um conector fornecido pela linguagem para ligar os componentes-base aos componentes transversais. Já em AspectJ, o conector é definido pela concretização dos conjuntos de ponto de junção abstratos do componente transversal por meio de extensão.

O mapeamento dos elementos de projeto para a implementação dos conectores é feita de forma direta e objetiva, independente da linguagem utilizada. Para isso, deve-se analisar as arquiteturas que contém componentes-base e transversais e identificar os pontos de junção a partir do relacionamento entre eles. Na Figura 4.58 são apresentadas duas situações genéricas em que um componente transversal entrecorta um componente-base. Na primeira (parte A), o componente transversal Comptransvist entrecorta todas as operações de CompBase, pois não há notas 


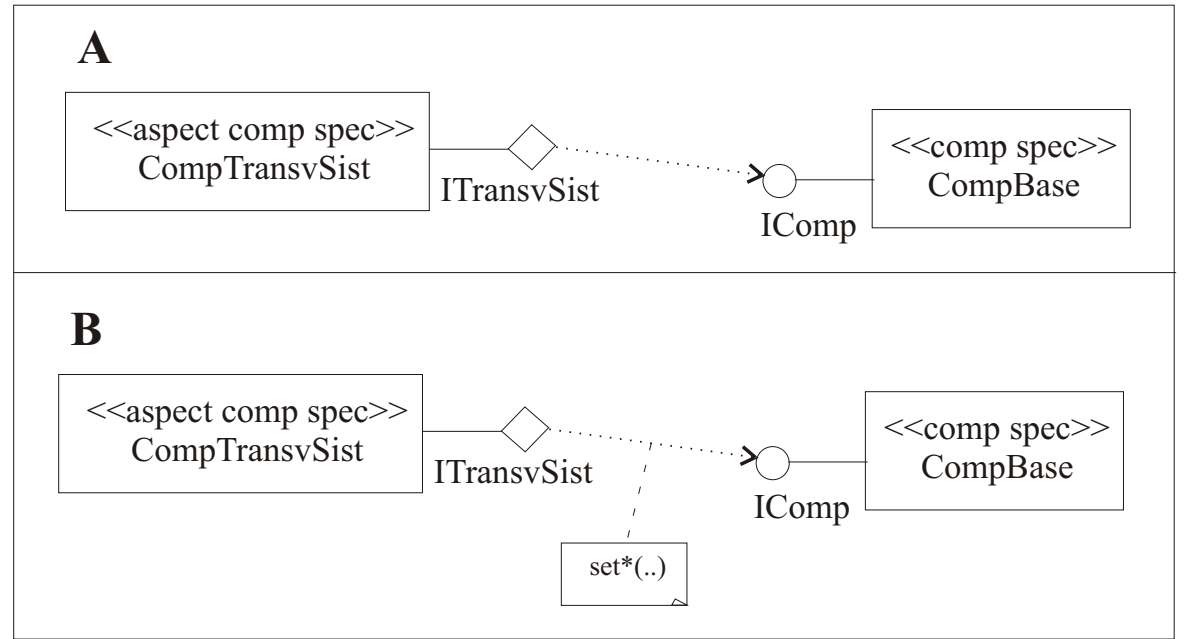

Figura 4.58: Cenários genéricos de entrecorte

indicando restrição das operações entrecortadas. Na segunda (parte B), o componente transversal CompTransvSist entrecorta apenas as operações que começam com set de CompBase.

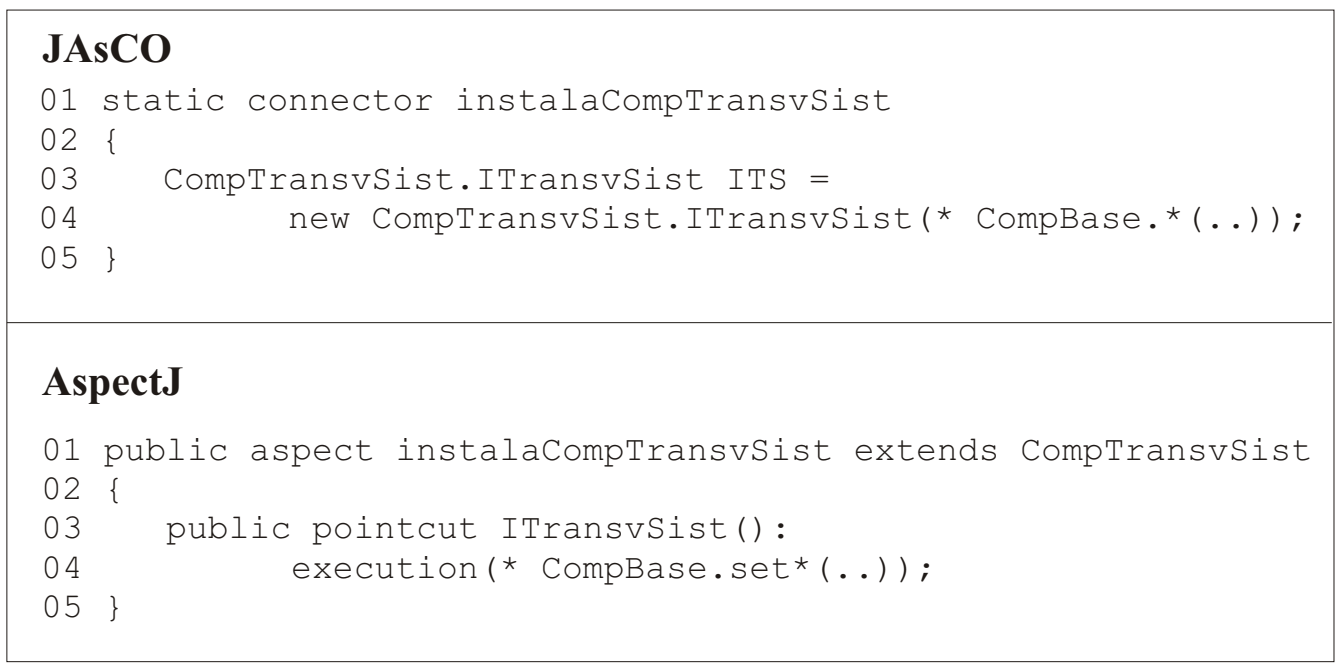

Figura 4.59: Implementação de Conectores na linguagem JAsCO e AspectJ

$\mathrm{Na}$ implementação dos conectores, faz-se o mapeamento direto dos pontos de junção identificados pela Figura 4.58 para o código do conector. Na primeira parte da Figura 4.59 é apresentada a implementação do conector na linguagem JAsCO para a situação A da Figura 4.58. O conector tem o nome de instalaCompTransvSist e o gancho ITransvSist é instanciado tendo como parâmetros os métodos concretos a serem entrecortados pelo componente transversal Comptransvist. Como no diagrama de componentes não havia restrições de operações a serem entrecortadas, é definido no conector que todas as operações do componente CompBase são entrecortadas. 
Na segunda parte da Figura 4.59 é apresentada a implementação de um conector na linguagem AspectJ para a situação B da Figura 4.58. O conector é implementado como um aspecto que concretiza o conjunto de ponto de junção abstrato que tem o nome da interface (ITransvSist) do componente ComptransvSist. No caso desse conector, o conjunto de ponto de junção é concretizado com todas as operações de CompBa se que começam com set.

Para melhor ilustrar o mapeamento do projeto de componente para a implementação dos conectores, é apresentado na Figura 4.60 parte do diagrama de componentes em que o componente transversal GerRegi stroOp entrecorta o componente-base GerReserva. Nota-se que não há notas indicando restrição de operações entrecortadas e portanto todas as operações da interface IGerEntrada são entrecortadas por GerRegistroop.

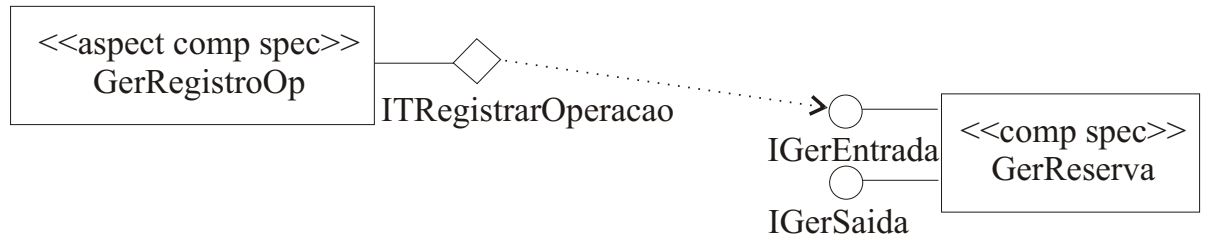

Figura 4.60: Diagrama parcial de componentes (GerReserva e GerRegistroOp)

Na Figura 4.61 é mostrado um conector implementado com a linguagem JAsCO, que liga o componente-base GerReserva (Figura 4.38) ao componente transversal GerRegistroOp e concretiza o método abstrato do construtor do gancho ITRegistraroperacao. O método abstrato do gancho é concretizado pelos métodos passados como parâmetro para o construtor do gancho e, neste caso, são todas as operações contidas na interface IGerEntrada. Para fazer isso, basta consultar a documentação das interfaces do sistema e verificar quais são as operações de IGerEntrada e especificá-las no conector.

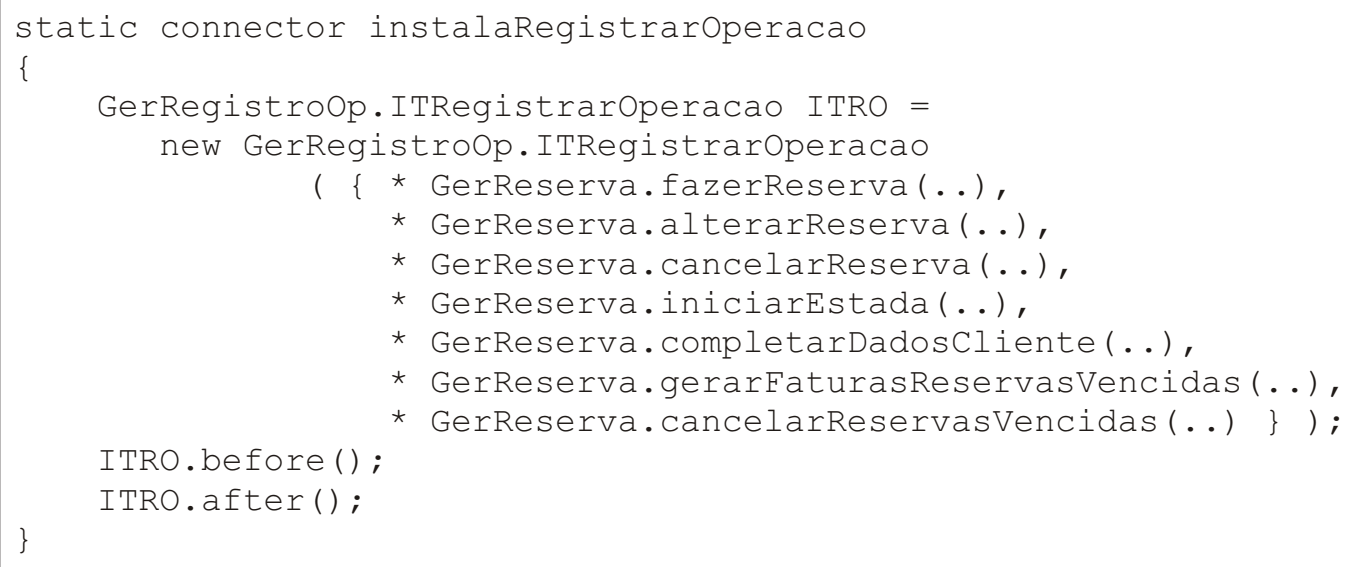

Figura 4.61: Código-fonte do conector que liga o componente GerReserva ao GerRegistroOp 
Já em AspectJ, os componentes transversais são ligados aos componentes-base por meio de aspectos concretos que estendem os aspectos abstratos e determinam os conjuntos de pontos de junção. $\mathrm{O}$ aspecto mostrado na Figura 4.62 estende o aspecto mostrado na Figura 4.40 e determina os pontos em que o componente GerReserva deve ser entrecortado pelo componente GerRegistroop, que são as operações de IGerEntrada.

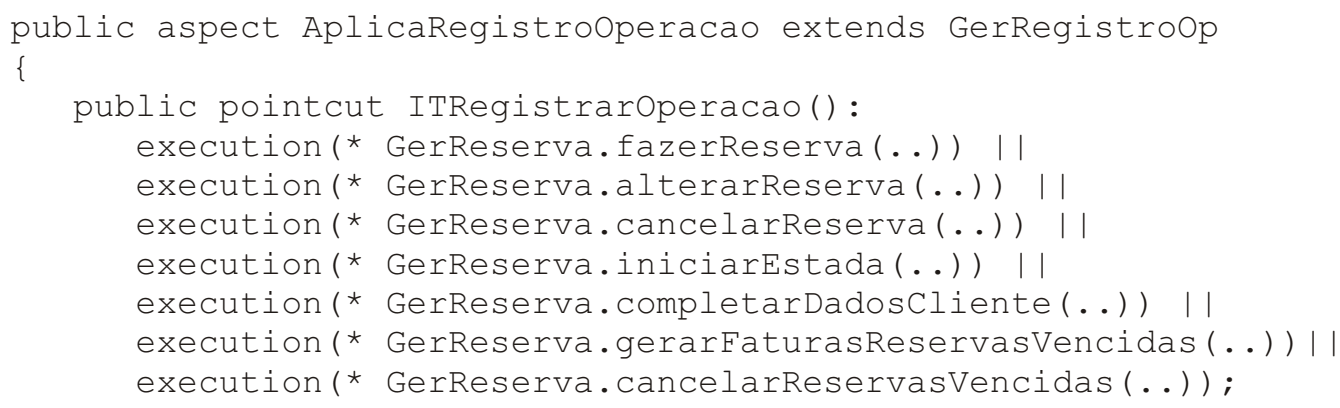

Figura 4.62: Aspecto concreto que determina os pontos em que GerReserva é entrecortado por GerRegistroOp

\subsection{Considerações Finais}

Neste capítulo, um método para o Desenvolvimento de Software Baseado em Componentes e Aspectos (DSBC/A) foi apresentado. O método é uma adaptação do método UML Componentes (Cheesman e Daniels, 2000) com a inclusão e alteração de etapas, atividades e artefatos para considerar aspectos no desenvolvimento. A UML é utilizada com algumas modificações para construir os artefatos de projeto dos componentes transversais.

A utilização do método para o DSBC/A direciona o projeto para que os interesses transversais do sistema sejam representados e implementados por componentes transversais. Além disso, o projeto é feito para que os componentes transversais não quebrem o encapsulamento dos outros componentes e entrecortem apenas as operações das interfaces dos componentes.

Além da utilização do método para o projeto de sistemas com componentes e aspectos, foi mostrado o mapeamento entre os elementos do projeto realizado e a implementação na linguagem JAsCO e AspectJ. Adicionalmente, foi mostrada uma estratégia de generalização e documentação de componentes transversais para que possam ser reusados em outras aplicações.

Apesar de terem sido usadas apenas as linguagens JAsCO e AspectJ na implementação, o método não é dependente de nenhuma linguagem específica. Seria possível, por exemplo, implementar o sistema com a linguagem FuseJ, que não possui construções como os componentes transversais e define o entrecorte por meio dos conectores. O mapeamento é simples, pois no projeto os interesses transversais estão em componentes separados e podem ser implementados como 
componentes regulares em FuseJ. As interações aspectuais (entrecorte) também estão especificadas no projeto e são mapeadas para os conectores da linguagem FuseJ definirem as composições aspectuais entre os componentes-base e os que implementam os interesses transversais. 


\section{Uso e Avaliação Comparativa do Método Proposto}

\subsection{Considerações Iniciais}

No capítulo anterior foi apresentado em detalhes o método para o DSBCA ilustrado por um Sistema de Reservas de Hotel com componentes e aspectos. Para avaliar o método proposto, foi realizado o projeto de um Sistema de Locação de Carros (SLC) pela Web e em seguida uma experiência de reúso de componentes transversais foi realizada. Um requisito não-funcional foi introduzido nas especificações do SLC e identificou-se que ele poderia ser implementado por um componente transversal. Esse componente transversal foi reusado do Sistema de Reservas de Hotel, pois o componente havia sido generalizado e documentado, o que permitiu seu reúso efetivo.

Além de utilizar o SLC para uma experiência de reúso, esse sistema foi escolhido para se fazer uma avaliação comparativa entre a solução descrita no trabalho de Sass (2003) e pela solução produzida pelo uso do método DSBC/A. Para fazer essa avaliação comparativa foi preparado um plano baseado nas recomendações de Kitchenham et al. (1995); Basili et al. (1986) para melhor apoiar a condução dos trabalhos.

Este capítulo está organizado da seguinte forma. Na Seção 5.2 é apresentada uma descrição sucinta do SLC e a arquitetura produzida com o método DSBC. A especificação completa do sistema e do projeto pode ser encontrada na dissertação de mestrado de Sass (2003). Na Seção 5.3 é apresentado o projeto do SLC com o método DSBC/A, mas somente com os artefatos mais importantes. A especificação completa do sistema pode ser vista no Apêndice B deste trabalho. $\mathrm{Na}$ Seção 5.4 é apresentada a experiência de reúso de um componente transversal. Na Seção 5.5 é 
apresentada a comparação entre o projeto do SLC com o uso do método UML Components e com o uso do método para o DSBC/A. Por fim, na Seção 5.6, as considerações finais são apresentadas.

\subsection{Projeto do Sistema de Locação de Carros(SLC) pelo método DSBC}

O Sistema de Locação de Carros (SLC) é um sistema construído para a Web cujo único produto comercializado são carros. Os clientes podem ter acesso aos tipos de automóveis disponíveis para locação por meio de serviços de busca e navegação do site. Os tipos de automóveis desejados podem ser selecionados e colocados em um carrinho de reservas com especificação de data de reserva. Quando a reserva é confirmada, o automóvel do tipo especificado fica disponível para ser retirado na loja real (física) na data especificada na reserva. O documento de especificação original, extraído da dissertação de mestrado de Sass (2003), é reproduzido no Apêndice B deste trabalho.

A arquitetura de componentes para o SLC foi desenvolvida por Sass (2003) em sua dissertação de mestrado, combinando o uso do método UML Components (Cheesman e Daniels, 2000) e padrões de uma arquitetura de sistema para Web (Alencar et al., 2002). A arquitetura produzida pode ser vista na Figura 5.1. As operações das interfaces dos componentes apresentados na Figura 5.1 podem ser vistas na Tabela 5.1. Na tabela, as operações de inclusão, alteração, consulta e remoção são representadas pelas colunas I, A, C, R e um X representa que a interface oferece essas operações.

Na Figura 1, os componentes cinza representam os componentes específicos do negócio e para os quais não havia correspondentes nos padrões de arquitetura WbIS (Alencar et al., 2002); o componente com dois asteriscos $(* *)$ representa um componente externo ao desenvolvimento do sistema, ou seja, será adquirido de terceiros; e os componentes de cor branca representam os componentes da arquitetura WbIS.

É importante notar que a arquitetura apresentada possui componentes com características somente de componente de sistema e de negócio, e componentes que possuem características dos dois tipos de componentes, ou seja, implementam as regras de negócio do sistema e ao mesmo tempo fazem a gestão de dados, como, por exemplo, o componente Invoice. Na análise da arquitetura apresentada, os componentes com essa característica híbrida foram considerados como componentes de sistema.

Os componentes de negócio que compõem a arquitetura do SLC são três ao todo, os quais são responsáveis por gerir os dados utilizados pelos componentes de sistema. Pode-se perceber, pela arquitetura apresentada, que os componentes de negócio Car, Customer e RentContract são utilizados pelos componentes de sistema.

Os componentes de sistema da arquitetura do SLC são oito ao todo. Na arquitetura, os componentes de sistemas podem ser identificados pelo fato de possuir interfaces oferecidas que não são 


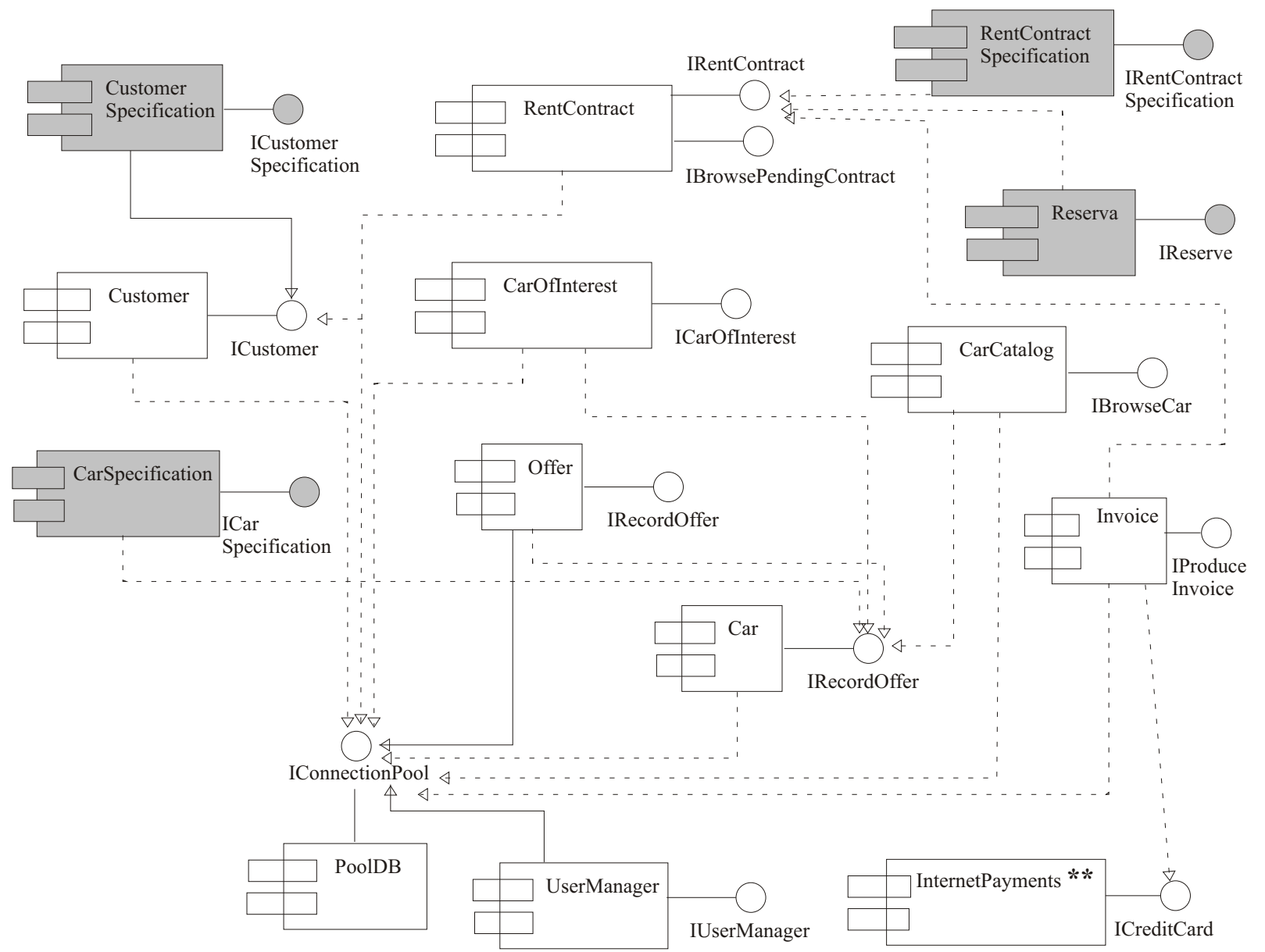

Figura 5.1: Arquitetura do Sistema de Locação de Carros produzido com o uso do método UML Componentes (Sass, 2003)

usadas por nenhum outro componente da arquitetura. Esses componentes são usados pelos componentes da camada de interface com o usuário que não estão representados na arquitetura. Por exemplo, o componente CarCatalog oferece a interface IBrowseCar que é utilizada quando um usuário deseja consultar os carros disponíveis para locação, em que o usuário solicita a consulta na camada de usuário, que delega a função para IBrowseCar pesquisar as informações necessárias no componente de negócio Car.

Apesar do componente UserManager não ser usado explicitamente por nenhum outro componente na arquitetura, ele não é um componente de sistema comum, pois é um componente de autenticação que possui características relacionadas aos interesses transversais do sistema. Os componentes da arquitetura não mencionados são os componentes de persistência (P○OlDB) e o de pagamento pela Internet (InternetPayments), que é externo ao desenvolvimento do sistema. 


\begin{tabular}{|c|c|c|c|c|c|}
\hline Interfaces & Operações & I & A & C & R \\
\hline ICar & updateSituationProduct()/ getSituationProduct() & $\mathrm{X}$ & $\mathrm{X}$ & $\mathrm{X}$ & $\mathrm{X}$ \\
\hline ICarSpecification & & $\mathrm{X}$ & $\mathrm{X}$ & $\mathrm{X}$ & $\mathrm{X}$ \\
\hline ICustomer & validateCustomer() & $\mathrm{X}$ & $\mathrm{X}$ & $\mathrm{X}$ & $\mathrm{X}$ \\
\hline ICstomerSpecification & & $\mathrm{X}$ & $\mathrm{X}$ & $\mathrm{X}$ & $\mathrm{X}$ \\
\hline IReserve & & $\mathrm{X}$ & $\mathrm{X}$ & $\mathrm{X}$ & $\mathrm{X}$ \\
\hline IRentContract & $\begin{array}{c}\text { excludeItemCustomerTrans() } \\
\text { calculateValueCustomerTrans() } \\
\text { insertItemsCustomerTrans() } \\
\text { getPendingItemsCustomer() } \\
\text { getPendingCustomerTrans() }\end{array}$ & $\mathrm{X}$ & $\mathrm{X}$ & $\mathrm{X}$ & $\mathrm{X}$ \\
\hline $\begin{array}{c}\text { calculateValue() } \\
\text { emitInvoice() }\end{array}$ & $\mathrm{X}$ & $\mathrm{X}$ & $\mathrm{X}$ & $\mathrm{X}$ \\
\hline IRentContractSpecification & getPendingTransCustomer() & $\mathrm{X}$ & $\mathrm{X}$ & & \\
\hline IProduceInvoice & validateUser() & $\mathrm{X}$ & $\mathrm{X}$ & $\mathrm{X}$ & \\
\hline IBrowsePendingRentContract & & $\mathrm{X}$ & $\mathrm{X}$ & $\mathrm{X}$ & $\mathrm{X}$ \\
\hline IUserManager & & $\mathrm{X}$ & $\mathrm{X}$ & & $\mathrm{X}$ \\
\hline IRecordOffer & & & & $\mathrm{X}$ & \\
\hline ICarOfInterest & & & \\
\hline IBrowseCar & & & \\
\hline
\end{tabular}

Tabela 5.1: Interfaces e Operações dos Componentes do SLC

\subsection{Projeto do Sistema de Locação de Carros(SLC) pelo método DSBC/A}

A seguir são mostrados alguns artefatos do projeto do SLC com o uso do método para o DSBC/A. Explicações e informações referente aos requisitos do sistema são apresentadas ao longo do texto, juntamente com os artefatos. A documentação completa desse projeto encontra-se em um documento de trabalho (Eler e Masiero, 2006a). O diagrama de casos de uso funcional do SLC é apresentado na Figura 5.2. Os atores do sistema são o cliente, que interage com o sistema pela Web para realizar a reserva do tipo de automóvel desejado, o gerente, responsável pelo gerenciamento do sistema, disponibilização de carros e cadastro de promoções, e o atendente, responsável pelos serviços de locação efetiva dos automóveis na loja real (física) da locadora de automóveis.

A seguir, na Figura 5.3 é apresentado o diagrama de casos de uso do SLC contendo os casos de uso funcionais integrados com o caso de uso não-funcional de Controle de Acesso. Os casos de uso não-funcionais de Autenticação de Usuário e Persistência não são mostrados por questões de legibilidade, assim como alguns casos de uso funcionais não relacionados ao caso de uso de Controle de Acesso e o ator Atendente.

Após identificar os casos de uso funcionais e não-funcionais do sistema e descrevê-los, o modelo conceitual funcional do sistema foi construído, como pode ser visto na Figura 5.4. No Modelo, pode-se observar que o recurso comercializado pela loja de locação de carros são os carros. Os carros possuem tipos que podem ser reservados pelos clientes. Nas reservas pela Web, os clientes 


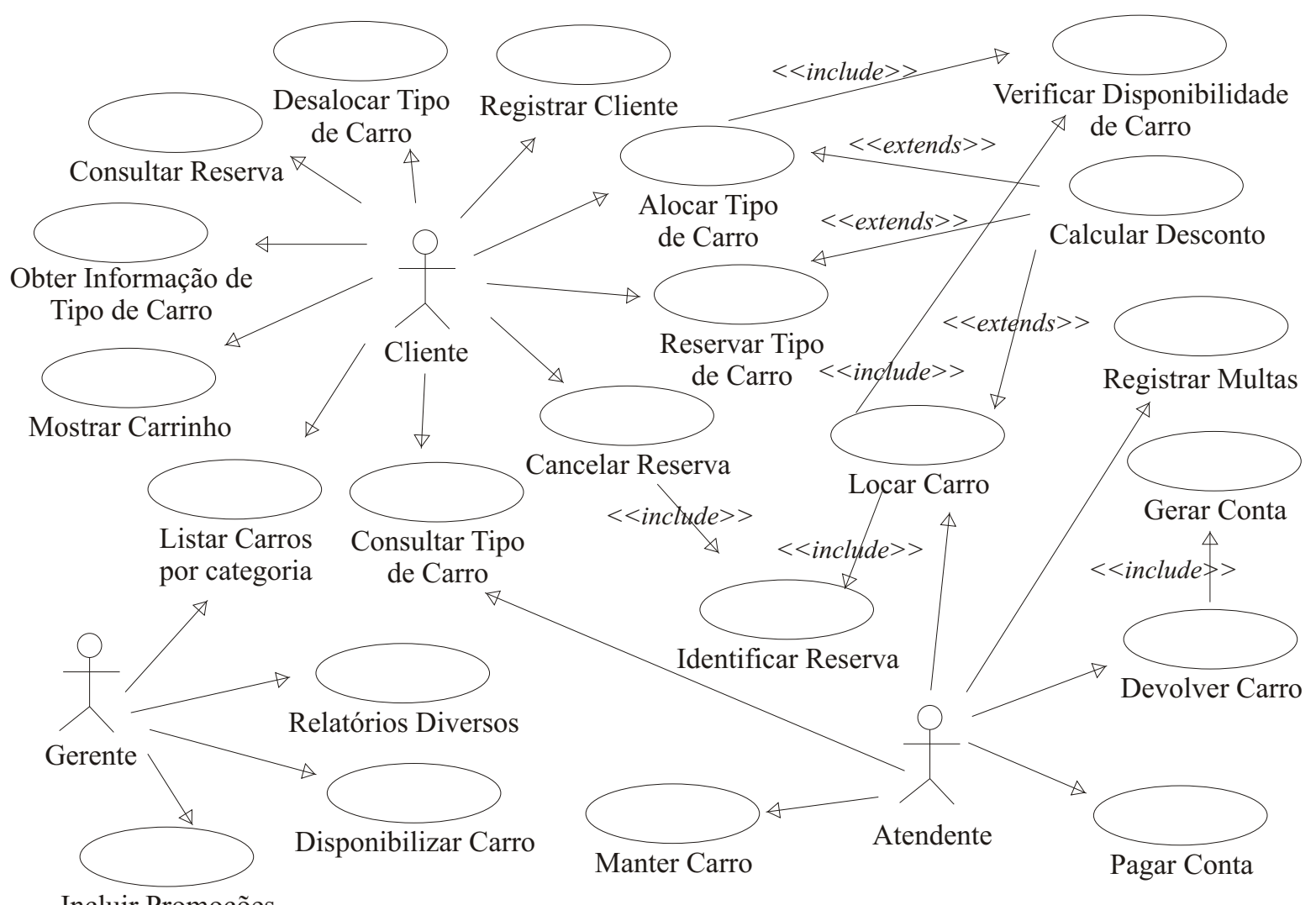

Incluir Promoções

Figura 5.2: Diagrama de Casos de Uso Funcional do SLC

selecionam e inserem os tipos de carros desejados em um carrinho de reservas e quando a reserva é confirmada uma lista de itens de reserva é gerada. Os tipos de carros são divididos em categorias que podem ocasionalmente ter promoções de locação. Na loja, o cliente pode retirar carros dos tipos reservados, gerando uma locação e itens de locação para cada carro locado. Na devolução do carro o cliente deve pagar a conta que contém o valor da locação e as multas que porventura podem ter sido aplicadas enquanto utilizava o carro locado.

Além do modelo conceitual funcional, alguns requisitos não-funcionais do sistema geraram representações no modelo conceitual. Na Figura 5.5 é apresentado o modelo conceitual nãofuncional do SLC. O modelo é referente aos requisitos não-funcionais de autenticação e controle de acesso. O sistema deve gerenciar usuários do sistema (autenticação) e controlar o acesso às operações do sistema. Para isso, cada usuário desempenha um papel no sistema e cada papel possui operações a que tem direito de executar.

Após realizar a Análise de Requisitos, iniciou-se a fase de Especificação dos Componentes do sistema. Primeiramente foram identificadas as interfaces de sistema com base nos casos de uso funcionais e as interfaces de negócio com base no modelo conceitual de negócios.

As interfaces de sistema identificadas foram reorganizadas para que o número de interfaces de sistema não fosse tão grande e operações relacionadas a um mesmo interesse ficassem na mesma interface. Decidiu-se que as interfaces de sistema seriam implementadas em dois componentes 


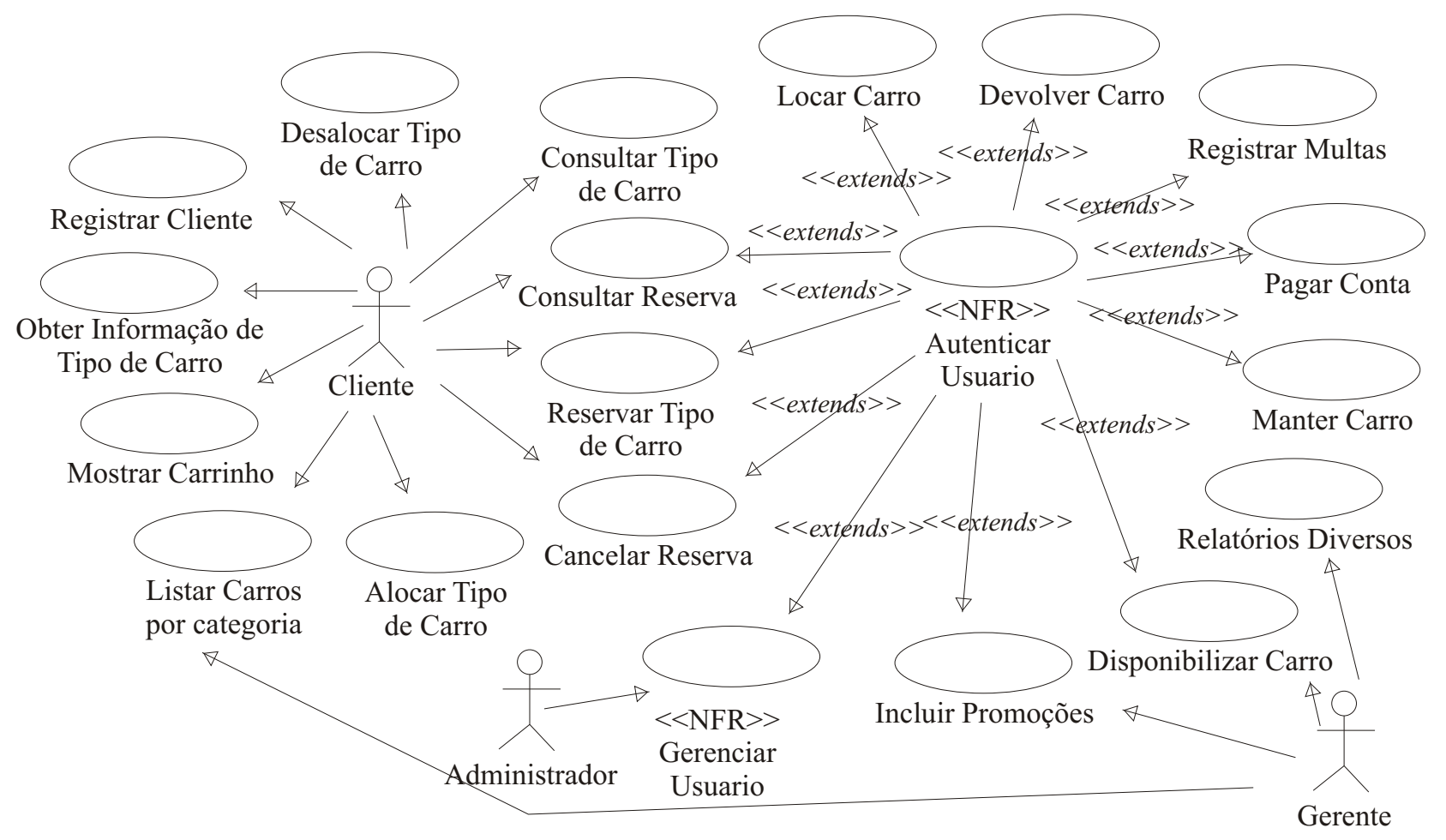

Figura 5.3: Diagrama de Casos de Uso Funcional e Não-Funcional (Controlar Acesso)

de sistema: um componente responsável por gerenciar as operações do sistema disponíveis pela interface pública na Web e um componente responsável por gerenciar as operações da loja real (física) da locadora de carros.

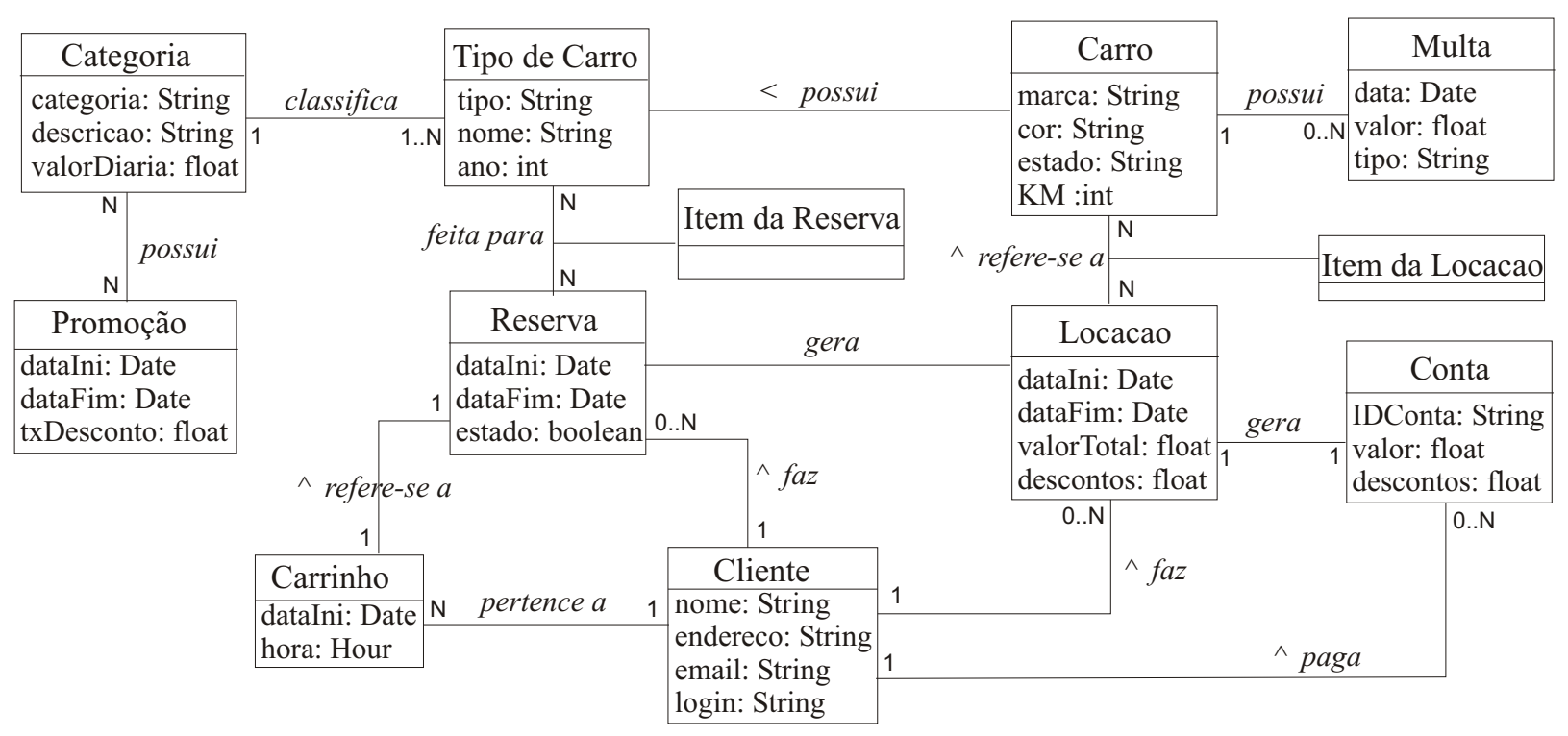

Figura 5.4: Modelo Conceitual Funcional do SLC 


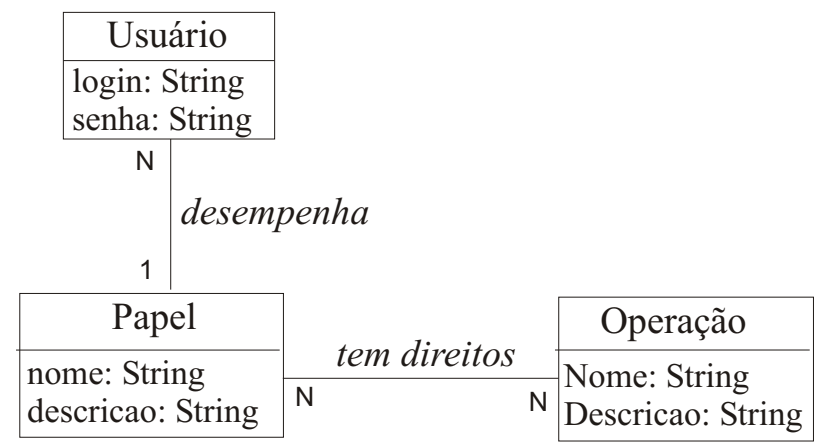

Figura 5.5: Modelo Conceitual Não-Funcional do SLC

A arquitetura de componentes-base do SLC pode ser vista na Figura 5.6. Nota-se, pela arquitetura, que os componentes-base de negócio identificados foram os componentes Gercliente, GerCarro, GerConta, Sistema de Multas e GerCarrinho. Os componentes de sistema são GerLocadoraAdm e GerLocadoraPub, responsáveis pelas operações que gerenciam a locadora de carros na loja física e pela Web, respectivamente.

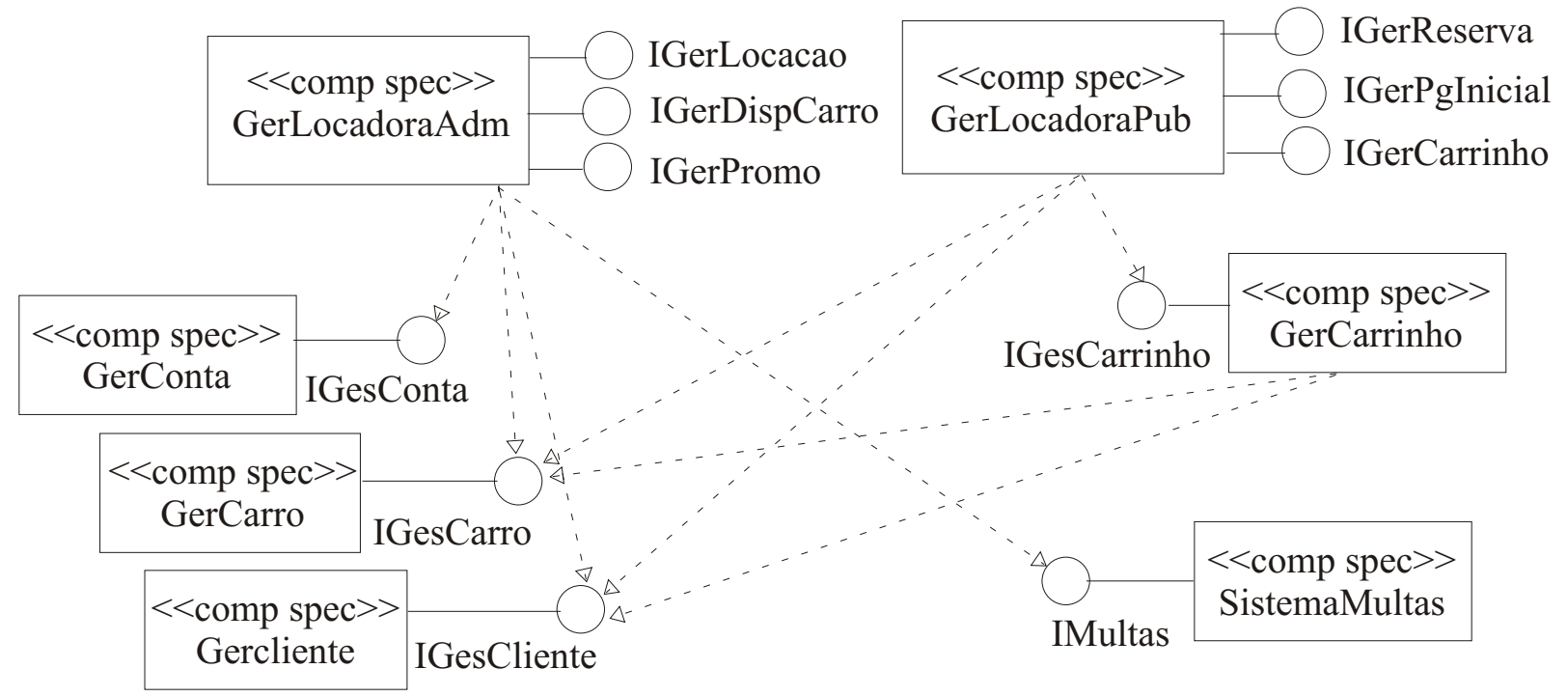

Figura 5.6: Arquitetura de componentes-base do SLC

As interfaces oferecidas pelo componente de sistema GerLocadoraPub possuem operações que podem ser acessadas pelos clientes do sistema pela Web. Essas operações implementam as funções de pesquisa, alocação e reserva de tipos de carros. Já as interfaces oferecidas pelo componente de sistema GerLocadoraAdm possuem operações que só podem ser acessadas por funcionários da loja, pois as operações oferecidas implementam funções para a locação efetiva dos carros, manutenção, promoções e pagamentos. As operações das interfaces dos componentes de sistema do SLC podem ser vistas na Figura 5.7. As operações das interfaces dos componentes de 
negócio não são apresentadas pois são basicamente operações de gestão de dados, como inclusão, alteração, remoção e atualização.

\begin{tabular}{|c|c|}
\hline GerLocadoraPub & \multirow{2}{*}{$\begin{array}{l}\text { GerLocadoraAdm } \\
\qquad \begin{array}{c|}<<\text { interface }>> \\
\text { IGerPromo } \\
\end{array}\end{array}$} \\
\hline $\begin{array}{l}<<\text { interface }>> \\
\text { JGerPoInicial }\end{array}$ & \\
\hline \multirow{3}{*}{$\begin{array}{l}\text { obterInformacaoTipoCarro() } \\
\text { consultarTipoCarro() } \\
\text { obterCategorias() } \\
\text { obterTiposCarro() } \\
\text { criarCliente() }\end{array}$} & incluirPromocao() \\
\hline & $\begin{array}{l}<<\text { interface }>> \\
\text { IGerDispCarro }\end{array}$ \\
\hline & \multirow{2}{*}{\begin{tabular}{|l|} 
obterCarro() \\
disponibilizarCarro()
\end{tabular}} \\
\hline $\begin{array}{c}<<\text { interface }>> \\
\text { IGerCarrinho }\end{array}$ & \\
\hline \multirow[b]{2}{*}{$\begin{array}{l}\text { colocarNoCarrinho() } \\
\text { informarQuantidade() } \\
\text { informarData() } \\
\text { verificarDisponibilidadeCarro() } \\
\text { calcularValor() } \\
\text { calcularTXDesconto() } \\
\text { calcularValorTotal() } \\
\text { retirarDoCarrinho() } \\
\text { obterItensCarrinho() } \\
\text { obterInformacaoTipoCarro() }\end{array}$} & $\begin{array}{c}<<\text { interface }>> \\
\text { IGerLocacao }\end{array}$ \\
\hline & \multirow{3}{*}{$\begin{array}{l}\text { obterReserva() } \\
\text { obterItensReserva() } \\
\text { obterInformacaoTipoCarro() } \\
\text { locarCarro() } \\
\text { calcularValor() } \\
\text { calcularTXDesconto() } \\
\text { calcularValorTotal() } \\
\text { selecionarItem() } \\
\text { informarQuantidade() } \\
\text { calcularValorTotalLocacao() } \\
\text { obterLocacao() } \\
\text { obterItensLocados() } \\
\text { devolverCarros() } \\
\text { gerarConta() } \\
\text { obterConta() } \\
\text { pagarConta() } \\
\text { obterMultasCarro() } \\
\text { registrarMultasCarro() }\end{array}$} \\
\hline $\begin{array}{c}<<\text { interface }>> \\
\text { IGerReserva }\end{array}$ & \\
\hline $\begin{array}{l}\text { fazerReserva() } \\
\text { obterReserva() } \\
\text { obterItensReserva() } \\
\text { obterReservasCliente() } \\
\text { cancelarReserva() }\end{array}$ & \\
\hline
\end{tabular}

Figura 5.7: Operações das interfaces de sistema do SLC

Após identificar as interfaces de sistema e de negócio e montar a arquitetura inicial de componentesbase do sistema, foi especificada a interação entre os componentes de sistema e os componentes de negócio. Cada operação das interfaces de sistema foi modelada com o uso de diagramas de colaboração da UML, as operações das interfaces de sistema foram especificadas e as operações das interfaces de negócio identificadas e especificadas.

$\mathrm{Na}$ etapa de identificação dos componentes transversais de sistema, foi analisada a lista de casos de uso transversais obtidas da etapa de Análise de Requisitos. Cada candidato foi verificado de acordo com os critérios estabelecidos no processo e decidiu-se que os casos de uso que deveriam gerar interfaces transversais são: calcular desconto, autenticar usuário, controlar acessoepersistir dados, que geraram as interfaces ITCalcularDesconto, ITAutenticarUsuario, ITControlarAcessoe ITPersistirDados, respectivamente. As interfaces de negócio responsáveis pela gestão de dados utilizados pelos componentes transversais de sistema foram identificadas a partir do modelo conceitual não-funcional do sistema. 
A arquitetura parcial de componentes-base do SLC com o componente transversal de sistema GerControleAces so é apresentada na Figura 5.8. Pode-se notar, pela figura, que GerControleAcesso entrecorta todas as operações das interfaces IGerLocadoraAdm e de IGerReserva, dos componentes GerLocadoraAdm e GerLocadoraPub, respectivamente.

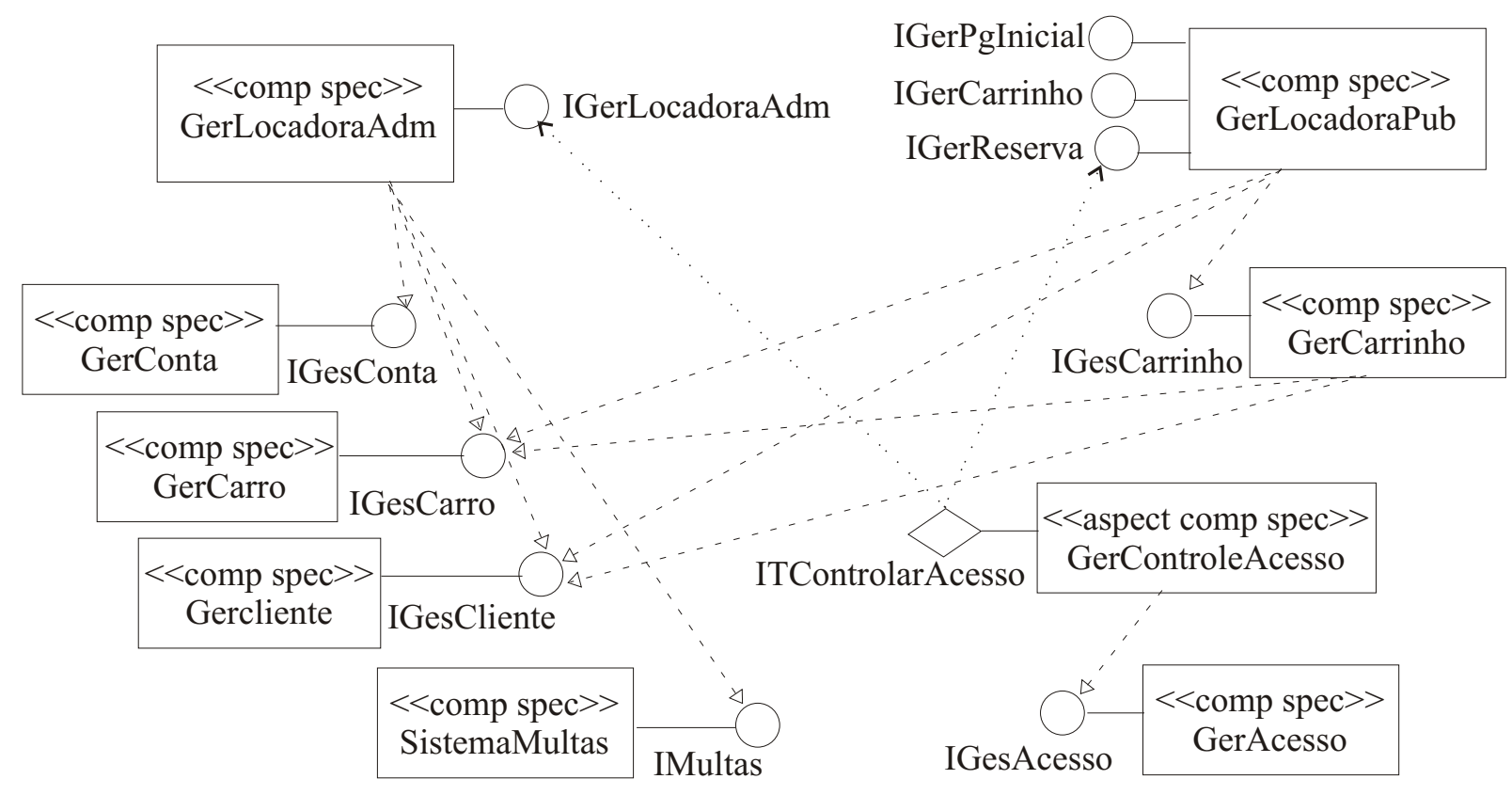

Figura 5.8: Arquitetura de componentes-base e transversais (GerControleAcesso)

Depois de montar a arquitetura de componentes do sistema contendo os componentes-base e transversais, foi modelada a interação entre os componentes-base para cada operação de sistema, a interação entre os componentes transversais para cada operação transversal e o entrecorte do componente transversal no componente-base. Com isso, foi possível identificar as operações das interfaces de negócio dos componentes-base e dos transversais e especificar as assinaturas das operações de sistema e de negócio.

Com as operações das interfaces do sistema identificadas e com as assinaturas especificadas, foi realizada a especificação de cada interface, tanto dos componentes-base quanto dos transversais, especificando os modelos de informação da interface, tipos utilizados e compartilhados, bem como os detalhes específicos de entrecorte para as interfaces transversais de sistema.

Com as interfaces especificadas e com as arquiteturas de componentes montadas, foi possível comparar o resultado do projeto do SLC com o método para o DSBC/A com o projeto baseado em componentes do SLC, produzido por Sass (2003) com o uso do método UML Componentes. A comparação entre os resultados dos projetos pode ser visto na seção 5.5 .

Um dos objetivos da utilização do método para o DSBC/A no desenvolvimento do Sistema de Locação de Carros foi avaliar a adequação do método para o desenvolvimento com componentes e aspectos. Nesse sentido o método cumpriu seu objetivo, pois seguindo as atividades e recomen- 
dações descritas no método foi possível construir, a partir de seu documento de requisitos, o SLC com componentes e aspectos que implementam todos os interesses previstos nos requisitos.

Outro objetivo alcançado foi o refinamento do método, pois foi observado durante o desenvolvimento que algumas atividades não estavam descritas em detalhes suficientes para que a atividade fosse executada de forma adequada. Diante disso, após o desenvolvimento as atividades do método foram descritas em maiores detalhes, juntamente com a notação para produzir os artefatos requeridos nas atividades.

\subsection{Reúso de Componentes Transversais}

Nesta seção é relatada a experiência de reúso de um componente transversal. O componente transversal reusado foi o componente responsável pelo registro de execução de operações de um sistema $(\log )$. Esse componente foi implementado inicialmente para o Sistema de Reservas de Hotel e após ter sido generalizado (ver seção 4.6.2) foi armazenado em um repositório de componentes juntamente com sua documentação (ver seção 4.6.3). Em seguida são mostradas as atividades ocorridas para o reúso do componente.

\subsubsection{Mudança nos requisitos do Sistema de Locação de Carros}

Para realizar a experiência de reúso de um componente transversal, foi criado um cenário de modificação dos requisitos do SLC em que um requisito não-funcional foi introduzido. O novo requisito é relativo à necessidade de se registrar a execução de algumas operações do sistema e sua descrição é apresentada a seguir:

"As operações de reserva, locação, registro de multas e pagamento das contas dos clientes devem ser registradas após sua execução. Deve-se registrar o usuário do sistema que executou a operação, bem como o horário e a operação executada."

Diante desse novo requisito, ao invés de se implementar um componente com o interesse de registro de operações, procurou-se por componentes transversais já implementados e documentados que atendessem às novas necessidades surgidas.

Como no Sistema de Reservas de Hotel foi implementado um componente de registro de operações, o qual foi generalizado e documentado, optou-se por analisar a documentação do componente e verificar se o componente existente atendia à necessidade da aplicação de Locação de Carros. A análise da documentação do componente de registro de operação é relatada a seguir.

\subsubsection{Análise da documentação do componente GerRegistroOp}

O componente de registro de operações generalizado recebeu o nome de GerRegistroOp. Podese notar pela especificação do componente (ver seção de documentação, Figura 4.53) que ele ofe- 
rece a interface transversal ITRegistraroperacao e requer as interfaces IGesAcesso e IGesRegistroOperacao.

A interface ITRegistrarOperacao possui a operação registraroperacaoExecutada (ver Figura 4.54 e 4.55) que, pela sua descrição, registra a operação executada com o usuário corrente e a data de execução. Uma das interfaces requeridas, IGesAcesso, possui a operação obterUsuarioRegistrado requerida, o que já existe no Sistema de Locação de Carros. Já a interface requerida IGesRegistroOperacao pode ser reusada do repositório de componentes, pois é o componente de negócio que faz a gestão de dados para o componente GerRegistroOp.

Nota-se também, pela documentação do componente GerReg i st roOp (ver Figura 4.54, 4.55 e 4.57), que a operação registrarOperacaoExecutada pode entrecortar as operações de outros componentes de duas maneiras: antes ou depois da execução da operação invocada. Isso faz com que neste quesito o componente GerRegistroop também satisfaça ao novo requisito do Sistema de Locação de Carros, pois no requisito é descrita a necessidade de se registrar algumas operação após sua execução.

Após verificar a descrição da operação registrarOperacaoExecutada, suas prés- e pós-condições e o comportamento da operação descrito pelo diagrama de colaboração da operação (ver Figura 4.56 e 4.57), concluiu-se que o componente atendia à necessidade da aplicação.

\subsubsection{Reúso no projeto}

Como o componente GerRegistroop atendia perfeitamente ao novo requisito que surgiu, decidiu-se reusar o componente. No projeto da aplicação, alguns artefatos da documentação de GerRegistroop foram utilizados como gabaritos (templates), como a arquitetura do componente que mostra o relacionamento com um componente-base e os diagramas de colaboração de entrecorte que mostram como o componente interage com os componentes entrecortados.

Na Figura 5.6 pode ser vista a arquitetura de componentes-base do Sistema de Locação de Carros. Na Figura 5.9 pode ser vista a arquitetura do Sistema de Locação de Carros com o componente transversal GerRegistroOp. Nota-se, pela Figura 5.9, que o componente GerRegistroOp entrecorta somente a operação fazerReserva (. . ) da interface IGerReserva do componente GerLocadoraPub e as operações registrarMultas (..), pagarConta(..) e locarCarro (. .) da interface IGerLocacao do componente GerLocadoraAdm, como especificado no novo requisito.

O comportamento da operação registrarOperacaoExecutada de ITRegistrarOperacao é conhecido pela documentação do componente GerRegistroOp, entretanto não se sabe o comportamento do entrecorte quando se der a composição do componente GerRegi st roOp com os componentes-base. Pela documentação do sistema pode-se ter um exemplo genérico para modelar a interação dos componentes no entrecorte.

Na Figura 5.10 a seguir é mostrado o comportamento do entrecorte de GerRegistroop nas operações entrecortadas (no caso, fazerReserva(.. )) da interface IGerReserva. 


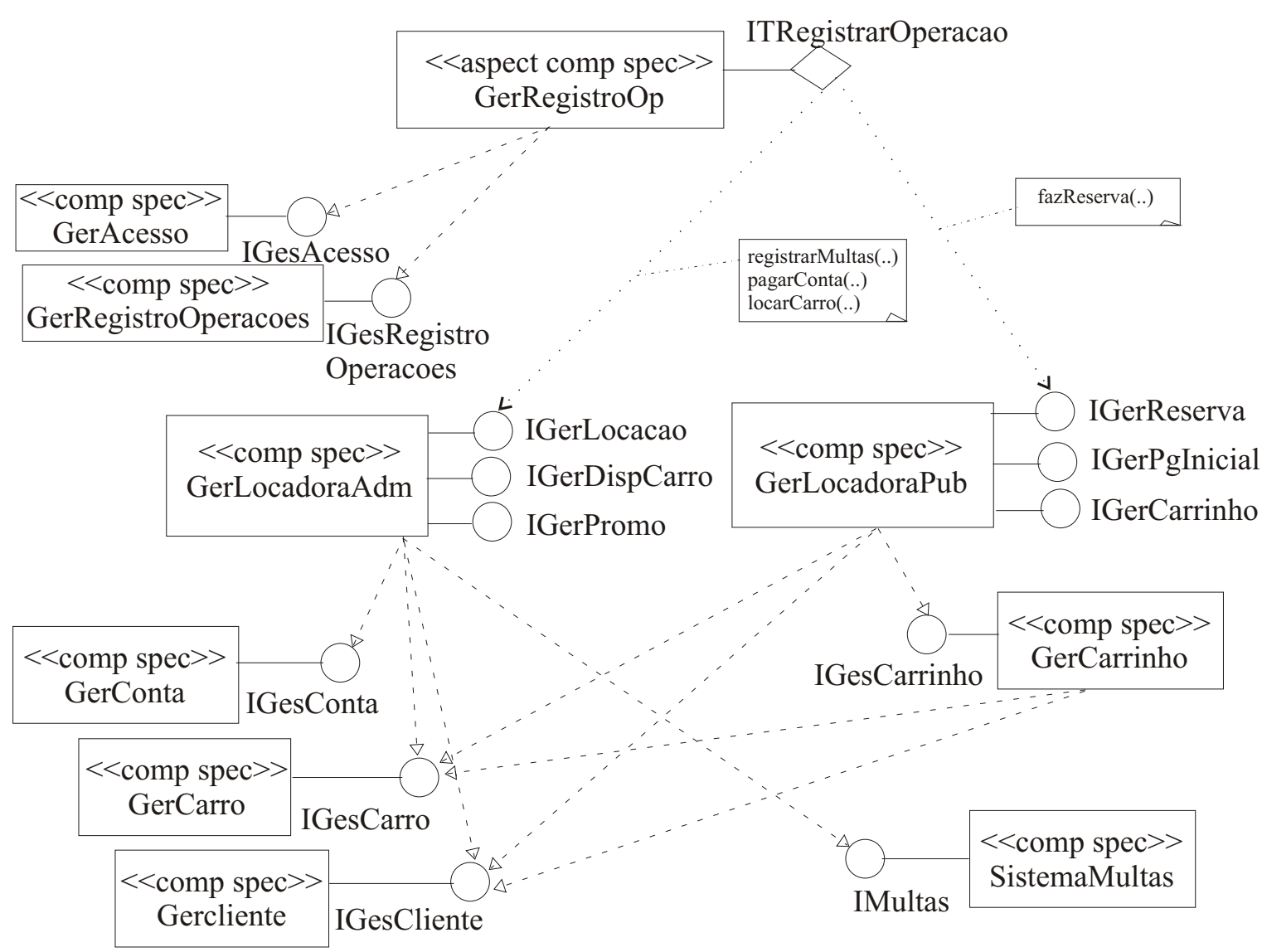

Figura 5.9: Arquitetura de Componentes do Sistema de Locação de Carros com o componente transversal GerRegistroOp

Nota-se que a diferença em relação ao modelo mostrado na documentação do componente (seção 4.6.3) é a substituição de Interface por IGerReserva e o componente CompBase por GerLocadoraPub, semelhantemente ao uso de templates proposto por Clarke e Baniassad (2005). Além disso, somente é modelado o entrecorte do tipo posterior (after), pois é o que satisfaz o novo requisito de registro de operações.

\subsubsection{Reúso de Código}

Após o projeto do Sistema de Locação de Carros ter evoluído com o componente transversal GerRegistroop, a implementação é feita de forma simples, pois não há a necessidade de implementação do componente. O que falta é a construção do conector que liga o componente transversal GerRegistroOp aos componentes-base do sistema. A implementação de um conector para o componente implementado na linguagem JAsCO é apresentado na Figura 5.11. Nota-se, pela Figura, que somente as operações previstas no projeto e no requisito são entrecortadas e somente o adendo posterior (after) é ativado (comando ITRO. after ()). 


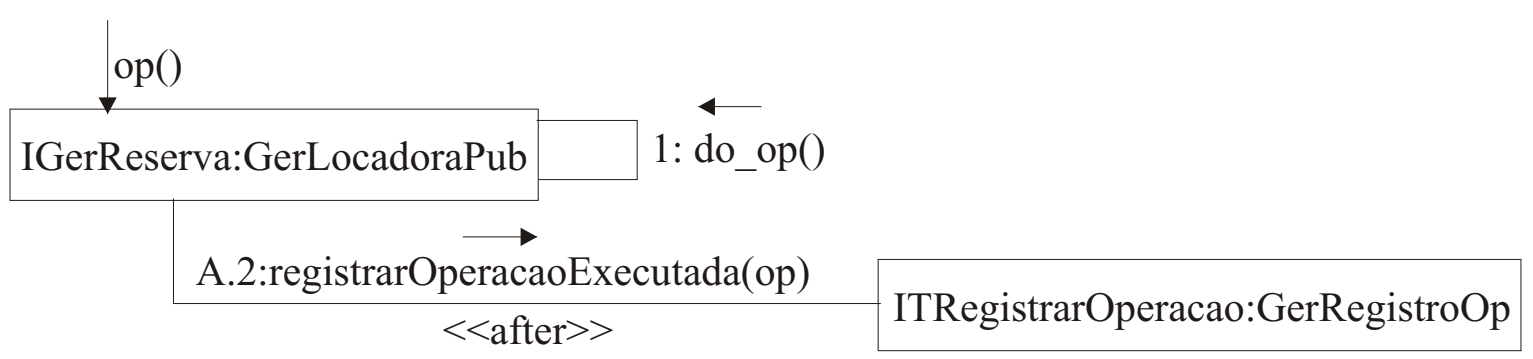

Figura 5.10: Interação entre GerRegistroOp e GerLocadoraPub (entrecorte)

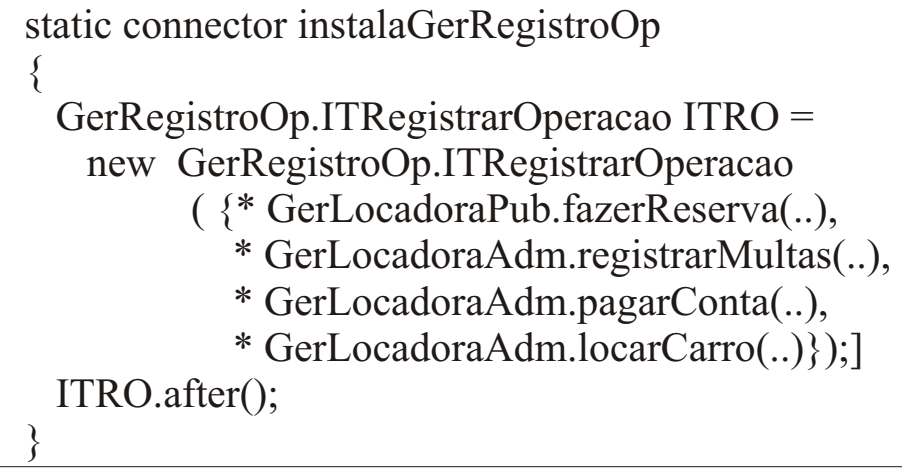

Figura 5.11: Conector em JAsCO para GerRegistroOp

Na Figura 5.12 é apresentado um conector para um componente implementado com a linguagem AspectJ. Nota-se, pela Figura, que apenas o conjunto de ponto de junção ITRegistrarOperacaoAfter relativo ao adendo posterior (after) foi estendido com as operações que devem ser entrecortadas pelo sistema.

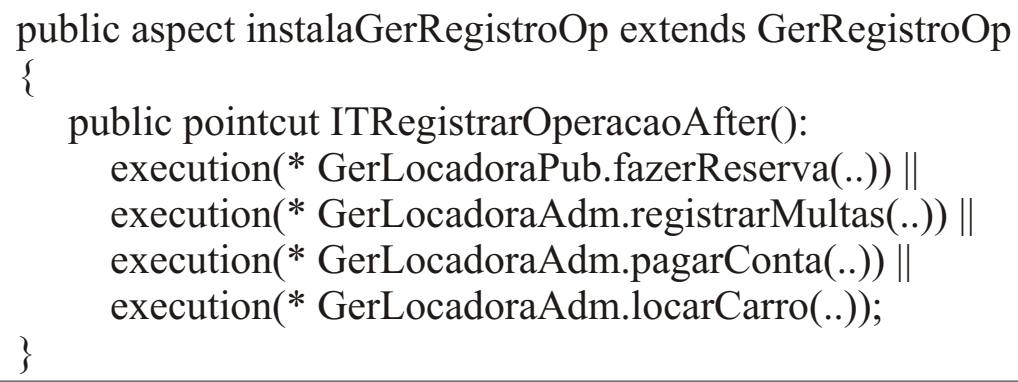

Figura 5.12: Conector em AspectJ para GerRegistroOp 


\subsubsection{Avaliação desta experiência de reúso}

A experiência de reúso de componentes transversais agregou valor ao método proposto e gerou a necessidade de implementar os componentes transversais de forma generalizada e também documentá-los para permitir o reúso em outras aplicações. Com isso, acrescentou-se no método a atividade de generalização e documentação dos componentes transversais (seções 4.6.2 e 4.6.3).

$\mathrm{Na}$ generalização dos componentes transversais, percebeu-se a necessidade de implementar os tipos de entrecorte possíveis que uma operação transversal pode realizar, ficando a cargo do desenvolvedor selecionar quais tipos de entrecortes deseja usar em sua aplicação específica. A estratégia de escolha do desenvolvedor está descrita na seção 4.6.2.

Após generalizar o componente, percebeu-se a necessidade de modificar a notação dos componentes generalizados em sua documentação. Sendo assim, as operações transversais das interfaces passaram a ter estereótipos com os tipos de entrecortes que podem ser utilizados, como pode ser visto na Figura 4.53. Além disso, percebeu-se que por vezes seria possível que interfaces transversais oferecessem mais de uma operação transversal e haver a necessidade de especificar quais pontos de junção cada operação entrecortaria. Como solução, decidiu-se que duas operações transversais podem estar na mesma interface somente se entrecortarem os mesmos conjuntos de ponto de junção, como explicado na seção 4.6 .3 e, neste caso, definir no diagrama de interação a ordem de precedência de sua atuação.

\subsection{Comparação entre o projeto DSBC/A e DSBC}

O segundo objetivo de ter escolhido o sistema de locação de carros foi poder fazer uma avaliação comparativa entre as duas soluções propostas pelos dois processos. Para tornar mais precisa essa comparação e eliminar qualquer possibilidade de contaminação, o autor desta dissertação não tomou contato com a solução de Sass (2003) antes de ter desenvolvido sua própria solução. Assim, o projeto DSBC/A foi única e exclusivamente baseado no documento de requisitos extraído do trabalho de Sass (2003) e apresentado no Apêndice B, com pequenas alterações de forma.

Além disso, foi feito um planejamento desse estudo de caso, com base nas recomendações de Kitchenham et al. (1995) para a condução de estudos de casos. Este planejamento é apresentado no Apêndice C. Embora esta avaliação comparativa não esteja sendo apresentada neste trabalho como um experimento formal do tipo estudo de caso, o planejamento realizado foi muito importante para melhorar a qualidade da avaliação e, conseqüentemente, para conseguir os resultados relatados nesta seção. A razão por não utilizar formalmente o planejamento foi ter sido percebido que a solução de Sass (2003) não fora projetada com base apenas no método UML Components, mas também baseado em uma arquitetura de sistemas para a Web (Alencar et al., 2002), o que dificultou a comparação e poderia apresentar distorções significativas. Optou-se, portanto, por uma comparação mais simples, sem levar em conta formalmente todas as hipóteses definidas no plano.

Os objetivos desse estudo de caso, conforme especificado pelo plano eram: 
1. Fazer uma segunda aplicação do processo DBSC/A proposto e verificar sua aplicabilidade e eventuais falhas, corrigindo-as e refinando o método. Estes resultados já foram relatados na seção 5.3.

2. Comparar a solução DSBC/A obtida com a solução DSBC de Sass (2003).

O projeto DSBC/A para o sistema de locação de carros e a avaliação comparativa foram realizados inteiramente pelo autor da dissertação, com a supervisão do orientador. No planejamento da avaliação, foram estabelecidas três hipóteses de trabalho: primeiro, esperava-se que o método para o DSBC/A identificasse explicitamente componentes transversais, que não são levados em consideração pelo método utilizado por Sass. Em segundo lugar, esperava-se que o processo DS$\mathrm{BC} / \mathrm{A}$ produzisse componentes menores e mais coesos e, terceiro, que uma maior quantidade de componentes transversais fosse identificada e especificada. Para a terceira hipótese, supôs-se que a comparação em relação a componentes transversais seria possível, considerando que no projeto de (Sass, 2003) os componentes transversais seriam identificáveis, mesmo que a chamada não se desse por entrecorte, mas por disparo de chamadas internas aos componentes que usam os componentes transversais.

A seguir é apresentada a avaliação comparativa organizada sob três ângulos. Primeiramente são feitos alguns comentários gerais e depois são analisados os resultados relativos às três hipóteses formuladas. Uma síntese da comparação, que embasa os comentários que são feitos a seguir é apresentada em três tabelas: 5.2 - componentes de negócio, 5.3 - componentes de sistema e 5.4 componentes transversais.

\subsubsection{Avaliação Geral}

As tabelas 5.2, 5.3 e 5.4 mostram que foi possível comparar os componentes e decidir quais eram equivalentes ou parcialmente equivalentes, apesar de terem nomes diferentes e de algumas decisões de projetos dificultarem a comparação. Isso ocorreu provavelmente porque Sass não seguiu apenas o método UML Components, mas também baseou a sua solução em uma proposta de arquitetura genérica de sistemas baseados na Web de Alencar et al. (2002). Entre as principais diferenças, notou-se que:

1. Gestão de dados. Alguns dados que deveriam ser geridos por componentes de negócios, de acordo com diretrizes do UML Components, foram separados em componentes diferentes, como é o caso, por exemplo, de Car e RentContract, que deveriam ser geridos pelo mesmo componente.

2. Escopo do sistema. Alguns requisitos do sistema, conforme definido no documento de requisitos, aparentemente não foram considerados na solução, ou não puderam ser identificados pelo autor desta dissertação. Este é o caso, por exemplo, do requisito de controle de acesso, não identificado na solução de Sass. O mesmo ocorreu com o componente Carrinho. 
3. Componentes de Sistema. Provavelmente por decisão de projeto, Sass pulverizou os componentes de sistema e produziu uma solução que possui praticamente uma interface por componente de sistema. A solução proposta nesta dissertação levou em conta a arquitetura de sistemas reais da Web, inclusive de empresas locadoras de carros (ver por exemplo www.localiza.com.br), que possuem uma interface pública na Web e um subsistema privado para uso de seus funcionários (intranet).

\begin{tabular}{|c|c|l|}
\hline DSBC/A & DSBC & Observações \\
\hline GerCliente & Customer & $\begin{array}{l}\text { As operações dos dois componentes são } \\
\text { praticamente as mesmas, com exceção da } \\
\text { operação validateCustomer(), cuja função } \\
\text { é autenticar o cliente. }\end{array}$ \\
\hline GerConta & Invoice & $\begin{array}{l}\text { As operações dos componentes são praticamente } \\
\text { iguais. Apesar de ser componente de sistema, } \\
\text { Invoice possui operações de gestão de dados. }\end{array}$ \\
\hline GerCarro & $\begin{array}{c}\text { Car } \\
\text { RentContract }\end{array}$ & $\begin{array}{l}\text { Car e RentContract são componentes de negócio } \\
\text { de DSBC que em DSBC/A são representados apenas } \\
\text { por GerCarro. Já CarOfInterest, é um componentes } \\
\text { de sistema e que possue operações de gestão de } \\
\text { dados que estão em GerCarro em DSBC/A. }\end{array}$ \\
\hline GerCarrinho & - & Este componente não aparece na arquitetura DSBC. \\
\hline
\end{tabular}

Tabela 5.2: Comparação entre os Componentes de Negócio da arquitetura DSBC/A e DSBC

\subsubsection{Tamanho dos componentes}

Considerando-se que a funcionalidade do sistema é a mesma para as duas soluções, pode-se inferir que se uma delas tem um número maior de componentes, estes serão, em média, menores. O termo "menor"está sendo usado aqui no sentido de que o componente tem menos funcionalidades e sua implementação exigirá menos linhas de código. Seria, portanto, mais coeso e com maior possibilidade de ser reusado. O raciocínio utilizado para a hipótese de um número menor de componentes na solução DSBC/A é que haveria um número maior de componentes transversais, funcionais e não funcionais, que estariam inseridos em componentes convencionais na solução de DSBC. Mas isso não se confirmou inteiramente, conforme análise apresentada na seção 5.5.3.

A análise do número de componentes nas duas soluções não é conclusiva e foi dificultada pela grande diferença entre os dois projetos, conforme comentado na seção 5.5.1. A contagem simples dos componentes revela que há 14 componentes na solução de Sass e 12 componentes na solução proposta nesta dissertação. Essa comparação é dificultada pelo fato de a solução DSBC/A ter apenas dois componentes de sistemas enquanto que a solução DSBC possui 8. Veja que na Tablela 3 usou-se o par componente mais interface para comparar os componentes de sistema. Em última análise, as operações contidas na interface, conforme mostrado na Figura 5.7, é que permitiram a 
comparação. Por outro lado, no caso dos componentes de negócio, há um componente (GerCarro) na solução DSBC/A que parece corresponder a 3 componentes na solução de Sass (Ver a Tabela 5.2).

\begin{tabular}{|c|c|c|}
\hline DSBC/A & DSBC & Observações \\
\hline $\begin{array}{l}\text { GerLocadoraAdm: } \\
\text { IGerDispCarro }\end{array}$ & $\begin{array}{l}\text { CarSpecification: } \\
\text { ICarSpecification }\end{array}$ & $\begin{array}{l}\text { A interface IGerDispCarro compreende funções } \\
\text { de disponibilização de carro, também } \\
\text { presente na interface ICarSpecification. }\end{array}$ \\
\hline $\begin{array}{l}\text { GerLocadoraAdm: } \\
\text { IGerPromo }\end{array}$ & $\begin{array}{l}\text { Offer: } \\
\text { IRecordOffer }\end{array}$ & $\begin{array}{l}\text { A interface IGerPromo compreende funções } \\
\text { de cadastro de promoção, assim como } \\
\text { a interface IRecordOffer. }\end{array}$ \\
\hline $\begin{array}{l}\text { GerLocadoraAdm: } \\
\text { IGerLocação }\end{array}$ & $\begin{array}{l}\text { RentContract: } \\
\text { IRentContract } \\
\text { IBrowsePendingContract } \\
\text { RentContractSpecification } \\
\text { IRentContractSpecification } \\
\text { Invoice: } \\
\text { IProduceInvoice }\end{array}$ & $\begin{array}{l}\text { IGerLocacao possui funções para realizar a locação } \\
\text { efetiva do carro, ou seja, quando o cliente retira } \\
\text { o carro da loja. Estas funções estão implementadas } \\
\text { nas interfaces relacionadas em DSBC/A. IGerLocacao } \\
\text { inclui localizar reserva, o que está implementado } \\
\text { em IBrowsePendingRentContract de RentContract. O } \\
\text { Valor da multa está inclusa no componente } \\
\text { RentContractSpecification, mas não o cadastro da } \\
\text { multa. Algumas operações de Conta estão no componente } \\
\text { IGerLocacao, porque na devolução do carro a conta já } \\
\text { é gerada e paga imediatamente - não é gerada uma fatura. }\end{array}$ \\
\hline $\begin{array}{l}\text { GerLocadoraPub: } \\
\text { IGerPgInicial }\end{array}$ & $\begin{array}{l}\text { CarCatalog: } \\
\text { IBrowseCar } \\
\text { CustomerSpecification: } \\
\text { ICustomerSpecification }\end{array}$ & $\begin{array}{l}\text { Em IGerPgInicial, existe a operação de consultar } \\
\text { carro, como em IBrowseCar de CarCatalog, e de } \\
\text { gerenciar clientes, como em ICustomerSpecification. }\end{array}$ \\
\hline $\begin{array}{l}\text { GerLocadoraPub: } \\
\text { IGerReserva }\end{array}$ & $\begin{array}{l}\text { Reserve: } \\
\text { IReserve }\end{array}$ & As operações de reserva são iguais. \\
\hline $\begin{array}{l}\text { GerLocadoraPub: } \\
\text { IGerCarrinho }\end{array}$ & - & $\begin{array}{l}\text { Esse componente não aparece na arquitetura } \\
\text { DSBC. }\end{array}$ \\
\hline- & $\begin{array}{l}\text { InternetPayments: } \\
\text { ICreditCard }\end{array}$ & $\begin{array}{l}\text { Não há correspondente na arquitetura DSBC/A. } \\
\text { Internet Payments é um componente externo ao } \\
\text { desenvolvimento do sistema. }\end{array}$ \\
\hline Sistema de Multas & - & $\begin{array}{l}\mathrm{Na} \text { arquitetura DSBC não aparece esse } \\
\text { componente externo ao desenvolvimento. }\end{array}$ \\
\hline
\end{tabular}

Tabela 5.3: Comparação entre os Componentes de Sistema da arquitetura DSBC/A e DSBC

\subsubsection{Componentes transversais}

Embora com diferentes abordagens, a comparação entre os dois projetos é mais interessante e reveladora quando se olham os componentes transversais. Primeiramente, em termos de contagem de componentes transversais, a solução de Sass identificou dois e a solução DSBC/A identificou e especificou 5, o que mostra a efetividade do método DSBC/A para os propósitos para o qual foi 
criado. A solução de Sass identificou e especificou dois componentes da arquitetura com características claramente transversais: PoolDB e UserManager (Ver Tabela 5.4). O primeiro gerencia o interesse transversal de persistência enquanto que o segundo cuida do interesse transversal de autenticação dos usuários. Ele também cuida da gestão dos dados necessários para realizar essa função, que no projeto DBSC/A fica separada como um componente transversal de sistema e um componente de negócio. Nota-se também que o interesse transversal funcional de desconto (GerDesconto) definido na solução DSBC/A, não foi identificado e projetado como um componente transversal na solução de Sass. De modo mais geral, não existe nenhum interesse transversal funcional na solução DSBC.

\begin{tabular}{|l|l|l|}
\hline DSBC/A & DSBC & Observações \\
\hline GerDesconto & - & $\begin{array}{l}\text { Em DSBC não aparece esse componente. } \\
\text { O cálculo do desconto parece ser feito } \\
\text { apenas pelas promoções cadastradas. }\end{array}$ \\
\hline GerControleAcesso & - & Em DSBC não aparece esse componente. \\
\hline GerAutenticacao & UserManager & $\begin{array}{l}\text { As implementações são correspondentes. } \\
\text { UserManager é responsável por autenticar } \\
\text { os usuários. Há uma operação de autenticação } \\
\text { também em Customer. }\end{array}$ \\
\hline GerPersistencia & PoolDB & $\begin{array}{l}\text { Os componentes são correspondentes. PoolDB } \\
\text { provavelmente é chamado pelos componentes } \\
\text { que precisam interagir com o banco de dados. } \\
\text { A implementação deve estar espalhada. }\end{array}$ \\
\hline GerAcesso & UserManager & $\begin{array}{l}\text { UserManager é responsável por armazenar } \\
\text { os dados dos usuários e realizar a autenticação, } \\
\text { enquanto GerAcesso é responsável por apenas } \\
\text { armazenar os dados dos usuários, papéis e operações. }\end{array}$ \\
\hline
\end{tabular}

Tabela 5.4: Comparação entre os Componentes Transversais da arquitetura DSBC/A e DSBC

Portanto, as conclusões a que se pode chegar deste estudo, com a ressalva de que não podem ser generalizadas para qualquer outro processo de desenvolvimento baseado em componentes e nem mesmo para outras aplicações que fossem modeladas com o método usado por Sass, mostram que:

1. O método DSBC de utilizado por Sass permite a identificação de componentes que implementam interesses transversais (como persiência, por exemplo).

2. O método DSBC/A encontrou um número maior de componentes transversais de do que o método utilizado por Sass para o sistema de locação de carros na Web. Em especial, Sass não identificou nenhum componente transversal funcional.

3. O método DSCB de Sass não leva em conta a separação de componentes de negócio e de sistema para os componentes transversais que identifica (mesmo que sua implementação não ocorre como componentes transversais). 
4. Nada foi concluído com relação à granularidade dos componentes identificados e especificados pelos dois métodos.

\subsection{Considerações Finais}

Neste capítulo foi apresentado o projeto do Sistema de Locação de Carros produzido com o uso do método UML Components por Sass (2003) e o projeto do mesmo sistema produzido com o uso do método para o DSBC/A proposto nesta dissertação.

A solução produzida com o uso dos dois métodos foi comparada de acordo com um plano efetuado que pode ser visto no Apêndice $\mathrm{C}$ deste trabalho. Além disso, foi mostrada uma experiência de reúso de um componente transversal. O componente foi implementado para o Sistema de Reservas de Hotel e foi reusado no Sistema de Locação de Carros.

A utilização do método para o DSBC/A no Sistema de Locação de Carros foi interessante pelo uso do método em um segundo exemplo, além do Sistema de Reservas de Hotel, o que permitiu o refinamento das atividades e artefatos do método.

A experiência de reúso permitiu que fossem estudados meios adequados de generalizar, documentar e reusar os componentes transversais em outras aplicações.

Pela comparação dos resultados produzidos pelos métodos DSBC e DSBC/A, pode-se observar a viabilidade da utilização do método para o DSBC/A para identificar e representar componentes transversais (aspectos), além de projetar componentes mais coesos do que o método para o DSBC para um mesmo sistema e, portanto, cumpre os objetivos para o qual foi criado. 


\subsection{Considerações Iniciais}

Nesta dissertação foi apresentado um método para o desenvolvimento de software baseado em componentes e aspectos. Para isso, foram apresentados inicialmente os conceitos, princípios e objetivos mais importantes do paradigma de desenvolvimento com componentes. Além dos conceitos básicos, foram apresentados alguns métodos de desenvolvimento com componentes encontrados na literatura, como o método UML Componentes (Cheesman e Daniels, 2000), Catalysis (D’Souza e Wills, 1999) e Kobra (Atkinson et al., 2000). As tecnologias de desenvolvimento com componentes também foram abordadas, como o EJB, CORBA e COM.

A partir do estudo do desenvolvimento baseado em componentes, observou-se que os interesses transversais de um sistema são implementados espalhados e entrelaçados pelos componentes. Isso causa problemas no entendimento, manutenção, evolução e reúso do sistema e dos componentes. Nas tecnologias de desenvolvimento de componentes atuais, os contêineres implementam alguns interesses transversais e os oferecem aos componentes como serviços. Essa foi uma evolução alcançada, mas a chamada aos serviços permanece espalhada nos componentes que usam os serviços e os serviços oferecidos pelos contêineres são fixos.

Diante desses problemas encontrados, apresentou-se a programação orientada a aspectos que pretende resolver ou amenizar os problemas causados pelo espalhamento e entrelaçamento de código nos programas orientados a objetos. Da mesma forma, abordagens que integram os conceitos dos componentes com a programação orientada a aspectos para encapsular os interesses transversais nos sistemas baseados em componentes e tornar os aspectos mais independentes de contexto e reusáveis foram apresentadas e discutidas. As abordagens apresentadas são de vários 
tipos, tanto de linguagens de programação orientadas a aspectos específicas para a implementação de componentes transversais quanto de métodos de desenvolvimento de e com componentes.

A partir do estudo dos componentes e da programação orientada a aspectos e as abordagens que combinam essas duas tecnologias, foi apresentado o método para o desenvolvimento baseado em componentes e aspectos (DSBC/A). O método é uma adaptação do UML Components (Cheesman e Daniels, 2000) e inclui e altera atividades para considerar aspectos no desenvolvimento de uma aplicação. Cada etapa e atividade do método foi apresentada em detalhes, juntamente com os artefatos requeridos e as modificações necessárias que devem ser feitas na notação UML para construí-los. Na apresentação do método foi utilizado um Sistema de Reservas de Hotel, tanto para exemplificar a utilização do método para o projeto do sistema quando para mostrar o mapeamento dos elementos de projeto produzido pelo método para a codificação. Além da implementação, também foram apresentadas estratégias de generalização e documentação dos componentes transversais para que possam ser reusados posteriormente em outras aplicações.

Para validar o trabalho feito, o método para o DSBC/A foi utilizado no desenvolvimento de um Sistema de Locação de Carros, que mostrou que o método é útil para o desenvolvimento com componentes e aspectos. Adicionalmente, identificaram-se atividades e artefatos do método que deveriam ser especificados em mais detalhes. O resultado do projeto com o método DSBC/A foi comparado aos resultados obtidos com o uso de um método DSBC em uma avaliação comparativa do método. Na avaliação concluiu-se que o método permite a construção de um sistema baseado em componentes modular, com baixo acoplamento entre os componentes e maior facilidade de reúso.

Apresentou-se também neste trabalho uma experiência de reúso de um componente transversal implementado para o Sistema de Reservas de Hotel. Esse componente foi generalizado, documentado e armazenado em um repositório. A partir da documentação do componente percebeu-se que ele atendia a um dos requisitos do Sistema de Locação de Carros e foi efetivamente reusado, tanto seu projeto quanto sua codificação, confirmando assim a validade do método em projetar componentes transversais para a implementação de sistemas de software.

\subsection{Contribuições}

A principal contribuição deste trabalho para a área de desenvolvimento de software com componentes e aspectos é o método para o DSBC/A proposto. O método possui etapas desde a Análise de Requisitos até o Provisionamento e Montagem dos Componentes. Além disso, a notação proposta para a construção da arquitetura do sistema com componentes e aspectos e dos diagramas que mostram a interação entre os componentes-base e transversais é simpes e objetiva, o que permite o mapeamento direto dos elementos do projeto para a implementação tanto em linguagens de propósito específico, como a JAsCO, quanto nas de propósito geral, como a AspectJ. 
Adicionalmente, este trabalho mostrou como um componente transversal pode ser generalizado, documentado e reusado em diferentes aplicações.

\subsection{Trabalhos Futuros}

O trabalho apresentado nesta dissertação descreveu propostas para apoiar a área de desenvolvimento baseado em componentes no sentido de projetar sistemas mais modulares. Entretanto, o trabalho não está completo e pode ser aperfeiçoado por meio de trabalhos futuros.

Primeiramente, o trabalho poderia ser aperfeiçoado pela aplicação do método em aplicações de outros domínios além de sistemas de informação, como aplicações científicas, de software básicos e sistemas de tempo real, por exemplo. Além disso, poderia ser utilizado para implementar sistemas reais aplicados na indústria. Com isso o método poderia ser melhor avaliado quanto à sua aplicabilidade e ser refinado de acordo com as necessidades que surgissem dessas experiências.

Em segundo lugar, seria interessante e de grande contribuição para este trabalho a realização de experimentos formais para verificar as vantagens em se desenvolver sistemas com componentes transversais utilizando este método em relação ao desenvolvimento com outros métodos, quer seja apenas com componentes ou com componentes e aspectos.

Em terceiro lugar, seria de grande importância a construção ou adaptação de ferramentas para apoiar o desenvolvimento com o método para o DSBC/A, desde a etapa de Análise de Requisitos até a Montagem dos componentes, em que os elementos de projeto fossem traduzidos automaticamente para o código.

Em quarto lugar, poderiam ser feitas investigações sobre como realizar as etapa de Teste e Implantação de componentes transversais para completar o método proposto.

Por fim, para contribuir com a área de desenvolvimento baseado em componentes e aspectos de uma maneira geral, existe a necessidade da construção de bibliotecas e repositórios de componentes especializados em armazenar componentes transversais. Essas bibliotecas e repositórios devem implementar mecanismos de armazenamento e busca que se alinham às características específicas dos componentes transversais. 


\section{Referências Bibliográficas}

ALDRICH, J. Open modules: A proposal for modular reasoning in aspect-oriented programming. 2004, p. 7-18.

Alencar, P. S. C.; Cowan, D. D.; Luo, M. A framework for community information systems. Ann. Software Eng., v. 13, n. 1-4, p. 381-411, 2002.

Almeida, H.; Loureiro, E.; Perkusich, A.; Costa, E. Usando aspectos para personalizar a execução de aplicações baseadas em componentes de prateleira. In: II Workshop Brasileiro de Desenvolvimento de Software Orientado a Aspectos, Uberlândia, MG, Brasil, 2005.

Araújo, J.; Moreira, A. M. D. An aspectual use-case driven approach. In: JISBD, 2003, p. 463-468.

Atkinson, C.; Bayer, J.; Laitenberg, O.; Zettel, J. Component -based software engineering: The kobra approach. In: Workshop on Component-Based Software Engineering, 2000.

Basili, V. R.; Selby, R. W.; Hutchens, D. H. Experimentation in software engineering. IEEE Trans. Softw. Eng., v. 12, n. 7, p. 733-743, 1986.

Brown, A. W.; WallnaU, K. C. Engineering of component-based systems. In: ICECCS, 1996, p. 414-422.

Brown, A. W.; Wallnau, K. C. The current state of cbse. IEEE Softw., v. 15, n. 5, p. 37-46, 1998.

Chavez, C. V. F. Um enfoque baseado em modelos para o design orientado a aspectos. Tese de Doutoramento, Departamento de Informática - Pontifícia Universidade Católica, Rio de Janeiro, RJ, 2004.

Cheesman, J.; Daniels, J. Uml components: A simple process for specifying componentbased software. Addison-Wesley, 2000. 
Clarke, S.; BAnIASSAD, E. Aspect-oriented analysis and design: The theme approach. Addison-Wesley Professional, 2005.

Clemente, P. J.; Hernández, J. Aspect component based software engineering. 2003.

Disponível em: http://www.cs.ubc.ca/ ycoady/acp4is03/papers/ clemente.pdf

Clemente, P. J.; SÁnchez, F.; PÉrez, M. A. Modeling with uml component-basead and aspect oriented programming systems. In: Seventh International Workshop on ComponentOriented Programming, Malaga, Spain, 2002.

Colyer, A.; RAshid, A.; Blair, G. The separation of concerns in program families. 2004. Disponível em: citeseer.ist.psu.edu/colyer04separation.html

COTTENIER, T.; ELRAD, T. Validation of context-dependent aspect-oriented adaptations to components. In: WCOP - Workshop on Component-Oriented Programming, 2004.

Councill, B.; Heineman, G. T. Definition of a software component and its elements, p. 5-19. 2001.

CRnKOVIC, I.; LARSSON, M. Component-based software engineering - new pardigm of software development. In: Euromicro Workshop on COMPONENT-BASED SOFTWARE ENGINEERING, 2001.

DijkstRA, E. W. The characterization of semantics, cáp. 3 Prentice-Hall, 1976.

D'SouZA, D.; WILls, A. Objects, components, and frameworks with uml: The catalysis approach. Boston-Ma, USA: Addison-Wesley, 1999.

Duclos, F.; Estublier, J.; Morat, P. Describing and using non functional aspects in component based applications. In: AOSD '02: Proceedings of the 1st international conference on Aspect-oriented software development, New York, NY, USA: ACM Press, 2002, p. 65-75.

Eler, M. M.; Masiero, P. C. Proposta de um método para o desenvolvimento de software baseado em componentes e aspectos. In: Workshop Brasileiro de Desenvolvimento Baseado em Componentes, 2005, p. 12-20.

Eler, M. M.; MASIERO, P. C. Projeto de um Sistema de Locação de Carros baseado em componentes e aspectos. Documento de Trabalho. Instituto de Ciências Matemáticas e de Computação, Universidade de São Paulo . 2006a.

Eler, M. M.; MASiero, P. C. Projeto de um Sistema de Reservas de Hotéis baseado em componentes e aspectos. Documento de Trabalho. Instituto de Ciências Matemáticas e de Computação, Universidade de São Paulo. 2006b. 
Elrad, T.; Kiczales, G.; Aksit, M.; Lieberher, K.; Ossher, H. Discussing Aspects of AOP. Communications of the ACM, v. 44, n. 10, p. 33-38, 2001.

Emmerich, W.; KAVEH, N. Component technologies: Java beans, com, corba, rmi, ejb and the corba component model. SIGSOFT Softw. Eng. Notes, v. 26, n. 5, p. 311-312, 2001.

FELlNER, K. J.; TUROWsKi, K. Classification framework for business components. In: HICSS '00: Proceedings of the 33rd Hawaii International Conference on System Sciences-Volume 8, IEEE Computer Society, 2000, p. 8047.

Filman, R. E.; Elrad, T.; Clarke, S.; AKşit, M. Aspect-Oriented software programming. Addison-Wesley, 2004.

Filman, R. E.; Friedman, D. P. Aspect-Oriented Programming is Quantification and Oliviousness. In: Advanced Separation of Concerns Workshop at the Conference on ObjectOriented Programming Systems, Languages, and Applications (OOPSLA), Minneapolis, Minnesota, USA: ACM, 2000.

Fuentes, L.; Troya, J. M. Towards an open multimedia service framework. ACM Comput. Surv., v. 32, n. 1es, p. 24, 2000.

GRUNDY, J. C. Multi-perspective specification, design and implementation of software components using aspects. 2000.

Disponível em: citeseer.ist.psu.edu/grundy0 0multiperspective.html

Grundy, J. C.; Mugridge, W. B.; Hosking, J. G. Constructing component-based software engineering environments: issues and experiences. Information Software Technology, v. 42, n. 2, p. 103-114, 2000.

Disponível em: citeseer.ist.psu.edu/grundy00 constructing.html

Grundy, J. C.; PATEl, R. Developing software components with the uml, enterprise java beans and aspects. In: Australian Software Engineering Conference, 2001, p. 127-136.

JACOBSON, I.; NG, P.-W. Aspect-oriented software development with use cases (addison-wesley object technology series). Addison-Wesley Professional, 2004.

Kazman, R.; Klein, M.; Clements, P. Atam: Method for architecture evaluation. 2000. Disponível em: citeseer.csail.mit.edu/kazmano0atam.html

Kiczales, G.; Hilsdale, E.; Hugunin, J.; Kersten, M.; Palm, J.; Griswold, W. Getting started with aspectj. Commun. ACM, v. 44, n. 10, p. 59-65, 2001 b.

Kiczales, G.; Hilsdale, E.; Hugunin, J.; Kersten, M.; Palm, J.; Griswold, W. G. An Overview of AspectJ. Lecture Notes in Computer Science, v. 2072, p. 327-355, 2001a. 
Kiczales, G.; Lamping, J.; Menhdhekar, A.; Maeda, C.; Lopes, C.; Loingtier, J.M.; Irwin, J. Aspect-Oriented Programming. In: Akşit, M.; MatsuoKA, S., eds. Proceedings European Conference on Object-Oriented Programming, v. 1241, Berlin, Heidelberg, and New York: Springer-Verlag, p. 220-242, 1997.

Kitchenham, B.; Pickard, L.; Pfleeger, S. L. Case studies for method and tool evaluation. IEEE Softw., v. 12, n. 4, p. 52-62, 1995.

Kunda, D.; Brooks, L. Component-Based Software Engineering for Developing Countries: Promises and Possibilities. 2000.

LAdDAD, R. AspectJ in Action - Practical Aspect-Oriented Programming. Greenwich, Connecticut: Manning Publications Co., 2003.

LARMAn, C. Applying uml and patterns: An introduction to object-oriented analysis and design and the unified process. Upper Saddle River, NJ, USA: Prentice Hall PTR, 2001.

Lieberherr, K.; Lorenz, D.; Mezini, M. Programming with Aspectual Components. Relatório Técnico NU-CCS-99-01, College of Computer Science, Northeastern University, Boston, MA, 1999.

Lopes, C.; Ngo, T. Unit-testing aspectual behavior. In: Workshop on Testing Aspect-Oriented Programs (WTAOP) - (AOSD’05), 2005.

Lopes, C. V. D: A Language Framework for Distributed Programming. Tese de Doutoramento, College of Computer Science, Northeastern University, Boston, MA, 1997.

Meijler, T. D.; Nierstrasz, O. Beyond objects: Components. In: PaPazoglou, M. P.; SChlageter, G., eds. Cooperative Information Systems: Current Trends and Directions, Academic Press, p. 49-78, 1997.

Disponível em: citeseer.ist.psu.edu/meijler98beyond.html

Moreira, A. M. D.; AraúJo, J. Handling unanticipated requirements change with aspects. In: SEKE, 2004, p. 411-415.

OSSHER, H.; TARR, P. Multi-dimensional separation of concerns and the hyperspace approach. In: Proceedings of the Symposium on Software Architectures and Component Technology: The State of the Art in Software Development, Kluwer, 2000.

Disponível em: citeseer.ist.psu.edu/ossher00multidimensional.html

OSSHER, H.; TARR, P. Using multidimensional separation of concerns to (re)shape evolving software. Commun. ACM, v. 44, n. 10, p. 43-50, 2001.

PARnAS, D. L. On the criteria to be used in decomposing systems into modules. Commun. $A C M$, v. 15, n. 12, p. 1053-1058, 1972. 
PrEe, W. Component-based software development - a new paradigm in software engineering? Software - Concepts and Tools, v. 18, n. 4, p. 169-174, 1997.

Pressman, R. S. Engenharia de software. Rio de Janeiro: McGraw-Hill, 2002.

RAShID, A.; MoreIRA, A.; ArA\&\#250;JO, J. Modularisation and composition of aspectual requirements. In: AOSD '03: Proceedings of the 2nd international conference on Aspectoriented software development, New York, NY, USA: ACM Press, 2003, p. 11-20.

Robillard, M. P. Separation of concerns and software components. In: Component Based Software Engineering Seminar, Vancouver, Canada, 2000.

Sametinger, J. Software engineering with reusable components. Springer-Verlag New York, Inc., 1997.

SASS, G. G. Proposta de uma arquitetura de componentes para sistemas de informação baseados na web: nível lógico. Dissertação de Mestrado, UEM - Universidade Estadual de Maringá, Maringá, PR, Brasil, 2003.

SuvÉE, D. Fusej: Achieving a symbiosis between aspects and components. 2004.

Disponível em: citeseer.ist.psu.edu/657999.html

SuVÉE, D. Jasco language reference 0.8.7. 2005.

Disponível em: http://ssel.vub.ac.be/jasco/documentation:main

Suvée, D.; Fraine, B.; VAnderperren, W. Fusej: An architectural description language for unifying aspects and components. In: Workshop on Software Engineering Properties of Languages for Aspect Technologies (SPLAT'05), Chicago, Illinois - USA, 2005.

SuveE, D. Fusej: Achieving a symbiosis between aspects and components. 2003.

Disponível em: citeseer.ist.psu.edu/657999.html

SuVÉE, D.; VANDERPERren, W.; JonCKers, V. Jasco: an aspect-oriented approach tailored for component based software development. In: AOSD, 2003, p. 21-29.

Suvée, D.; VAnderperren, W.; WagelaAr, D.; Jonckers, V. There are no aspects. In: Software Composition Workshop (ETAPS), 2004, p. 142-162.

Disponível em: http://www.ida.liu.se/ uweas/sc2004/ sc2004-proceedings.pdf

SZYPERSKI, C. Component software: Beyond object-oriented programming. ACM Press/Addison- Wesley Publishing Co., 1998.

Szyperski, C.; Gruntz, G. D.; Murer, S. Component software - beyond object-oriented programming. Addison-Wesley / ACM Press, 2002. 
TARr, P. L.; OSShER, H.; HARrison, W. H.; JR., S. M. S. N degrees of separation: Multidimensional separation of concerns. In: International Conference on Software Engineering, 1999, p. 107-119.

Disponível em: citeseer.csail.mit.edu/tarr99degrees.html

TEAM, T. A. The AspectJ programming guide. 2003.

Disponível em: http://dev.eclipse.org/viewcvs/indextech.cgi/ $\sim$ checkout / aspect j-home/doc/progguide/index.html

Vanderperren, W.; Suvée, D.; Verheecke, B.; Cibrán, M. A.; Jonckers, V. Adaptive programming in JAsCo. 2005, p. 75-86.

Werner, C. M. L.; BragA, R. M. Desenvolvimento baseado em componentes. In: Tutorial - Simpósio Brasileiro de Engenharia de Software (SBES), João Pessoa - Paraíba, 2000.

WiLls, A. C. Components and connectors: catalysis techniques for designing component infrastructures, p. 307-319. 2001. 


\section{Documento de Requisitos do Sistema de Reservas de uma Rede de Hotéis}

\section{A.1 Descrição Geral do Sistema}

O Sistema de Reserva de Hotel consiste em um sistema de gerenciamento das reservas das acomodações de um hotel de uma rede de hotéis. Atualmente, cada hotel tem seu próprio sistema, que são incompatíveis entre si. No novo sistema a ser construído, as reservas podem ser feitas por telefone, ligando diretamente para uma central de reservas ou para o hotel, ou então pela Internet. Cada hotel tem diferentes tipos de acomodação que podem ser reservados por um cliente, cujos dados devem ser registrados no sistema. O cliente pode confirmar, modificar, cancelar ou ocupar sua reserva (iniciar estada) e receber uma acomodação do tipo escolhido, nesta última situação. Uma vantagem do novo sistema será a possibilidade de oferecer acomodações em hotéis alternativos quando o hotel desejado já estiver cheio. No hotel, será possível fazer as reservas nos balcões de atendimento e nos escritórios. Cada hotel tem um gerente responsável por controlar as reservas, mas qualquer usuário autorizado pode fazê-las. O tempo desejado para fazer uma reserva por telefone ou pessoalmente é de três minutos. Para agilizar o processo, detalhes de clientes que já estiveram no hotel serão armazenados e disponibilizados para uso. O controle do pagamento das locações de quarto e taxas por reserva não ocupada sem cancelamento será realizado por um sistema de pagamento existente. O hotel possui um gerente que é responsável pelo gerenciamento do hotel, acomodações, funcionários, etc, um administrador do Sistema de Reservas que é responsável por gerenciar o sistema, atribuir permissões de acesso, etc. 


\section{A.2 Requisitos Funcionais}

\section{A.2.1 Operações básicas do sistema}

1. O sistema deve permitir a inclusão, alteração e remoção de hotéis, com os seguintes atributos: identificação, nome, endereço, telefone, IE.

2. O sistema deve permitir a inclusão, alteração e remoção de acomodações do hotel, com os seguintes atributos: número da acomodação, descrição, tipo de acomodação e situação atual (vago ou ocupado). O sistema deve permitir a inclusão, alteração e remoção de tipos de acomodação oferecidos pelo hotel, com os seguintes atributos: código do tipo de acomodação, descrição e preço.

3. O sistema deve permitir a inclusão, alteração e remoção de clientes do hotel, com os seguintes atributos: nome, endereço, cidade, estado, bairro, telefone, fax, e-mail e documento de identificação (CPF e RG).

4. O sistema deve permitir a inclusão, alteração e remoção de empresas que possuem convênio com o hotel, com os seguintes atributos: Nome, CGC, endereço, cidade, estado, bairro, telefone, fax, e-mail e taxa de desconto.

5. O Sistema deve permitir a associação de clientes a empresas conveniadas. Os clientes associados a uma empresa conveniada recebe desconto nos serviços de reserva, de acordo com a empresa.

\section{A.2.2 Reserva}

6. O sistema deve permitir o processamento de reservas de acomodações de um hotel, devendo ser registrados os seguintes atributos: identificação do hotel, identificação do cliente, data de início da estada, data de fim da estada e tipo de acomodação.

Existe vaga de acomodação no hotel se há pelo menos um tipo de acomodação desejado disponível no período solicitado e se após a reserva haverá pelo menos um tipo de acomodação de qualquer tipo disponível no mesmo período. A decisão se há acomodação disponível dá-se pelo cálculo a seguir:

$\mathrm{R}=(\mathrm{A}-\mathrm{B}>0) \mathrm{e}(\mathrm{Ta}-\mathrm{Tb}>1)$

A: total de quartos disponíveis de um certo tipo. B: somatória das reservas existentes para um certo tipo de quarto em um determinado período.

Ta: total de quartos (de qualquer tipo). Tb: total de reservas.

OBS1: O Cálculo é feito para cada dia do período. OBS2: No cálculo do valor contam-se as noites dormidas. Se a reserva é de 04/02 a 10/02, contam-se os dias de 04 a 09, ou seja, 6 dias. 
7. O sistema deve enviar ao cliente os dados referentes à sua reserva e um código da reserva por e-mail.

8. O sistema deve permitir que os clientes que já confirmaram a reserva no hotel cancelem ou modifiquem os dados da reserva.

9. O sistema deve permitir o processamento da ocupação da reserva do hotel, iniciando a estada do cliente no hotel, devendo ser registrados os seguintes atributos: identificação da reserva e número do quarto ocupado.

10. O sistema deve gerar dados referentes às estadas dos clientes para o sistema de faturamento existente, bem como dos casos em que o cliente não ocupou a reserva sem cancelá-la. Neste último caso é cobrado o valor de uma diária do cliente.

Os preços das diárias variam de acordo com o dia da semana e descontos são oferecidos para empresas que possuem convênio com o hotel.

\section{A.2.3 Emissão de relatórios e consultas}

11. Consultar se uma acomodação está ocupada ou não.

12. Consultar o número de reservas de um certo tipo de acomodação em um certo dia.

13. Listar as reservas de um certo dia/período.

\section{A.3 Requisitos Não Funcionais}

\section{A.3.1 Segurança}

14. O Sistema deve permitir a inclusão, alteração e remoção de usuários do sistema.

15. O sistema deve permitir a autenticação de seus usuários.

16. O sistema deve oferecer mecanismos para criptografia das senhas dos usuários. O mecanismo deve ser utilizado em duas situações: no armazenamento da senha e na autenticação do usuário.

17. O sistema deve gerar arquivos de registro das operações de entrada realizadas no sistema. $\mathrm{O}$ registro deve conter a data/hora, usuário registrado no sistema e a operação executada. 


\section{A.3.2 Controle de Acesso}

18. O sistema deve oferecer meios para permitir a execução de operações de acordo com o tipo do usuário autenticado no sistema.

O sistema deve permitir a atribuição de papéis aos usuários do sistema e a definição de quais operações do sistema cada papel tem direito de acesso.

\section{A.3.3 Persistência}

19. O sistema deve permitir que os dados necessários para o gerenciamento do hotel sejam armazenados em um banco de dados.

\section{A.3.4 Desempenho}

20. A reserva deve ser feita em menos de 3 minutos (por telefone ou pessoalmente).

\section{A.4 Glossário}




\begin{tabular}{|l|l|}
\hline Termo & Descrição \\
\hline \hline Rede de Hotéis & Empreendimento que possui vários hotéis. \\
\hline Hotel & $\begin{array}{l}\text { Estabelecimento comercial que possui acomodações que podem ser alu- } \\
\text { gadas por um período de tempo. }\end{array}$ \\
\hline Acomodação & Acomodação do hotel que será ocupada pelos clientes - apartamento. \\
\hline Tipo de Acomodação & $\begin{array}{l}\text { Padrão de conforto de acomodação do Hotel. Exemplo: padrão, luxo e } \\
\text { suíte. }\end{array}$ \\
\hline Tipo de Ocupação & $\begin{array}{l}\text { Refere-se à quantidade de pessoas que podem ocupar a acomodação. Exem- } \\
\text { plo: simples, duplo e triplo. }\end{array}$ \\
\hline Usuário do Sistema & Pessoa que possui acesso às operações do Sistema de Reserva de Hotéis. \\
\hline Papel & $\begin{array}{l}\text { Função que um usuário desempenha no Sistema. Por exemplo: cliente, } \\
\text { recepcionista, gerente de reservas, gerente geral e administrador. }\end{array}$ \\
\hline Cliente & Pessoa que faz reserva de apartamentos do hotel. \\
\hline Recepcionista & $\begin{array}{l}\text { Pessoa responsável por atender os clientes do hotel e realizar operações } \\
\text { como fazer reservas e dar entrada no hotel. }\end{array}$ \\
\hline Gerente de Reservas & $\begin{array}{l}\text { Pessoa responsável pelo gerenciamento das operações relativas às reservas } \\
\text { efetuadas no hotel. }\end{array}$ \\
\hline Gerente de Hotel & $\begin{array}{l}\text { Pessoa responsável pelo gerenciamento de um Hotel (funcionários, aco- } \\
\text { modações, etc). }\end{array}$ \\
\hline Administrador & Pessoa responsável pelo gerenciamento do Sistema de Reserva de Hotéis. \\
\hline Reserva & $\begin{array}{l}\text { Procedimento pelo qual um tipo de acomodação fica reservado para um } \\
\text { cliente, garantindo que haverá disponibilidade desse tipo de acomodação } \\
\text { quando o cliente fizer sua ocupação da reserva. }\end{array}$ \\
\hline Estada & $\begin{array}{l}\text { Procedimento pelo qual o cliente ocupa a reserva por ele realizada, re- } \\
\text { cebendo um quarto para acomodar-se e iniciar sua estada. A estada também } \\
\text { pode ocorrer sem reserva. }\end{array}$ \\
\hline Valor subtraído do preço das diárias das acomodações em determinadas \\
ocasiões.
\end{tabular}

Tabela A.1: Glossário 
APÊNDICE

$B$

Documento de Requisitos do Sistema de Locação de Carros

\section{B.1 OBJETIVO}

Desenvolver um SI para e-commerce que realize a locação de carros, denominado e-rent-a-car. Este sistema representa uma loja virtual cujo único produto comercializado são os carros. O cliente poderá ter acesso aos automóveis por meio do serviço de busca, disponível em qualquer local do site. O cliente poderá realizar uma locação selecionando os itens de interesse, colocando-o em um "carrinho"de reserva, e em caso de confirmar a reserva, o cliente ainda poderá especificar a data, atual ou não, que ele precisará do carro locado e a forma de pagamento.

\section{B.2 DEFINIÇÃO DO PROBLEMA}

Existem dois personagens no e-rent-a-car:

1. o cliente: aluga e devolve o carro, e liquida a dívida, quando for o caso;

2. o gerente: para o qual os relatórios e consultas são enviados. Determina também as operações de cadastros e gerencia o sistema.

O atributo estado na entidade carro pode assumir cinco estados, conforme segue:

1. indisponível: o carro será comercializado pela loja, porém não está liberado por motivos de manutenção; 
2. disponível: o carro está regular, e pode ser alugado;

3. alocado: o carro estava disponível e foi selecionada por algum cliente e colocado em sua "carrinho de reservas";

4. reservado: O carro esta indisponível, pois foi reservado para algum cliente;

5. locado: o carro foi efetivamente alugado por algum cliente.

Tendo em vista a descrição da loja e os estados possíveis em que cada item pode estar são identificadas as seguintes ações:

1. informar: o cliente requisita informações sobre um item;

2. alocar: um item disponível é escolhido pelo cliente para posterior locação e "reservado"para ele;

3. desalocar: o cliente desiste de alugar um carro e o mesmo se torna disponível para locação;

4. locar: o cliente efetivamente loca um carro;

5. cancelar: o cliente abandona a reserva de um carro, e este volta a ser disponível;

6. reservar: o cliente seleciona um carro indisponível para ser locado futuramente e este é reservado para ele, desde que no período solicitado o carro não esteja reservado para outro cliente;

7. alterar: o administrador altera informações a respeito do carro, como sua quilometragem;

8. excluir: o administrador exclui um carro do estoque por ter sido vendido, roubado ou batido;

9. disponibilizar: o administrador coloca o carro no estoque para locação.

As regras para locação de um carro consistem de:

1. o carro está disponível, se ele não estiver em manutenção ou locado;

2. não é permitida a locação de um carro quando a data informada para a locação coincidir com a data de uma locação já reservada.

As regras de preço são definidas como segue:

1. o carro será cadastrado com um valor por km rodado;

2. ainda poderá ser inserido no preço da locação o valor de multas efetuadas no período;

3. dependendo da forma de pagamento poderá haver descontos no valor final da locação. 


\section{B.2.1 DESCRIÇÃO DOS SERVIÇOS}

Os vários serviços a serem oferecidos pela loja são descritos abaixo.

\section{Serviço Página Inicial}

Este serviço fornece informações gerais sobre a loja, sendo o ponto de vista/partida do cliente. Em termos do produto, a única ação que pode ser eventualmente realizada é informar, com o objetivo de disponibilizar informações a respeito de carros em destaque. Essas informações consistem de atributos como nome, marca, ano, cor e são acessados apenas para leitura.

Este serviço é simples (tendo em vista que a ação informar é simples) e possui requisitos de atomicidade e durabilidade simples, uma vez que os atributos acessados são estáticos e replicáveis. Em termos de requisitos de processamento, este serviço demanda, além da leitura de arquivos para construção da página, consultas atributo-valor.

\section{Serviço de Busca}

O serviço de busca disponibiliza informações sobre carros a partir de critérios de busca fornecidos pelos usuários. No caso do e-rent-a-car, um produto satisfaz a uma busca quando os seus campos nome, marca e ano contêm a cadeia de caracteres especificada na consulta.

\section{Serviço de Navegação}

O serviço de navegação é muito semelhante ao serviço de busca. A única diferença entre eles é que os critérios de navegação são pré-definidos (os carros são divididos em categorias) e não determinados pelos clientes como na busca.

\section{Serviço de Colocação no Carrinho}

O serviço de colocação no carrinho permite a um cliente registrar sua opção de locação. A única ação executada é alocar, que altera o estado do carro de disponível para alocado e tem caráter temporário. Se a locação for realizada os dados serão armazenados na entidade locação juntamente com o código da locação.

Excluindo o serviço página pessoal, para todos os demais, é necessário identificar o cliente para que o carro possa ser locado por ele. Essa identificação é feita através de um parâmetro, o identificador do cliente, que somente é disponível quando o cliente efetuou seu username ou seu cadastramento no sistema. 


\section{Serviço de Locação}

O serviço de locação permite a efetivação de opções de reserva através do serviço de colocação no carrinho. Para cada um dos itens selecionados deve ser aplicada a ação locar, mudando o estado desses itens para locado em caráter definitivo, o que também classifica o serviço como tal.

\section{Serviço de Cadastramento}

O serviço de cadastramento é responsável pela inserção de um novo cliente no sistema e permitir que ele realize locações na loja. Esse serviço não executa nenhuma ação que atinja diretamente o ciclo de vida do carro, desta forma ele pode ser classificado como um serviço simples. O cliente fornece diversas informações pessoais, como nome, endereço e e-mail, escolhe um username (nome para acesso do sistema) e uma senha, e requisita o cadastro. O sistema então armazena tais dados e gera um número identificador do cliente. O cliente poderá fazer uma locação, somente, se estiver cadastrado no sistema.

\section{Serviço de Validação}

O serviço de username permite que o cliente possa ser identificado pelo sistema. Através das informações username e password, o sistema permite que o cliente realize a locação. 
APÊNDICE

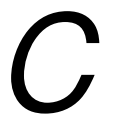

Plano de Estudo de Caso para a Avaliação Comparativa entre os métodos DSBC e DSBC/A

\section{C.1 Identificação do Contexto do Estudo de Caso}

- Tratamento: método de desenvolvimento de software baseado em componentes e aspectos (DSBC/A);

- Controle: método de desenvolvimento baseado em componentes utilizado por (Sass, 2003).

- Objeto Experimental: projeto do Sistema de Locação de Carros, baseado no mesmo conjunto de requisitos, desenvolvido pelo método DSBC/A.

- Participante: Marcelo Medeiros Eler;

- Projeto Piloto: Desenvolvimento do projeto de um Sistema de Locação de Carros utilizando o método DSBC/A.

Os itens a seguir apresentam as restrições deste estudo de caso:

- Patrocinador: Programa de Pós-Graduação em Ciência da Computação do ICMC e CNPq.

- Recursos disponíveis: 
- Documento de requisitos do Sistema de Locação de Carros

- método de desenvolvimento baseado em componentes (UML Components);

- método de desenvolvimento baseado em componentes e aspectos (proposto nesta dissertação);

- ferramentas de modelagem;

- linguagem Java, versão 1.4.2;

- linguagem JAsCO.

- Cronograma: no período de 15/08/2005 a 27/09/2005;

- Objetivo do estudo de caso: o estudo de caso aborda o desenvolvimento baseado em componentes e aspectos de um sistema de locação de carros, seguindo um método (DSBC/A) com notação e atividades específicas para tal. O objetivo é comparar a arquitetura de componentes obtida pela utilização do DSBC/A com outra produzida anteriormente de forma convencional (UML Components). Pretende-se observar se a aplicação do DSBC/A indica alguma capacidade de identificar e representar componentes que apresentem menor granularidade e mais coesão, bem como promover melhor separação de interesses na concepção e construção de sistema baseado em componentes.

\section{C.2 Definição das Hipóteses}

Para cada aspecto do método/ferramenta que deve ser investigado, são definidas algumas hipóteses. São elas:

- Hipótese Nula (H0): não há diferença significativa entre a aplicação do DSBC/A e UML Components na construção de uma arquitetura baseada em componentes.

- Hipótese Alternativa (H1): O tratamento permite identificar e representar componentes transversais (aspectos) e o controle não leva em conta explicitamente;

- Hipótese Alternativa (H2): os componentes identificados e representados pelo tratamento possuem granuralidade mais fina, são mais coesos e reusáveis do que os produzidos pelo controle;

- Hipótese Alternativa (H3): o tratamento identifica mais componentes transversais do que o controle;

- Efeito 1: Observar a viabilidade da utilização do DSBC/A para identificar e representar componentes transversais (aspectos), além de projetar componentes mais coesos do que o controle para um mesmo sistema e, portanto, cumpre os objetivos para o qual foi criado

- Efeito 2: Refinar o tratamento caso se note durante sua aplicação que há atividades não cobertas ou deficientes. 
- Variável de Resposta:

- Granularidade: Número de componentes

- Coesão: Análise do nome e descrição do componente. Contagem dos tipos de coesão encontrados e classificação decrescente.

- Número de componentes transversais identificados.

\section{C.3 Seleção do Projeto Piloto}

Considera-se como projeto piloto o desenvolvimento de um sistema de locação de carros pela Web (Rent a car), típico do domínio que pretende-se enfatizar nesta dissertação: sistemas de informação baseados na Web. Adicionalmente, este sistema foi escolhido por já haver disponível publicamente uma solução de projeto criada seguindo o controle (Sass, 2003).

\section{C.4 Identificação do Método de Comparação}

Optou-se por comparar o resultado do estudo de caso com o resultado de um projeto similar. Neste caso, já existe uma solução para o sistema de locação de carros produzida pelo controle.

\section{C.5 Redução dos Efeitos dos Fatores de Distorção}

Esta etapa tem o objetivo de especificar os fatores de distorção de um estudo de caso. A seguir estão alguns fatores de distorção, sendo os três primeiros definidos por Kitchenham (1996).

- usar o estudo de caso como instrumento para aprender a utilizar o método/ferramenta: este fator pode prejudicar o estudo se o método/ferramenta que está sendo avaliado estiver sendo utilizado por membros da equipe de avaliação, que não possuem um prévio conhecimento de tal método/ferramenta;

- a equipe de avaliação encontra-se demasiadamente entusiasmada ou cética: este fator pode prejudicar a avaliação se a equipe tem como objetivo adotar uma nova versão de um método/ferramenta que já está sendo utilizada. Isto acontece quando a equipe deseja verificar novas funcionalidades ou atualizações do método/ferramenta existente;

- comparar diferentes tipos de projetos: este fator pode prejudicar o estudo, pois projetos de domínios diferentes geram resultados significantemente diferentes, impossibilitando, assim, serem utilizados para a sua análise. 
- ser contaminado com a solução "controle": este fator pode prejudicar o estudo, pois o projetista do sistema, ao conhecer a solução gerada pelo controle, pode inconscientemente tomar as mesmas decisões do projeto existente.

Nenhuma das variáveis acima influencia o projeto: o método de desenvolvimento proposto já foi utilizado pelo sujeito do estudo de caso; a avaliação dos resultados será feita de forma imparcial, com o objetivo de validar e refinar o método proposto com resultados reais; os projetos serão realizados para o mesmo sistema; o sujeito só terá contato com a solução controle após ter concluído o objeto experimental.

\section{C.6 Planejamento do Estudo de Caso}

\section{C.6.1 Definição}

(a) motivação: A tecnologia de aspectos tem sido utilizada em várias atividades do ciclo de vida de um software, principalmente no desenvolvimento orientado a objetos. Recentemente, o uso de aspectos foi introduzido no desenvolvimento baseado em componentes e linguagens específicas foram criadas para isso. Diante disso, propôs-se um método para o desenvolvimento de software baseado em componentes e aspectos, com o objetivo de produzir uma arquitetura de componentes mais coesos e reusáveis e promover uma melhor separação de interesses.

(b) objeto de estudo: o método de desenvolvimento baseado em componentes e o método proposto.

(c) propósito: avaliar as diferenças entre as arquiteturas produzidas pelo controle e pelo tratamento com os propósitos de avaliar a utilização prática do tratamento e refiná-lo caso seja necessário.

(d) perspectiva: o estudo é realizado sob a perspectiva do Projetista de Software;

(e) contexto: é utilizado o método de comparação Projetos Replicados por existir um projeto realizado anteriormente.

\section{C.6.2 Planejamento}

(a) projeto experimental: neste estudo de caso não serão utilizadas técnicas estatísticas (Basili et al., 1986), visto que o conjunto de fatores, variáveis de resposta e métricas é pequeno e pelo estudo não ser realizado várias vezes;

(b) critérios: os critérios utilizados baseiam-se na variável de e nas hipóteses;

(c) medição: objetiva, por meio da variável de resposta; e subjetiva, por meio da interpretação dos valores da variável de resposta; 


\section{C.6.3 Operação}

(a) preparação: o projeto piloto é o projeto definido para o estudo de caso;

(b) execução: segue o método de desenvolvimento baseado em componentes e aspectos proposto. A coleta de dados é realizada com base na variável de resposta do estudo de caso;

(c) análise: realizada por meio da análise dos componentes produzidos pelo tratamento e controle;

\section{C.6.4 Interpretação}

(a) contexto de interpretação: a interpretação dos dados neste estudo de caso não será feita por métodos estatístico (Basili et al., 1986) por causa do reduzido número de variáveis de resposta e valores para estas, coletados durante a execução do estudo de caso;

(b) extrapolação: nenhuma estratégia de extrapolação (Basili et al., 1986) será utilizada por causa da reduzida amostra de dados do estudo de caso;

(c) impacto: o impacto dos resultados é apresentado na forma de sugestões de melhorias para o método avaliado, caso sejam necessárias. 